\title{
Oral contraceptive pill, progestogen or estrogen pre- treatment for ovarian stimulation protocols for women undergoing assisted reproductive techniques (Review)
}

Smulders B, van Oirschot SM, Farquhar C, Rombauts L, Kremer JAM

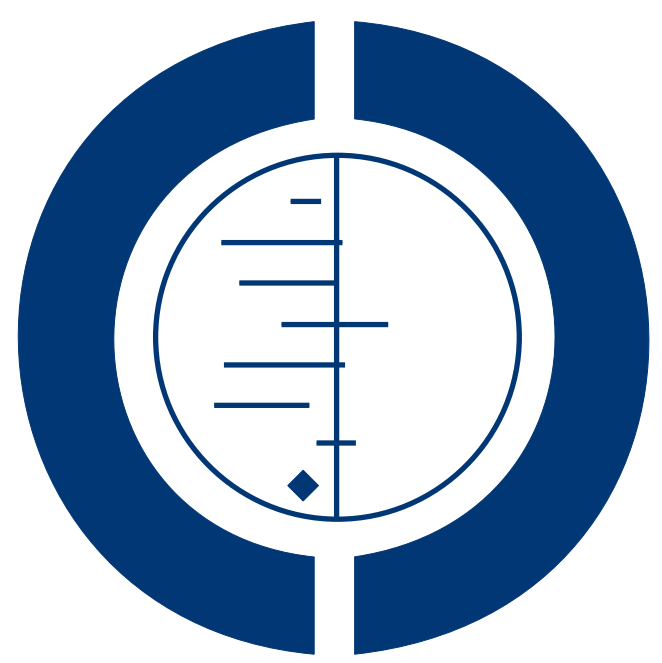

\section{THE COCHRANE COLLABORATION $^{\circledR}$}

This is a reprint of a Cochrane review, prepared and maintained by The Cochrane Collaboration and published in The Cochrane Library 2010, Issue 11

http://www.thecochranelibrary.com

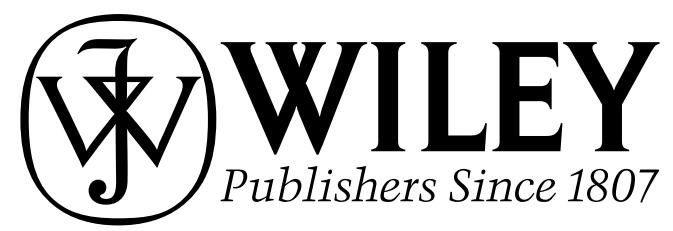

Oral contraceptive pill, progestogen or estrogen pre-treatment for ovarian stimulation protocols for women undergoing assisted reproductive techniques (Review)

Copyright $\odot 2010$ The Cochrane Collaboration. Published by John Wiley \& Sons, Ltd. 
TABLE OF CONTENTS

HEADER . . . . . . . . . . . . . . . . . . . . . . . . . . . . . . . . . . . . . . . . . . . . .

ABSTRACT . . . . . . . . . . . . . . . . . . . . . . . . . . . . . . . . . . . . . . . . . . .

PLAIN LANGUAGE SUMMARY . . . . . . . . . . . . . . . . . . . . . . . . . . . . . . . . . . . . . . . .

BACKGROUND . . . . . . . . . . . . . . . . . . . . . . . . . . . . . . . . . . . . . 3

OBJECTIVES . . . . . . . . . . . . . . . . . . . . . . . . . . . . . . . . . . . . . . . . . . . . . . . . .

METHODS . . . . . . . . . . . . . . . . . . . . . . . . . . . . . . . . . . . . . . . . . .

Figure 1. . . . . . . . . . . . . . . . . . . . . . . . . . . . . . . . . . . . . . 47

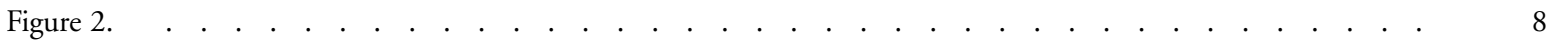

RESULTS . . . . . . . . . . . . . . . . . . . . . . . . . . . . . . . . . . . . . . . 9

Figure 3. . . . . . . . . . . . . . . . . . . . . . . . . . . . . . . . . . . . . . . .

Figure 4. . . . . . . . . . . . . . . . . . . . . . . . . . . . . . . . . . . . . . 18

Figure 5. . . . . . . . . . . . . . . . . . . . . . . . . . . . . . . . . . . . . . . .

Figure 6. . . . . . . . . . . . . . . . . . . . . . . . . . . . . . . . . . . . . 22

Figure 7. . . . . . . . . . . . . . . . . . . . . . . . . . . . . . . . . . . . . . 23

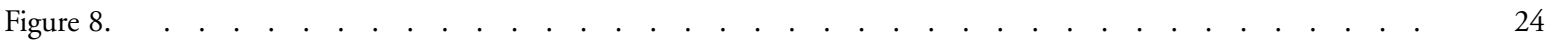

Figure 9. . . . . . . . . . . . . . . . . . . . . . . . . . . . . . . . . . . . . . 25

Figure 10. . . . . . . . . . . . . . . . . . . . . . . . . . . . . . . . . . . . . . .

Figure 11. . . . . . . . . . . . . . . . . . . . . . . . . . . . . . . . . . . . . . 27

Figure 12. . . . . . . . . . . . . . . . . . . . . . . . . . . . . . . . . . . . . . 28

Figure 13. . . . . . . . . . . . . . . . . . . . . . . . . . . . . . . . . . . . . . $\quad . \quad 29$

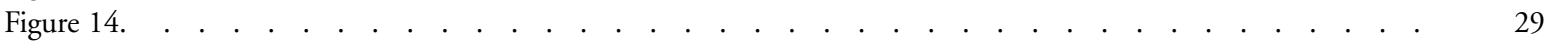

Figure $15 . \quad$. . . . . . . . . . . . . . . . . . . . . . . . . . . . . . . . . . . . . $\quad 30$

Figure 16. . . . . . . . . . . . . . . . . . . . . . . . . . . . . . . . . . . . . . . .

Figure 17. . . . . . . . . . . . . . . . . . . . . . . . . . . . . . . . . . . . . .

Figure 18. . . . . . . . . . . . . . . . . . . . . . . . . . . . . . . . . . . . . . .

Figure 19. . . . . . . . . . . . . . . . . . . . . . . . . . . . . . . . . . . . . .

DISCUSSION . . . . . . . . . . . . . . . . . . . . . . . . . . . . . . . . . . . . . . . .

AUTHORS' CONCLUSIONS . . . . . . . . . . . . . . . . . . . . . . . . . . . . . . . . . . . . . . . .

ACKNOWLEDGEMENTS . . . . . . . . . . . . . . . . . . . . . . . . . . . . . . . . . . . . . . . 39

REFERENCES . . . . . . . . . . . . . . . . . . . . . . . . . . . . . . . . . . . . . . . . . 39

CHARACTERISTICS OF STUDIES . . . . . . . . . . . . . . . . . . . . . . . . . . . . . . . . . . . . . . . . .

DATA AND ANALYSES . . . . . . . . . . . . . . . . . . . . . . . . . . . . . . . . . . . . . . . . . . . . . . . . . . .

Analysis 1.1. Comparison 1 Combined OCP versus no Rx, Outcome 1 Live births. . . . . . . . . . . . . . . 89

Analysis 1.2. Comparison 1 Combined OCP versus no Rx, Outcome 2 Ongoing pregnancies. . . . . . . . . . . . . 90

Analysis 1.3. Comparison 1 Combined OCP versus no Rx, Outcome 3 Clinical/ongoing pregnancies. . . . . . . 91

Analysis 1.4. Comparison 1 Combined OCP versus no Rx, Outcome 4 Oocytes retrieved. . . . . . . . . . . . . . 93

Analysis 1.5. Comparison 1 Combined OCP versus no Rx, Outcome 5 Days of gonadotrophin treatment. . . . . . 94

Analysis 1.6. Comparison 1 Combined OCP versus no Rx, Outcome 6 Amount of gonadotrophins administered. .96

Analysis 1.7. Comparison 1 Combined OCP versus no Rx, Outcome 7 Pregnancy losses. . . . . . . . . . . . . . . 97

Analysis 1.8. Comparison 1 Combined OCP versus no Rx, Outcome 8 Ovarian cyst formation. . . . . . . . . . . 99

Analysis 1.9. Comparison 1 Combined OCP versus no Rx, Outcome 9 Multiple pregnancies. . . . . . . . . . . . 100

Analysis 1.10. Comparison 1 Combined OCP versus no Rx, Outcome 10 OHS syndrome. . . . . . . . . . . 101

Analysis 2.1. Comparison 2 Progestogen versus placebo/ no Rx, Outcome 1 Live births. . . . . . . . . . . . . . 102

Analysis 2.2. Comparison 2 Progestogen versus placebo/ no Rx, Outcome 2 Ongoing pregnancies. . . . . . . . . 103

Analysis 2.3. Comparison 2 Progestogen versus placebo/ no Rx, Outcome 3 Clinical pregnancies. . . . . . . . . . 104

Analysis 2.4. Comparison 2 Progestogen versus placebo/ no Rx, Outcome 4 Oocytes retrieved. . . . . . . . . . . . 105

Analysis 2.5. Comparison 2 Progestogen versus placebo/ no Rx, Outcome 5 Days of gonadotrophin treatment. . . 106

Analysis 2.6. Comparison 2 Progestogen versus placebo/ no Rx, Outcome 6 Amount of gonadotrophins administered. 107

Analysis 2.7. Comparison 2 Progestogen versus placebo/ no Rx, Outcome 7 Pregnancy losses. . . . . . . . . . . . . 108

Analysis 2.8. Comparison 2 Progestogen versus placebo/ no Rx, Outcome 8 Ovarian cyst formation. . . . . . . . . 109

Analysis 2.9. Comparison 2 Progestogen versus placebo/ no Rx, Outcome 9 Multiple pregnancies. . . . . . . . . . 110

Oral contraceptive pill, progestogen or estrogen pre-treatment for ovarian stimulation protocols for women undergoing assisted

reproductive techniques (Review)

Copyright $\odot 2010$ The Cochrane Collaboration. Published by John Wiley \& Sons, Ltd. 
Analysis 3.1. Comparison 3 Estrogen versus no Rx, Outcome 1 Live births. . . . . . . . . . . . . . . .

Analysis 3.2. Comparison 3 Estrogen versus no Rx, Outcome 2 Ongoing pregnancies. . . . . . . . . . . . . . . . .

Analysis 3.3. Comparison 3 Estrogen versus no Rx, Outcome 3 Clinical pregnancies. . . . . . . . . . . . . . .

Analysis 3.4. Comparison 3 Estrogen versus no Rx, Outcome 4 Oocytes retrieved. . . . . . . . . . . . . . . .

Analysis 3.5. Comparison 3 Estrogen versus no $\mathrm{Rx}$, Outcome 5 Days of gonadotrophin treatment. . . . . . . .

Analysis 3.6. Comparison 3 Estrogen versus no Rx, Outcome 6 Amount of gonadotrophins administered. . . . . .

Analysis 3.7. Comparison 3 Estrogen versus no Rx, Outcome 7 Pregnancy losses. . . . . . . . . . . . . . . .

Analysis 3.8. Comparison 3 Estrogen versus no Rx, Outcome 8 Ovarian cyst formation. . . . . . . . . . . . . .

Analysis 3.9. Comparison 3 Estrogen versus no Rx, Outcome 9 Multiple pregnancies. . . . . . . . . . . . . .

Analysis 3.10. Comparison 3 Estrogen versus no Rx, Outcome 10 OHS syndrome. . . . . . . . . . . . . .

Analysis 4.1. Comparison 4 Combined OCP versus progestogen, Outcome 1 Live births. . . . . . . . . . . . .

Analysis 4.2. Comparison 4 Combined OCP versus progestogen, Outcome 2 Ongoing pregnancies. . . . . . . . 121

Analysis 4.3. Comparison 4 Combined OCP versus progestogen, Outcome 3 Clinical pregnancies. . . . . . . . 121

Analysis 4.4. Comparison 4 Combined OCP versus progestogen, Outcome 4 Oocytes retrieved. . . . . . . . . . 122

Analysis 4.5. Comparison 4 Combined OCP versus progestogen, Outcome 5 Amount of gonadotrophins administered. 123

Analysis 4.6. Comparison 4 Combined OCP versus progestogen, Outcome 6 Pregnancy losses. . . . . . . . . . . . 123

Analysis 4.7. Comparison 4 Combined OCP versus progestogen, Outcome 7 Multiple pregnancies. . . . . . . . . 124

Analysis 5.1. Comparison 5 Combined OCP versus estrogen, Outcome 1 Live births. . . . . . . . . . . . . . . . 125

Analysis 5.2. Comparison 5 Combined OCP versus estrogen, Outcome 2 Ongoing pregnancies. . . . . . . . . . . 126

Analysis 5.3. Comparison 5 Combined OCP versus estrogen, Outcome 3 Clinical pregnancies. . . . . . . . . . . . 127

Analysis 5.4. Comparison 5 Combined OCP versus estrogen, Outcome 4 Oocytes retrieved. . . . . . . . . . . . . . 128

Analysis 5.5. Comparison 5 Combined OCP versus estrogen, Outcome 5 Amount of gonadotrophins administered. 128

Analysis 5.6. Comparison 5 Combined OCP versus estrogen, Outcome 6 Pregnancy losses. . . . . . . . . . . . . 129

Analysis 5.7. Comparison 5 Combined OCP versus estrogen, Outcome 7 Multiple pregnancies. . . . . . . . . 130

Analysis 6.1. Comparison 6 Progestogen versus estrogen, Outcome 1 Live births. . . . . . . . . . . . . . . . . . 130

Analysis 6.2. Comparison 6 Progestogen versus estrogen, Outcome 2 Ongoing pregnancies. . . . . . . . . . . . . . 131

Analysis 6.3. Comparison 6 Progestogen versus estrogen, Outcome 3 Clinical pregnancies. . . . . . . . . . . . . 131

Analysis 6.4. Comparison 6 Progestogen versus estrogen, Outcome 4 Oocytes retrieved. . . . . . . . . . . . . . . . 132

Analysis 6.5. Comparison 6 Progestogen versus estrogen, Outcome 5 Amount of gonadotrophins administered. . . 133

Analysis 6.6. Comparison 6 Progestogen versus estrogen, Outcome 6 Pregnancy losses. . . . . . . . . . . . . . . . . 133

Analysis 6.7. Comparison 6 Progestogen versus estrogen, Outcome 7 Multiple pregnancies. . . . . . . . . . . . . . 134

ADDITIONAL TABLES . . . . . . . . . . . . . . . . . . . . . . . . . . . . . . . . . . . . . . . .

APPENDICES . . . . . . . . . . . . . . . . . . . . . . . . . . . . . . . . . . . . . . . . . . . . . . .

WHAT'S NEW . . . . . . . . . . . . . . . . . . . . . . . . . . . . . . . . . . . . . 153

HISTORY . . . . . . . . . . . . . . . . . . . . . . . . . . . . . . . . . . . . . . . . 153

CONTRIBUTIONS OF AUTHORS . . . . . . . . . . . . . . . . . . . . . . . . . . . . . . . . . . . . . . . . . . . . . .

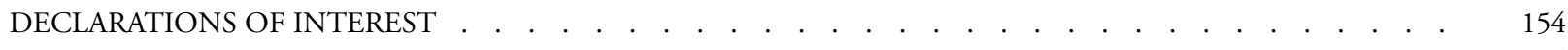

SOURCES OF SUPPORT . . . . . . . . . . . . . . . . . . . . . . . . . . . . . . . . . . . . . . . . . . . . . . . 154

DIFFERENCES BETWEEN PROTOCOL AND REVIEW . . . . . . . . . . . . . . . . . . . . . . . . . . . . . . . 155

INDEX TERMS . . . . . . . . . . . . . . . . . . . . . . . . . . . . . . . . . . . . . . . . . . . . . 155

Oral contraceptive pill, progestogen or estrogen pre-treatment for ovarian stimulation protocols for women undergoing assisted 
[Intervention Review]

\title{
Oral contraceptive pill, progestogen or estrogen pre- treatment for ovarian stimulation protocols for women undergoing assisted reproductive techniques
}

\author{
Brechtje Smulders ${ }^{1}$, Sanne M van Oirschot ${ }^{1}$, Cindy Farquhar ${ }^{2}$, Luk Rombauts ${ }^{3}$, Jan AM Kremer ${ }^{4}$ \\ ${ }^{1}$ Medical School, Radboud University Nijmegen, Nijmegen, Netherlands. ${ }^{2}$ Obstetrics and Gynaecology, University of Auckland, Auck- \\ land, New Zealand. ${ }^{3}$ Monash IVF and Department of O\&G, Monash University, Melbourne, Australia. ${ }^{4}$ Obstetrics \& Gynaecology, \\ Radboud University Nijmegen Medical Centre, Nijmegen, Netherlands
}

Contact address: Sanne M van Oirschot, Medical School, Radboud University Nijmegen, Nijmegen, Netherlands. sannevanoirschot@student.ru.nl.

Editorial group: Cochrane Menstrual Disorders and Subfertility Group.

Publication status and date: Edited (no change to conclusions), published in Issue 11, 2010.

Review content assessed as up-to-date: 15 November 2008.

Citation: Smulders B, van Oirschot SM, Farquhar C, Rombauts L, Kremer JAM. Oral contraceptive pill, progestogen or estrogen pretreatment for ovarian stimulation protocols for women undergoing assisted reproductive techniques. Cochrane Database of Systematic Reviews 2010, Issue 1. Art. No.: CD006109. DOI: 10.1002/14651858.CD006109.pub2.

Copyright (C) 2010 The Cochrane Collaboration. Published by John Wiley \& Sons, Ltd.

\begin{abstract}
A B S T R A C T
Background

For many subfertile women, assisted reproductive techniques (ART) is the only hope for a pregnancy and live birth. The combined oral contraceptive pill (OCP) given prior to the hormone therapy in an IVF cycle may result in better pregnancy outcomes of ART.
\end{abstract}

Objectives

To assess whether pre-treatment with combined OCPs, progestogens or estrogens in ovarian stimulation protocols affects outcomes in subfertile couples undergoing ART.

Search methods

We searched the Cochrane Menstrual Disorders and Subfertility Group Specialised Register, The Cochrane Central Register of Controlled Trials, MEDLINE, EMBASE, CINAHL, PsycINFO. Other electronic resources on the Internet, reference list of relevant articles were also searched as well as the ESHRE abstracts (2008). All these searches were conducted in November 2008.

\section{Selection criteria}

Randomised controlled trials of pre-treatment with combined OCP, progestogen or estrogen in subfertile women undergoing IVF/ ICSI.

\section{Data collection and analysis}

Two authors independently extracted the data and assessed risk of bias. We calculated Peto odds ratios for dichotomous data and weighted mean difference for continuous variables. Authors of trials were contacted in case of missing data.

Oral contraceptive pill, progestogen or estrogen pre-treatment for ovarian stimulation protocols for women undergoing assisted reproductive techniques (Review)

Copyright $\odot 2010$ The Cochrane Collaboration. Published by John Wiley \& Sons, Ltd. 


\section{Main results}

No evidence of effect was found with regard to the number of live births when using a pre-treatment. However, the combined OCP in $\mathrm{GnRH}$ antagonist cycles, compared to no pre-treatment, is associated with fewer clinical pregnancies (Peto OR 0.69, 95\% CI 0.50 to $0.9 ; \mathrm{P}=0.03$ ) and more days and a higher amount of gonadotrophin therapy (respectively: MD $1.44,95 \% \mathrm{CI} 1.15$ to $1.72 ; \mathrm{P}<$ 0.00001; and MD 231.14, 95\% CI 161.50 to 300.78; P < 0.00001). Also compared to placebo or no pre-treatment, a progestogen pre-treatment in GnRH agonist cycles, is associated with more clinical pregnancies (Peto OR 1.95, 95\% CI 1.20 to 3.17; P = 0.007) and fewer ovarian cysts (Peto OR 0.21, 95\% CI 0.12 to 0.35 ; P < 0.00001). At last, in estrogen pre-treated GnRH antagonist cycles, compared to no pre-treatment, more oocytes are retrieved (MD 2.01, 95\% CI 1.76 to 2.25; P < 0.00001), but a higher amount of gonadotrophin therapy is needed (MD 207.08, 95\% CI 167.77 to 246.39; P < 0.00001). For the other outcomes no evidence of effect was found or there were not enough studies available in the subgroup for pooling.

\section{Authors' conclusions}

There was evidence of improved pregnancy outcomes with progestogen pre-treatment and poorer pregnancy outcomes with a combined OCP pre-treatment. However, we conclude that major changes in ART protocols should not be made at this time, since the number of overall studies in the subgroups is small and reporting of the major outcomes is inadequate.

\section{PLAIN LANGUAGE SUMMARY}

\section{Pre-treatments in IVF/ICSI cycles}

In vitro fertilisation (IVF) and intra cytoplasmic sperm injection (ICSI) are important techniques for women who have trouble getting pregnant. IVF and ICSI cycles consist of a few steps. First the woman receives hormone therapy to stimulate her ovaries in producing egg cells. When a few egg cells are mature enough to be fertilized, the woman receives a single hormone injection. This triggers the ovaries to release the egg cells, so they can be gathered by the clinician. The eggs are then fertilised outside the woman's body and become embryos. At last one or two embryos are transferred into the womb.

Before the first step in IVF or ICSI cycles (hormone therapy), a pre-treatment with a combined oral contraceptive pill (OCP) can be given. A combined OCP contains both progestogen and oestrogen. Pre-treatment with a progestogen or oestrogen alone could also be used before the hormone therapy. These pre-treatments suppress the woman's own hormone production. This might improve the woman's response to the hormone therapy in IVF/ICSI cycles. In this way, adverse events such as cyst formation and the number of pregnancy losses might be reduced and pregnancy outcomes might be improved.

The aim of this review is to assess if pre-treatments with a combined OCP or a progestogen or oestrogen influence these outcomes in IVF/ICSI cycles. This is done by pooling results of more than one study, which will hopefully provide a more solid conclusion. We were able to include 23 studies: a reasonable number. However, due to the formation of subgroups, we have only pooled results of five studies maximum.

Pre-treatment with a combined OCP seems to result in fewer clinical pregnancies. More days of gonadotrophin therapy and a higher amount of gonadotrophins are needed. This is mainly important with regard to the financial aspect of the IVF/ICSI treatment. A pretreatment with progestogen is associated with more clinical pregnancies and fewer ovarian cysts. Ovarian cysts are frequent reasons for cycle cancellation. In oestrogen pre-treated cycles more eggs are retrieved, but a higher amount of gonadotrophin therapy is needed.

A limitation of this review is that most included studies were small and of poor quality.

The need for a pre-treatment with oral contraceptives should be clearly explained to the woman undergoing IVF, because this might be hard to understand when you are trying to get pregnant.

For definitions of terminology see our Glossary.

Oral contraceptive pill, progestogen or estrogen pre-treatment for ovarian stimulation protocols for women undergoing assisted 


\section{B A C K G R O U N D}

For definitions of terminology see our Glossary.

\section{Description of the condition}

For subfertile women, assisted reproductive techniques (ART) such as in vitro fertilisation (IVF) and intra cytoplasmic sperm injection (ICSI) can be a way to achieve pregnancy. Pregnancy and live birth rates are higher with IVF than with expectant management (Pandian 2005).

An IVF cycle has the following stages: ovarian stimulation, oocyte retrieval, fertilisation of the egg and transfer of the embryo. Ovarian stimulation involves the administration of gonadotrophins. These hormones stimulate growth and maturation of the follicle. Gonadotrophins include follicle stimulating hormone (FSH) and luteinising hormone (LH). There are two different gonadotrophin preparations; human menopausal gonadotrophin (hMG) which consists of both FSH and LH, and a more recent therapy, recombinant follicle stimulating hormone ( $\mathrm{rFSH})$. There is insufficient evidence of difference between these treatments in ongoing pregnancy or live birth rate and other aspects with relation to IVF (Van Wely 2003).

There are a number of undesirable events associated with gonadotrophin therapy that can complicate treatment and outcomes: ovarian hyperstimulation syndrome, premature LH-surge and multiple pregnancy (Dodson 1989). In some women undergoing IVF therapy these problems occur because the endogenous FSH and LH production is too dominant (Awadalla 1987). Gonadotrophin releasing hormone analogues ( $\mathrm{GnRHa}$ ) have been administered to inhibit the production of endogenous FSH and LH (Dodson 1989; Awadalla 1987). GnRH is a hormone that occurs naturally in the woman's body and that regulates the production of gonadotrophins. There are two different kinds of $\mathrm{GnRH}$ analogues: agonists or antagonists. The difference lies in their mechanism of action. GnRH agonists bind to the GnRH-receptors in the pituitary gland and initially stimulate the release of gonadotrophins ('flare-up'). Negative feedback causes a decrease in the number of $\mathrm{GnRH}$-receptors, which results in the release of fewer gonadotrophins. In a traditional treatment protocol, $\mathrm{GnRH}$ agonists are administered prior to commencing gonadotrophins, ensuring that the flare-up will be over by the time gonadotrophins are injected. Conversely, GnRH antagonists can be started after gonadotrophin therapy has been administered because they bind competitively to the receptor, causing immediate suppression of the endogenous production of FSH and LH (Tarlatzis 2006). Therefore $\mathrm{GnRH}$ analogues can prevent a premature $\mathrm{LH}$-surge and synchronize the follicle cohort.

The authors of a Cochrane Review comparing GnRH agonists with $\mathrm{GnRH}$ antagonist cycles, concluded that the use of $\mathrm{GnRH}$ antagonists results in a reduction in the incidence of severe ovarian hyperstimulation syndrome and fewer days of $\mathrm{GnRH}$ analogue and $\mathrm{hMG}$ treatment, however this is at the expense of a statistically significantly (albeit slightly) lowered ongoing pregnancy rate (OR 0.82, 95\% CI 0.69 to $0.98, \mathrm{P}=0.03$ ) (Al-Inany 2006).

When a few follicles reach maturity after gonadotrophin stimulation and $\mathrm{GnRH}$ analogue treatment, human Chorionic Gonadotrophin (hCG) is administered to trigger ovulation and 34 to 36 hours later, oocyte retrieval is undertaken and the egg is fertilised outside the body. Following fertilisation, the embryos are either transferred on day two or three (cleavage stage) or on day five or six (blastocyst stage). Luteal phase support is typically provided as a progestogen or a hCG treatment, or as a combination of both.

\section{Description of the intervention}

Oral contraceptive pills (OCP) are widely used by women of different ages to prevent pregnancy. They are also indicated for a range of menstrual and gynaecological conditions, such as acne vulgaris, polycystic ovary syndrome and menorrhagia (Arowojolu 2007; Harwood 2007; Irvine 1999). Combined pills consisting of oestrogen and progestogen reduce the women's own production of FSH and LH by way of a negative feedback (Cohen 1979; Gaspard 1984). The combined OCP suppresses gonadal function and, in the absence of a LH-surge, no flare-up or premature ovulation will occur. Only progestogen has a contraceptive effect (Erkkola 2007). Progestogen has the ability to slow GnRH pulsatility of the pituitary gland, thereby reducing gonadotrophin surges and, according to dose, inhibiting ovulation (Anderson 1990; Erkkola 2007; Le Nestour 1993; Moudgal 1985). Estrogen is added in the combined OCP to regulate the bleeding patterns, though it is also capable of reducing FSH levels (De Ziegler 1998; Le Nestour 1993).

Most of progestogen-only pills do not inhibit ovulation although higher doses of progestogen may do so (Erkkola 2007).

\section{How the intervention might work}

The combined oral contraceptive pill (OCP) given prior to gonadotrophin in an in vitro fertilisation cycle assists synchronisation of the follicular development and prevents the occurrence of spontaneous LH-surges (Gonen 1990). Huirne reports similar data as well as a reduction of the occurrence of large follicles prior to day eight (Huirne 2006a). In a further study, both the combined OCP and progestogen have a suppressive effect on $\mathrm{LH}$ and FSH secretion. However, oestrogen administration (in a dosage of $4 \mathrm{mg} /$ day) does not suppress serum LH and FSH values (Cédrin-Durnerin 2007).

It is found that the resulting pituitary suppression of combined OCPs in GnRH antagonist cycles is associated with slower follicular growth and lowered serum estradiol levels in the early part of the cycle. This results in a longer duration of $\mathrm{rFSH}$ stimulation 
and a higher total $\mathrm{rFSH}$ consumption than in antagonist cycles without pre-treatment (Cédrin-Durnerin 2007).

Combined oral contraceptive pre-treatment in an ovarian stimulation protocol before IVF can reduce cyst formation, shorten the length of GnRH analogue treatment and reduce the amount of gonadotrophin needed, without negatively affecting the pregnancy rate (Biljan 1998). Pituitary suppression seems to occur earlier with progestogen pre-treatment and fewer ovarian cysts are formed, when compared with no pre-treatment (Engmann 1999). Combined oral contraceptive pre-treatment can be used for scheduling oocyte retrieval on days of the working week, which is important with antagonist cycles (Barmat 2005; Gonen 1990; Huirne 2006). Scheduling is of benefit for the clinicians and people in the laboratory, since these people usually do not work on weekends.

\section{Why it is important to do this review}

There is some debate regarding the effects of the combined OCP upon pregnancy rate. Higher rates of clinical pregnancy and live birth have been reported when dual suppression protocols and $\mathrm{GnRH}$ analogues were compared to a $\mathrm{GnRH}$ analogue protocol without the use of oral contraceptives in non RCTs (Damario 1997; Keltz 2007). However, other non randomised studies have found no evidence of effect with regard to pregnancy rate (Bellver 2007; Galera 2004).

As illustrated, there is a lack of consensus regarding whether pretreatment with combined oral contraceptives in ovarian stimulation protocols improves rates of pregnancy and live birth. Furthermore, the effects of pre-treatment with progestogen or oestrogen on IVF outcomes is unclear. The results of many smaller randomised controlled trials can be pooled in a systematic review and may provide a more definitive answer regarding the role of the combined oral contraceptive pill, progestogens or estrogens in assisted reproductive therapy.

\section{O B J E C T I VES}

To determine whether pre-treatment with the combined oral contraceptive pill, a progestogen or an oestrogen in ovarian stimulation protocols affects outcomes in subfertile couples undergoing any form of assisted reproductive therapy.

\section{MET HODS}

\section{Criteria for considering studies for this review}

- Only truly randomised controlled trials (RCTs) were included in this review. We included both published and unpublished studies and we excluded trials with quasirandomisation.

- Cross-over trials were included in this review, but excluded from analysis unless pre-crossover data are available, as the design is inappropriate in this context.

\section{Types of participants}

Women of any age with subfertility, regardless of any cause, undergoing assisted reproductive therapy.

We only excluded two types of participants from this review. The first is women with premature ovarian failure, because these women require a totally different ovarian stimulation protocol. The second is women who participated in ovarian stimulation protocols as oocyte donors.

\section{Types of interventions}

1. Pre-treatment with a combined OCP prior to gonadotrophins with or without $\mathrm{GnRH}$ analogues (agonist or antagonist) versus no pre-treatment or placebo prior to gonadotrophins with or without GnRH analogues (agonist or antagonist)

2. Pre-treatment with progestogen prior to gonadotrophins with or without $\mathrm{GnRH}$ analogues (agonist or antagonist) versus no pre-treatment or placebo prior to gonadotrophins with or without GnRH analogues (agonist or antagonist)

3. Pre-treatment with oestrogen prior to gonadotrophins with or without GnRH analogues (agonist or antagonist) versus no pre-treatment or placebo prior to gonadotrophins with or without $\mathrm{GnRH}$ analogues (agonist or antagonist)

4. Pre-treatment with a combined OCP prior to gonadotrophins with or without $\mathrm{GnRH}$ analogues (agonist or antagonist) versus pre-treatment with a progestogen prior to gonadotrophins with or without $\mathrm{GnRH}$ analogues (agonist or antagonist)

5. Pre-treatment with a combined OCP prior to gonadotrophins with or without $\mathrm{GnRH}$ analogues (agonist or antagonist) versus pre-treatment with an oestrogen prior to gonadotrophins with or without $\mathrm{GnRH}$ analogues (agonist or antagonist)

6. Pre-treatment with a progestogen prior to gonadotrophins with or without $\mathrm{GnRH}$ analogues (agonist or antagonist) versus pre-treatment with an oestrogen prior to gonadotrophins with or without GnRH analogues (agonist or antagonist) We excluded studies that compare different doses of the same pretreatment.

Types of outcome measures 


\section{Primary outcomes}

- Number of live births per woman randomised - defined as the delivery of a fetus with signs of life after twenty completed weeks of gestational age, counted as live birth event. When there are multiple live births (e.g. twins or triplets), these are counted as one live birth event (Griffin 2002).

\section{Secondary outcomes}

- Number of ongoing pregnancies per woman randomised defined as evidence of a gestational sac with fetal heart motion at twelve weeks or later, confirmed with ultrasound. When there are multiple gestational sacs in one patient, these are counted as one ongoing pregnancy (Griffin 2002).

- Number of clinical/ongoing pregnancies per woman randomised - defined as evidence of a gestational sac with fetal heart motion at six weeks or later, confirmed with ultrasound. When there are multiple gestational sacs in one patient, these are counted as one clinical pregnancy (Griffin 2002).

- Number of oocytes retrieved per woman randomised

- Days of gonadotrophin treatment per woman randomised

- Amount of gonadotrophins administered per woman randomised

\section{Adverse outcomes}

- Number of pregnancy loss per woman randomised - defined as the sum of the number of spontaneous abortions (pregnancy loss before twenty completed weeks of gestation) and the number of stillbirths (pregnancy loss after twenty completed weeks of gestation) (Griffin 2002).

- Number of women with ovarian cyst formation - defined as any intraovarian sonolucent structure with a mean diameter of 15 mm or more confirmed with ultrasound at least one week after start pituitary suppression (Biljan 1998).

- Number of multiple pregnancies per woman randomised when there are multiple gestational sacs in one patient, these are counted as one multiple pregnancy.

- Number of ovarian hyperstimulation (OHS) syndrome per woman randomised - defined as a condition that can occur from drugs used in ART, through stimulating a large number of follicles in the ovary to develop and ovulate (MDSG Module 2008).

\section{Search methods for identification of studies}

We obtained all studies that describe (or might describe) randomised controlled trials of pre-treatment with combined oral contraceptive pills, progestogen or oestrogen therapy prior to GnRH analogues (agonists or antagonists) and gonadotrophins or gonadotrophins alone in women undergoing in vitro fertilisation, using the following search strategies.

\section{Electronic searches}

- The Menstrual Disorders and Subfertility Group (MDSG) Specialised Register of controlled trials has been searched for any relevant trials using the terms 'in vitro fertilization' or 'intracytoplasmic sperm injection' or 'ART' or 'controlled ovarian' AND 'oral contraceptive' or 'combined oral contraceptives' or 'progestogen' or 'oestrogen' in the titles, abstracts and keywords; 1947 -17 November 2008 (Appendix 1).

We searched the following electronic databases using Ovid software:

- Cochrane Central Register of Controlled Trials (CENTRAL); from inception - 17 November 2008 (Appendix 2);

- MEDLINE; 1950 - 17 November 2008 (Appendix 3). We combined this search with the Cochrane highly sensitive search strategy for identifying randomised trials (Higgins 2008);

- EMBASE; 2007 - 17 November 2008 (Appendix 4). We combined this search with trial filters developed by the Scottish Intercollegiate Guidelines Network (SIGN);

- Cumulative Index to Nursing and Allied Health Literature (CINAHL); 1982 - 17 November 2008 (Appendix 5). We combined this search with trial filters developed by the Scottish Intercollegiate Guidelines Network (SIGN); and

- PsycINFO; 1806 - 17 November 2008 (Appendix 6).

We did not restrict the search by language. We managed output of these searches with a reference manager, Endnote (EndNote). Through this program, duplicates can be found and removed.

\section{Searching other resources}

In addition, we searched some other resources than the electronic databases mentioned above to obtain more relevant trials. We accessed all the web sites on 18 November 2008, except for OpenSIGLE.

- Trial registers for ongoing and registered trials: Current Controlled Trials (http://www.controlled-trials.com), ClinicalTrials.gov (http://clinicaltrials.gov/ct2/home), and The World Health Organisation International Trials Registry Platform Search Portal (http://www.who.int/trialsearch).

- Citation indexes (http://scientific.thomson.com/products/ sci).

- PubMed (http://www.ncbi.nlm.nih.gov/pubmed); we combined this search with random control filters for PubMed (Higgins 2008).

- Conference abstracts on the ISI Web of Knowledge (http:// isiwebofknowledge.com).

- ClinicalStudyResults provides clinical trial results of marketed pharmaceuticals (http://www.clinicalstudyresults.org).

- Open System for Information on Grey Literature (http:// opensigle.inist.fr, accessed on 26 November 2008).

- All the reference lists of the studies obtained with the electronic databases. 
- Handsearching of the abstracts of the 24th annual meeting of the European society of human reproduction and embryology in Barcelona (Spain), 6 to 9 July 2008 (ESHRE 2008).

\section{Data collection and analysis}

\section{Selection of studies}

Two review authors ( $\mathrm{BS}$ and $\mathrm{SvO}$ ) independently scanned the titles and abstracts of all the studies found with the search to exclude those which did not meet the inclusion criteria. We discussed any disagreement or doubt, whether a study is eligible for inclusion or not, with a third review author (CF) to achieve consensus. We obtained full text of those RCTs deemed eligible for inclusion where possible, and subjected them to critical appraisal of their risk of bias. Where appropriate, we included them in this systematic review.

Subsequently, we constructed a table of Characteristics of included studies for those trials considered suitable for inclusion. We produced another table, Characteristics of excluded studies, for those that did not satisfy the inclusion criteria. In this table we listed the reasons for exclusion.

\section{Data extraction and management}

The review authors ( $\mathrm{BS}$ and $\mathrm{SvO}$ ) independently extracted the data using data extraction forms, which we designed for this particular review (Appendix 7; Appendix 8). We resolved any discrepancies by discussion and the help of a third review author (CF).

The data extraction forms included risk of bias criteria and methodological details. The information about the studies is included in the review and presented in the tables of Characteristics of included studies. We managed the data using Review Manager 5 software (RevMan).

We extracted the following information from the studies selected for the review:

\section{Trial characteristics}

- Quality of allocation concealment

- Method of randomisation

- Trial design: cross-over or parallel

- Blinding of investigator, patient and outcome assessors

- Details on dropouts and intention-to-treat analysis used

- Presence of power calculation

- Duration, timing and location of the trial (single or multi centre)

- Number of patients randomised, excluded, analysed and lost to follow-up

- Source of funding

Characteristics of participants

- Women's age

- Body Mass Index (BMI)
- Cause of subfertility

- Duration of subfertility

- Previous number of ART treatment cycles

- Poor response to ovarian stimulation

\section{Characteristics of interventions}

- Preparations used for pre-treatment, pituitary desensitization and ovarian stimulation

- Dosage of preparations

- Length of each different treatment in days

- Treatment protocol (timing of administration of pretreatments, gonadotrophins and GnRH analogues)

- Type of protocol (long versus short agonist protocol; single versus multiple antagonist protocol; fixed versus flexible antagonist protocol)

\section{Types of outcome measures}

As described above (see Criteria for considering studies for this review).

\section{Assessment of risk of bias in included studies}

We assessed and reported on the risk of bias of included studies in accordance with the Cochrane Handbook for Systematic Reviews of Interventions (Higgins 2008) which recommends the explicit reporting of the following domains:

- Sequence generation

Was sequence generation adequate (e.g. use of a random number table, a computer random number generator or coin tossing), inadequate (e.g. use of date of birth or clinical record number) or unclear (insufficient information about the process of sequence generation)?

- Allocation concealment

Was allocation concealment adequate (e.g. use of central allocation or opaque sealed envelopes), inadequate (e.g. use of an open random allocation schedule, date of birth or case record number) or unclear (insufficient information about the process of allocation concealment)?

- Blinding of participants, providers and outcome assessors

Was blinding adequate (e.g. participants and researchers were all blinded and it was unlikely that blinding could have been broken, either participants or some researchers are not blinded but outcome assessment was blinded or no blinding was used but this is not likely to influence outcomes), inadequate (e.g. no blinding or incomplete blinding and outcomes are likely to be influenced by this) or unclear (insufficient information about the process of blinding)?

- Incomplete outcome data

Were outcome data addressed adequately (e.g. there were no missing outcome data, reasons for missing outcome data were unlikely to be related to true outcome or missing outcome data were balanced in numbers across intervention groups), inadequate (e.g. reasons for missing outcome data were likely to be related to true outcome) or unclear (insufficient information about the process of addressing outcome data)?

- Selective outcome reporting 
Was the study free of selective reporting? Adequate (e.g. the study protocol is available and all pre-specified outcomes have been reported or the study protocol is not available but it is clear that all pre-specified outcomes have been reported), inadequate (e.g. not all pre-specified primary outcomes have been reported) or unclear (insufficient information about the process of outcome reporting).

- Other sources of bias for RCTs

Was the study free of other bias? Adequate (the study seems to be free of other bias), inadequate (e.g. extreme baseline imbalance, a potential source of bias related to the specific study design used or early stopping) or unclear (insufficient information about other sources of bias).

By using a simple form (Appendix 7; Appendix 8) two review authors (BS and $\mathrm{SvO}$ ) separately assessed these domains as 'yes' (indicating a low risk of bias), 'unclear' (indicating an uncertain risk of bias) or 'no' (indicating a high risk of bias).

The assessments of the two review authors were compared and we resolved any discrepancies in the interpretation of the risk of bias of a study by discussion with a third review author. We did not automatically exclude any study as a result of a rating of 'Unclear' or 'No'. Where it was unclear, we contacted authors of studies about the methods used and also sought any missing data.

We presented the results of the risk of bias assessment in the tables of Characteristics of included studies within the review, including commentary about each of the domains. This led to an overall assessment of the risk of bias of included studies (Figure 1; Figure 2).

Figure I. Methodological quality graph: review authors' judgements about each methodological quality item presented as percentages across all included studies.

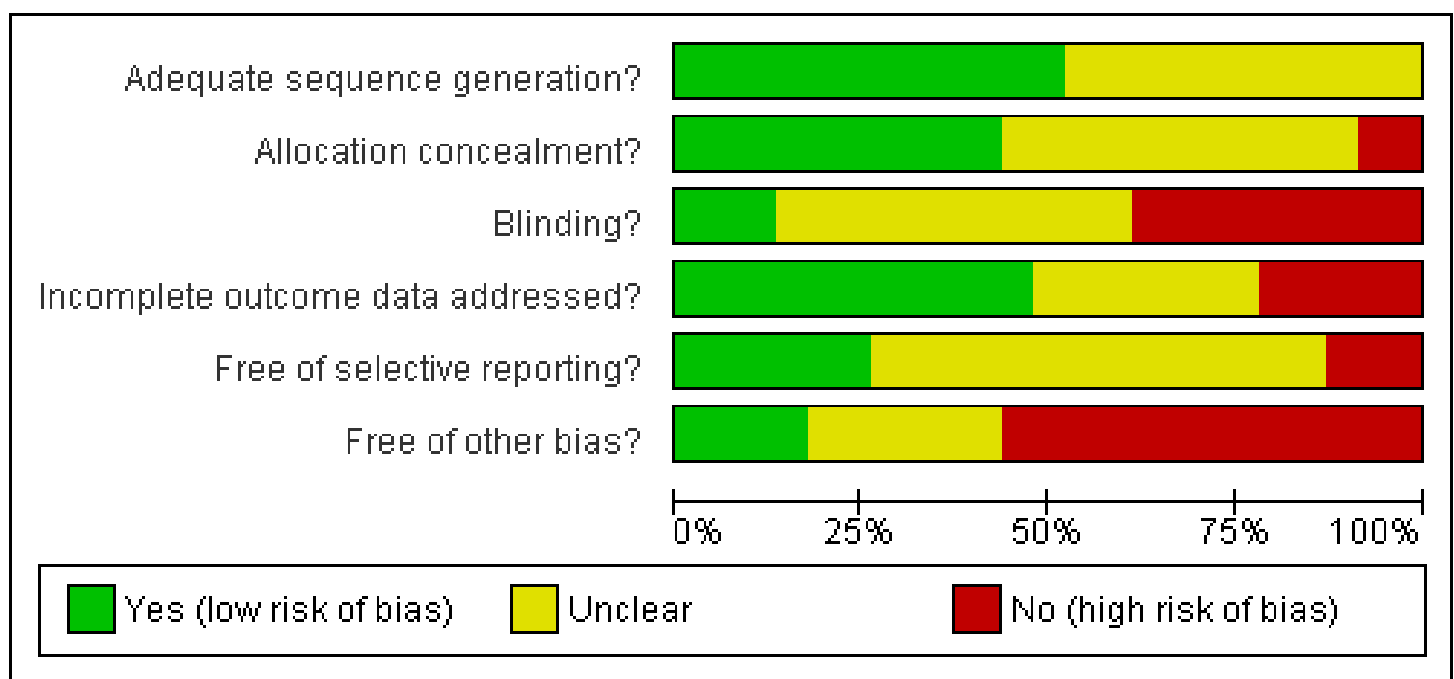

Oral contraceptive pill, progestogen or estrogen pre-treatment for ovarian stimulation protocols for women undergoing assisted 
Figure 2. Methodological quality summary: review authors' judgements about each methodological quality item for each included study.

\begin{tabular}{|c|c|c|c|c|c|c|}
\hline & 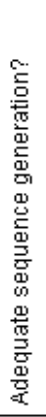 & 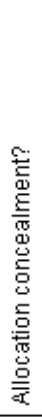 & 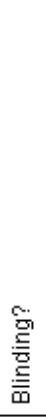 & 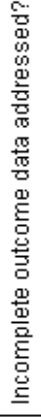 & 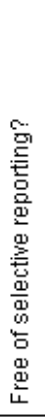 & 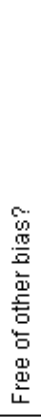 \\
\hline Aston 1995 & $?$ & + & + & + & $?$ & $?$ \\
\hline Biljan 1998a & + & + & ? & & $?$ & \\
\hline Cédrin-Durnerin 1996 & $?$ & $?$ & $?$ & & $?$ & \\
\hline Cédrin-Durnerin 2007 & + & & & & ? & \\
\hline Daly 2002 & $?$ & $?$ & C. & ? & ? & \\
\hline Ditkoff 1996 & + & & & & ? & \\
\hline Engmann 1999 & + & + & + & & + & \\
\hline Fanchin 2001 & $?$ & $?$ & ? & $?$ & & \\
\hline Fanchin $2003 a$ & + & + & 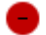 & & ? & \\
\hline Franco Jr 2003 & + & & & & $?$ & \\
\hline Hugues 1994 & $?$ & $?$ & ? & ? & 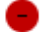 & \\
\hline Huirne 2006a & + & $?$ & $?$ & & $?$ & \\
\hline Huirne 2006b & + & + & . & & + & \\
\hline Hwang 2004 & + & + & + & & + & $?$ \\
\hline Kim 2005 & + & ? & - & ? & $?$ & \\
\hline Kolibianakis 2006 & + & & - & & + & \\
\hline Obruca 2001 & $?$ & ? & $?$ & $?$ & ? & \\
\hline Raoofi 2008 & $?$ & $?$ & $?$ & & $?$ & \\
\hline Rombauts 2006 & $?$ & + & - & & + & $?$ \\
\hline Salat-Baroux 1988 & $?$ & $?$ & ? & + & $?$ & $?$ \\
\hline Shaker 1995 & + & + & ? & + & + & \\
\hline Tan 2001 & $?$ & $?$ & $?$ & $?$ & & $?$ \\
\hline Wang 2008 & $?$ & $?$ & ? & $?$ & ? & $?$ \\
\hline
\end{tabular}

Oral contraceptive pill, progestogen or estrogen pre-treatment for ovarian stimulation protocols for women undergoing assisted 


\section{Measures of treatment effect}

For dichotomous data, we expressed results for each study as Peto odds ratios (OR) with $95 \%$ confidence intervals (CI). For continuous variables, we reported the data as a weighted mean difference (WMD) with $95 \%$ confidence intervals.

\section{Unit of analysis issues}

In order to avoid analysis errors, we only pooled data that report outcomes per woman randomised.

\section{Dealing with missing data}

In case of missing data in the included studies, we contacted the original investigators by e-mail or post to request relevant missing information. If we did not receive a reply, we sent a reminder to the authors a couple of weeks later. Furthermore, we contacted the members of the MDSG-group to ask if they know any of the authors personally or have contact details.

We reported the data according to intention-to-treat where possible.

\section{Assessment of heterogeneity}

Before any meta-analysis was done, we judged whether there was sufficient similarity between the eligible studies in their design and clinical characteristics to ensure that pooling is valid. We assessed statistical heterogeneity in the results of trials by using the $\mathrm{Chi}^{2}$ test. A low $\mathrm{P}$ value (or a large $\mathrm{Chi}^{2}$ statistic relative to its degree of freedom) will potentially provide evidence of heterogeneity of intervention effects and show that results are not influenced by chance alone (Higgins 2008).

We used the $\mathrm{I}^{2}$ statistic to assess the impact of the heterogeneity on the meta-analysis. We interpreted the result of the $\mathrm{I}^{2}$ statistic as follow:

- $0 \%$ to $40 \%$ : might not be important;

- $30 \%$ to $60 \%$ : may represent moderate heterogeneity;

- $50 \%$ to $90 \%$ : may represent substantial heterogeneity; and

- $75 \%$ to $100 \%$ : considerable heterogeneity (Higgins 2008).

If we found marked clinical or statistical heterogeneity ( $\mathrm{I}^{2}$ more than $50 \%$ ), we explored reasons for this heterogeneity by using sensitivity analysis.

\section{Assessment of reporting biases}

To investigate the potential for publication bias, we planned to use a funnel plot, but due to the small number of studies per subgroup this was not possible.

\section{Data synthesis}

We carried out statistical analysis using Review Manager 5 (RevMan). We used fixed-effect meta-analysis for combining data. If we found heterogeneity between studies sufficient to suggest that treatment effects may differ between trials, we explored this by sensitivity analysis. We planned to do a random-effects metaanalysis if required, but this was not necessary.

\section{Subgroup analysis and investigation of heterogeneity}

To reduce heterogeneity between studies, we pooled the data of GnRH agonist and GnRH antagonist cycles separately by performing subgroup analyses on different treatment protocols:

- GnRH agonist in study group versus $\mathrm{GnRH}$ agonist in control group

- $\mathrm{GnRH}$ antagonist in study group versus $\mathrm{GnRH}$ antagonist in control group

- GnRH antagonist in study group versus $\mathrm{GnRH}$ agonist in control group

- GnRH agonist in study group versus GnRH antagonist in control group

Furthermore, we did subgroup analysis on low responder patients. Unfortunately, we could only include one trial in each subgroup which made pooling impossible.

Furthermore, we planned to do subgroup analyses on women's age; poor response; agonist long, short and ultra-short protocol; and the duration of pre-treatment. However, due to the small number of included studies per comparison, we were not able to do subgroup analyses on these aspects.

\section{Sensitivity analysis}

We planned to use a sensitivity analysis to explore whether the findings from the meta-analysis were dependent on aspects within individual studies deemed eligible for inclusion. Aspects we planned to do a sensitivity analysis on, were random sequence generation, allocation concealment and the overall assessment of risk of bias. Due to the small number of studies in each subgroup, we were unable to do any sensitivity analyses.

\section{R E S U L T S}

\section{Description of studies}

See: Characteristics of included studies; Characteristics of excluded studies; Characteristics of studies awaiting classification; Characteristics of ongoing studies. 


\section{Results of the search}

After searching the electronic databases, we found a total of 1049 studies: 492 studies in the MDSG specialised register of controlled trials, 123 studies in CENTRAL, 350 studies in MEDLINE, 61 studies in EMBASE, 3 studies in CINAHL and 20 studies in PsycINFO. After removing the duplicates and searching other resources, there were approximately 900 studies left. Around 200 studies seemed eligible for inclusion, after the first screening of titles and abstracts and we were able to include 23 studies in this review.

\section{Included studies}

The following is a summary of the methods, participants, interventions and outcomes of all the included studies. Full details of these domains (for each study separately) can be found in the tables of Characteristics of included studies.

\section{Methods in included studies}

The main analyses were based on 23 trials, which involved a total of 2596 women randomised to treatment.

The three largest trials included in this review were Kolibianakis 2006 (504 women), Rombauts 2006 (351 women) and Huirne 2006a (182 women). The smallest trial was Fanchin 2001 with fourteen women randomised. Four trials used a cross-over design, of which only two reported pre-cross-over data (Daly 2002; Wang 2008). The other two studies can not be used in our analysis since only post-cross-over data is available (Cédrin-Durnerin 1996; Fanchin 2001). The other nineteen trials used a parallel design. Four studies were conducted in multiple centres, according to their articles (Cédrin-Durnerin 2007; Huirne 2006a; Huirne 2006b; Rombauts 2006).

The trials took place in (or authors came from): France (six trials: Cédrin-Durnerin 1996; Cédrin-Durnerin 2007; Fanchin 2001; Fanchin 2003a; Hugues 1994; Salat-Baroux 1988); United Kingdom (two trials: Aston 1995; Shaker 1995); Canada (two trials: Biljan 1998a; Tan 2001); United Kingdom and Canada (Engmann 1999); United States of America (two trials: Daly 2002; Ditkoff 1996); Austria (Obruca 2001); Belgium (Kolibianakis 2006); Brazil (Franco Jr 2003); China (Wang 2008); Iran (Raoofi 2008); South Korea (Kim 2005); Taiwan (Hwang 2004); Australia, Denmark, Jordan and Norway (Rombauts 2006); The Netherlands and Belgium (Huirne 2006b); and The Netherlands, Belgium, France and Austria (Huirne 2006a).

Of the 23 included studies, ten performed and adhered a power calculation (Aston 1995; Biljan 1998a; Engmann 1999; Fanchin 2003a; Huirne 2006a; Huirne 2006b; Hwang 2004; Kim 2005; Kolibianakis 2006; Rombauts 2006). Seven studies did not adhere a power calculation (Cédrin-Durnerin 1996; Cédrin-Durnerin 2007; Ditkoff 1996; Franco Jr 2003; Raoofi 2008; Salat-Baroux 1988; Shaker 1995) and of five studies this is unclear, because there was only an abstract available (Daly 2002; Fanchin 2001; Hugues 1994; Obruca 2001; Tan 2001). Of one trial it was unclear, because we only have the article in a foreign language of which only the most important sections were translated (Wang 2008).

Only one of the included trials seems to have used a true intentionto-treat analysis (Kim 2005), which means that all outcomes of all the randomised women are used in the final analysis.

Of the other included trials it seems that this was not done. Nine trials analysed data of all randomised women for a few of the outcomes, but not for all (for example, the table of baseline characteristics is usually constructed by analysing data of all randomised women, but the number of oocytes retrieved is calculated from data of only women that reached oocyte retrieval).

Six trials used no intention-to-treat analysis for any of their outcomes (Aston 1995; Engmann 1999; Fanchin 2003a; Franco Jr 2003; Kolibianakis 2006; Rombauts 2006) and of the other seven trials it is unclear whether they used an intention-to-treat analysis because there is not enough information available (Daly 2002; Fanchin 2001; Hugues 1994; Obruca 2001; Raoofi 2008; Shaker 1995; Tan 2001).

\section{Participants in included studies}

\section{Inclusion criteria}

Of the 23 studies, 18 studies included women with a regular IVF/ ICSI indication, five trials only included women who had a special indication for IVF. Two trials only included women who are poor responders (Kim 2005; Wang 2008). One trial only included women with limited ovarian reserve (Daly 2002). Another trial only included women with polycystic ovary syndrome (Hwang 2004) and the last trial only included women if they had an ovarian cyst of over $5 \mathrm{~mm}$ in diameter or an endometrial thickness of over $5 \mathrm{~mm}$ and serum $\mathrm{E}_{2}$ concentration $>100 \mathrm{pmol} / \mathrm{L}$ after fourteen days of GnRH agonist treatment (Shaker 1995).

Thirteen of the studies mentioned an age limit as an inclusion criteria. Four studies only included women less than 38 years of age (Cédrin-Durnerin 2007; Franco Jr 2003; Huirne 2006b; SalatBaroux 1988). Five studies only included women less than 39 years of age (Fanchin 2003a; Huirne 2006a; Hwang 2004; Kolibianakis 2006; Rombauts 2006). The other four studies used age limits above 40 years of age: one study used an upper limit of 41 years of age (Daly 2002), two studies an upper limit of 42 years of age (Cédrin-Durnerin 1996; Kim 2005) and one study used an upper limit of 44 years of age (Engmann 1999). Lower limits were defined in five of these 13 studies: four studies used a lower limit of 18 years of age (Engmann 1999; Huirne 2006a; Huirne 2006b; Rombauts 2006), and for one study the lower age limit was 28 years of age (Kim 2005). Ten studies did not mention an age limit in their description of the women.

Other common inclusion criteria were the presence of regular menstrual cycles (Cédrin-Durnerin 2007; Fanchin 2003a; Huirne 
2006b; Rombauts 2006) and a BMI of less than 29 or 30 $\mathrm{kg} / \mathrm{m}^{2}$ (Cédrin-Durnerin 2007; Fanchin 2003a; Huirne 2006b; Kolibianakis 2006; Rombauts 2006).

\section{Exclusion criteria}

Five studies excluded women with an evidence of poor response. Two studies defined this as any previous ART cycles with less than three oocytes (Huirne 2006a; Huirne 2006b), the first study also excluded women if they had a history of three or more consecutive ART cycles without a clinical pregnancy. Another study defined this as less than five oocytes in a previous IVF attempt or less than five follicles in a spontaneous cycle (Cédrin-Durnerin 2007), and one study defined this as more than three unsuccessful controlled ovarian stimulation cycles or a history of low or no ovarian response during FSH/hMG (Rombauts 2006). One study did not mention how they defined poor response to ovarian stimulation in their trial (Kolibianakis 2006).

Other common exclusion criteria were: a high baseline serum FSH level (Cédrin-Durnerin 2007; Ditkoff 1996; Engmann 1999; Huirne 2006b; Hwang 2004; Kolibianakis 2006), the evidence of ovarian cysts or endometrioma (Aston 1995; Engmann 1999; Kolibianakis 2006) and polycystic ovary syndrome (Huirne 2006b; Rombauts 2006).

\section{Interventions in included studies}

Three of the 23 studies have more than two study arms and can be used in more than one comparison (Cédrin-Durnerin 2007; Kim 2005; Rombauts 2006).

\section{Combined OCP versus placebo or no pre-treatment}

In eleven trials (with a total of thirteen comparisons) the study group was given a pre-treatment with a combined OCP, while the control group received no pre-treatment. None of these studies used a placebo in the control group. Seven trials used ethinyl estradiol as the oestrogen component in a daily dose of 30 mg (Cédrin-Durnerin 2007; Huirne 2006a; Huirne 2006b; Kolibianakis 2006; Obruca 2001; Raoofi 2008; Rombauts 2006). Five trials used $150 \mu \mathrm{g}$ desogestrel daily (Cédrin-Durnerin 2007; Kolibianakis 2006; Obruca 2001; Raoofi 2008; Rombauts 2006) and two trials used $150 \mu \mathrm{g}$ levonorgestrel daily as the progestogen component (Huirne 2006a; Huirne 2006b). One study used Diane-35, which contains $35 \mu \mathrm{g}$ ethinyl estradiol and $2 \mathrm{mg}$ cyproterone acetate (Hwang 2004). From three studies there are not enough data available on the type of combined OCP used (Biljan 1998a; Kim 2005; Wang 2008).

The starting days of pre-treatment in all eleven trials varied from cycle day one to five. Five studies started the combined OCP pre-treatment on cycle day one (Biljan 1998a; Kolibianakis 2006; Obruca 2001; Raoofi 2008; Rombauts 2006). Two studies started the pre-treatment on cycle day two or three (Cédrin-Durnerin
2007; Huirne 2006b). One study started the pre-treatment on a variable cycle day from one to five (Huirne 2006a). Another study started the pre-treatment on cycle day five (Hwang 2004). From two studies there are not enough data available on the start day of pre-treatment (Kim 2005; Wang 2008).

The duration of pre-treatment in all eleven trials varied from fourteen days to three consecutive cycles. Three studies used a fixed duration of fourteen days of pre-treatment (Biljan 1998a; Kolibianakis 2006; Raoofi 2008). Two studies used a variable duration of pre-treatment of 14 to 28 days (Huirne 2006b; Rombauts 2006). Three other studies used a variable duration of around two or three weeks minimum to around four weeks maximum (Cédrin-Durnerin 2007, 15 to 21 days; Obruca 2001, 18 to 28 days; Huirne 2006a, 21 to 28 days). The longest pre-treatment duration of three consecutive cycles was used by Hwang 2004. From two studies there are not enough data available on the duration of pre-treatment (Kim 2005; Wang 2008).

Two studies used agonists in both treatment groups. One study used buserelin acetate (long protocol) (Biljan 1998a) and the other used a depot of triptorelin acetate (Raoofi 2008).

Six studies used antagonists in both treatment groups. Three of these studies used ganirelix acetate (Cédrin-Durnerin 2007; Kolibianakis 2006; Rombauts 2006), one study used cetrorelix acetate (Obruca 2001), one used antide (Huirne 2006b) and the other one did not mention which $\mathrm{GnRH}$ antagonist was used (Kim 2005).

Four trials used an antagonist in the study group and an agonist in the control group. Two used cetrorelix acetate as antagonist and buserelin acetate as agonist (Huirne 2006a; Hwang 2004). One used ganirelix acetate as antagonist and nafarelin acetate as agonist (Rombauts 2006). The other study did not mention which GnRH analogues were used (Kim 2005).

One trial used an agonist in the study group and an antagonist in the control group, but did not mention which $\mathrm{GnRH}$ analogues were used (Wang 2008).

\section{Progestogen versus placebo or no pre-treatment}

In eight trials the study group was given a pre-treatment with a progestogen, while the control group received placebo (Aston 1995) or no pre-treatment. Five studies used norethisterone $10 \mathrm{mg}$ daily (Cédrin-Durnerin 1996; Cédrin-Durnerin 2007; Ditkoff 1996; Engmann 1999; Hugues 1994), one study used medroxyprogesterone acetate $10 \mathrm{mg}$ daily (Aston 1995) and one study used ethynodiol acetate $4 \mathrm{mg}$ daily (Salat-Baroux 1988). Another study used a single injection of $100 \mathrm{mg}$, but did not mention what type of progestogen they used (Shaker 1995).

The starting days of pre-treatment in all eight trials varied from cycle day one to nineteen. Two studies started the pre-treatment with progestogen on cycle day one (Ditkoff 1996; Engmann 1999). Three other studies started the pre-treatment on cycle day fifteen (Cédrin-Durnerin 1996; Cédrin-Durnerin 2007; Salat-Baroux 
1988). One study started the pre-treatment on cycle day sixteen or seventeen (Shaker 1995) and another study on cycle day nineteen (Aston 1995). From one study there are not enough data available on the start day of pre-treatment (Hugues 1994).

The duration of progestogen pre-treatment varied from one day to twenty days. In one study the women received one single injection (Shaker 1995). One study used a duration of pre-treatment of five days (Engmann 1999). Another study used a duration of seven days (Aston 1995) and one study of eight days (Ditkoff 1996). Two trials used a variable duration of ten to fifteen days (Cédrin-Durnerin 2007; Hugues 1994) and one trial had a variable duration of eleven to seventeen days (Salat-Baroux 1988). At last, there was one study that used a variable duration of twelve to twenty days (Cédrin-Durnerin 1996).

Six trials used an agonist in both treatment groups. Three studies used buserelin acetate (Aston 1995; Engmann 1999; Shaker 1995), one study used triptorelin (Cédrin-Durnerin 1996), one study used leuprolide acetate (Ditkoff 1996) and another study used dTRP6-LHRH (Hugues 1994).

One trial used an antagonist (ganirelix acetate) in both treatment groups (Cédrin-Durnerin 2007).

One trial did not use GnRH analogues for pituitary desensitization. Women that participated in this study only received pure FSH and hMG (Salat-Baroux 1988).

\section{Estrogen versus placebo or no pre-treatment}

In three trials the study group was given a pre-treatment with oestrogen, while the control group received no pre-treatment. Two studies used micronized 17- $\beta \mathrm{E}_{2}$ (Cédrin-Durnerin 2007; Fanchin 2003a) and one study used estradiol valerate (Franco Jr 2003). All these studies used a dosage of $4 \mathrm{mg}$ daily.

The starting days of pre-treatment in all three trials varied from cycle day 15 to 21 . One study started the pre-treatment on cycle day 20 (Fanchin 2003a) and one on cycle day 21 (Franco Jr 2003). The other study started the pre-treatment ten days before the presumed menses (Cédrin-Durnerin 2007).

The duration of pre-treatment in all three trials varied from ten to seventeen days. In one study the duration varied from ten to fifteen days (Cédrin-Durnerin 2007). The other two studies used a fixed duration of pre-treatment of eleven days (Fanchin 2003a) and fourteen days (Franco Jr 2003).

Two trials used an antagonist in both treatment groups, one trial used ganirelix acetate (Cédrin-Durnerin 2007) and the other used cetrorelix acetate (Fanchin 2003a).

One trial used an antagonist (ganirelix acetate) in the study group and an agonist (nafarelin acetate) in the control group (Franco Jr 2003).

\section{Combined OCP versus progestogen}

There was only one study that compared a combined OCP with progestogen (Cédrin-Durnerin 2007). The women in the com- bined OCP group received ethinyl estradiol $30 \mu \mathrm{g}$ and desogestrel $150 \mu \mathrm{g}$ daily and the women in the progestogen group received norethisterone $10 \mathrm{mg}$ daily. This study started the combined OCP pre-treatment on cycle day two or three with a duration of 15 to 21 days. The progestogen pre-treatment was started on cycle day fifteen with a duration of ten to fifteen days. Both groups received a $\mathrm{GnRH}$ antagonist (ganirelix acetate).

\section{Combined OCP versus oestrogen}

In two trials a pre-treatment of combined OCP was compared with a pre-treatment of oestrogen. One trial used ethinyl estradiol $30 \mu \mathrm{g}$ and desogestrel $150 \mu \mathrm{g}$ daily as a combined OCP and micronized $17-\beta \mathrm{E}_{2} 4 \mathrm{mg}$ daily as oestrogen pre-treatment (Cédrin-Durnerin 2007). The combined OCP pre-treatment started on cycle day two or three with a duration of 15 to 21 days. The oestrogen pre-treatment started ten days before the presumed menses with a duration of ten to fifteen days and both groups received the $\mathrm{GnRH}$ antagonist ganirelix acetate .

The other study did not mention which combined OCP was used, but used two mg ethinyl estradiol as an oestrogen pre-treatment (Daly 2002). This study only described that the oestrogen pretreatment was administered in the luteal phase of the preparation cycle, but did not report about exact starting days and durations of pre-treatment. The combined OCP group received a $\mathrm{GnRH}$ agonist (leuprolide acetate) and the oestrogen group received a $\mathrm{GnRH}$ antagonist (ganirelix acetate).

\section{Progestogen versus oestrogen}

There was only one study that compared progestogen with oestrogen (Cédrin-Durnerin 2007). The women in the progestogen group received norethisterone ten $\mathrm{mg}$ daily and the women in the oestrogen group received micronized $17-\beta \mathrm{E}_{2} 4 \mathrm{mg}$ daily. This study started the progestogen pre-treatment on cycle day fifteen with a duration of ten to fifteen days. The oestrogen pre-treatment started ten days before the presumed menses with also a duration of ten to fifteen days. Both groups received a GnRH antagonist (ganirelix acetate).

\section{Outcomes in included studies}

\section{Primary outcome}

The number of live births was reported in seven studies (CédrinDurnerin 1996; Cédrin-Durnerin 2007; Ditkoff 1996; Engmann 1999; Franco Jr 2003; Huirne 2006a; Kim 2005). 


\section{Secondary outcomes}

The number of ongoing pregnancies was reported in eight studies. This was defined as a positive heart activity at a gestational age of twelve weeks by three studies (Huirne 2006a; Huirne 2006b; Kim 2005). One study used the same definition but did not mention when they performed the ultrasound scan (Ditkoff 1996). Two studies defined this as a pregnancy developing beyond twelve weeks (Cédrin-Durnerin 2007; Kolibianakis 2006) and one study defined this as a pregnancy assessed by ultrasound at twelve to sixteen weeks or later (Rombauts 2006). The last study defined ongoing pregnancy as a viable pregnancy and did not mention how they assessed this (Daly 2002).

The number of clinical pregnancies was reported in eighteen studies. Five studies defined clinical pregnancy as the presence of one or more fetal hearts confirmed with ultrasound (US), performed at least four weeks after embryo transfer (Biljan 1998a; Fanchin 2003a, US after six weeks; Franco Jr 2003; Kim 2005; Raoofi 2008). Two other studies used the same definition, but one of these also included the fetal sacs without heart activity (Huirne 2006a) and the other performed the US scan at seven weeks after embryo transfer (Hwang 2004). One study defined clinical pregnancy as the presence of one or more intrauterine sacs confirmed with US, at a gestational age of six weeks (Huirne 2006b). Of one study we used a positive pregnancy test with evidence of a gestational sac to define clinical pregnancy, because no clinical or ongoing pregnancy rate was available (Engmann 1999). Another study defined clinical pregnancy as the evidence of a clinical gestational sac (Ditkoff 1996). Of the other eight studies it was not clear how they defined this outcome (Aston 1995; Cédrin-Durnerin 1996; Cédrin-Durnerin 2007; Daly 2002; Obruca 2001; Salat-Baroux 1988; Shaker 1995; Wang 2008). If no clinical pregnancy rates were reported, we used the ongoing pregnancy rates (if available) for our analysis.

The number of oocytes retrieved was reported in fourteen studies (Biljan 1998a; Cédrin-Durnerin 2007; Ditkoff 1996; Franco Jr 2003; Huirne 2006a; Huirne 2006b; Hwang 2004; Kim 2005; Obruca 2001; Raoofi 2008; Rombauts 2006; Salat-Baroux 1988; Shaker 1995; Wang 2008). One study only mentioned the number of cumulus-oocyte complexes (Kolibianakis 2006) and three studies the number of mature oocytes or follicles (Cédrin-Durnerin 1996; Engmann 1999; Fanchin 2003a), but we assumed that this means the same as the number of oocytes retrieved and therefore we pooled the data of these studies.

The number of days of gonadotrophin treatment was reported in twelve studies (Biljan 1998a; Ditkoff 1996; Engmann 1999; Franco Jr 2003; Huirne 2006a; Huirne 2006b; Hwang 2004; Kim 2005; Kolibianakis 2006; Rombauts 2006; Shaker 1995; Wang 2008).

The amount of gonadotrophins administered in IU was reported by eight studies (Cédrin-Durnerin 2007; Fanchin 2003a; Franco Jr 2003; Huirne 2006a; Huirne 2006b; Kim 2005; Kolibianakis 2006; Rombauts 2006). Another seven studies reported the amount of gonadotrophins administered in the number of ampoules used, but we can not use these data in our analysis (Biljan 1998a; Cédrin-Durnerin 1996; Ditkoff 1996; Engmann 1999; Hwang 2004; Shaker 1995; Wang 2008).

\section{Adverse outcomes}

The number of pregnancy losses was reported by eight studies. One study described this as the proportion of patients with initially positive hCG in whom pregnancy failed to develop before 12 weeks of gestation (Kolibianakis 2006). The other seven studies did not describe a definition (Daly 2002; Engmann 1999; Franco Jr 2003; Hwang 2004; Kim 2005; Rombauts 2006; Salat-Baroux 1988).

The number of women with ovarian cysts was reported by eight studies. Of one study we used the number of functional ovarian cysts with a diameter of $10 \mathrm{~mm}$ or more, measured after one week of GnRH agonist treatment (Engmann 1999). Four studies defined an ovarian cyst as an intraovarian sonolucent structure with a mean diameter of $14 \mathrm{~mm}$ or more, measured after seven to twelve days of pituitary suppression (Aston 1995, after twelve days; Biljan 1998a, after seven days; Ditkoff 1996, after eight days; Franco Jr 2003, not reported). One study reported ovarian cysts when they reached a diameter of more than $28 \mathrm{~mm}$, measured seven and fourteen days after pituitary suppression (Raoofi 2008). One study did not mention how they defined ovarian cyst formation and when they measured this (Huirne 2006b).

One study only reported cyst formation as reason for cycle cancellation, but it is unclear if there were more cysts formed that did not lead to cycle cancellation (Salat-Baroux 1988). We did not use these data in our analysis.

The number of multiple pregnancies was reported by five studies. One study defined this as multiple clinical pregnancies (Huirne 2006a). Another study described the number of ongoing or live born twin pregnancies (Hwang 2004). Three studies did not describe when the number of multiple pregnancies was measured (Cédrin-Durnerin 2007; Franco Jr 2003; Kim 2005).

The number of OHS syndrome was reported by three studies. One study used the WHO classification criteria to diagnose OHS syndrome and divided the women in categories of mild (grade I), moderate (grade II) or severe (grade III) (Rombauts 2006), the other two studies did not mention how they diagnosed OHS syndrome (Franco Jr 2003; Hwang 2004).

\section{Excluded studies}

We referred to a total of 67 studies that describe pre-treatments with combined OCPs, progestogens or estrogens, but which were not eligible for inclusion for various reasons. Some of the following studies had multiple reasons for exclusion, but we only mentioned the reason we thought was most important. Full details of reasons for exclusion can be found in the table of Characteristics of excluded studies. 
Nineteen studies were excluded because they did not describe randomised controlled trials, for the main reason that they did not randomise their participants (Benadiva 1988; Cédrin-Durnerin 1995; Cohen 1987; Copperman 2003; Couzinet 1995; Ditkoff 1997; Forman 1991; Frydman 1986; Galera 2004; Godin 2003; Gonen 1990; Lindheim 1996; Neal 1993; Palomba 2008; Schoolcraft 1997; Surrey 1989; Tarlatzis 1993; Weisman 1989; Yokota 2006). Twenty-three studies were also no randomised controlled trials, for the main reason that their design was retrospective (al-Mizyen 2000; Bellver 2007; Bendikson 2006; Biljan 1998b; Chung 2006; Damario 1997; Dickey 2001; Duvan 2008; Frederick 2004; Gonzalez 1995; Keltz 2007; Kovacs 2001; Leondires 1999; Loutradis 2003; Min 2005; Mirkin 2003; Pados 1995; Pinkas 2008; Ramsewak 2005; Talebian 2004; Talebian 2007; Yoshida 2005; Zhao 2008). Another five studies were no randomised controlled trials, for the main reason that the women served as their own controls in previous cycles (Branigan 1998; Fanchin 2003b; Fisch 1996; Mulangi 1997; Surrey 1998). At last there were seven studies that were no randomised controlled trials because they had a single arm study design (Brodt 1993; De Ziegler 1999; Gerli 1989; Hugues 1992; Meldrum 2002; Meldrum 2008; Sanghvi 2002).

Six studies were excluded because they compared two (or more) different dosages, timings or ways of administration of the same pre-treatment (Davy 2004; Gomez 2000; Karande 2004; Lewin 2002; Mashiach 1989; Russell 1997).

Three studies were excluded because the women only received ovarian stimulation, but no embryo transfer was performed as part of an ART cycle (Anderson 1990; Letterie 2000; Steinkampf 1991).

Two studies were excluded because the women were oocyte donors (Doody 2001; Martinez 2006) and one study was excluded because the women had premature ovarian failure (Tartagni 2007).

At last, there was one study that we excluded because the oestrogen pre-treatment was not stopped before oocyte retrieval, but continued to be used as luteal phase support (Jung 2000).

\section{Ongoing studies}

One study might be eligible for inclusion in this review, but is still ongoing. We contacted the researchers, which replied that the trial is expected to be finished in June 2009 and that they are not able to share data with us until that date. More information on this trial can be found in the table of Characteristics of ongoing studies.

\section{Risk of bias in included studies}

A complete overview of classification of risk of bias domains can be found in the tables of Characteristics of included studies and in Figure 1 and Figure 2.

\section{Allocation}

All 23 included trials were claimed to be randomised, but in twelve trials the method of randomisation was not reported. Seven trials used computer generated random numbers to randomise the women (Biljan 1998a; Engmann 1999; Fanchin 2003a; Huirne 2006a; Huirne 2006b; Hwang 2004; Kolibianakis 2006). Three studies used a table of random numbers (Cédrin-Durnerin 2007; Franco Jr 2003; Shaker 1995) and one study accomplished the randomisation by tossing a coin (Ditkoff 1996).

If randomisation is not done properly, there might be a difference in baseline characteristics between the women in the treatment groups. This may influence the outcomes measured in the trial. Therefore it is important that the method of randomisation is reported. Due to the high number of included studies that did not report the method of randomisation (twelve out of 23 studies), there might be a higher risk of bias.

Ten studies were classified as 'yes' with regard to allocation concealment. Four studies used sealed envelopes to conceal the allocation (Biljan 1998a; Cédrin-Durnerin 2007; Hwang 2004; Shaker 1995). In five studies the randomisation was done by a third party (Aston 1995, hospital pharmacy and numbered bottles; Engmann 1999, clinic nurses and sealed envelopes; Fanchin 2003a, independent person; Huirne 2006b, independent person from independent monitoring company; Rombauts 2006, central remote allocation). Another study centralised the randomisation process (Ditkoff 1996).

Two studies were classified as 'no' with regard to allocation concealment, because they reported that the sequence of allocation was not concealed (Franco Jr 2003; Kolibianakis 2006). One study reported that allocation was concealed, but not how this was done (Huirne 2006a), therefore we classified this as 'unclear'. The other ten studies did not report any information about allocation concealment, and were also classified as 'unclear'.

Because nearly all outcomes of this review are not subjective, a poorly designed allocation concealment method of studies is not likely to have a big influence on these outcomes. For example, the number of live births is not likely to be influenced by the clinician if he or she knows which treatment the woman receives. However, OHS syndrome is diagnosed on clinical symptoms and so there might be a bigger risk of bias when the clinician is aware of the treatment assigned to each woman. Nevertheless, even not subjective outcomes may be influenced indirectly if allocation is not concealed.

\section{Blinding}

Three trials used blinding. One study used a placebo in the control group and reported that the study was double blind (Aston 1995). Another study used no placebo, so women could guess their treatment status, but the clinicians were blinded (Engmann 1999). The last study reported that the laboratory staff was blinded (Hwang 2004). 
Nine trials reported that the study was open labelled or not blind ( Cédrin-Durnerin 2007; Daly 2002; Ditkoff 1996; Fanchin 2003a; Franco Jr 2003; Huirne 2006b; Kim 2005; Kolibianakis 2006; Rombauts 2006). The other eleven studies did not report whether the women, outcome assessors or investigators were blinded. As with allocation concealment, poor blinding is less likely to influence the objective outcomes such as live birth, but it might have a bigger influence on the diagnosis of OHS syndrome.

\section{Incomplete outcome data}

Of the 23 studies, eleven addressed incomplete outcome data ( Aston 1995; Cédrin-Durnerin 1996; Ditkoff 1996; Engmann 1999; Franco Jr 2003; Huirne 2006a; Huirne 2006b; Hwang 2004; Kolibianakis 2006; Salat-Baroux 1988; Shaker 1995). In these trials the numbers and reasons for withdrawals are reported. We noticed a few imbalances in reasons for withdrawal between the study group and control group in the following studies. One study reported six withdrawals due to endometrioma, of which five were in the control group and only one in the study group (Aston 1995). Another study reported five withdrawals due to inadequate response, of which four were in the control group and only one in the study group (Salat-Baroux 1988). The third study reported three withdrawals due to risk of severe OHS syndrome in the control group and none in the study group (Hwang 2004). The last study also reported more withdrawals due to risk of OHS syndrome in the control group $(\mathrm{n}=2)$ than in the study group $(\mathrm{n}=$ 0) (Shaker 1995).

Five studies were classified as 'no', because the journal article did not report the numbers and reasons for withdrawals (in each treatment group) (Biljan 1998a; Cédrin-Durnerin 2007; Fanchin 2003a; Raoofi 2008; Rombauts 2006). We classified the other six studies as 'unclear', because there was only an abstract available that did not report any information on the numbers and reasons for withdrawal.

Incomplete outcome data can bias the results of our review, especially with regard to adverse outcomes. For example, a study might have withdrawals due to OHS syndrome that they do not report. Also imbalances in reasons for withdrawal can occur because of differences in interventions between the study group and control group. For example, when there are more withdrawals due to OHS syndrome in the control group, this can be in favour of the intervention used in the study group. The risk of bias might increase if authors do not report on this.

\section{Selective reporting}

Although we did not retrieve any of the protocols or raw data of any trial, we classified six studies as free of selective reporting, because these trials reported data on all the outcomes mentioned in the 'Methods' section of their article (Engmann 1999; Huirne 2006b; Hwang 2004; Kolibianakis 2006; Rombauts 2006; Shaker 1995).
The other seventeen studies did not report in their 'Methods' section which outcomes they were going to measure.

Because we do not know if the authors of the included studies reported all the data they retrieved in their trial, we are not able to provide a judgement about this domain.

\section{Other potential sources of bias}

Four studies were classified as 'yes', because there were no differences in baseline characteristics between the treatment groups and the number of women randomised per group was reported (Engmann 1999; Huirne 2006a; Huirne 2006b; Kolibianakis 2006).

We classified thirteen studies as 'no' with regard to other potential sources of bias. Eight studies reported no data on baseline characteristics or mentioned only one or two in the text of their articles (Cédrin-Durnerin 1996; Cédrin-Durnerin 2007; Daly 2002; Ditkoff 1996; Franco Jr 2003; Hugues 1994; Kim 2005; Obruca 2001). Two studies only reported the number of cycles in the study group and control group and did not report the number of women in each group (Biljan 1998a; Shaker 1995). Two trials did not report the number of women or cycles randomised to each group (Fanchin 2001; Raoofi 2008), and one did report the number of women analysed in each group, but not the number of women randomised to each group (Fanchin 2003a). The other six studies were classified as 'unclear', because there were not enough data on baseline characteristics available. Of these six studies, one also used a slightly different treatment protocol in both groups (Salat-Baroux 1988).

Although we classified four studies as 'yes', it is difficult to know if a study is truly free of other bias, because there are so many different potential sources of bias. It is impossible to provide a judgement about this domain based on the limited data available for us.

\section{Effects of interventions}

\section{Combined OCP versus no pre-treatment}

\section{Live births Analysis I.I}

COCP + Antagonist versus Antagonist (five studies included) - Only one study in this subgroup reported the number of live births and found three live births in the study group $(\mathrm{n}=21)$ and seven in the control group ( $\mathrm{n}=24)$, Peto OR 95\% CI 0.43 (0.11 to 1.74 ); $\mathrm{P}=0.24$ (Cédrin-Durnerin 2007).

COCP + Antagonist versus Agonist (three studies included) - There was only one study that reported the number of live births in this subgroup. This study found a number of seventeen live births in 
both the study $(\mathrm{n}=91)$ and control group $(\mathrm{n}=91)$, Peto OR 95\% CI 1.00 (0.48 to 2.10); $\mathrm{P}=1.0$ (Huirne 2006a).

COCP + Antagonist versus Antagonist, low response (one study included) - This study found that there were eight live births in the study group $(\mathrm{n}=27)$ and five in the control group $(\mathrm{n}=27)$, Peto OR 95\% CI 1.82 (0.53 to 6.25); P= 0.34 (Kim 2005).

COCP + Antagonist versus Agonist, low response (one study included) - This study found that there were eight live births in the study group $(\mathrm{n}=27)$ and six in the control group $(\mathrm{n}=28)$, Peto OR 95\% CI 1.53 (0.46 to 5.09); $\mathrm{P}=0.49$ (Kim 2005).

\section{Ongoing pregnancies Analysis $\mathbf{I . 2}$}

COCP + Antagonist versus Antagonist (five studies included) - The results of four studies, with a total of 847 women, have been pooled in this subgroup. No statistically significant difference was found ,Peto OR 0.74; 95\% CI 0.53 to $1.03, \mathrm{P}=0.07$.

COCP + Antagonist versus Agonist (three studies included) - The results of two studies, with a total of 416 women, have been pooled in this subgroup. No statistically significant difference was found, Peto OR 0.76 ; $95 \%$ CI 0.47 to $1.23, \mathrm{P}=0.27$.

COCP + Antagonist versus Antagonist, low response (one study included) - This study found an ongoing pregnancy rate of eight in the study group $(\mathrm{n}=27)$ and five in the control group $(\mathrm{n}=27)$, Peto OR 95\% CI 0.1.82 (0.53 to 6.25); $\mathrm{P}=0.34$ (Kim 2005). COCP + Antagonist versus Agonist, low response (one study included) - This study found an ongoing pregnancy rate of eight in the study group $(\mathrm{n}=27)$ and six in the control group $(\mathrm{n}=28)$, Peto OR 95\% CI 1.53 (0.46 to 5.09); $\mathrm{P}=0.49$ (Kim 2005).

See Figure 3 for the graph and details of this outcome.

Figure 3. Forest plot of comparison: I Combined OCP versus no Rx, outcome: I.2 Ongoing pregnancies.

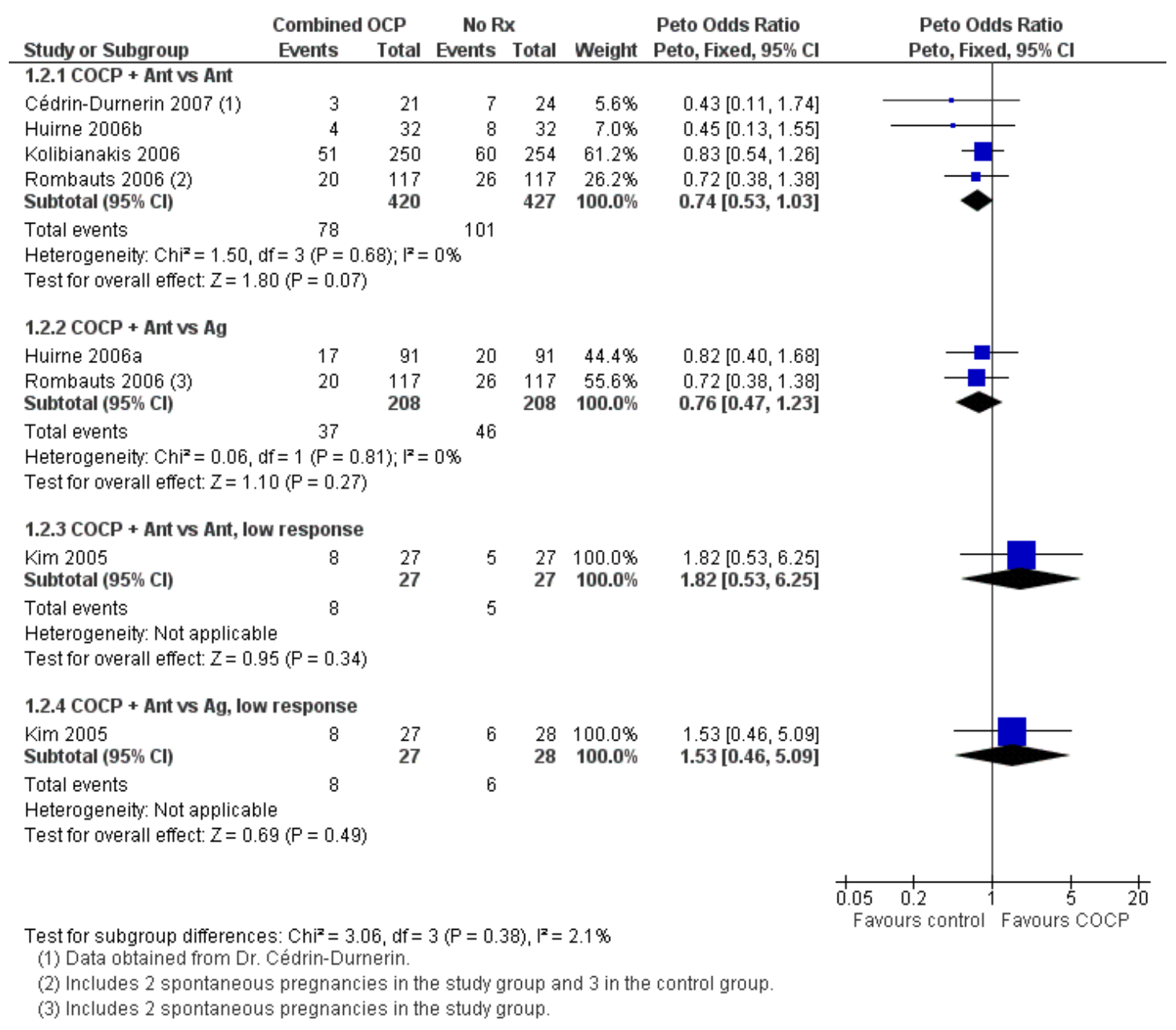

Oral contraceptive pill, progestogen or estrogen pre-treatment for ovarian stimulation protocols for women undergoing assisted 


\section{Clinical/ongoing pregnancies Analysis I.3}

COCP + Agonist versus Agonist (two studies included) - Both studies reported the number of clinical pregnancies, but due to a lack of data we can not pool these results. The first study reported a clinical pregnancy rate per cycle started of $37.2 \%$ in the study group and $33.3 \%$ in the control group, which comes down to 19 clinical pregnancies out of 51 cycles in the combined OCP group and 17 clinical pregnancies out of 51 cycles in the control group (Biljan 1998a). The other study reported a pregnancy rate of $9 \%$ in the study group and $11 \%$ in the control group, but did not report the number of women per group (Raoofi 2008). Both studies found that their results were not statically significant. Peto OR $1.19 ; 95 \%$ CI 0.53 to $2.66, \mathrm{P}=0.27$

COCP + Antagonist versus Antagonist (five studies included) - Four RCTs have been pooled in this subgroup, with a total of 847 women. Of two of these studies we used the number of ongoing pregnancies, since no data on clinical pregnancy rate were available. There was a statistically significant difference in the rates of clinical/ongoing pregnancies with fewer clinical/ongoing pregnancies occurring in the group pre-treated with a combined OCP (Peto OR 0.69; 95\% CI 0.50 to $0.96, \mathrm{P}=0.03$ ). Of one study the clinical pregnancy rate per embryo transfer is known, but not the number of embryo transfers performed (Obruca 2001). The clin- ical pregnancy rate was $29.7 \%$ in the study group and $41.2 \%$ in the control group, this result did not reach significance according to the authors.

COCP + Antagonist versus Agonist (three studies included) - Three studies have been pooled in this subgroup, with a total of 472 women. Of one of these studies we used the number of ongoing pregnancies, since no data on clinical pregnancy rate were available. No statistically significant result was found (Peto OR 0.82; 95\% CI 0.53 to $1.26, \mathrm{P}=0.36$ ).

COCP + Antagonist versus Antagonist, low response (one study included) - This study found a clinical pregnancy rate of nine in the study group $(\mathrm{n}=27)$ and six in the control group $(\mathrm{n}=27)$, Peto OR 1.72; 95\% CI 0.53 to 5.60, P = 0.37 (Kim 2005).

COCP + Antagonist versus Agonist, low response (one study included) - This study found a clinical pregnancy rate of eight in the study group $(n=27)$ and seven in the control group $(n=28)$, Peto OR 1.49; 95\% CI 0.47 to $4.71, \mathrm{P}=0.50$ (Kim 2005).

COCP + Agonist versus Antagonist, low response (one study included) - This trial found that the number of clinical pregnancies was 22 in the study group $(\mathrm{n}=63)$ and 18 in the control group ( $\mathrm{n}=58$ ), Peto OR 1.19; $95 \%$ CI 0.56 to 2.53 , with a P value of 0.65 (Wang 2008).

See Figure 4 for the graph and details of this outcome. 
Figure 4. Forest plot of comparison: I Combined OCP versus no Rx, outcome: I.3 Clinical/ongoing pregnancies.

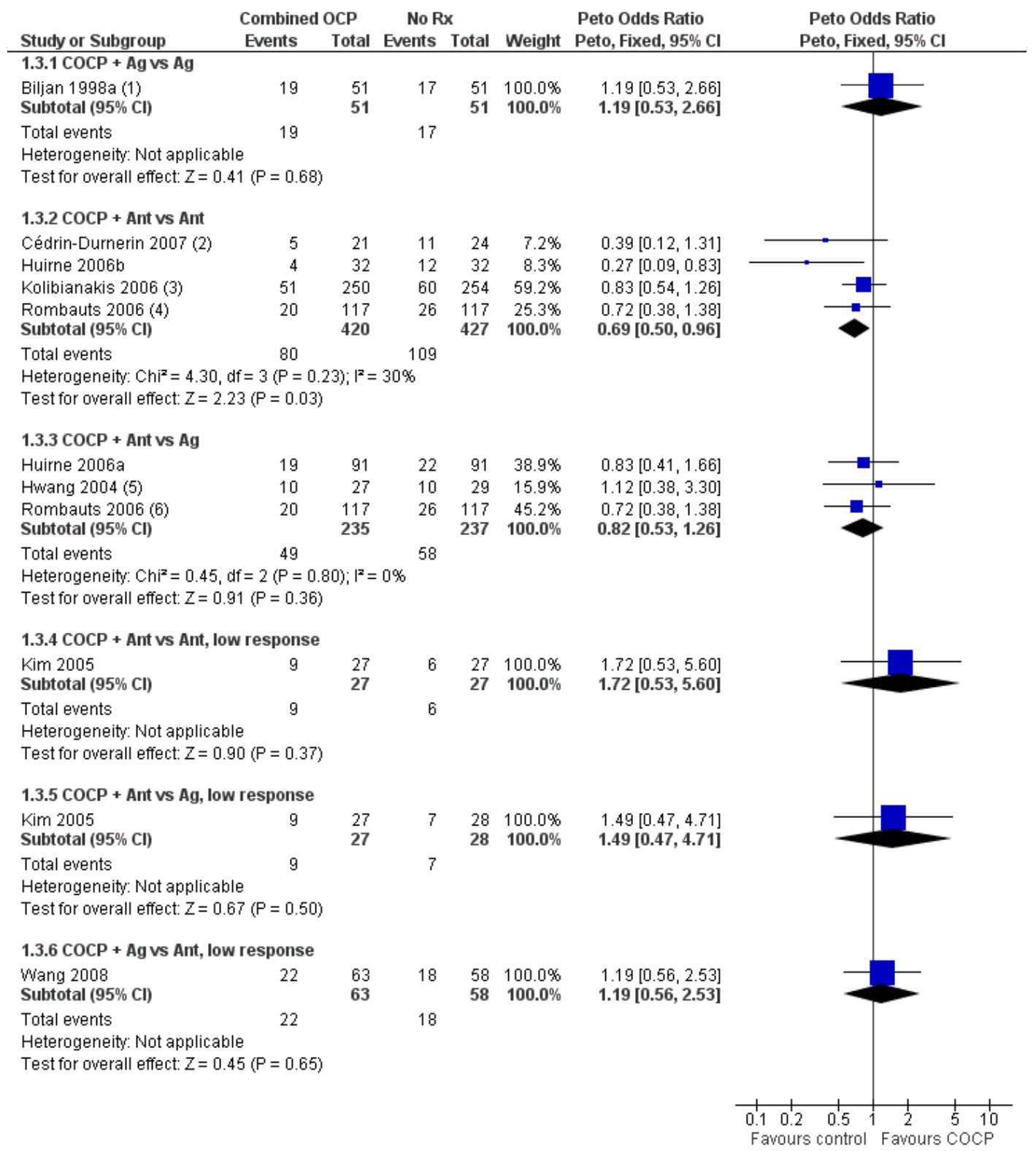

(1) Numbers calculated from rates; Number of women per group unknown, only number of cycles known.

(2) Data obtained from Dr. Cédrin-Durnerin.

(3) Ongoing pregnancies.

(4) Ongoing pregnancies. Includes 2 spontaneous pregnancies in the study group and 3 in the control group.

(5) Calculated from rates.

(6) Ongoing pregnancies. Includes 2 spontaneous pregnancies in the study group. 


\section{Oocytes retrieved Analysis I.4}

COCP + Agonist versus Agonist (two studies included) - Both studies looked at the number of oocytes retrieved, but we were not able to pool or analyse these data. The first study reported a median of eleven oocytes retrieved (range seven to 19) in the study group (n $=51$ cycles) and a median of ten oocytes retrieved (range 7 to 15) in the control group ( $\mathrm{n}=51$ cycles) (Biljan 1998a). Because of the statistical method used in this study, we can not analyse these data. The other study reported a mean number of oocytes retrieved of $5.0( \pm 2.8)$ in the study group and $5.4( \pm 5.7)$ in the control group (Raoofi 2008). This study did not report the number of women or cycles in each treatment group, and therefore we can not use these data in our analysis.

COCP + Antagonist versus Antagonist (five studies included) - Results of all five included trials have been pooled, with a total of 891 women. No statistically significant difference was found for this outcome (MD 0.23 ; $95 \%$ CI -0.55 to $1.01, \mathrm{P}=0.56$ ). However, we found a substantial amount of heterogeneity; the $\mathrm{I}^{2}$ statistic is $64 \%$. No obvious reasons were identified for the heterogeneity in this comparison. An overview of characteristics of the studies for this subgroup are reported in Table 1.

COCP + Antagonist versus Agonist (three studies included) - The results of three RCTs have been pooled in this subgroup, with a total of 440 women. No statistically significant result was found (MD -0.01; 95\% CI -1.54 to $1.53, \mathrm{P}=0.99$ ).

COCP + Antagonist versus Antagonist, low response (one study included) - This study found a mean number of $4.8( \pm 2.0)$ oocytes retrieved in the study group $(\mathrm{n}=27)$ and a mean number of 4.4 $( \pm 1.8)$ oocytes retrieved in the control group $(\mathrm{n}=27)$, Peto OR 0.27 ; $95 \% \mathrm{CI}-0.61$ to $1.41, \mathrm{P}=0.44$ (Kim 2005).

COCP + Antagonist versus Agonist, low response (one study included) - This study found a mean number of $4.8( \pm 2.0)$ oocytes retrieved in the study group $(\mathrm{n}=27)$ and a mean number of 4.7 $( \pm 2.1)$ oocytes retrieved in the control group $(\mathrm{n}=28)$,Peto OR $0.10 ; 95 \%$ CI -0.98 to $1.18, \mathrm{P}=0.86$ (Kim 2005).

COCP + Agonist versus Antagonist, low response (one study included) - This study found a mean number of $4.40( \pm 2.1)$ oocytes retrieved in the study group $(n=59)$ and $5.41( \pm 2.65)$ in the control group $(\mathrm{n}=51)$, Peto OR -1.01 ; $95 \% \mathrm{CI}-1.91$ to $0.11, \mathrm{P}$ $=0.03$ (Wang 2008).

See Figure 5 for the graph and details of this outcome. 
Figure 5. Forest plot of comparison: I Combined OCP versus no Rx, outcome: I.4 Oocytes retrieved.

\begin{tabular}{|c|c|c|c|c|c|c|c|c|}
\hline \multirow[b]{2}{*}{ Study or Subgroup } & \multicolumn{3}{|c|}{ Combined OCP } & \multicolumn{3}{|c|}{ No $R x$} & \multicolumn{2}{|r|}{ Mean Difference } \\
\hline & Mean & SD & Total & Mean & SD & Total & Weight & IV, Fixed, 95\% C \\
\hline 1.4.1 COCP + Ant vs Ant & & & & & & & & \\
\hline Cédrin-Durnerin 2007 & 14 & 8.3 & 21 & 9.9 & 5.4 & 24 & $3.5 \%$ & $4.10[-0.06,8.2$ \\
\hline Huirne 2006b (1) & 13.5 & 6.7 & 31 & 10.2 & 6 & 32 & $6.2 \%$ & \\
\hline Kolibianakis 2006 (2) & 12.8 & 7.7 & 209 & 13.2 & 8.8 & 203 & $23.9 \%$ & $-0.40[-2.00,1$ \\
\hline Obruca 2001 (3) & 5.8 & 3.4 & 75 & 6.3 & 3.4 & 75 & $51.6 \%$ & $-0.50[-1.59,0.5$ \\
\hline $\begin{array}{l}\text { Rombauts } 2006 \text { (4) } \\
\text { Subtotal }(95 \% \mathrm{Cl})\end{array}$ & 13.1 & 7.8 & $\begin{array}{l}111 \\
447\end{array}$ & 11.5 & 7.6 & $\begin{array}{l}110 \\
444\end{array}$ & $\begin{array}{r}14.8 \% \\
100.0 \%\end{array}$ & $\begin{array}{r}1.60[-0.43,3.63 \\
\mathbf{0 . 2 3}[-\mathbf{0 . 5 5}, \mathbf{1 . 0 1}\end{array}$ \\
\hline
\end{tabular}

Heterogeneity: $\mathrm{Chi}^{2}=11.07, \mathrm{df}=4(\mathrm{P}=0.03) ; \mathrm{I}^{2}=64 \%$

Test for overall effect: $Z=0.58(P=0.56)$

\subsubsection{COCP + Ant vs Ag}

Huirne 2006a (5)

Hwang 2004 (6)

11.47 .3

$16.3-6.4$

$\begin{array}{lll}85 & 10.9 & 10.9\end{array}$

$84 \quad 30.1 \% \quad 0.50[-2.30,3.30]$

Rombauts 2006 (7)

Subtotal $(95 \% \mathrm{Cl})$

$\begin{array}{llllllll}13.1 & 7.8 & 111 & 12.9 & 8.7 & 111 & 50.0 \% & 0.20[-1.97,2.37]\end{array}$

Heterogeneity: $\mathrm{Chi}^{2}=0.70, \mathrm{df}=2(P=0.70) ; \mathrm{I}^{2}=0 \%$

Test for overall effect: $Z=0.01(P=0.99)$

1.4.3 COCP + Ant vs Ant, low response

Kim 2005

$\begin{array}{lll}4.8 & 2 & 27\end{array}$

$\begin{array}{llll}4.4 & 1.8 & 27 & 100.0 \%\end{array}$

Subtotal $(95 \% \mathrm{Cl})$

$0.40[-0.61,1.41]$

Heterogeneity: Not applicable

Test for overall effect: $Z=0.77(P=0.44)$

1.4.4 COCP + Ant vs Ag, low response

Kim $2005 \quad 4.8 \quad 2$

Subtotal $(95 \% \mathrm{Cl})$

$\begin{array}{ll}4.8 \quad 2 & 27 \\ & 27\end{array}$

$\begin{array}{lll}27 & 4.7 & 2.1\end{array}$

$28100.0 \%$

$2800 \% \quad 0.10[-0.98,1.18]$

Heterogeneity: Not applicable

Test for overall effect: $Z=0.18(P=0.86)$

1.4.5 COCP + Ag vs Ant, low response

Wang $2008(8) \quad 4.4 \quad 2.1$

$\begin{array}{lll}4.4 & 2.1 \quad 59\end{array}$

Subtotal $(95 \% \mathrm{Cl})$

59
59

5.412 .65

$51 \quad 100.0 \% \quad-1.01[-1.91,-0.11]$

Heterogeneity: Not applicable

Test for overall effect: $Z=2.19(P=0.03)$

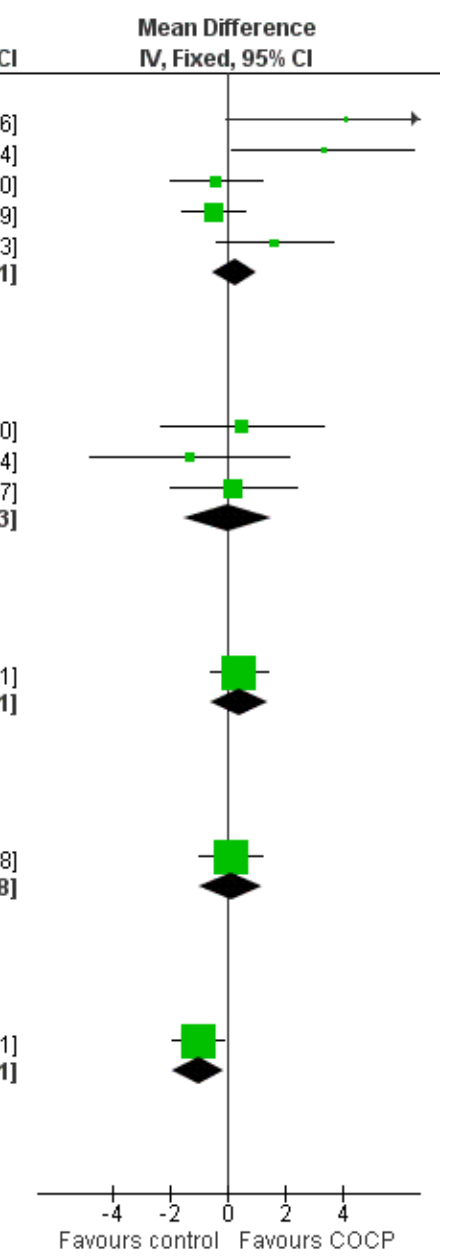
(1) No ITT in COCP group
(2) No ITT. 'Cumulus oocyte complexes'.
(3) Unsure about ITT.
(4) No ITT.
(5) No ITT
(6) No ITT.
(7) No ITT.
(8) No ITT. 


\section{Days of gonadotrophin treatment Analysis I.5}

COCP + Agonist versus Agonist (two studies included) - Only one study reported on the number of days of gonadotrophin treatment (Biljan 1998a). This study found a median of ten days (range 9 to $11)$ in the study group ( $\mathrm{n}=51$ cycles) and a median of twelve days (range 11 to 12 ) in the control group ( $\mathrm{n}=51$ cycles). Because of the statistical method used in this study, we can not analyse these data.

$C O C P+$ Antagonist versus Antagonist (five studies included) - Three RCTs have been pooled in this subgroup for this outcome, with a total of 689 women. There was a significant difference, with fewer days of gonadotrophin treatment in the group that did not receive pre-treatment with a combined OCP (MD 1.44; 95\% CI 1.15 to $1.72, \mathrm{P}<0.00001)$. Heterogeneity in this meta-analysis was high, with an $\mathrm{I}^{2}$ statistic of $95 \%$. A possible explanation for the high heterogeneity might be that Kolibianakis 2006 uses a shorter duration of pre-treatment than the other studies. We did a sensitivity analysis to explore this heterogeneity and found that removing Kolibianakis 2006 from this meta-analysis reduced heterogeneity to $22 \%$. This did not change the results substantially. An overview of characteristics of the studies for this subgroup are reported in Table 1 .

COCP + Antagonist versus Agonist (three studies included) - Also, three RCTs have been pooled in this subgroup, with a total of 434 women. There was a significant difference in this outcome, with fewer days of gonadotrophin treatment in the group that did not receive pre-treatment with a combined OCP (MD 0.51; 95\% CI 0.17 to $0.84, \mathrm{P}=0.003)$. The heterogeneity was high, with an $\mathrm{I}^{2}$ statistic of $92 \%$. The only substantial difference that we noticed was that Rombauts 2006 used a different type of GnRH antagonist and agonist and had a higher starting dose of gonadotrophins than the other studies. We did a sensitivity analysis on the outcome number of days of gonadotrophin therapy and found that removing Rombauts 2006 from this meta-analysis reduced heterogeneity to $9 \%$. An overview of characteristics of the studies for this subgroup are reported in Table 2.

COCP + Antagonist versus Antagonist, low response (one study included) - This study found a mean number of $10.0( \pm 1.4)$ days of gonadotrophin treatment in the study group $(\mathrm{n}=27)$ and a mean number of $9.7( \pm 1.4)$ days in the control group ( $\mathrm{n}=27)$, MD 0.30; $95 \%$ CI -0.45 to $1.05, \mathrm{P}=0.43$ (Kim 2005).

COCP + Antagonist versus Agonist, low response - This study found a mean number of $10.0( \pm 1.4)$ days of gonadotrophin treatment in the study group $(\mathrm{n}=27)$ and a mean number of $11.6( \pm 1.7)$ days in the control group $(\mathrm{n}=28), \mathrm{MD}-1.60 ; 95 \% \mathrm{CI}-2.42$ to $0.78, \mathrm{P}=0.0001(\mathrm{Kim} 2005)$.

COCP + Agonist versus Antagonist, low response (one study included) - This study found that the mean length of gonadotrophin therapy was $9.60( \pm 1.90)$ days in the study group $(\mathrm{n}=59)$ and $9.65( \pm 1.60)$ in the control group $(\mathrm{n}=51), \mathrm{MD}-0.50 ; 95 \% \mathrm{CI}$ -0.70 to $0.60, \mathrm{P}=0.88$ (Wang 2008).

See Figure 6 for the graph and details of this outcome. 
Figure 6. Forest plot of comparison: I Combined OCP versus no Rx, outcome: I.5 Days of gonadotrophin treatment.

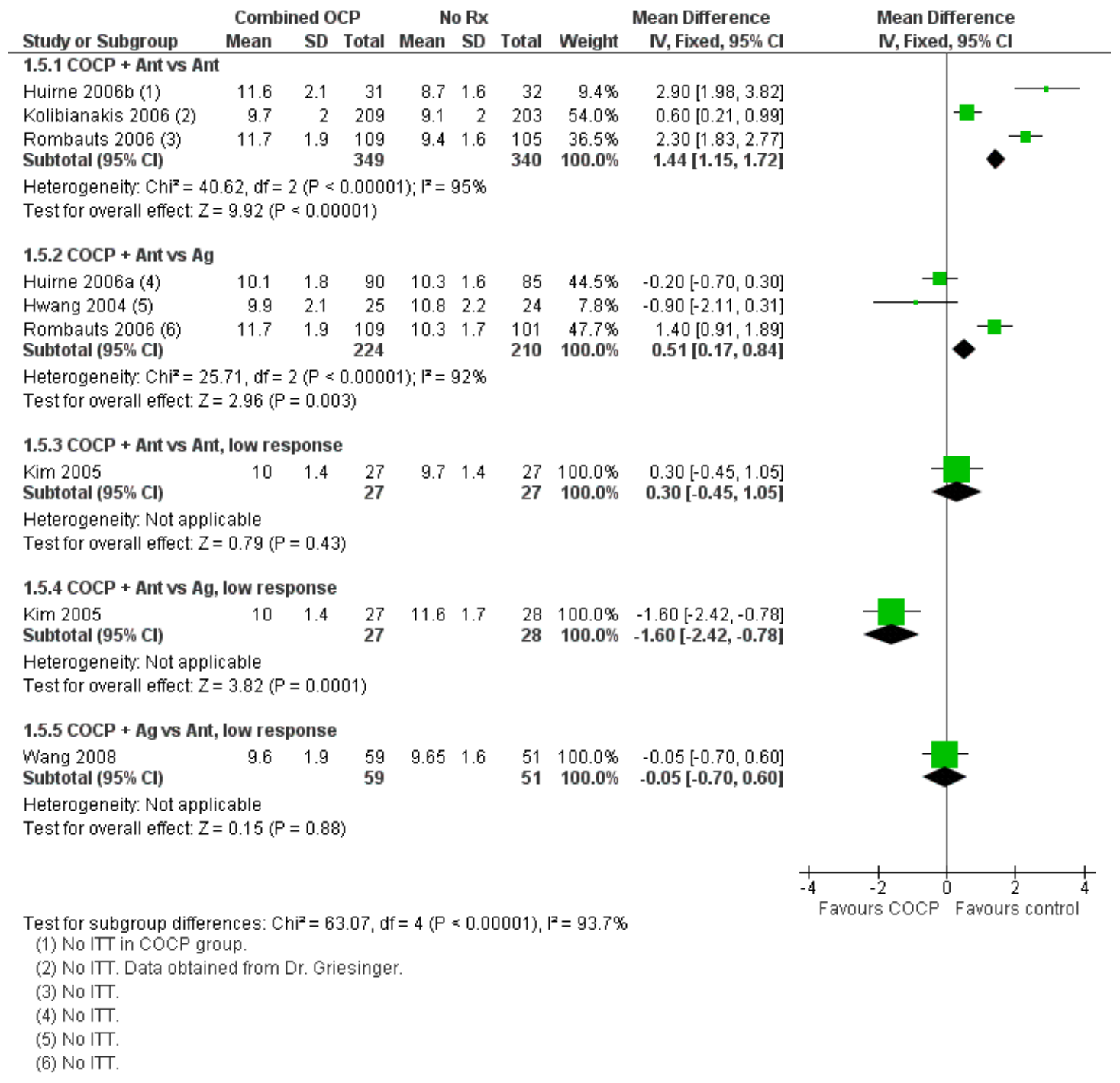

\section{Amount of gonadotrophins administered Analysis I.6}

COCP + Antagonist versus Antagonist (five studies included) - The results of four studies have been pooled in this subgroup and for this outcome, with a total of 734 women. There was a statistically significant difference, with fewer gonadotrophins administered in the group that did not receive pre-treatment with a combined OCP (MD 231.14; 95\% CI 161.50 to 300.78, P < 0.00001). Heterogeneity in this meta-analysis was high with an $\mathrm{I}^{2}$ statistic of $93 \%$. We did a sensitivity analysis to explore this heterogeneity and found that a possible explanation could be that Kolibianakis 2006 uses a shorter duration of pre-treatment than the other studies. By removing Kolibianakis 2006 from the meta-analysis heterogeneity was reduced to $43 \%$. This did not change the results substantially. An overview of characteristics of the studies for this subgroup are reported in Table 1 .

COCP + Antagonist versus Agonist (three studies included) - Two RCTs have been pooled for this outcome, with a total of 385 women. There was a significant difference favouring the group that did not receive pre-treatment with a combined OCP (MD 209.52; $95 \% \mathrm{CI} 61.16$ to $357.87, \mathrm{P}=0.006)$. The heterogeneity in this 
subgroup was also high, with an $\mathrm{I}^{2}$ statistic of $90 \%$. We were not able to perform a sensitivity analysis, because there were only two studies that reported the amount of gonadotrophins administered in this subgroup. An overview of characteristics of these two studies are reported in Table 2.

COCP + Antagonist versus Antagonist, low response (one study included) - This study reported a mean amount of $2963.9( \pm 433.1)$ IU gonadotrophins administered in the study group $(\mathrm{n}=27)$ and a mean of $2931.5( \pm 464.1)$ IU in the control group ( $n=27)$, MD
32.40; 95\% CI -207.04 to 271.84, $\mathrm{P}=0.79$ (Kim 2005).

COCP + Antagonist versus Agonist, low response (one study included) - This study reported a mean amount of $2963.9( \pm 433.1)$ IU gonadotrophins administered in the study group $(\mathrm{n}=27)$ and a mean of $3390.2( \pm 443.2)$ IU in the control group $(n=28)$, MD $-426.30 ; 95 \%$ CI -657.90 to $-194.70, \mathrm{P}=0.0003$, which makes this difference statistically significant (Kim 2005).

See Figure 7 for the graph and details of this outcome.

Figure 7. Forest plot of comparison: I Combined OCP versus no Rx, outcome: I.6 Amount of gonadotrophins administered.

\begin{tabular}{|c|c|c|c|c|c|c|c|c|c|}
\hline \multirow[b]{2}{*}{ Study or Subgroup } & \multicolumn{3}{|c|}{ Combined OCP } & \multicolumn{2}{|c|}{ No $\mathrm{Rx}$} & \multirow[b]{2}{*}{ Total } & \multirow[b]{2}{*}{ Weight } & Mean Difference & \multirow{2}{*}{$\begin{array}{l}\text { Mean Difference } \\
\mathrm{IV} \text {, Fixed, } 95 \% \mathrm{Cl}\end{array}$} \\
\hline & Mean & SD & Total & Mean & SD & & & IV, Fixed, $95 \% \mathrm{Cl}$ & \\
\hline \multicolumn{10}{|l|}{ 1.6.1 COCP + Ant vs Ant } \\
\hline Cédrin-Durnerin 2007 & 2,174 & 723 & 21 & 1,734 & 551 & 24 & $3.4 \%$ & $440.00[60.24,819.76]$ & \\
\hline Huirne 2006b (1) & 2,958 & 1,162 & 31 & 1,950 & 616 & 32 & $2.3 \%$ & $1008.00[546.62,1469.38]$ & $\longrightarrow$ \\
\hline Kolibianakis 2006 (2) & 1,943 & 402 & 209 & 1,818 & 398 & 203 & $81.3 \%$ & $125.00[47.75,202.25]$ & \\
\hline Rombauts 2006 (3) & 2,667 & 880.7 & 109 & $1,965.7$ & 515.5 & 105 & $13.1 \%$ & $701.30[508.80,893.80]$ & \\
\hline Subtotal $(95 \% \mathrm{Cl})$ & & & 370 & & & 364 & $100.0 \%$ & $231.14[161.50,300.78]$ & \\
\hline \multicolumn{10}{|c|}{ Heterogeneity: $\mathrm{Chi}^{2}=42.22, \mathrm{df}=3(\mathrm{P}<0.00001) ;\left.\right|^{2}=93 \%$} \\
\hline \multicolumn{10}{|l|}{ 1.6.2 COCP + Ant vs Ag } \\
\hline Huirne 2006a (4) & 1,919 & 638 & 90 & 1,949 & 773 & 85 & $49.6 \%$ & $-30.00[-240.66,180.66]$ & \\
\hline Rombauts 2006 (5) & 2,667 & 880.7 & 109 & $2,221.8$ & 655.3 & 101 & $50.4 \%$ & $445.20[236.23,654.17]$ & \\
\hline Subtotal $(95 \% \mathrm{Cl})$ & & & 199 & & & 186 & $100.0 \%$ & $209.52[61.16,357.87]$ & \\
\hline \multicolumn{10}{|c|}{$\begin{array}{l}\text { Heterogeneity: } \mathrm{Chi}^{2}=9.85, \mathrm{df}=1(\mathrm{P}=0.002) ; \mathrm{I}^{2}=90 \% \\
\text { Test for overall effect: } Z=2.77(P=0.006)\end{array}$} \\
\hline \multicolumn{10}{|c|}{ 1.6.3 COCP + Ant vs Ant, low response } \\
\hline $\begin{array}{l}\text { Kim } 2005 \\
\text { Subtotal }(95 \% \mathrm{Cl})\end{array}$ & $2,963.9$ & 433.1 & $\begin{array}{l}27 \\
27\end{array}$ & $2,931.5$ & 464.1 & $\begin{array}{l}27 \\
27\end{array}$ & $\begin{array}{l}100.0 \% \\
\mathbf{1 0 0 . 0} \%\end{array}$ & $\begin{array}{r}32.40[-207.04,271.84] \\
32.40[-207.04,271.84]\end{array}$ & \\
\hline \multicolumn{10}{|c|}{$\begin{array}{l}\text { Heterogeneity: Not applicable } \\
\text { Test for overall effect: } Z=0.27(P=0.79)\end{array}$} \\
\hline \multicolumn{10}{|c|}{ 1.6.4 COCP + Ant vs Ag, low response } \\
\hline $\begin{array}{l}\text { Kim } 2005 \\
\text { Subtotal }(95 \% \mathrm{Cl})\end{array}$ & $2,963.9$ & 433.1 & $\begin{array}{l}27 \\
27\end{array}$ & $3,390.2$ & 443.2 & $\begin{array}{l}28 \\
28\end{array}$ & $\begin{array}{l}100.0 \% \\
\mathbf{1 0 0 . 0} \%\end{array}$ & $\begin{array}{l}-426.30[-657.90,-194.70] \\
-426.30[-657.90,-194.70]\end{array}$ & \\
\hline \multirow{2}{*}{\multicolumn{10}{|c|}{$\begin{array}{l}\text { Heterogeneity: Not applicable } \\
\text { Test for overall effect: } Z=3.61(P=0.0003)\end{array}$}} \\
\hline & & & & & & & & & \\
\hline & & & & & & & & & 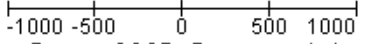 \\
\hline \multicolumn{10}{|c|}{$\begin{array}{l}\text { Test for subgroup differences: } \mathrm{Chi}^{2}=29.96, \mathrm{df}=3(\mathrm{P}<0.00001), \mathrm{I}^{2}=90.0 \% \\
\text { (1) No ITT in COCP group. } \\
\text { (2) No ITT. Data obtained from Dr. Griesinger. } \\
\text { (3) No ITT. } \\
\text { (4) No ITT. } \\
\text { (5) No ITT. }\end{array}$} \\
\hline
\end{tabular}

\section{Pregnancy losses Analysis I.7}

COCP + Antagonist versus Antagonist (five studies included) - The results of four trials have been pooled in this subgroup, with a total of 847 women. The number of pregnancy losses did not differ statistically significantly between groups (Peto OR 1.26; 95\% CI
0.76 to $2.12, \mathrm{P}=0.37$ ).

COCP + Antagonist versus Agonist (three studies included) - The results of three trials have been pooled, with a total of 472 women. There was no statistically significant result (Peto OR 0.52; 95\% CI 0.24 to $1.10, \mathrm{P}=0.09$ ).

COCP + Antagonist versus Antagonist, low response (one study in- 
cluded) - This study found that there was one pregnancy loss in both the study $(\mathrm{n}=27)$ and the control group $(\mathrm{n}=27) \mathrm{OR} 1.0$; 95\% CI 0.06 to 16.42 (Kim 2005).

COCP + Antagonist versus Agonist, low response (one study included) - This study found that there was one pregnancy loss in both the study $(\mathrm{n}=27)$ and the control group $(\mathrm{n}=28)$, OR 1.04; 95\% CI 0.06 to $17.04, \mathrm{P}=0.98$ (Kim 2005).

See Figure 8 for the graph and details of this outcome.

Figure 8. Forest plot of comparison: I Combined OCP versus no Rx, outcome: I.7 Pregnancy losses.

\begin{tabular}{|c|c|c|c|c|c|c|c|}
\hline \multirow[b]{2}{*}{ Study or Subgroup } & \multicolumn{2}{|c|}{ Combined OCP } & \multicolumn{2}{|c|}{ No $\mathrm{Rx}$} & \multirow[b]{2}{*}{ Weight } & \multirow{2}{*}{$\begin{array}{l}\text { Peto Odds Ratio } \\
\text { Peto, Fixed, } 95 \% \text { Cl }\end{array}$} & \multirow{2}{*}{$\begin{array}{c}\text { Peto Odds Ratio } \\
\text { Peto, Fixed, } 95 \% \mathrm{Cl}\end{array}$} \\
\hline & Events & Total & Events & Total & & & \\
\hline \multicolumn{8}{|l|}{ 1.7.1 COCP + Ant vs Ant } \\
\hline Cédrin-Durnerin 2007 (1) & 2 & 21 & 5 & 24 & $10.4 \%$ & $0.43[0.09,2.13]$ & \\
\hline Huirne 2006b (2) & 4 & 32 & 5 & 32 & $13.5 \%$ & $0.78[0.19,3.14]$ & \\
\hline Kolibianakis 2006 & 28 & 250 & 16 & 254 & $69.3 \%$ & $1.85[1.00,3.43]$ & \\
\hline Rombauts 2006 & 1 & 117 & 3 & 117 & $6.8 \%$ & $0.36[0.05,2.61]$ & \\
\hline Subtotal $(95 \% \mathrm{Cl})$ & & 420 & & 427 & $100.0 \%$ & $1.26[0.76,2.12]$ & \\
\hline Total events & 35 & & 29 & & & & \\
\hline \multirow{2}{*}{\multicolumn{8}{|c|}{$\begin{array}{l}\text { Heterogeneity: } C h i^{2}=5.20, d f=3(P=0.16) ;\left.\right|^{2}=42 \% \\
\text { Test for overall effect: } Z=0.89(P=0.37)\end{array}$}} \\
\hline & & & & & & & \\
\hline \multicolumn{8}{|l|}{ 1.7.2 COCP + Ant vs Ag } \\
\hline Huirne 2006a (3) & 8 & 91 & 10 & 91 & $60.5 \%$ & $0.78[0.30,2.07]$ & \\
\hline Hwang 2004 (4) & 1 & 27 & 2 & 29 & $10.7 \%$ & $0.54[0.05,5.41]$ & \\
\hline Rombauts 2006 & 1 & 117 & 7 & 117 & $28.8 \%$ & $0.21[0.05,0.87]$ & \\
\hline Subtotal $(95 \% \mathrm{Cl})$ & & 235 & & 237 & $100.0 \%$ & $0.52[0.24,1.10]$ & \\
\hline Total events & 10 & & 19 & & & & \\
\hline \multicolumn{8}{|c|}{$\begin{array}{l}\text { Heterogeneity: } C h i^{2}=2.23, \mathrm{df}=2(P=0.33) ;\left.\right|^{2}=10 \% \\
\text { Test for overall effect: } Z=1.71(P=0.09)\end{array}$} \\
\hline \multicolumn{8}{|c|}{ 1.7.3 COCP + Ant vs Ant, low response } \\
\hline Kim 2005 & 1 & 27 & 1 & 27 & $100.0 \%$ & $1.00[0.06,16.42]$ & \\
\hline Subtotal (95\% Cl) & & 27 & & 27 & $100.0 \%$ & $1.00[0.06,16.42]$ & \\
\hline Total events & 1 & & 1 & & & & \\
\hline \multirow{2}{*}{\multicolumn{8}{|c|}{$\begin{array}{l}\text { Heterogeneity: Not applicable } \\
\text { Test for overall effect: } Z=0.00(P=1.00)\end{array}$}} \\
\hline & & & & & & & \\
\hline \multicolumn{8}{|c|}{ 1.7.4 COCP + Ant vs Ag, low response } \\
\hline Kim 2005 & 1 & 27 & 1 & 28 & $100.0 \%$ & $1.04[0.06,17.04]$ & \\
\hline Subtotal (95\% Cl) & & 27 & & 28 & $100.0 \%$ & $1.04[0.06,17.04]$ & \\
\hline \multirow{4}{*}{$\begin{array}{l}\text { Total events } \\
\text { Heterogeneity: Not applica } \\
\text { Test for overall effect: } Z=0\end{array}$} & 1 & & 1 & & & & \\
\hline & e & & & & & & \\
\hline & $3(P=0.9$ & & & & & & \\
\hline & & & & & & & 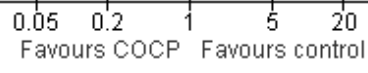 \\
\hline \multicolumn{8}{|c|}{$\begin{array}{l}\text { (1) Calculated from the number of clinical pregnancies minus the number of live births. } \\
\text { (2) Calculated from the number of positive pregnancy tests minus the number of ongoing pregnancies. } \\
\text { (3) Calculated from the number of positive pregnancy tests minus the number of live births. } \\
\text { (4) Calculated from rates. }\end{array}$} \\
\hline
\end{tabular}


or analysed because the number of women in each study or control group is unknown. The first study found that the number of women in which cyst formation occurred was none in the study group $(\mathrm{n}=51$ cycles $)$ and 27 in the control group $(\mathrm{n}=51$ cycles $)$ (Biljan 1998a). This result was statistically significant according to the authors OR 0.O7; 95\% CI 0.03 to 0.16 , (P<0.0001). Raoofi 2008 reported no women with cyst formation in both the study group and the control group.

COCP + Antagonist versus Antagonist (five studies included) - In this subgroup, the number of women with ovarian cysts was reported by one study, that found two women with ovarian cysts in the study group $(\mathrm{n}=32)$ and four women in the control group (n = 32), OR 0.48; 95\% CI 0.09 to 2.57, P = 0.39 (Huirne 2006b).

\section{Multiple pregnancies Analysis 1.9}

COCP + Antagonist versus Antagonist (five studies included) - Only one study in this subgroup reported this outcome and found two multiple pregnancies in the study group $(n=21)$ and one in the control group ( $\mathrm{n}=24)$, withOR 2.32; $95 \%$ CI 0.23 to $23.65 \mathrm{P}$ value of 0.48 (Cédrin-Durnerin 2007).

COCP + Antagonist versus Agonist (three studies included) - Two of the trials included in this subgroup reported on this outcome, with a total of 238 women. The pooling of these results showed no statistically significant difference between treatment groups (Peto OR 1.02; 95\% CI 0.37 to $2.82, \mathrm{P}=0.96$ ).

COCP + Antagonist versus Antagonist, low response (one study included) - The only study in this subgroup (Kim 2005) found two multiple pregnancies in the study group $(\mathrm{n}=27)$ and one in the control group ( $\mathrm{n}=27$ ), OR 2.00; 95\% CI 0.20 to $20.08, \mathrm{P}=0.56$. $C P+$ Antagonist versus Agonist, low response (one study included) The only study in this subgroup (Kim 2005) found two multiple pregnancies in the study group $(\mathrm{n}=27)$ and one in the control group ( $\mathrm{n}=28$ ), OR 2.08 ; $95 \%$ CI 0.21 to $20.84, \mathrm{P}=0.53$.

See Figure 9 for the graph and details of this outcome.

Figure 9. Forest plot of comparison: I Combined OCP versus no Rx, outcome: I.9 Multiple pregnancies.

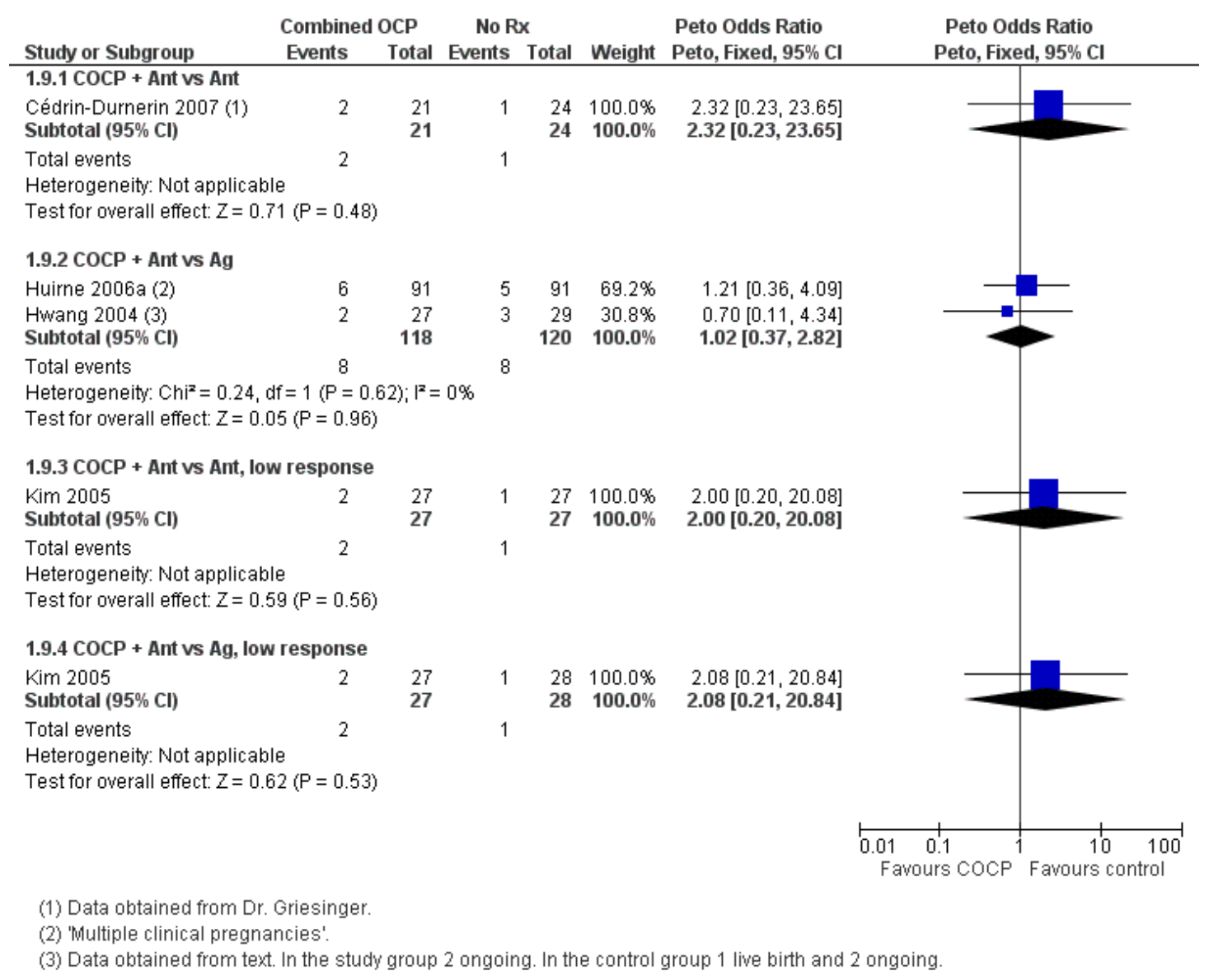

Oral contraceptive pill, progestogen or estrogen pre-treatment for ovarian stimulation protocols for women undergoing assisted 


\section{OHS syndrome Analysis I.10}

COCP + Antagonist versus Antagonist (five studies included) - Only one study in this subgroup reported on this outcome and found three women with OHS syndrome in the study group $(\mathrm{n}=117)$ and two women with OHS syndrome in the control group ( $\mathrm{n}=$ 117), OR 1.50; 95\% CI 0.26 to 8.80, P = 0.65 (Rombauts 2006). COCP + Antagonist versus Agonist (three studies included) - Two studies, with a total of 290 women, reported on this outcome. The pooling showed no statistically significant difference between treatment groups (Peto OR 0.63; 95\% CI 0.21 to $1.92, \mathrm{P}=0.42$ ). See Figure 10 for the graph and details of this outcome.

Figure 10. Forest plot of comparison: I Combined OCP versus no Rx, outcome: I.IO OHS syndrome.

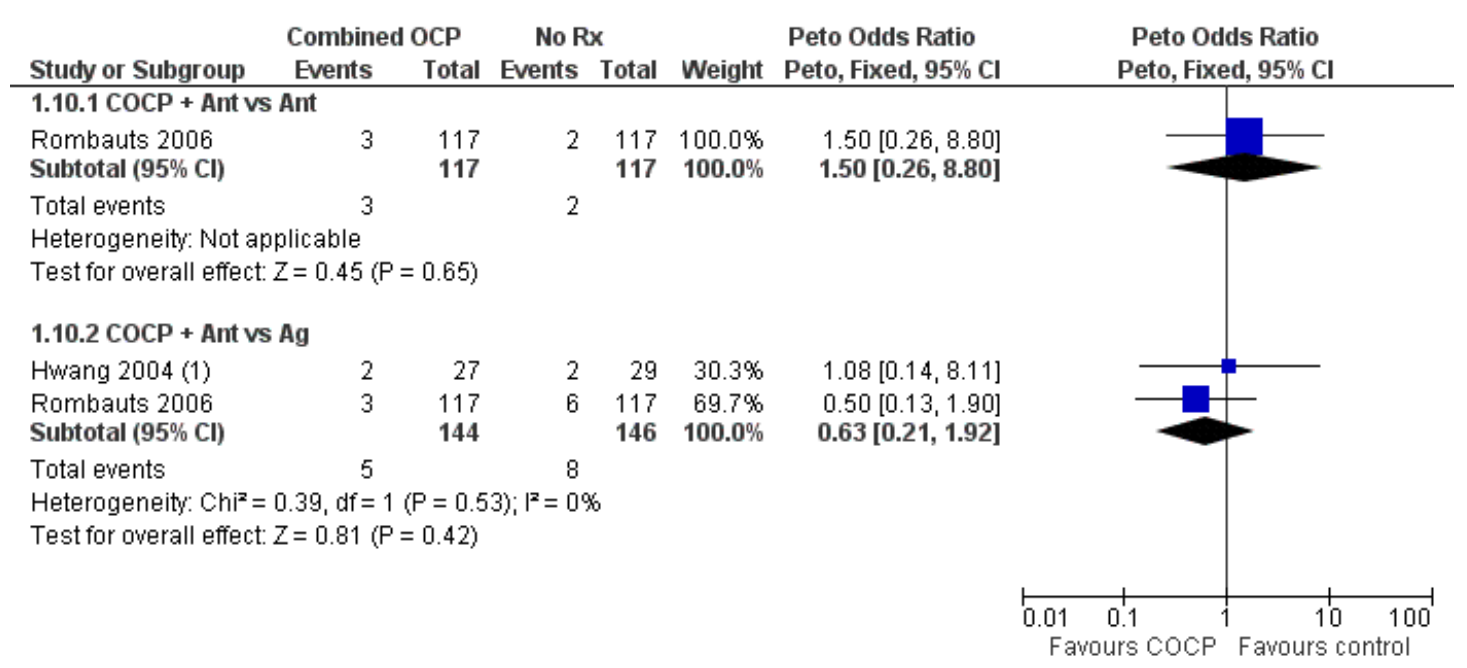

(1) Calculated from rates.

\section{Progestogen versus placebo or no pre-treatment}

\section{Live births Analysis 2.1}

Progestogen + Agonist versus Agonist (six studies included) - Two of the studies in this subgroup reported on the live birth rate, with a total of 222 women. There was no statistically significant difference found between the study group and the control group (Peto OR 1.35; 95\% CI 0.69 to 2.62, P = 0.38).

Progestogen + Antagonist versus Antagonist (one study included) Only one study could be included in this subgroup and this study found a number of five live births in the study group $(\mathrm{n}=23)$ and seven live births in the control group $(\mathrm{n}=24)$, Peto OR 0.68; $95 \%$ CI 0.19 to 2.50, $\mathrm{P}=0.56$ (Cédrin-Durnerin 2007).

See Figure 11 for the graph and details of this outcome. 
Figure II. Forest plot of comparison: 2 Progestogen versus placebo/ no Rx, outcome: 2.1 Live births.

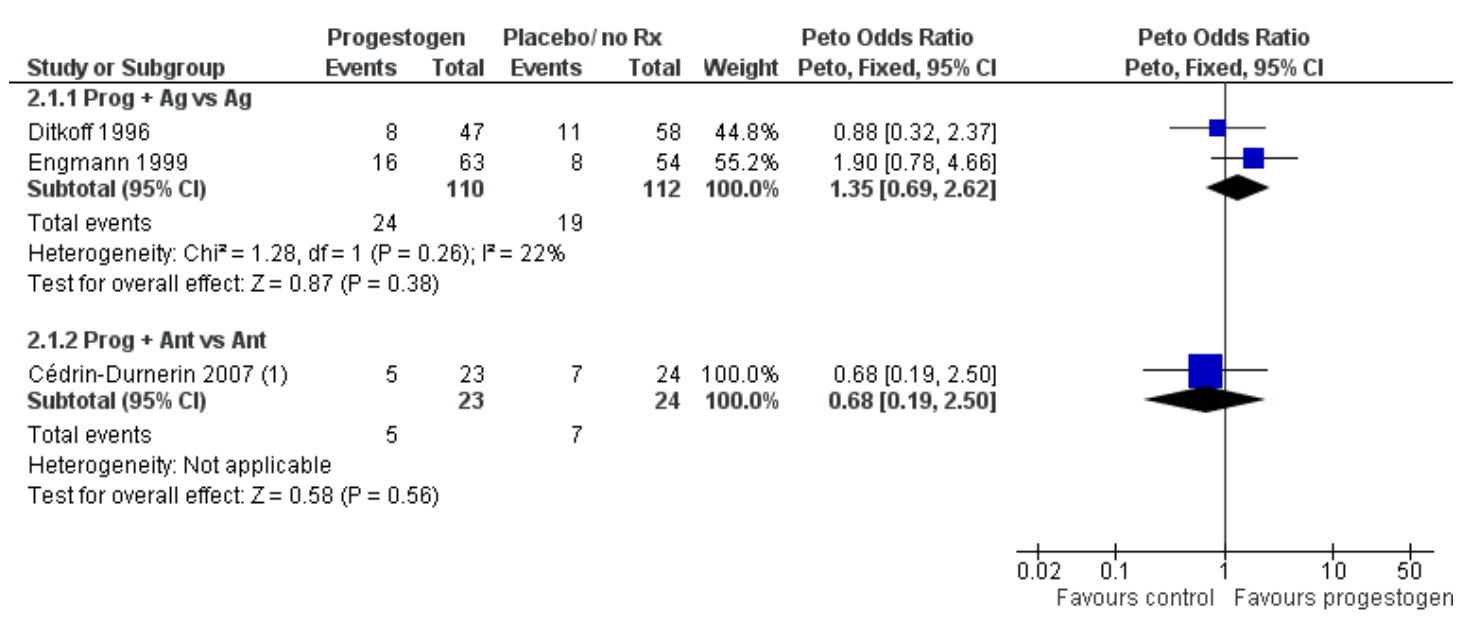

(1) Data obtained from Dr. Griesinger.

\section{Ongoing pregnancies Analysis $\mathbf{2 . 2}$}

Progestogen + Agonist versus Agonist (six studies included) - Only one study in this subgroup reported ongoing pregnancy rate ( Ditkoff 1996). The number of ongoing pregnancies was found to be eleven in the study group $(\mathrm{n}=47)$ and twelve in the control group ( $=58$ ), Peto OR 1.17; 95\% CI 0.46 to $2.95, \mathrm{P}=0.74$.

Progestogen + Antagonist versus Antagonist (one study included) The only study in this subgroup reported five ongoing pregnancies in the study group $(n=23)$ and seven in the control group $(n=24)$, Peto OR 0.68; 95\% CI 0.19 to 2.50, P = 0.56 (Cédrin-Durnerin 2007).

Progestogen + Gonadotrophins versus Gonadotrophins (one study included) - This study found two ongoing pregnancies in the study group $(\mathrm{n}=21)$ and three in the control group $(\mathrm{n}=21)$, Peto OR 0.64; $95 \%$ CI 0.10 to 4.06, $\mathrm{P}=0.64$ (Salat-Baroux 1988).

\section{Clinical/ongoing pregnancies Analysis 2.3}

Progestogen + Agonist versus Agonist (six studies included) - Results of three of the studies in this subgroup could be pooled with a total of 374 women. Of one of these studies we used the number of positive pregnancy tests, because no data on clinical pregnancy rate were available. A statistically significant result was found, with more clinical pregnancies obtained in the group pre-treated with a progestogen (Peto OR 1.95; 95\% CI 1.20 to $3.17, \mathrm{P}=0.007$ ). Another study in this subgroup reported on this outcome (Shaker 1995), but because only the number of cycles per group was known and not the number of women, data have not been pooled. In this study the number of clinical pregnancies was seven in the study group ( $\mathrm{n}=22$ cycles) and four in the control group ( $\mathrm{n}=29$ cycles). This result was not statistically significant according to the authors.

Progestogen + Antagonist versus Antagonist (one study included) The only study in this subgroup (Cédrin-Durnerin 2007) found a number of seven clinical pregnancies in the study group $(n=23)$ and twelve in the control group $(\mathrm{n}=24)$, Peto OR 0.53; $95 \% \mathrm{CI}$ 0.17 to $1.69, \mathrm{P}=0.28$.

Progestogen + Gonadotrophins versus Gonadotrophins (one study included) - The only study in this subgroup (Salat-Baroux 1988) found a number of three clinical pregnancies in the study group $(\mathrm{n}=21)$ and four in the control group $(\mathrm{n}=21)$, Peto OR 0.72; 95\% CI 0.14 to $3.56, \mathrm{P}=0.68$.

See Figure 12 for the graph and details of this outcome. 
Figure I2. Forest plot of comparison: 2 Progestogen versus placebo/ no Rx, outcome: 2.3 Clinical pregnancies.

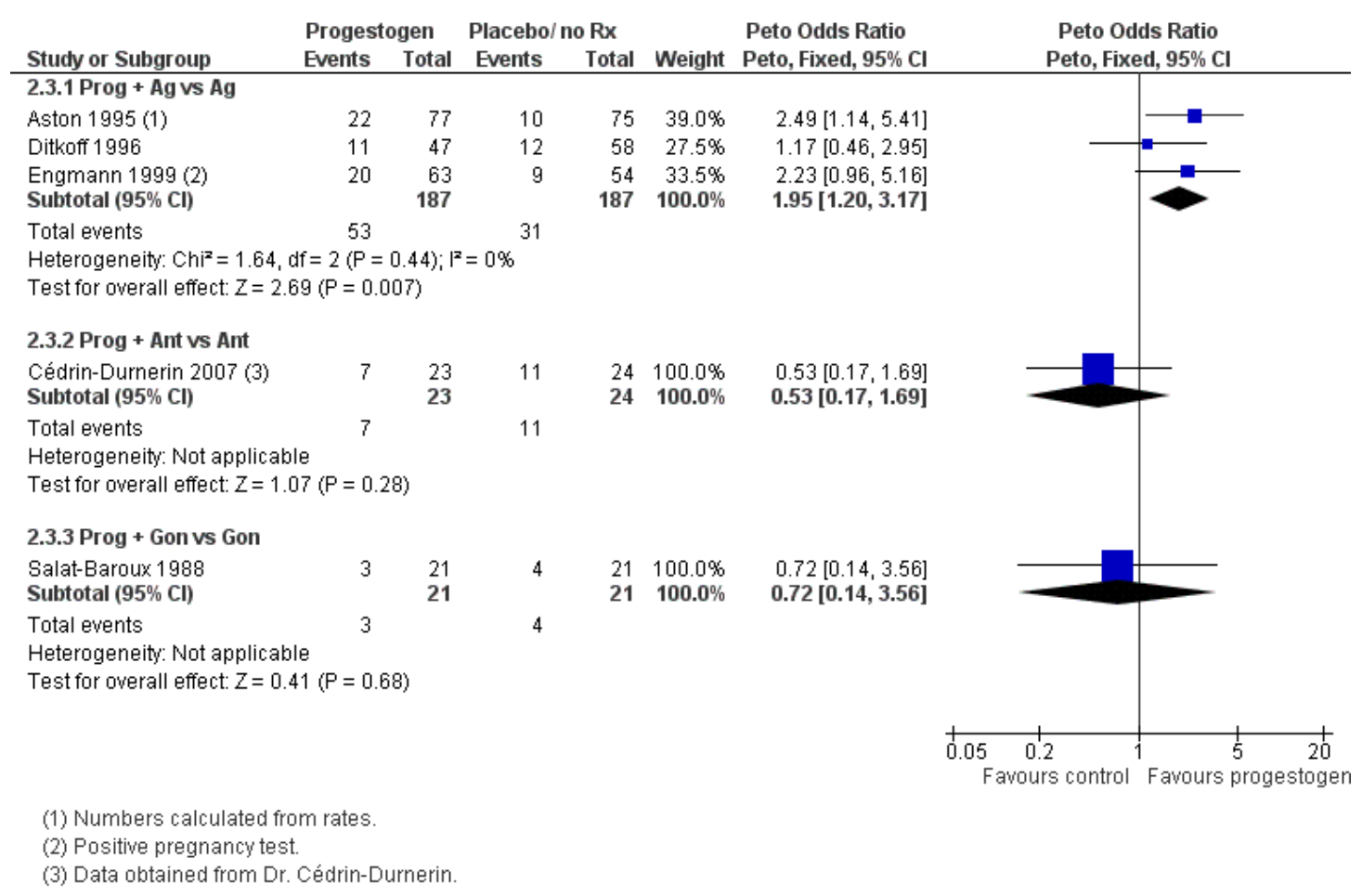

\section{Oocytes retrieved Analysis $\mathbf{2 . 4}$}

Progestogen + Agonist versus Agonist (six studies included) - Results of two of the studies in this subgroup have been pooled, with a total of 210 women. No statistically significant result was found (MD -0.56; 95\% CI -2.13 to $1.01, \mathrm{P}=0.48$ ) There was one other study in this subgroup that reported the mean number of oocytes retrieved, but because this was analysed per cycle (in stead of per woman randomised), we have not pooled the data of this study (Shaker 1995). The mean number of oocytes retrieved was $9.82( \pm 1.09)$ in the study group $(\mathrm{n}=22)$ and $9.1( \pm 1.09)$ in the control group $(n=29)$ and this result was not statistically significant according to the authors, but no P values were given.
Progestogen + Antagonist versus Antagonist (one study included) - Only one study could be included in this subgroup (CédrinDurnerin 2007). This study found that the mean number of oocytes retrieved was $12.6( \pm 7.3)$ in the study group $(\mathrm{n}=23)$ and $9.9( \pm 5.4)$ in the control group $(\mathrm{n}=24)$, Peto OR 2.70 ; $95 \% \mathrm{CI}$ -0.98 to $6.38, \mathrm{P}=0.15$.

Progestogen + Gonadotrophins versus Gonadotrophins (one study included) - The only study in this subgroup (Salat-Baroux 1988) found that the mean number of oocytes retrieved was $4.9( \pm 0.9)$ in the study group $(n=13)$ and $4.9( \pm 0.6)$ in the control group $(\mathrm{n}=16)$, Peto OR 0.00 ; $95 \%$ CI -0.57 to $0.57, \mathrm{P}=1.00$. See Figure 13 for the graph and details of this outcome. 
Figure 13. Forest plot of comparison: 2 Progestogen versus placebo/ no Rx, outcome: 2.4 Oocytes retrieved.

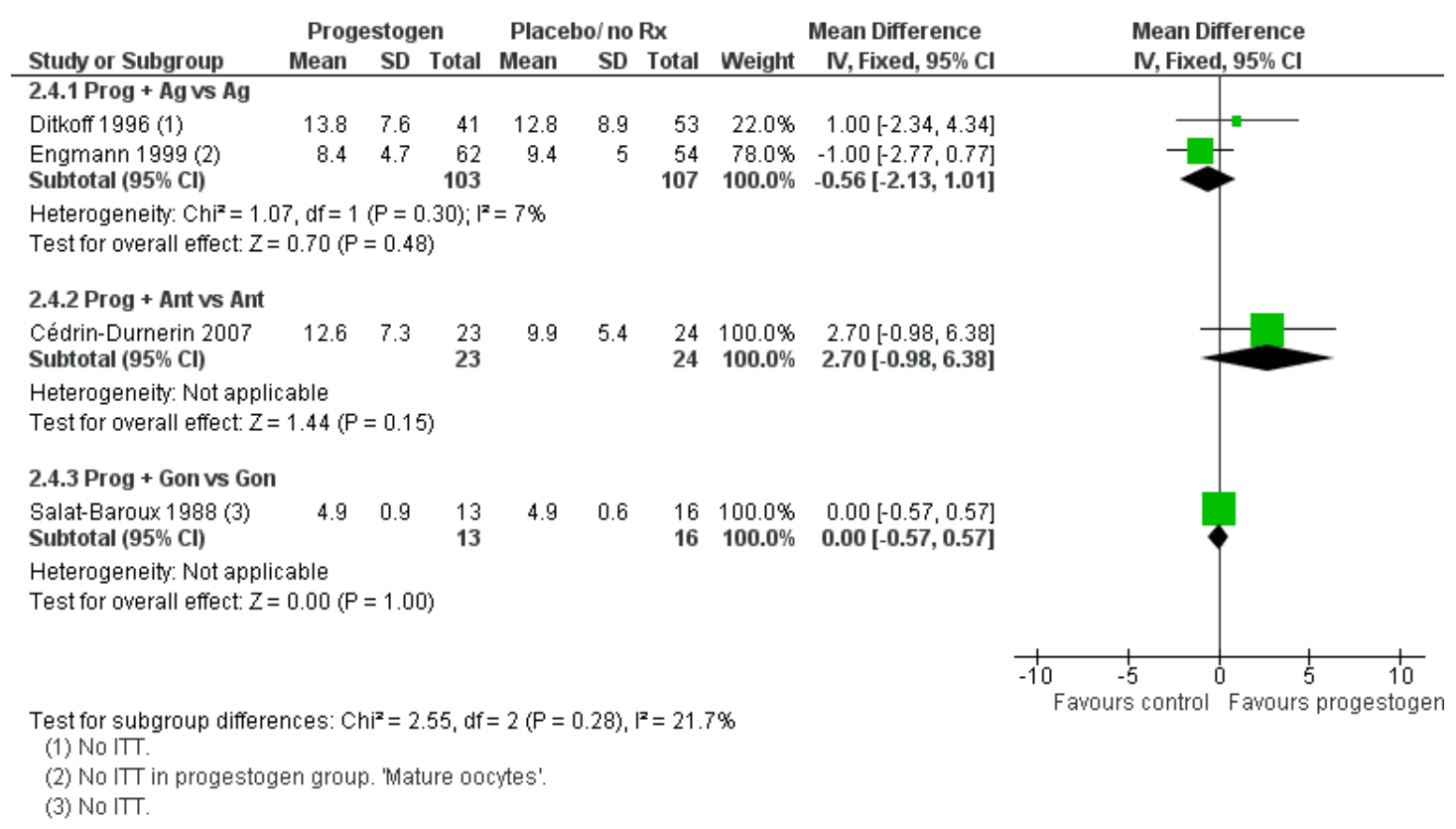

\section{Days of gonadotrophin treatment Analysis $\mathbf{2 . 5}$}

Progestogen + Agonist versus Agonist (six studies included) - Results of two RCTs in this subgroup have been pooled, with a total of 210 women. No statistically significant difference was found (MD 0.08 ; $95 \% \mathrm{CI}-0.35$ to $0.50, \mathrm{P}=0.73)$. Another study in this subgroup only reported the mean number of days of gonadotrophin therapy per cycle (in stead of per woman randomised) and found that this was $11.8( \pm 0.51)$ in the study group $(\mathrm{n}=22)$ and 11.48 $( \pm 0.37)$ in the control group $(n=29)$ (Shaker 1995). This result did not reach statistical significance according to the authors.

See Figure 14 for the graph and details of this outcome.

Figure 14. Forest plot of comparison: 2 Progestogen versus placebo/ no Rx, outcome: 2.5 Days of gonadotrophin treatment.

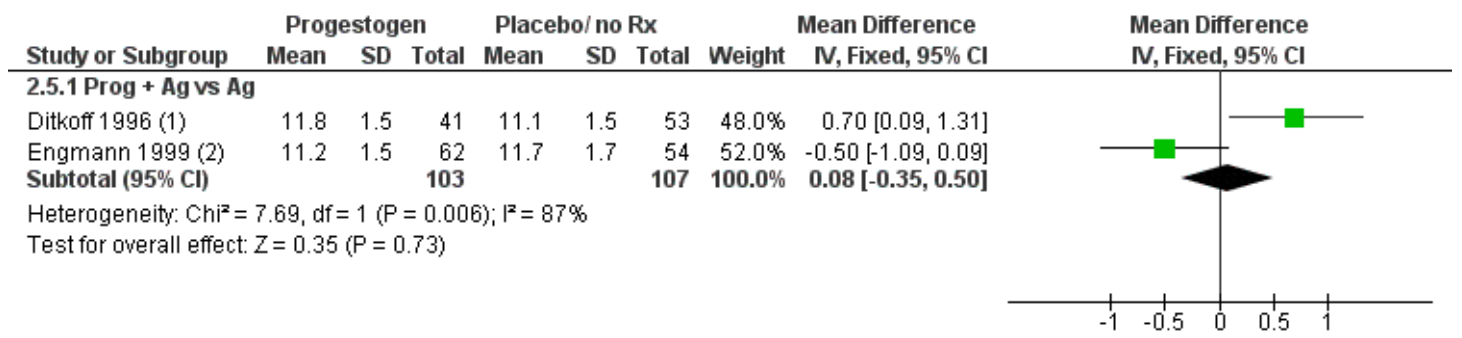

Test for subgroup differences: Not applicable

Favours progestogen Favours control

(1) No ITT

(2) No ITT in progestogen group.

Oral contraceptive pill, progestogen or estrogen pre-treatment for ovarian stimulation protocols for women undergoing assisted 


\section{Amount of gonadotrophins administered Analysis 2.6}

Progestogen + Antagonist versus Antagonist (one study included) Only one trial reported on this outcome (Cédrin-Durnerin 2007) and found that the mean amount of gonadotrophins administered was 2,010 $( \pm 670)$ IU in the study group $(\mathrm{n}=23)$ and $1,734( \pm$ $551)$ IU in the control group ( $\mathrm{n}=24)$, Peto OR 2.76.00; $95 \% \mathrm{CI}$ $0 .-75.53$ to $672.53, \mathrm{P}=0.12$.

\section{Pregnancy losses Analysis $\mathbf{2 . 7}$}

Progestogen + Agonist versus Agonist (six studies included) - Results of two trials of this subgroup have been pooled, with a total of 222 women. There was no statistically significant difference found between the study group and the control group (Peto OR 2.17; 95\% CI 0.71 to $6.69, \mathrm{P}=0.18$ ).

Progestogen + Antagonist versus Antagonist (one study included) The only study in this subgroup (Cédrin-Durnerin 2007) did not report on the number of pregnancy losses, but we calculated this number by subtracting the number of live births from the number of clinical pregnancies. Through this we found two pregnancy losses in the study group $(\mathrm{n}=23)$ and five in the control group ( $\mathrm{n}$ = 24), Peto OR 0.39; 95\% CI 0.08 to $1.92, \mathrm{P}=0.25$.

Progestogen + Gonadotrophins versus Gonadotrophins (one study included) - The only trial included in this subgroup found one pregnancy loss in each treatment group ( $\mathrm{n}=21$ in each group), but we are not sure if the follow up was long enough to detect all pregnancy losses (Salat-Baroux 1988) .

See Figure 15 for the graph and details of this outcome.

Figure 15. Forest plot of comparison: 2 Progestogen versus placebo/ no Rx, outcome: 2.7 Pregnancy losses.

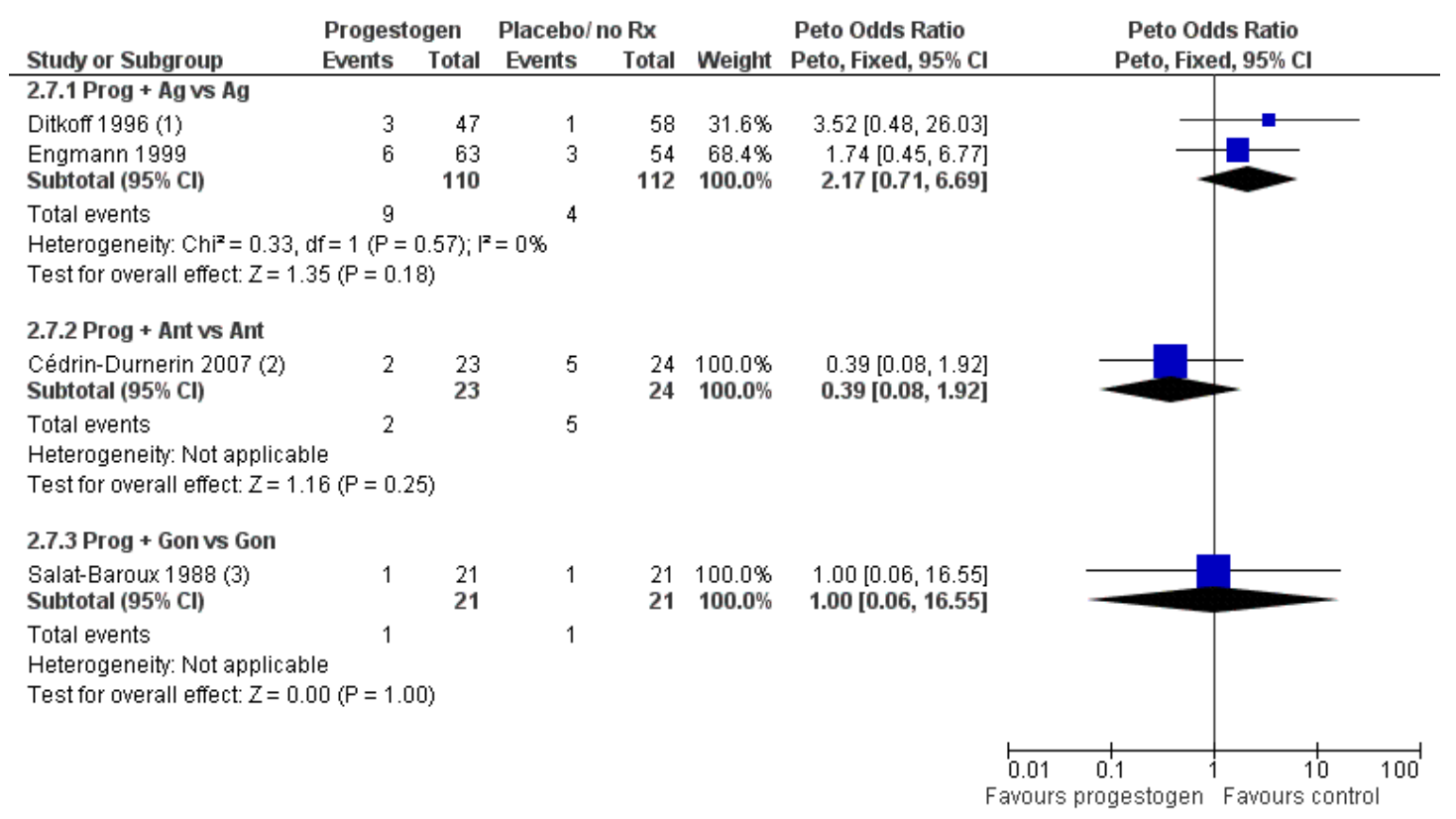

(1) Calculated from the number of clinical pregnancies minus the number of live births.

(2) Calculated from the number of clinical pregnancies minus the number of live births.

(3) Data obtained from text, not sure whether follow up was long enough. 


\section{Ovarian cyst formation Analysis $\mathbf{2 . 8}$}

Progestogen + Agonist versus Agonist (six studies included) - Three of the studies in this subgroup, with a total of 374 women, reported on this outcome and data have been pooled. We found that there was a statistically significant difference, with less ovarian cyst formation in the group pre-treated with a progestogen (Peto OR $0.21 ; 95 \%$ CI 0.12 to $0.35, \mathrm{P}<0.00001$ ).

See Figure 16 for the graph and details of this outcome.

Figure 16. Forest plot of comparison: 2 Progestogen versus placebo/ no Rx, outcome: 2.8 Ovarian cyst formation.

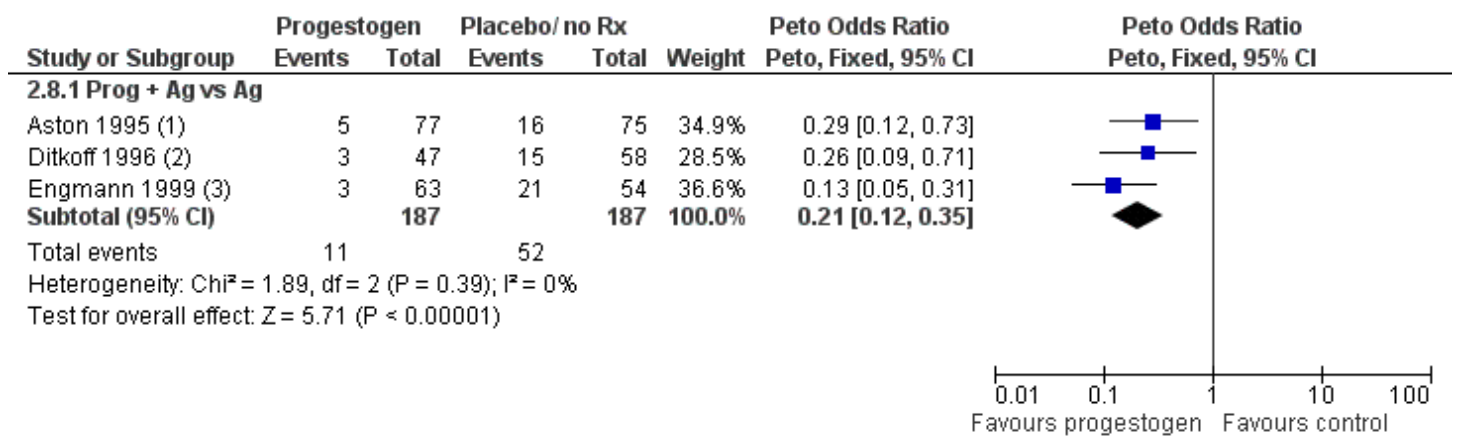

\footnotetext{
(1) Measured after 12 days of pituitary suppression.

(2) Measured after 8 days of pituitary suppression.

(3) Measured after 7 days of pituitary suppression.
}

\section{Multiple pregnancies Analysis $\mathbf{2 . 9}$}

Progestogen + Antagonist versus Antagonist (one study included) - The only trial included in this subgroup found one multiple pregnancy in both the study group $(\mathrm{n}=23)$ and control group $(\mathrm{n}$ = 24), Peto OR 1.04; 95\% CI 0.06 to $17.23, \mathrm{P}=0.98$ (CédrinDurnerin 2007).

\section{OHS syndrome}

None of the studies in which the study group was administered a progestogen pre-treatment reported on the number of women with OHS syndrome.

\section{Estrogen versus no pre-treatment}

\section{Live births Analysis 3.I}

Estrogen + Antagonist versus Antagonist (two studies included) Only one study in this subgroup reported on this outcome and found three live births in the study group $(\mathrm{n}=25)$ and seven in the control group $(n=24)$, Peto OR 0.36 ; $95 \%$ CI 0.0 .09 to 1.41 , $\mathrm{P}=0.14$ (Cédrin-Durnerin 2007).

Estrogen + Antagonist versus Agonist (one study included) - Only one study was included in this subgroup, and this study found five live births in the study group $(\mathrm{n}=16)$ and two in the control group $(\mathrm{n}=6)$, Peto OR 0.91; 95\% CI 0.13 to $6.53, \mathrm{P}=0.93$ (Franco Jr 2003).

\section{Ongoing pregnancies Analysis 3.2}

Estrogen + Antagonist versus Antagonist (two studies included) Only one study in this subgroup reported on this outcome and found three ongoing pregnancies in the study group $(\mathrm{n}=25)$ and seven in the control group $(\mathrm{n}=24)$, Peto OR 0.36; 95\% CI 0.09 to $1.41 \mathrm{P}=0.14$ (Cédrin-Durnerin 2007).

Estrogen + Antagonist versus Agonist (one study included) - This 
study found five ongoing pregnancies in the study group $(\mathrm{n}=16)$ and two in the control group $(\mathrm{n}=6)$, Peto OR $0.91 ; 95 \%$ CI 0.13 to $6.53, \mathrm{P}=0.93$ (Franco Jr 2003).

\section{Clinical/ongoing pregnancies Analysis 3.3}

Estrogen + Antagonist versus Antagonist (two studies included) Both studies in this subgroup, with a total 139 women, reported on the number of clinical pregnancies and data have been pooled. No statistically significant difference was found (Peto OR 0.79; 95\% CI 0.38 to $1.62, \mathrm{P}=0.52$ ).

Estrogen + Antagonist versus Agonist (one study included) - The only study in this subgroup found five clinical pregnancies in the study group $(n=16)$ and two in the control group $(n=6)$, Peto OR 1.35; 95\% CI 0.13 to $6.53, \mathrm{P}=0.93$ (Franco Jr 2003). See Figure 17 for the graph and details of this outcome.

Figure 17. Forest plot of comparison: 3 Estrogen versus no Rx, outcome: 3.3 Clinical pregnancies.

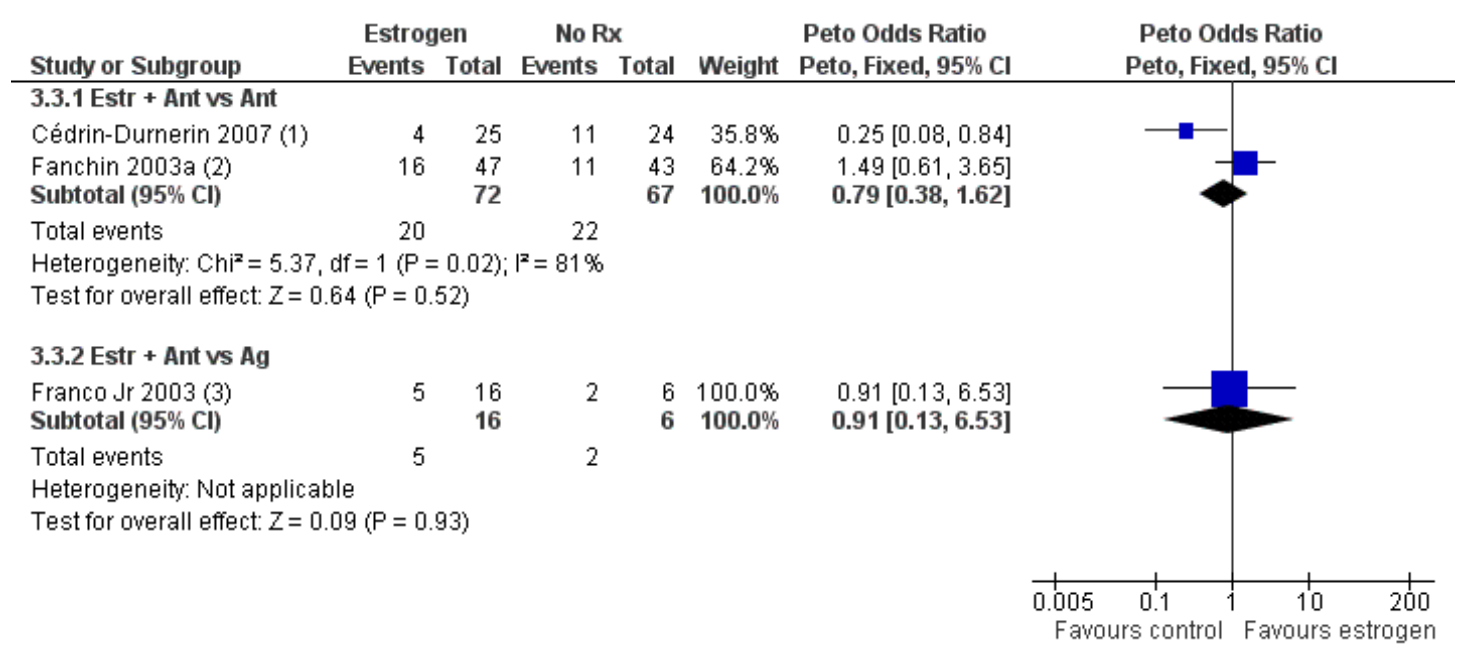

\footnotetext{
(1) Data obtained from Dr. Cédrin-Durnerin.

(2) No ITT. Calculated from rates.

(3) Includes 2 spontaneous pregnancies in the study group.
}

\section{Oocytes retrieved Analysis 3.4}

Estrogen + Antagonist versus Antagonist (two studies included) Both studies in this subgroup, with a total of 136 women, reported on the number of oocytes retrieved and data have been pooled. A statistically significant difference was found, with more oocytes retrieved in the group pre-treated with oestrogen (MD 2.01; 95\% CI 1.76 to $2.25, \mathrm{P}<0.00001)$.

Estrogen + Antagonist versus Agonist (one study included) - This study found a mean number of oocytes retrieved of $10.5( \pm 6.5)$ in the study group $(\mathrm{n}=14)$ and of $10.1( \pm 4.6)$ in the control group $(\mathrm{n}=6$ ), Peto OR $-2.50 ; 95 \% \mathrm{CI}-4.61$ to $5.41, \mathrm{P}=0.88$ (Franco Jr 2003).

See Figure 18 for the graph and details of this outcome.

Oral contraceptive pill, progestogen or estrogen pre-treatment for ovarian stimulation protocols for women undergoing assisted 
Figure 18. Forest plot of comparison: 3 Estrogen versus no Rx, outcome: 3.4 Oocytes retrieved.

\begin{tabular}{|c|c|c|c|c|c|c|c|c|c|}
\hline \multirow[b]{2}{*}{ Study or Subgroup } & \multicolumn{3}{|c|}{ Estrogen } & \multicolumn{3}{|c|}{ No $\mathrm{Rx}$} & \multicolumn{2}{|r|}{ Mean Difference } & \multirow{2}{*}{$\begin{array}{l}\text { Mean Difference } \\
\text { IV, Fixed, } 95 \% \mathrm{Cl}\end{array}$} \\
\hline & Mean & SD & Total & Mean & SD & Total & Weight & IV, Fixed, 95\% Cl & \\
\hline \multicolumn{10}{|l|}{ 3.4.1 Estr + Ant vs Ant } \\
\hline Cédrin-Durnerin 2007 (1) & 13.1 & 7 & 22 & 9.9 & 5.4 & 24 & $0.5 \%$ & $3.20[-0.44,6.84]$ & \\
\hline Fanchin 2003a (2) & 9.3 & 0.7 & 47 & 7.3 & 0.5 & 43 & $99.5 \%$ & $2.00[1.75,2.25]$ & \\
\hline Subtotal $(95 \% \mathrm{Cl})$ & & & 69 & & & 67 & $100.0 \%$ & $2.01[1.76,2.25]$ & \\
\hline \multicolumn{10}{|c|}{$\begin{array}{l}\text { Heterogeneity: } \mathrm{Chi}^{2}=0.42, \mathrm{df}=1(P=0.52) ;\left.\right|^{2}=0 \% \\
\text { Test for overall effect: } Z=15.78(P<0.00001)\end{array}$} \\
\hline \multicolumn{10}{|l|}{ 3.4.2 Estr + Ant vs Ag } \\
\hline $\begin{array}{l}\text { Franco Jr } 2003(3) \\
\text { Subtotal }(95 \% \mathrm{Cl})\end{array}$ & 10.5 & 6.5 & $\begin{array}{l}14 \\
14\end{array}$ & 10.1 & 4.6 & $\begin{array}{l}6 \\
6\end{array}$ & $\begin{array}{l}100.0 \% \\
\mathbf{1 0 0 . 0} \%\end{array}$ & $\begin{array}{l}0.40[-4.61,5.41] \\
\mathbf{0 . 4 0}[-\mathbf{4 . 6 1}, \mathbf{5 . 4 1}]\end{array}$ & \\
\hline \multicolumn{10}{|c|}{$\begin{array}{l}\text { Heterogeneity: Not applicable } \\
\text { Test for overall effect: } Z=0.16(P=0.88)\end{array}$} \\
\hline $\begin{array}{l}\text { Test for subgroup differenc } \\
\text { (1) No ITT in estrogen gro } \\
\text { (2) No ITT. 'Mature follicle } \\
\text { (3) No ITT. }\end{array}$ & S: $\mathrm{Chi}^{2}=$ & $=0.39$ & a $d f=1$ & $(\mathrm{P}=0$ & 53), $\left.\right|^{2}$ & $=0 \%$ & & & $\begin{array}{ccccc}-4 & -2 & 0 & 2 & 4 \\
\text { Favours control } & \text { Favours estrogen }\end{array}$ \\
\hline
\end{tabular}

\section{Days of gonadotrophin treatment Analysis 3.5}

Estrogen + Antagonist versus Agonist (one study included) - Only one study was included in this subgroup, and this study found that the mean number of days of gonadotrophin therapy was 10.3 $( \pm 1.6)$ in the study group $(\mathrm{n}=14)$ and $12.8( \pm 1.7)$ in the control group $(n=6)$, with a P value of 0.002 (Franco Jr 2003).

\section{Amount of gonadotrophins administered Analysis 3.6}

Estrogen + Antagonist versus Antagonist (two studies included) Both studies in this subgroup, with a total of 136 women, reported on this outcome and results have been pooled. A statistically significant difference was found with fewer gonadotrophins admin- istered in the group that did not receive pre-treatment with oestrogen (MD 207.08; 95\% CI 167.77 to 246.39, P < 0.00001). A moderate amount of heterogeneity was found, with an $\mathrm{I}^{2}$ statistic of $57 \%$. We could not perform a sensitivity analysis, because there were only two studies that reported the outcome in this subgroup. An overview of characteristics of the studies for this subgroup are reported in Table 3 .

Estrogen + Antagonist versus Agonist (one study included) - This study found that the mean amount of gonadotrophins administered was 2,500 IU $( \pm 484)$ in the study group $(n=14)$ and 2,516 $\mathrm{IU}( \pm 484)$ in the control group $(\mathrm{n}=6)$, Peto OR $-16.0 ; 95 \% \mathrm{CI}$ -478.88 to $446.88, \mathrm{P}=0.95$ (Franco Jr 2003).

See Figure 19 for the graph and details of this outcome. 
Figure 19. Forest plot of comparison: 3 Estrogen versus no Rx, outcome: 3.6 Amount of gonadotrophins administered.

\begin{tabular}{|c|c|c|c|c|c|c|c|c|c|}
\hline Study or Subgroup & \multicolumn{3}{|c|}{ Estrogen } & \multicolumn{3}{|c|}{ No $\mathrm{Rx}$} & \multicolumn{2}{|r|}{ Mean Difference } & $\begin{array}{l}\text { Mean Difference } \\
\text { N, Fixed, } 95 \% \mathrm{Cl}\end{array}$ \\
\hline \multicolumn{10}{|l|}{ 3.6.1 Estr + Ant vs Ant } \\
\hline Cédrin-Durnerin 2007 (1) & 1,700 & 524 & 22 & 1,734 & 551 & 24 & $1.6 \%$ & $-34.00[-344.71,276.71]$ & \\
\hline $\begin{array}{l}\text { Fanchin } 2003 \mathrm{a}(2) \\
\text { Subtotal }(\mathbf{9 5} \% \mathrm{Cl})\end{array}$ & 2,674 & 91 & $\begin{array}{l}47 \\
69\end{array}$ & 2,463 & 100 & $\begin{array}{l}43 \\
67\end{array}$ & $\begin{array}{r}98.4 \% \\
100.0 \%\end{array}$ & $211.00[171.37,250.63]$ & \\
\hline \multicolumn{10}{|c|}{$\begin{array}{l}\text { Heterogeneity: } \mathrm{Ch}^{2}=2.35, \mathrm{df}=1(\mathrm{P}=0.13) ; \mathrm{I}^{2}=57 \% \\
\text { Test for overall effect: } Z=10.33(\mathrm{P}=0.00001)\end{array}$} \\
\hline \multicolumn{10}{|l|}{ 3.6.2 Estr + Ant vs Ag } \\
\hline $\begin{array}{l}\text { Franco Jr } 2003(3) \\
\text { Subtotal }(95 \% \mathrm{Cl})\end{array}$ & 2,500 & 484 & $\begin{array}{l}14 \\
14\end{array}$ & 2,516 & 484 & $\begin{array}{l}6 \\
6\end{array}$ & $\begin{array}{l}100.0 \% \\
\mathbf{1 0 0 . 0} \%\end{array}$ & $\begin{array}{l}-16.00[-478.88,446.88] \\
-16.00[-478.88,446.88]\end{array}$ & \\
\hline \multicolumn{10}{|c|}{$\begin{array}{l}\text { Heterogeneity: Not applicable } \\
\text { Test for overall effect: } Z=0.07(P=0.95)\end{array}$} \\
\hline \multicolumn{10}{|c|}{$\begin{array}{l}\text { Test for subgroup differences: } \mathrm{Chi}^{2}=0.89, \mathrm{df}=1(\mathrm{P}=0.35), \mathrm{I}^{2}=0 \% \\
\text { (1) No ITT in estrogen group. } \\
\text { (2) No ITT. } \\
\text { (3) No ITT. }\end{array}$} \\
\hline
\end{tabular}

\section{Pregnancy losses Analysis 3.7}

Estrogen + Antagonist versus Antagonist (two studies included) Only one study reported on this outcome and found one pregnancy loss in the study group $(\mathrm{n}=25)$ and five pregnancy losses in the control group ( $\mathrm{n}=24$ ), Peto OR 0.22 ; $95 \%$ CI 0.04 to 1.17 , $\mathrm{P}=0.08$ (Cédrin-Durnerin 2007).

Estrogen + Antagonist versus Agonist - The only study included in this subgroup found no pregnancy losses in both treatment groups (study group $\mathrm{n}=16$; control group $\mathrm{n}=6$ ).

\section{Ovarian cyst formation Analysis 3.8}

Estrogen + Antagonist versus Agonist (one study included) - The only study included in this subgroup found no ovarian cyst formation in both treatment groups (study group $\mathrm{n}=16$; control group $\mathrm{n}=$ 6).

\section{Multiple pregnancies Analysis 3.9}

Estrogen + Antagonist versus Antagonist (two studies included) Only one study reported on this outcome and found no multiple pregnancies in the study group $(\mathrm{n}=25)$ and one in the control group $(\mathrm{n}=24)$, Peto OR 0.13; 95\% CI 0.00 to $6.55, \mathrm{P}=0.31$ (Cédrin-Durnerin 2007).

Estrogen + Antagonist versus Agonist (one study included) - Only one trial could be included in this subgroup (Franco Jr 2003). The number of multiple pregnancies was two in the study group ( $\mathrm{n}=$ 14) and none in the control group $(n=6)$, Peto OR 4.52; $95 \%$ CI 0.20 to $101.00, \mathrm{P}=0.34$.

\section{OHS syndrome Analysis 3.10}

Estrogen + Antagonist versus Agonist (two studies included) - The only study included in this subgroup found no women with OHS syndrome in both treatment groups (study group $\mathrm{n}=16$; control group $\mathrm{n}=6$ ).

\section{Combined OCP versus Progestogen}

Only one trial could be included in this intervention (CédrinDurnerin 2007). This trial used a GnRH antagonist in both treatment groups. None of the results of this trial were found to be statistically significant.

\section{Live births Analysis 4.I}

The number of live births was found to be three in the combined OCP group $(\mathrm{n}=21)$ and five in the progestogen group $(\mathrm{n}=23)$, Peto OR $0.61 ; 95 \%$ CI 0.13 to $2.79, \mathrm{P}=0.53$.

\section{Ongoing pregnancies Analysis $\mathbf{4 . 2}$}

The number of ongoing pregnancies was also found to be three in the combined OCP group $(\mathrm{n}=21)$ and five in the progestogen group $(\mathrm{n}=23$ ), Peto OR $0.61 ; 95 \%$ CI 0.13 to $2.79, \mathrm{P}=0.53$.

\section{Clinical/ongoing pregnancies Analysis 4.3}

The number of clinical pregnancies was five in the combined OCP group $(\mathrm{n}=21)$ and seven in the progestogen group $(\mathrm{n}=23)$, Peto OR $0.72 ; 95 \%$ CI 0.19 to $2.68, \mathrm{P}=0.63$. 


\section{Oocytes retrieved Analysis 4.4}

The mean number of oocytes retrieved was $14( \pm 8.3)$ in the combined OCP group $(\mathrm{n}=21)$ and $12.6( \pm 7.3)$ in the progestogen group $(\mathrm{n}=23)$, Peto OR $1.40 ; 95 \% \mathrm{CI}-3.24$ to $6.04, \mathrm{P}=0.55$.

\section{Days of gonadotrophin treatment Analysis 4.5}

This outcome was not reported by this study.

\section{Amount of gonadotrophins administered}

The mean amount of gonadotrophins administered was 2,174 IU $( \pm 723)$ in the combined OCP group $(n=21)$ and $2,010 \mathrm{IU}( \pm$ $670)$ in the progestogen group $(\mathrm{n}=23)$, Peto OR 164.00; $95 \%$ CI -249.03 to $577.03, \mathrm{P}=0.44$.

\section{Pregnancy losses Analysis 4.6}

The number of pregnancy losses in both treatment groups was two (study group $\mathrm{n}=21$; control group $\mathrm{n}=23$ ), Peto OR1.10; $95 \%$ CI 0.14 to $8.43, \mathrm{P}=0.92$.

\section{Ovarian cyst formation}

This outcome was not reported by this study.

\section{Multiple pregnancies Analysis 4.7}

There were two multiple pregnancies in the combined OCP group $(\mathrm{n}=21)$ and one in the progestogen group $(\mathrm{n}=23)$, Peto OR 2.22; $95 \%$ CI 0.22 to $22.56, \mathrm{P}=0.50$.

\section{OHS syndrome}

This outcome was not reported by this study.

\section{Combined OCP versus Estrogen}

\section{Live births Analysis 5.I}

COCP + Antagonist versus Estrogen + Antagonist (one study included) - The number of live births was found to be three in the combined OCP group $(\mathrm{n}=21)$ and three in the oestrogen group $(\mathrm{n}=25)$, Peto OR $1.22 ; 95 \%$ CI 0.22 to $6.69, \mathrm{P}=0.82$ (Cédrin-Durnerin 2007).

\section{Ongoing pregnancies Analysis $\mathbf{5 . 2}$}

COCP + Antagonist versus Estrogen + Antagonist (one study included) - The number of ongoing pregnancies was also found to be three in the combined OCP group $(\mathrm{n}=21)$ and three in the oestrogen group $(\mathrm{n}=25)$, Peto OR 1.22 ; $95 \%$ CI 0.22 to $6.69, \mathrm{P}$ $=0.82$ (Cédrin-Durnerin 2007).

COCP + Agonist versus Estrogen + Antagonist (one study included) - The number of ongoing pregnancies was one in the combined OCP group $(n=12)$ and seven in the oestrogen group $(n=13)$. This is a statistically significant difference Peto OR 0.13 ; 95\% CI 0.03 to $0.70, \mathrm{P}=0.02$ (Daly 2002).

\section{Clinical/ongoing pregnancies Analysis 5.3}

COCP + Antagonist versus Estrogen + Antagonist (one study included) - The number of clinical pregnancies was five in the combined OCP group $(\mathrm{n}=21)$ and four in the oestrogen group $(\mathrm{n}=25)$, Peto OR $1.62 ; 95 \%$ CI 0.38 to $6.90, \mathrm{P}=0.51$ (Cédrin-Durnerin 2007).

COCP + Agonist versus Estrogen + Antagonist (one study included) - The number of clinical pregnancies was two in the combined OCP group $(\mathrm{n}=12)$ and eight in the oestrogen group $(\mathrm{n}=13)$. This is a statistically significant difference, Peto OR $0.17 ; 95 \%$ CI 0.03 to $0.80, \mathrm{P}=0.02$ (Daly 2002).

\section{Oocytes retrieved Analysis $\mathbf{5 . 4}$}

COCP + Antagonist versus Estrogen + Antagonist (one study included) - The mean number of oocytes retrieved was $14 \pm 8.3$ in the combined OCP group $(\mathrm{n}=21)$ and $13.1 \pm 7$ in the oestrogen group $(\mathrm{n}=22)$, Peto OR $0.90 ; 95 \% \mathrm{CI}-3.70$ to $5.50, \mathrm{P}=0.70$ (Cédrin-Durnerin 2007).

\section{Days of gonadotrophin treatment}

This outcome was not reported by these studies.

\section{Amount of gonadotrophins administered Analysis 5.5}

COCP + Antagonist versus Estrogen + Antagonist (one study included) - The mean amount of gonadotrophins administered was $2,174 \mathrm{IU}( \pm 723)$ in the combined OCP group $(\mathrm{n}=21)$ and 1,700 IU $( \pm 524)$ in the oestrogen group $(n=22)$. This is a statistically significant difference, with Peto OR 474.00; 95\% CI 95.10 to 852.90, P = 0.01 (Cédrin-Durnerin 2007).

\section{Pregnancy losses Analysis 5.6}

COCP + Antagonist versus Estrogen + Antagonist (one study included) - The number of pregnancy losses in the combined OCP group was two $(\mathrm{n}=21)$ and in the oestrogen group the number was one $(\mathrm{n}=25)$, Peto OR 2.43 ; 95\% CI 0.24 to $24.79, \mathrm{P}=0.45$ (Cédrin-Durnerin 2007). 
COCP + Agonist versus Estrogen + Antagonist (one study included)

- In each group there was one pregnancy loss (study group $\mathrm{n}=12$; control group $\mathrm{n}=13$ ), Peto OR 1.09; 95\% CI 0.06 to $18.49, \mathrm{P}=$ 0.95 (Daly 2002).

\section{Ovarian cyst formation}

This outcome was not reported by these studies.

\section{Multiple pregnancies Analysis 5.7}

COCP + Antagonist versus Estrogen + Antagonist (one study included) - There were two multiple pregnancies in the combined OCP group $(n=21)$ and none in the oestrogen group $(n=25)$, Peto OR 9.40; 95\% CI 0.56 to $156.66, \mathrm{P}=0.12$ (Cédrin-Durnerin 2007).

\section{OHS syndrome}

This outcome was not reported by these studies.

\section{Progestogen versus Estrogen}

Only one trial could be included in this subgroup (CédrinDurnerin 2007). This trial used a GnRH antagonist in both treatment groups. None of the results of this trial were found to be statistically significant.

\section{Live births Analysis 6.1}

The number of live births was found to be five in the progestogen group $(\mathrm{n}=23)$ and three in the oestrogen group $(\mathrm{n}=25)$, Peto OR $1.99 ; 95 \%$ CI 0.44 to $8.94, \mathrm{P}=0.37$.

\section{Ongoing pregnancies Analysis 6.2}

The number of ongoing pregnancies was also found to be five in the progestogen group $(n=23)$ and three in the oestrogen group $(\mathrm{n}=25)$, with Peto OR 1.99 ; $95 \%$ CI 0.44 to $8.94, \mathrm{P}=0.37$.

\section{Clinical/ongoing pregnancies Analysis 6.3}

The number of clinical pregnancies was seven in the progestogen group $(n=23)$ and four in the oestrogen group $(n=25)$, with a $P$ value of 0.24 .

\section{Oocytes retrieved Analysis 6.4}

The mean number of oocytes retrieved was $12.6( \pm 7.3)$ in the progestogen group $(n=23)$ and $13.1( \pm 7)$ in the oestrogen group $(\mathrm{n}=22)$, with Peto OR 2.23 ; $95 \%$ CI 0.59 to $8.44, \mathrm{P}=0.81$.

\section{Days of gonadotrophin treatment}

This outcome was not reported by this study.

\section{Amount of gonadotrophins administered Analysis 6.5}

The mean amount of gonadotrophins administered was 2,010 IU $( \pm 670)$ in the progestogen group $(\mathrm{n}=23)$ and $1,700 \mathrm{IU}( \pm 524)$ in the oestrogen group $(\mathrm{n}=22)$, Peto OR $-0.50 ; 95 \%$ CI -4.68 to 3.68, $\mathrm{P}=0.08$.

\section{Pregnancy losses Analysis 6.6}

There were two pregnancy losses in the progestogen group ( $\mathrm{n}=$ $23)$ and one in the oestrogen group $(n=25)$, Peto OR 310.00; $95 \%$ CI -40.60 to $660.60, \mathrm{P}=0.51$.

\section{Ovarian cyst formation}

This outcome was not reported by this study.

\section{Multiple pregnancies Analysis 6.7}

There was one multiple pregnancy in the progestogen group (n $=23)$ and none in the oestrogen group $(\mathrm{n}=25)$, Peto OR 8.06; 95\% CI 0.16 to $407.60, \mathrm{P}=0.30$.

\section{OHS syndrome}

This outcome was not reported by this study.

\section{DISCUSSION}

\section{Summary of main results}

This systematic review on the role of pre-treatment with the combined OCP, a progestogen or an oestrogen prior to ART cycles, has pooled the results of studies for three of the six interventions. For the other interventions, we have not been able to pool any results, since only one study could be included in the subgroups of these interventions.

No statistically significant results were found for the primary outcome of live births. We were able to pool results of two trials that used progestogen as a pre-treatment and compared this with no pre-treatment or placebo. This showed no evidence for a difference in the number of live births. For the other interventions, we have not been able to pool results of two or more studies, so no sound conclusion can be given.

For the outcome of ongoing pregnancies, we have been able to pool results of two or more studies that compared a pre-treatment with the combined OCP with no pre-treatment. None of these 
showed evidence for a treatment effect. We have not been able to pool results for the other interventions.

With regard to the outcome clinical pregnancy rate, we found a statistically significant result in two subgroups of two different interventions. In comparison 1.3.2 (COCP plus antagonist versus antagonist) this difference was in favour of the group not pretreated with the combined OCP, with fewer clinical pregnancies being achieved in the study group. In comparison 1.3.3 (COCP plus antagonist versus agonist), we pooled the results of three studies and found no statistically significant difference. However, in comparison 2.3.1 (progestogen plus agonist versus agonist) there was a statistically significant difference in favour of the group pretreated with the progestogen. In this comparison, the number of clinical pregnancies was increased in the study group. For the other interventions and subgroups, we have not been able to pool results of two or more studies.

For the outcome of the number of oocytes retrieved we have been able to pool results of four subgroups in three different interventions and only one of these showed a statistically significant difference. This difference was found in comparison 3.4.1 (oestrogen plus antagonist versus antagonist), with more oocytes being retrieved after pre-treatment with an oestrogen.

Two other outcomes that showed statistically significant differences were the number of days of gonadotrophin therapy and the amount of gonadotrophins administered. These differences were found in the comparisons 1.5.1 and 1.6.1 (COCP plus antagonist versus antagonist) and comparisons 1.5.2 and 1.6.2 (COCP plus antagonist versus agonist). All these differences were in favour of the groups that did not receive pre-treatment, with fewer days of gonadotrophin therapy and a smaller amount of gonadotrophins administered in the control group. A statistically significant difference with regard to the amount of gonadotrophins administered was also found in the comparison 3.6.1 (oestrogen plus antagonist versus antagonist). This difference was also in favour of the control group. Furthermore we have been able to pool the results of two studies in comparison 2.6.1 (progestogen plus agonist versus agonist), with regard to the number of days of gonadotrophin treatment and we found no evidence for a treatment effect. For the other interventions and subgroups we have not been able to pool any data.

These results are mainly important with regard to the financial aspects of the IVF/ICSI treatment and might be explained because of a longer duration of ovarian suppression. Instead of suppression with only a $\mathrm{GnRH}$ analogue as in the control group, the ovaria were also suppressed with a combined OCP or oestrogen in the pre-treatment group. However, this might result in less need for GnRH analogue administration as suggested by Griesinger 2008, but we did not address this outcome in our review.

With regard to the number of pregnancy losses, we have been able to pool the results for three subgroups in two interventions, but we found no evidence for a treatment effect.

The only adverse outcome that showed a statistically significant difference was found in comparison 2.8.1 (progestogen plus agonist versus agonist). The number of ovarian cysts was shown to be increased in the control group that did not receive hormonal pretreatment. This is clinically important, because a frequent reason for cycle cancellation is the occurrence of ovarian cysts. It is unclear whether the formation of ovarian cysts in the studies of this comparison has lead to cycle cancellation, because this was not reported. The lower incidence of ovarian cysts in progestogen pretreated cycles, might explain the higher clinical pregnancy rates because fewer cycles have to be cancelled. This was also suggested in another review on combined OCP pre-treatment (Griesinger 2008).

For the outcome of multiple pregnancies and OHS syndrome we have been able to pool results for one subgroup in the intervention that compared a combined OCP pre-treatment with no pretreatment, but this showed no statistically significant difference. For the other interventions or subgroups we were not able to pool any results with regard to these outcomes.

\section{Overall completeness and applicability of evidence}

Although we were able to include 23 studies across 6 comparisons, there were insufficient data to report on the primary outcome of live births. Using subgroups of different GnRH antagonist and agonist protocols also limited the ability to pool data. There were also limited data for many of the secondary outcomes and almost all of the adverse outcomes.

This review did include women with polycystic ovary syndrome (PCOS), but there was only one study of 56 randomised women that only included a diagnosis of PCOS. Five other studies have used PCOS or ovarian cysts as an exclusion criteria. These studies have randomised a total of 1118 women, so almost half of all the women in this review were not diagnosed with PCOS. Because of the small proportion of women with PCOS included in this review, results might not be relevant for these women.

Also, we planned on doing subgroup analysis on poor responders and there were two included randomised trials that used poor response to ovarian stimulation as an inclusion criteria. These studies randomised a total of 203 women. However, we have not been able to pool results of these two studies, since they used a different ovarian stimulation protocol. Therefore, although a relatively large number of poor responder patients is included, this review might not be applicable to women who have a history of poor response. An outcome that we did not address was the number of days of $\mathrm{GnRH}$ analogue treatment. This could be considered in the update as pre-treatment with a combined OCP, progestogen or oestrogen, may result in a reduction in the amount of $\mathrm{GnRH}$ analogues administered. This is mainly important with regard to the financial aspect of the treatment. 


\section{Quality of the evidence}

Because of the few studies in each subgroup (with a maximum of six studies), a solid conclusion regarding the objective of this review is not possible.

In this review we included 23 studies with a total of 2596 women. These 23 studies were distributed to six comparisons and thirteen subgroups. Three of the studies were used in more than one subgroup, due to the existence of three or four study arms.

A possible methodological limitation of the included studies is that an intention-to-treat (ITT) analysis was not carried out on all the outcomes that the studies reported. Most of the studies used an ITT analysis to describe baseline characteristics of the women, but did not analyse the (continuous) data according to a true ITT definition, which describes that all randomised women should be included in the final analyses. Blinding was only used in $13 \%$ of the studies but this was not considered a major problem because women in the placebo arm would have been able to recognise which treatment they were receiving because of bleeding patterns. Other smaller concerns were the inconsistency of the outcomes reported. Definitions of oocytes retrieved, cyst formation and clinical pregnancy, differed between studies. Also, different units were used to describe gonadotrophin usage.

\section{Potential biases in the review process}

A strength of this review is the grouping of the studies into subgroups regarding the type of down regulation used (agonist or antagonist). Nonetheless, there is still some substantial heterogeneity in a few of the statistically significant outcomes, such as the number of days of gonadotrophin administration, but this may be explained by differences in treatment protocols between studies. The major limitation of this review is the poor reporting of all outcomes that are important to clinicians prior to making changes to treatment protocols. In particular, the outcomes of live birth rate but also pregnancy losses, cyst formation, cycle cancellation, multiple pregnancies and women with OHS syndrome are missing from the majority of the studies.

Furthermore, we were not able to construct a funnel plot, due to the small number of studies in each subgroup. Therefore we could not examine if publication bias was present.

\section{Agreements and disagreements with other studies or reviews}

To our knowledge, there is one systematic review on combined OCP pre-treatment available (Griesinger 2008). This review investigates the effect of a combined OCP pre-treatment in a $\mathrm{GnRH}$ antagonist cycle versus no pre-treatment, and included four studies (Cédrin-Durnerin 2007; Huirne 2006b; Kolibianakis 2006; Rombauts 2006). All of these studies are also included in our review, but we have included two more studies in this subgroup (Kim
2005; Obruca 2001). Due to a lack of data, despite contacting the author, or differences in treatment protocols we were not able to pool their results. Because the systematic review of Dr Griesinger included the same studies and investigated almost the same outcomes, it is not surprising that we reach the same conclusions. In his review, Dr Griesinger found no significant effects on ongoing pregnancies. Also, he found a significant difference in favour of the control group with regard to the number of days and amount of gonadotrophin administration.

\section{AUTHORS' CONCLUSIONS}

\section{Implications for practice}

It is not possible to make recommendations for clinical practice on the basis of this review. Although we did find some significant differences in a few outcomes for three comparisons, more studies are required before major changes should be made to ART protocols. Besides this, there are a few other important aspects to consider when deciding if a pre-treatment with a combined OCP, a progestogen or an oestrogen should be given. First of all, a pretreatment with one of these drugs results in a longer duration and a higher amount of gonadotrophin treatment, which is expensive. Secondly, the pre-treatment with one of these drugs means the need for a longer duration of the IVF/ICSI cycle and this is a burden to the woman. And last, if pre-treatment with combined OCP, progestogen or oestrogen will be given, this should be clearly explained to the woman, because the need for oral contraceptive drugs might be hard to understand when you are trying to get pregnant.

The positive effect of a pre-treatment with progestogen on the rate of clinical pregnancies found in this review is surprising, since a pre-treatment with a combined OCP seems to yield lower clinical pregnancy rates. In our review we also found that a pre-treatment with progestogen results in the formation of fewer ovarian cysts. This is important, since ovarian cysts have a negative effect on the number of pregnancies, because ART cycles have to be cancelled. However, only one study that used a combined OCP pre-treatment reported on the number of ovarian cyst formation and this study also found a statistically significant difference in favour of the combined OCP group. Unless more research is done on the underlying mechanism that could explain these effects, no implications for practice can be made.

If pre-treatment with progestogens seems to result in a better IVF/ ICSI outcome, this could be clinically and financially important. The administration of progestogen is easy, appears to be safe for the woman and it is less expensive than combined OCP pre-treatment.

\section{Implications for research}

More and larger RCTs are needed that randomise subfertile women 
with regular IVF/ICSI indications, undergoing a pre-treatment with a combined OCP, progestogen or oestrogen in GnRH analogue plus gonadotrophin cycles. Especially pre-treatments with the combined OCP or a progestogen are of interest for further research. The most important outcome that should be addressed is the number of live births. Other outcomes that are important are the formation of ovarian cysts, pregnancy losses and the number of women with OHS syndrome. Furthermore, research on poor responder patients is necessary, because we were unable to include many trials with poor responder patients.

\section{ACKNOWLEDGEMENTS}

We would like to thank He Haojie, Bolarinde Ola, Pan LIngya and Li Shangwei, the authors of the original protocol.
We are also grateful to Marian Showell, the Trial Search Co-ordinator of MDSG, for inventing a search strategy and to Jane Clarke, the Review Group Co-ordinator of the MDSG and to Vanessa Jordan, NZ Cochrane fellow, for answering our questions.

Furthermore, we would like to thank Dr G Griesinger for kindly supplying us with information on the trials that he included in his review.

Also thanks to Dr JG Franco Jr, Dr EC Ditkoff, Dr I CédrinDurnerin, Dr CH Kim and M Grynberg (on behalf of Dr R Fanchin) for sending us more data on their studies.

At last we would like to thank all the members of the MDSG for their assistance in contacting the authors from the included trials. Special thanks to S. Dias and X. Zhu for their help with foreign language articles.

\section{RE F E R E N C E S}

\section{References to studies included in this review}

Aston 1995 \{published data only\}

Aston K, Arthur I, Masson GM, Jenkins JM. Progestogen therapy and prevention of functional ovarian cysts during pituitary desensitisation with $\mathrm{GnRH}$ agonists. British Journal of Obstetrics and Gynaecology 1995;102:835-7.

Biljan 1998a \{published data only\} Biljan MM, Mahutte NG, Dean N, Hemmings R, Bissonnette F. Prospective randomized trial on effect of pretreatment with an oral contraceptive (OC) on the length of time required for pituitary suppression by gonadotropin releasing hormone agonist $(\mathrm{GnRH}-\mathrm{a})$ and subsequent implantation and pregnancy rates. Fertility and Sterility 1998; Vol. Suppl 1, 70, issue 3:S133.

Biljan MM, Mahutte NG, Dean N, Hemmings R, Bissonnette F, Tan SL. Effects of pretreatment with an oral contraceptive on the time required to achieve pituitary suppression with gonadotropin-releasing hormone analogues and on subsequent implantation and pregnancy rates. Fertility and Sterility 1998;70(6):1063-9.

Cédrin-Durnerin 1996 \{published data only\} Cédrin-Durnerin I, Bulwa S, Hervé F, Martin-Pont B, Uzan M, Hugues JN. The hormonal flare-up following gonadotrophin-releasing hormone agonist administration is influenced by a progestogen pretreatment. Human Reproduction 1996;11(9):1859-63.

Cédrin-Durnerin I, Bulwa S, Hervé F, Pecqueux L, Uzan $\mathrm{M}$, Hugues JN. Influence of norethisterone pretreatment on the initial flare-up induced by a gonadotrophin-releasing hormone agonist in a short protocol for IVF. 11th Annual Meeting of ESHRE. Hamburg, Germany, 1995. Human Reproduction. 1995; Vol. 10 Abstract Book 2:116.
Cédrin-Durnerin 2007 \{published data only\}

Cédrin-Durnerin I, Bständig B, Parneix I, Bied-Damon V, Avril C, Decanter C, et al.Effects of oral contraceptive, synthetic progestogen or natural estrogen pre-treatments on the hormonal profile and the antral follicle cohort before GnRH antagonist protocol. Human Reproduction 2007;22 (1):109-16. [DOI: 10.1093/humrep/de1340] Hugues JN, Cédrin-Durnerin I, Bständig B, Parneix I, Bied-Damon V, Avril C, et al.Consequences of different steroid pre-treatments on the hormonal profile and on the antral follicular count prior to an IVF antagonist protocol. Abstracts of the 21st Annual Meeting of the ESHRE. Copenhagen, Denmark, 2005.

Daly 2002 \{published data only\}

Daly DC, Daly CL, Mayo D, Jacobs A. Oocyte recruitment in IVF patients with limited ovarian reserve (LOR), maximizing quality of oocytes and embryos. Fertility and Sterility 2002; Vol. Suppl 1, 78, issue 3:S148-9.

Ditkoff 1996 \{published data only\}

Ditkoff EC, Sauer MV. A combination of norethindrone acetate and leuprolide acetate blocks the gonadotrophinreleasing hormone agonistic response and minimizes cyst formation during ovarian stimulation. Human Reproduction 1996;11(5):1035-7.

Engmann 1999 \{published data only\}

Engmann L, Maconochie N, Bekir J, Tan SL. A prospective randomized study to assess the effect of progestogen therapy during pituitary desensitization with $\mathrm{GnRH}$ agonist in the prevention of functional ovarian cyst formation. Abstracts from ASRM/CFAS Conjoint Annual Meeting. Toronto, Canada, 1999. Fertility and Sterility. 1999; Vol. 72, issue 3, Suppl 1:S10-1.

Engmann L, Maconochie N, Bekir J, Tan SL. Progestogen therapy during pituitary desensitization with gonadotropin- 
releasing hormone agonist prevents functional ovarian cyst formation: A prospective, randomized study. American Journal of Obstetrics and Gynecology 1999;181(3):576-82. Engmann L, Maconochie N, Tan SL, Bekir J. Progestogen therapy during pituitary desensitization with $\mathrm{GnRH}$ agonist prevents functional ovarian cyst formation - a prospective randomized study. British Fertility Society Abstracts. Human Fertility. 1999; Vol. 2, issue 2:190-1.

\section{Fanchin 2001 \{published data only\}}

Fanchin R, Schonauer L, Cunha Filho J, Kadoch I, Cohen Bacrie P, Frydman R. Luteal E2 administration reduces size and improves homogeneity of selectable follicles on cycleday 3: bases for novel controlled ovarian hyperstimulation (COH) concepts. Fertility and Sterility 2001; Vol. Suppl 1, 76 , issue 3:S90.

\section{Fanchin 2003a \{published data only\}}

Fanchin R, Salomon L, Castelo-Branco A, Olivennes F, Frydman N, Frydman R. Luteal estradiol administration coordinates FSH-induced follicular growth and improves the outcome of $\mathrm{GnRH}$ antagonist $\mathrm{COH}$ protocols. Abstracts of the 19th Annual meeting of the ESHRE. Madrid, Spain, 2003. Human Reproduction. 2003; Vol. 18, issue Suppl 1.

Fanchin R, Salomon L, Castelo-Branco A, Olivennes F, Frydman N, Frydman R. Luteal estradiol pre-treatment coordinates follicular growth during controlled ovarian hyperstimulation with $\mathrm{GnRH}$ antagonists. Human Reproduction 2003;18(12):2698-703. [DOI: 10.1093/ humrep/deg516]

Franco Jr 2003 \{published data only\} Franco Jr JG, Baruffi RLR, Petersen CG, Mauri AL, Felipe V, Contart P. Comparison of ovarian stimulation with recombinant FSH after 2nd phase protocols with GnRH Analogs (I - estradiol + Ganirelix versus II Nafarelin) [Comparação da estimulação ovariana com FSH recombinante após protocolo de $2^{a}$ fase com análogos do GnRH (I - estradiol + Ganirelix versus II - Nafarelin)]. Jornal Brasileiro de Reproducao Assistida 2003;7(1):26-32.

Hugues 1994 \{published data only\}

Hugues JN, Cédrin-Durnerin I, Hervé F, Huet-Pecqueux L, Santarelli J. Incidence of preprogrammed norethisterone on the intensity of 'flare up' (flush) caused by GnRH agonist according to the IVF protocol [poster] [Incidence d'une préprogrammation par la noréthistérone sur la qualité du flare-up induit par un agoniste du $\mathrm{GnRH}$ en protocole court de FIV]. Contraception, Fertilite, Sexualite 1994; Vol. 22 , issue 5:331.

Huirne 2006a \{published data only\} Huirne JA, Hugues JN, Pirard C, Fischl F, Sage JC, Pouly $\mathrm{JL}$, et al.Cetrorelix in an oral contraceptive-pretreated stimulation cycle compared with buserelin in IVF/ICSI patients treated with $\mathrm{r}-\mathrm{hFSH}$ : a randomized, multicentre, phase IIIb study. Human Reproduction 2006;21(6): 1408-15. [DOI: 10.1093/humrep/de1030]
Huirne 2006b \{published data only\}

Huirne JAF, van Loenen ACD, Donnez J, Pirard C, Homburg R, Schats R, et al.Effect of an oral contraceptive pill on follicular development in IVF/ICSI patients receiving a GnRH antagonist: a randomized study. Reproductive Biomedicine Online 2006;13(2):235-45.

Van Loenen ACD, Huirne JAF, Schats R, Donnez J, Lambalk CB. An open-label multicentre, randomized, parallel, controlled phase II study to assess the feasibility of a new programming regimen using an oral contraceptive prior to the administration of recombinant $\mathrm{FSH}$ and a GnRH-antagonist in patients undergoing ART (IVFICSI) treatment. Abstracts of the 17th Annual Meeting of the ESHRE. Lausanne, Switzerland, 2001. Human Reproduction. 2002; Vol. 17 Abstract Book 1:144-5.

\section{Hwang 2004 \{published data only\}}

Hwang JL, Seow KM, Lin YH, Huang LW, Hsieh BC, Tsai YL, et al.Ovarian stimulation by concomitant administration of cetrorelix acetate and HMG following Diane-35 pre-treatment for patients with polycystic ovary syndrome: a prospective randomized study. Human Reproduction 2004;19(9):1993-2000. [DOI: 10.1093/ humrep/deh375]

Kim 2005 \{published data only\} Kim CH, Lee HA, Lee JW, Lee YJ, Nah HY, Hong $\mathrm{SH}$, et al.The efficacy of oral contraceptive pretreatment in controlled ovarian hyperstimulation using a $\mathrm{GnRH}$ antagonist for low responders [poster]. Abstracts of the 21st Annual Meeting of the ESHRE. Copenhagen, Denmark, 2005. Human Reproduction. 2005; Vol. 20 Suppl 1: i105-6.

\section{Kolibianakis 2006 \{published data only\}}

Kolibianakis EM, Albano C, Tournaye H, Camus M, Van Steirteghem A, Devroey P. Pre-treatment with oral contraceptive pill affects adversely implantation rate in IVF/ICSI cycles stimulated with rec-FSH and GnRH antagonists. Fertility and Sterility 2003; Vol. Suppl 3, 80: S67.

Kolibianakis EM, Papanikolaou EG, Camus M, Tournaye H, Van Steirteghem AC, Devroey P. Effect of oral contraceptive pill pretreatment on ongoing pregnancy rates in patients stimulated with $\mathrm{GnRH}$ antagonists and recombinant FSH for IVF. A randomized controlled trial. Human Reproduction 2006;21(2):352-7. [DOI: 10.1093/ humrep/dei348]

Obruca 2001 \{published data only\} Obruca A, Fischl F, Huber J. Programming oocyte retrieval using oral contraceptive pretreatment before ovarian stimulation with a GnRH antagonist (Cetrotide) protocol. Abstracts of the 17th Annual Meeting of the ESHRE. Lausanne, Switzerland, 2001. Human Reproduction. 2002; Vol. 17 Abstract Book 1:89.

\section{Raoofi 2008 \{published data only\}}

Raoofi Z, Aflatoonian A. Ovarian cysts formation during depot formulation of GnRH-a therapy and the effect of pretreatment with oral contraceptive pills on subsequent 
implantation and pregnancy rate in ART cycles. Iranian Journal of Pharmaceutical Research 2008;7(2):109-13.

Rombauts 2006 \{published data only\}

Rombauts L, Healy D, Norman RJ, Speirs A, Watkins B, Yovich J, et al.A comparative randomized trial to assess the impact of oral contraceptive pretreatment on follicular growth and hormone profiles in $\mathrm{GnRH}$ antagonist-treated patients. Human Reproduction 2006;21(1):95-103. [DOI: 10.1093/humrep/dei302]

Salat-Baroux 1988 \{published data only\}

Salat-Baroux J, Antoine JM, Alvarez S, Cornet D, Tibi C, Mandelbaum J, et al.Programmed ovulation induction and oocyte retrieval for in vitro fertilization. Journal of In Vitro Fertilization and Embryo Transfer 1988;5(3):153-7.

Shaker 1995 \{published data only\}

Shaker AG, Pittrof R, Zaidi J, Bekir J, Kyei-Mensah A, Tan SL. Administration of progestogens to hasten pituitary desensitization after the use of gonadotropin-releasing hormone agonist in in vitro fertilization - a prospective randomized study. Fertility and Sterility 1995;64(4):791-5.

Tan 2001 \{published data only\}

Tan SL, Biljan M. Fixed scheduling of long protocol of GNRH agonists - use of oral contraceptive (OC) or progestogen pre-treatment. 6th International Symposium on GnRH Analogues in Cancer and Human Reproduction. Geneva, Switzerland, 2001. Gynecological Endocrinology. 2001; Vol. 15 Suppl 2:31.

Wang 2008 \{published data only\}

Wang B, Sun HX, Hu YL, Chen H, Zhang NY. Application of GnRH-antagonist to IVF-ET for patients with poor ovarian response. National Journal of Andrology [Zhonghua Nan Ke Xue] 2008;14(5):423-6.

\section{References to studies excluded from this review}

al-Mizyen 2000 \{published data only\}

al-Mizyen E, Sabatini L, Lower AM, Wilson CMY, al-

Shawaf T, Grudzinskas JG. Does pretreatment with progestogen or oral contraceptive pills in low responders followed by the $\mathrm{GnRHa}$ flare protocol improve the outcome of IVF-ET?. Journal of Assisted Reproduction and Genetics 2000;17(3):140-6.

Anderson 1990 \{published data only\}

Anderson RE, Stein AL, Paulson RJ, Stanczyk FZ, Vijod AG, Lobo RA. Effects of norethindrone on gonadotropin and ovarian-steroid secretion when used for cycle programming during in vitro fertilization. Fertility and Sterility 1990;54(1):96-101.

Bellver 2007 \{published data only\}

Bellver J, Albert C, Labarta E, Pellicer A. Early pregnancy loss in women stimulated with gonadotropinreleasing hormone antagonist protocols according to oral contraceptive pill pretreatment. Fertility and Sterility 2007; 87(5):1098-101. [DOI: 10.1016/j.fertnstert.2006.08.098]

Benadiva 1988 \{published data only\}

Benadiva CA, Ben-Rafael Z, Blasco L, Tureck R, Mastroianni LJ, Flickinger GL. Ovarian response to human menopausal gonadotropin following suppression with oral contraceptives. Fertility and Sterility 1988;50(3):516-8.

Bendikson 2006 \{published data only\}

Bendikson K, Milki AA, Speck-Zulak A, Westphal LM. Comparison of $\mathrm{GnRH}$ antagonist cycles with and without oral contraceptive pretreatment in potential poor prognosis patients. Clinical and Experimental Obstetrics and Gynecology 2006;33(3):145-7.

Biljan 1998b \{published data only\} Biljan MM, Mahutte NG, Dean N, Hemmings R, Bissonnette F, Tan SL. Pretreatment with an oral contraceptive is effective in reducing the incidence of functional ovarian cyst formation during pituitary suppression by gonadotropin-releasing hormone analogues. Journal of Assisted Reproduction and Genetics 1998;15(10): 599-604.

Branigan 1998 \{published data only\} Branigan EF, Estes MA. Treatment of high responders with oral contraceptive pills (OC) before ovarian hyperstimulation for IVF. Fertility and Sterility 1998; Vol. 69, issue 3:599.

\section{Brodt 1993 \{published data only\}}

Brodt J, Taubert HD. Planned ovarian stimulation with preadministered contraceptives in an in-vitro fertilization program [Programmierte ovarielle stimulation mittels ovulationshemmer-vorbehandlung in einem in vitro fertilisations(IVF)-programm]. Archives of Gynecology and Obstetrics 1993;254(1-4):246-8.

Chung 2006 \{published data only\} Chung MT, Tsai YC, Chen SH, Loo TC, Tang HH, Lin LY. Influence of pituitary suppression with triphasic or monophasic oral contraceptives on the outcome of in vitro fertilization and embryo transfer. Journal of Assisted Reproduction and Genetics 2006;23:343-6. [DOI: 10.1007/ s10815-006-9056-y]

Cohen 1987 \{published data only\} Cohen J, Debache C, Solal P, Serkine AM, Achard B, Boujenah $A$, et al.Results of planned in-vitro fertilization programming through the pre-administration of the oestrogen-progesterone combined pill. Human Reproduction 1987;2(1):7-9.

Copperman 2003 \{published data only\} Copperman AB, Mukherjee T, Sandler B, Grunfeld L, Bergh PA, Scott RT. Pre-treatment with oral contraceptive pill improves outcome in IVF cycles of poor-responders using the GnRH antagonist. Fertility and Sterility 2003; Vol. Suppl 3, 80:S108.

Couzinet 1995 \{published data only\} Couzinet B, Young J, Brailly S, Chanson P, Schaison G. Even after priming with ovarian steroids or pulsatile gonadotropin-releasing hormone administration, naltrexone is unable to induce ovulation in women with functional hypothalamic amenorrhoea. Journal of Clinical Endocrinology and Metabolism 1995;80(7):2102-7. 
Cédrin-Durnerin 1995 \{published data only\}

Cédrin-Durnerin I, Hervé F, Huet-Pecqueux L, Kottler ML, Hugues JN. Progestogen pretreatment in the shortterm protocol does not affect the prognostic value of the oestradiol flare-up in response to a $\mathrm{GnRH}$ agonist. Human Reproduction 1995;10(11):2904-8.

Damario 1997 \{published data only\} Damario MA, Barmat L, Liu HC, Davis OK, Rosenwaks Z. Dual suppression with oral contraceptives and gonadotrophin releasing-hormone agonists improves invitro fertilization outcome in high responder patients. Human Reproduction 1997;12(11):2359-65.

Davy 2004 \{published data only\} Davy C, Guibert J, Blanchet V, Nataf E, Olivennes F. The 'wash out' period do not create asynchrony of the follicle cohort when contraceptive pill is used to program GnRH antagonist IVF cycles. Abstracts of the 20th Annual Meeting of the ESHRE. Berlin, Germany, 2004. Human Reproduction. 2004; Vol. 19 Suppl 1:i5-6. Olivennes F, Sr, Davy C, Guibert J, Nataf E, Blanchet $\mathrm{V}$. Asynchrony of the follicle cohort is not induced by the "wash out" period when contraceptive pill is used to program GnRH antagonist IVF cycles. Fertility and Sterility 2004; Vol. Suppl 2, 82:S234.

De Ziegler 1999 \{published data only\}

De Ziegler D, Brioschi PA, Benchaa C, Campana A, Ditesheim PJ, Fanchin R, et al.Programming ovulation in the menstrual cycle by a simple innovative approach: back to the future of assisted reproduction. Fertility and Sterility 1999;72(1):77-82.

Dickey 2001 \{published data only\}

Dickey RP, Sartor BM, Taylor SN, Lu PY, Rye PH, Pyrzak R. Oral contraceptives, not GnRH suppression, may be responsible for very low endogenous $\mathrm{LH}$ during IVF cycles. Fertility and Sterility 2001; Vol. Suppl 3, 76, issue 3:S237.

Ditkoff 1997 \{published data only\} Ditkoff EC, Prosser R, Zimmermann RC, Lindheim $S$, Sauer MV. The addition of norethindrone acetate to leuprolide acetate for ovarian suppression has no adverse effect on ovarian stimulation. Journal of Assisted Reproduction and Genetics 1997;14(2):92-6.

Doody 2001 \{published data only\} Doody KJ, Langley M, Marek D, Doody K. Oral contraceptive pre-treatment for IVF cycles employing recombinant FSH and a GnRH antagonist. Fertility and Sterility 2001; Vol. Suppl 1, 76, issue 3:S236.

Duvan 2008 \{published data only\}

Duvan CI, Berker B, Turhan NO, Satiroglu H. Oral contraceptive pretreatment does not improve outcome in microdose gonadotrophin-releasing hormone agonist protocol among poor responder intracytoplasmic sperm injection patients. Journal of Assisted Reproduction and Genetics 2008;25:89-93. [DOI: 10.1007/s10815-0089203-8]
Fanchin 2003b \{published data only\}

Fanchin R, Cunha Filho J, Schonauer L, Kadoch I, Cohen Bacri P, Frydman R. Co-ordination of early antral follicles by luteal estradiol administration: basis for novel controlled ovarian hyperstimulation. Abstracts of the 18th Annual Meeting of the ESHRE. Vienna, Austria, 2002. Human Reproduction. 2002; Vol. 17 Abstract Book 1:88-9. Fanchin R, Cunha-Filho JS, Schonauer LM, Kadoch IJ, Cohen-Bacri P, Frydman R. Coordination of early antral follicles by luteal estradiol administration provides a basis for alternative controlled ovarian hyperstimulation regimens. Fertility and Sterility 2003;79(2):316-21.

Fisch 1996 \{published data only\}

Fisch B, Royburt M, Pinkas H, Avrech OM, Goldman GA, Bar J, et al.Augmentation of low ovarian response to superovulation before in vitro fertilization following priming with contraceptive pills. Israel Journal of Medical Sciences 1996;32(12):1172-6.

Forman 1991 \{published data only\}

Forman RG, Demouzon J, Feinstein MC, Testart J, Frydman R. Studies on the influence of gonadotrophinlevels in the early follicular phase on the ovarian response to stimulation. Human Reproduction 1991;6(1):113-7.

Frederick 2004 \{published data only\}

Frederick J, DaCosta V, Wynter S, Reid M, Frederick C, McKenzie C. Effect of the oral contraceptive pill on patients undergoing controlled ovarian hyperstimulation. West Indian Medical Journal 2004;53(1):39-43.

Frydman 1986 \{published data only\} Frydman R, Forman R, Rainhorn JD, Belaisch-Allart J, Hazout A, Testart J. A new approach to follicular stimulation for in vitro fertilization: programed oocyte retrieval. Fertility and Sterility 1986;46(4):657-62.

Galera 2004 \{published data only\} Galera F, Verdu V, Villafañex V, Garijo E, Rayward J, Bajo JM. Comparison of plasmatic steroid levels with and without previous oral contraceptive administration in GnRH antagonist IVF cycles. Fertility and Sterility 2004; Vol. Suppl 2, 82:S32.

Gerli 1989 \{published data only\} Gerli S, Remohi J, Partrizio P, Borrero C, Balmaceda JP, Silber SJ, et al.Programming of ovarian stimulation with norethindrone acetate in IVF/GIFT cycles. Human Reproduction 1989;4(7):746-8.

Godin 2003 \{published data only\} Godin PA, Gaspard O, Jouan C, Thonon F, Hincourt N, Ravet $S$, et al.Importance of estradiol priming in in-vitro maturation cycles. Abstracts of the 19th Annual Meeting of the ESHRE. Madrid, Spain, 2003. Human Reproduction. 2003; Vol. 18 Suppl 1:153.

Gomez 2000 \{published data only\} Gomez E, Ballesteros A, Landeras J, Munoz M, Martinez MC. Preparation of endometrium with oral oestradiol valerate versus transdermal oestradiol for cryopreserved embryo transfer: a prospective randomized study. Abstracts

Oral contraceptive pill, progestogen or estrogen pre-treatment for ovarian stimulation protocols for women undergoing assisted 
of the 16th Annual Meeting of the ESHRE. Bologna, Italy, 2000. Human Reproduction. 2000; Vol. 15:175-6.

Gonen 1990 \{published data only\}

Gonen Y, Jacobson W, Casper RF. Gonadotropin suppression with oral contraceptives before in vitro fertilization. Fertility and Sterility 1990;53(2):282-7.

Gonzalez 1995 \{published data only\} Gonzalez P, Maloul S, Ciuffardi I, Frederick JL, Balmaceda JP, Asch RH. The use of progestins for programming assisted reproductive cycles and gonadotropin-releasing hormone agonist flare-up protocols in older patients. Fertility and Sterility 1995;63(2):249-51.

Hugues 1992 \{published data only\} Hugues JN, Attalah M, Hervé F, Martin-Pont B, Kottler ML, Santarelli J. Effects of short-term GnRH agonist human menopausal gonadotropin stimulation in patients pre-treated with progestogen. Human Reproduction 1992;7 (8):1079-84.

Jung 2000 \{published data only\}

Jung H, Roh HK. The effects of E2 supplementation from the early proliferative phase to the late secretory phase of the endometrium in hMG-stimulated IVF-ET. Journal of Assisted Reproduction and Genetics 2000;17(1):28-33.

Karande 2004 \{published data only\}

Karande VC, Latash WDZ, Birkenkamp T, Cavanaugh J, Melone K, Hazlett D. Preliminary report of a prospective randomized controlled trial comparing the use of NuvaRing ${ }^{\circledR}$ to Desogen ${ }^{\circledR}$ in in vitro fertilization cycles with ganirelix acetate. Fertility and Sterility 2004; Vol. Suppl 2, 82:S31-2.

Keltz 2007 \{published data only\} Keltz MD, Gera PS, Skorupski J, Stein DE. Comparison of FSH flare with and without pretreatment with oral contraceptive pills in poor responders undergoing in vitro fertilization. Fertility and Sterility 2007;88(2):350-3. [DOI: 10.1016/j.fertnstert.2006.11.123]

Keltz MD, Sharma P, Stein DE. Comparison of FSH flare in poor responders undergoing in vitro fertilization (IVF) with and without prior oral contraceptive suppression. Fertility and Sterility 2003; Vol. 80:S107.

Kovacs 2001 \{published data only\}

Kovacs P, Barg PE, Witt BR. Hypothalamic-pituitary suppression with oral contraceptive pills does not improve outcome in poor responder patients undergoing in vitro fertilization-embryo transfer cycles. Journal of Assisted Reproduction and Genetics 2001;18(7):391-4.

Leondires 1999 \{published data only\} Leondires MP, Escalpes M, Segars JH, Scott RT, Miller BT. Microdose follicular phase gonadotropin-releasing hormone agonist (GnRH-a) compared with luteal phase GnRH-a for ovarian stimulation at in vitro fertilization. Fertility and Sterility 1999;72(6):1018-23.

Letterie 2000 \{published data only\} Letterie GS. Inhibition of gonadotropin surge by a brief mid-cycle regimen of ethinyl estradiol and norethindrone: possible role in in vitro fertilization. Gynecological

Endocrinology 2000;14(1):1-4.

Lewin 2002 \{published data only\}

Lewin A, Fatum M, Shufaro Y, Simon A, Reubinoff B, Laufer N, et al.Artificial endometrial preparation for frozenthawed embryo transfer using oral oestradiol and a new lowdose vaginal progesterone preparation: Endometrin tablets. Human Reproduction 2001; Vol. Suppl 1, 16:152.

Lewin A, Pisov G, Turgeman R, Fatum M, Shufaro Y, Simon A, et al.Simplified artificial endometrial preparation, using oral estradiol and novel vaginal progesterone tablets: A prospective randomized study. Gynecological Endocrinology 2002;16(2):131-6.

Lindheim 1996 \{published data only\} Lindheim SR, Barad DH, Witt B, Ditkoff E, Sauer MV. Short-term gonadotropin suppression with oral contraceptives benefits poor responders prior to controlled ovarian hyperstimulation. Journal of Assisted Reproduction and Genetics 1996;13(9):745-7.

Loutradis 2003 \{published data only\}

Loutradis D, Stefanidis K, Drakakis P, Kallianidis K, El Sheikh A, Milingos S, et al.Does pre-treatment with micronized progesterone affect the ovarian response to a gonadotropin releasing hormone agonist flare-up protocol?. Gynecological Endocrinology 2003;17(2):101-6.

Martinez 2006 \{published data only\}

Martínez F, Boada M, Coroleu B, Clua E, Parera N, Rodríguez I, et al.A prospective trial comparing oocyte donor ovarian response and recipient pregnancy rates between suppression with gonadotrophin-releasing hormone agonist $(\mathrm{GnRHa})$ alone and dual suppression with a contraceptive vaginal ring and GnRH. Human Reproduction 2006;21(8):2121-5.

Mashiach 1989 \{published data only\} Mashiach S, Dor J, Goldenberg M, Shalev J, Blankstein J, Rudake E, et al.Protocols for induction of ovulation the concept of programmed cycles. Annals of the New York Academy of Sciences 1988;541:37-45.

Mashiach S, Dor J, Goldenberg M, Shalev J, Levran D, Rudak E, et al.Programmed oocyte retrieval: clinical and biological effects of oral contraceptives administered before in vitro fertilization. Gynecological Endocrinology 1989;3(2): 107-15.

Meldrum 2002 \{published data only\} Meldrum D, Scott R, Levy MJ, Alper M, Noyes N. A pilot study to assess oral contraceptive (OC) pretreatment in women undergoing controlled ovarian hyperstimulation $(\mathrm{COH})$ in ganirelix acetate cycles. Fertility and Sterility 2002; Vol. Suppl 1, 78, issue 3:S176.

\section{Meldrum 2008 \{published data only\}} Meldrum DR, Cassidenti DL, Rosen GF, Yee B, Wisot AL. Oral contraceptive pretreatment and half dose of ganirelix does not excessively suppress LH and may be an excellent choice for scheduling IUI cycles. Journal of Assisted Reproduction and Genetics 2008;25:417-20. [DOI: 10.1007/s10815-008-9244-z]

Oral contraceptive pill, progestogen or estrogen pre-treatment for ovarian stimulation protocols for women undergoing assisted 
Min 2005 \{published data only\}

Min JK, Claman P. Oral contraceptive (OC) pre-treatment does not influence oocyte yield in poor responders undergoing gonadotropin releasing hormone $(\mathrm{GnRH})$ antagonist cycles for in vitro fertilization (IVF). Fertility and Sterility 2005; Vol. Suppl 1, 84:S45-6.

Mirkin 2003 \{published data only\}

Mirkin S, Stadtmauer LA, Gibbons WE, Oehninger S. Clinical and endocrine impact of pretreatment with oral contraceptive pills in poor responders undergoing IVF with a combination of microdose flare leuprolide acetate and high dose gonadotropins. Fertility and Sterility 2003; Vol. Suppl 3, 80:S190-1.

\section{Mulangi 1997 \{published data only\}} Mulangi AS, Nelson-White TM, Racowsky C, Gelety TJ. Follicular phase endocrine response to oral contraceptives (OCs) followed by gonadotropin releasing hormone agonist (GnRHa) for down-regulation prior to controlled ovarian hyperstimulation $(\mathrm{COH})$ for the purpose of IVF. Fertility and Sterility 1997; Vol. Suppl 1, 68:S6.

Neal 1993 \{published data only\}

Neal GS, Sultan KM, Liu HC, Davis OK, Rosenwaks Z. A dual approach to ovarian suppression using oral contraceptive pills and leuprolide acetate in high responder patients undergoing IVF. Abstracts of the American Fertility Society conjointly with the Canadian Fertility and Andrology Society. Fertility and Sterility. 1993:S111.

Pados 1995 \{published data only\}

Pados G, Tarlatzis BC, Bontis J, Lagos S, Papadimas J, Spanos E, et al.Evaluation of different ovarian stimulation protocols for in vitro fertilization. Gynecological Endocrinology 1995;9:103-12. [DOI: 10.3109/ 09513599509160198]

Palomba 2008 \{published data only\} Palomba S, Falbo A, Orio F, Russo T, Tolino A, Zullo F. Pretreatment with oral contraceptives in infertile anovulatory patients with polycystic ovary syndrome who receive gonadotropins for controlled ovarian stimulation. Fertility and Sterility 2008;89(6):1838-42. [DOI: 10.1016/ j.fertnstert.2007.05.035]

Pinkas 2008 \{published data only\} Pinkas H, Sapir O, Avrech OM, Ben-Haroush A, Ashkenzi J, Fisch B, et al.The effect of oral contraceptive pill for cycle scheduling prior to $\mathrm{GnRH}$-antagonist protocol on IVF cycle parameters and pregnancy outcome. Journal of Assisted Reproduction and Genetics 2008;25:29-33. [DOI: 10.1007/ s10815-007-9189-7]

Ramsewak 2005 \{published data only\}

Ramsewak SS, Duffy S, Taylor J, Woodward B. The oral contraceptive pill effectively permits cycle batching for an intermittent in vitro fertilization programme in Trinidad and Tobago. West Indian Medical Journal 2005;54(2): 127-9.

Russell 1997 \{published data only\}

Russell JB, Knezevich KM, Fabian KF, Dickson JA. Unstimulated immature oocyte retrieval: early versus mid follicular endometrial priming. Fertility and Sterility 1997; 67(4):616-20.

Sanghvi 2002 \{published data only\}

Sanghvi A, Noyes N, Krey LC. An oral contraceptive (OCP) microdose flare leuprolide acetate (LA) stimulation protocol is useful for poor prognosis patients undergoing in vitro fertilization (IVF). Fertility and Sterility 2002; Vol. Suppl 1, 78:S149.

Schoolcraft 1997 \{published data only\} Schoolcraft W, Schlenker T, Gee M, Stevens J, Wagley L. Improved controlled ovarian hyperstimulation in poor responder in vitro fertilization patients with a microdose follicle-stimulating hormone flare, growth hormone protocol. Fertility and Sterility 1997;67(1):93-7.

Steinkampf 1991 \{published data only\} Steinkampf MP, Hammond KR, Blackwell RE. Effect of estrogen/progestin administration on the ovarian response to gonadotropins: a randomized, prospective study. Fertility and Sterility 1991;55(3):642-3.

Surrey 1989 \{published data only\}

Surrey ES, Cedars MI. The effect of gonadotropin suppression on the induction of ovulation in premature ovarian failure patients. Fertility and Sterility 1989;52(1): $36-41$.

\section{Surrey 1998 \{published data only\}}

Surrey ES, Bower J, Hill DM, Ramsey J, Surrey MW. Clinical and endocrine effects of a microdose $\mathrm{GnRH}$ agonist flare regimen administered to poor responders who are undergoing in vitro fertilization. Fertility and Sterility 1998; Vol. 69, issue 3:419-24.

Talebian 2004 \{published data only\} Talebian S, Krey LC, Noyes N. Use of oral contraceptives with $\mathrm{GnRH}$ antagonists and recombinant gonadotropins in IVF cycles have no deleterious effect on pregnancy outcome. Fertility and Sterility 2004; Vol. Suppl 2, 82:S234.

Talebian 2007 \{published data only\}

Talebian S, Krey LC, Reh A, Granguly N, Liu M, Noyes N. Oral contraceptive (OC) pre-treatment in GnRH antagonist (ANT) cycles is a reasonable option to control the timing of IVF cycles. Fertility and Sterility 2007; Vol. Suppl 1, 88: S291.

Tarlatzis 1993 \{published data only\} Tarlatzis BC, Pazaitou K, Bili H, Bontis J, Papadimas J, Lagos $S$, et al.Growth hormone, oestradiol, progesterone and testosterone concentrations in follicular fluid after ovarian stimulation with various regimes for assisted reproduction. Human Reproduction 1993;8(10):1612-6.

Tartagni 2007 \{published data only\} Tartagni M, Cicinelli E, De Pergola G, De Salvia MA, Lavopa C, Loverro G. Effects of pretreatment with estrogens on ovarian stimulation with gonadotropins in women with premature ovarian failure: a randomized, placebocontrolled trial. Fertility and Sterility 2007;87(4):858-61. [DOI: 10.1016/j.fertnstert.2006.08.086] 
Weisman 1989 \{published data only\}

Weisman Z, Dirnfeld M, Lissak A, Sorokin Y, Abramovici $\mathrm{H}$. Oral contraceptive pills and follicular fluid hormones in an in vitro fertilization program. Fertility and Sterility 1989; 52(3):451-3.

Yokota 2006 \{published data only\}

Yokota Y, Yokota M, Yokota H, Makita M, Sato S, Araki $\mathrm{Y}$. A novel procedure for improving pregnancy rates in frequent repeated IVF failure: estrogen rebound combined with GnRH agonist flare. Abstracts of the 22nd Annual Meeting of the ESHRE. Prague, Czech Republic, 2006. Human Reproduction. 2006; Vol. 21 Suppl 1:1130-1.

Yoshida 2005 \{published data only\}

Yoshida A, Kakinuma M, Matsuba T, Seida K, Suzuki $\mathrm{H}$, Tanaka M. Effectiveness of using estradiol-GnRH antagonist protocol with unsuccessful oral contraceptive pill-GnRH antagonist protocol cases (full term pregnancies had not resulted) in in-vitro fertilization (IVF) cycles. Fertility and Sterility 2005; Vol. Suppl 1, 84:S45.

Zhao 2008 \{published data only\}

Zhao JZ, Lin XH, Huang XF, Lin JJ, Lin WQ, Ye BL. Effect of desogestrel and ethinyl estradiol pretreatment in superovulation cycles with short protocol. Chinese Journal of Obstetrics and Gynecology [Zhonghua Fu Chan Ke Za Zhi] 2008;43(2):102-5.

\section{References to studies awaiting assessment}

Tavmergen 2009 \{published and unpublished data\} Tavmergen E, von Mauw, Witjes H, Mannaerts B. Outcome of a trial to identify predicative factors for ovarian response in a $\mathrm{GnRH}$ antagonist protocol with or without oral contraceptive scheduling. Abstracts of the 25th Annual meeting of ESHRE. July 2009.

\section{References to ongoing studies}

Organon 2008 \{published data only\}

Organon. A randomized, open-label clinical trial to identify predictive factors for controlled ovarian stimulation using a fixed daily dose of $200 \mathrm{IU}$ recombinant FSH in GnRH antagonist regimen with or without oral contraceptive scheduling. http://clinicaltrials.gov/ct2/home June 2009.

\section{Additional references}

\section{Al-Inany 2006}

Al-Inany HG, Abou-Setta AM, Aboulghar M. Gonadotrophin-releasing hormone antagonists for assisted conception (Review). Cochrane Database of Systematic Reviews 2006, Issue 3. [DOI: 10.1002/ 14651858.CD001750.pub2]

\section{Anderson 1990}

Anderson RE, Stein AL, Paulson RJ, Stanczyk FZ, Vijod AG, Lobo RA. Effects of norethindrone on gonadotropin and ovarian steroid secretion when used for cycle programming during in vitro fertilization. Fertility and Sterility 1990;54(1):96-101.
Arowojolu 2007

Arowojolu AO, Gallo MF, Lopez LM, Grimes DA, Garner SE. Combined oral contraceptive pills for treatment of acne. Cochrane Database of Systematic Reviews 2007, Issue 1. [DOI: 10.1002/14651858.CD004425.pub3]

\section{Awadalla 1987}

Awadalla SG, Friedman CI, Chin NW, Dodds W, Park JM, Kim MH. Follicular stimulation for in vitro fertilization using pituitary suppression and human menopausal gonadotropins. Fertility and Sterility 1987;48(5):811-5.

Barmat 2005

Barmat LI, Chantilis SJ, Hurst BS, Dickey RP. A randomized prospective trial comparing gonadotropinreleasing hormone $(\mathrm{GnRH})$ antagonist/ recombinant follicle-stimulating hormone ( $\mathrm{rFSH}$ ) versus $\mathrm{GnRH}$-agonist/ $\mathrm{rFSH}$ in women pretreated with oral contraceptives before in vitro fertilization. Fertility and Sterility 2005;83(2): 321-30. [DOI: 10.1016/j.fertnstert.2004.06.076]

\section{Biljan 1998}

Biljan MM, Mahutte NG, Dean N, Hemmings R, Bissonnette F, Tan SL. Effects of pretreatment with an oral contraceptive on the time required to achieve pituitary suppression with gonadotropin-releasing hormone analogues and on subsequent implantation and pregnancy rates. Fertility and Sterility 1998;70(6):1063-9.

\section{Cohen 1979}

Cohen BL, Katz M. Pituitary and ovarian function in women receiving hormonal contraception. Contraception 1979;20(5):475-87.

\section{Cédrin-Durnerin 2007}

Cédrin-Durnerin I, Bstandig B, Parneix I, Bied-Damon V, Avril C, Decanter C, et al.Effects of oral contraceptive, synthetic progestogen or natural estrogen pre-treatments on the hormonal profile and the antral follicle cohort before GnRH antagonist protocol. Human Reproduction 2007;22 (1):109-16. [DOI: 10.1093/humrep/del340]

\section{Damario 1997}

Damario MA, Barmat L, Liu HC, Davis OK, Rosenwaks Z. Dual suppression with oral contraceptives and gonadotrophin releasing-hormone agonists improves invitro fertilization outcome in high responder patients. Human Reproduction 1997;12(11):2359-65.

\section{De Ziegler 1998}

De Ziegler D, Jaaskelainen AS, Brioschi PA, Fanchin R, Bulletti C. Synchronization of endogenous and exogenous FSH stimuli in controlled ovarian hyperstimulation (COH). Human Reproduction 1998;13(3):561-4.

\section{Dodson 1989}

Dodson WC. Role of gonadotropin releasing hormone agonists in ovulation induction. Journal of Reproductive Medicine 1989;34(1):76-9.

EndNote

Thomson Reuters. EndNote. X1. Thomson Reuters, 2008. 


\section{Engmann 1999}

Engmann L, Maconochie N, Bekir J, Tan SL. Progestogen therapy during pituitary desensitization with gonadotropinreleasing hormone agonist prevents functional ovarian cyst formation: a prospective, randomized study. American Journal of Obstetrics and Gynecology 1999;181(3):576-82.

\section{Erkkola 2007}

Erkkola R. Recent advances in hormonal contraception. Obstetrics and Gynecology 2007;19:547-53.

\section{ESHRE 2008}

Abstracts of the 24th annual meeting of the European society of human reproduction and embryology. Barcelona, Spain, 2008. Human Reproduction. Oxford University Press, Vol. 23 Suppl 1: Abstract Book.

\section{Gaspard 1984}

Gaspard UJ, Dubois M, Gillain D, Franchimont P, Duvivier $\mathrm{J}$. Ovarian function is effectively inhibited by a low-dose triphasic oral contraceptive containing ethinylestradiol and levonorgestrel. Contraception 1984;29(4):305-18.

\section{Gonen 1990}

Gonen Y, Jacobson W, Casper RE. Gonadotropin suppression with oral contraceptives before in vitro fertilization. Fertility and Sterility 1990;53(2):282-7.

\section{Griesinger 2008}

Griesinger G, Venetis CA, Marx T, Diedrich K, Tarlatzis BC, Kolibianakis EM. Oral contraceptive pill pretreatment in ovarian stimulation with $\mathrm{GnRH}$ antagonists for IVF: a systematic review and meta-analysis. Fertility and Sterility 2008;90(4):1055-63. [DOI: 10.1016/ j.fertnstert.2007.07.1354]

\section{Griffin 2002}

Griffin PD, Rowe PJ, Vayena E, editors. Medical, ethical and social aspects of assisted reproduction. Geneva, Switzerland, 2001. Current practices and controversies in assisted reproduction: report of a WHO meeting.. World Health Organisation, 2002. [: ISBN 924159030 0]

\section{Harwood 2007}

Harwood K, Vuguin P, DiMartino-Nardi J. Current approaches to the diagnosis and treatment of polycystic ovarian syndrome in youth. Hormone Research 2007;68(5): 209-17. [DOI: 10.1159/000101538]

\section{Higgins 2008}

Higgins JPT, Green S. Cochrane Handbook for Systematic Reviews of Interventions. Version 5.0.0 (updated February 2008). www.cochrane-handbook.org. The Cochrane Collaboration, 2008.

Huirne 2006

Huirne JA, Hugues JN, Pirard C, Fischl F, Sage JC, Pouly $\mathrm{JL}$, et al.Cetrorelix in an oral contraceptive-pretreated stimulation cycle compared with buserelin in IVF/ICSI patients treated with $\mathrm{r}-\mathrm{hFSH}$ : a randomized, multicentre, phase IIIb study. Human Reproduction 2006;21(6): 1408-15. [: 10.1093/humrep/del030]

\section{Huirne 2006a}

Huirne JA, van Loenen AC, Donnez J, Pirard C, Homburg $\mathrm{R}$, Schats $\mathrm{R}$, et al.Effect of an oral contraceptive pill on follicular development in IVF/ICSI patients receiving a $\mathrm{GnRH}$ antagonist: a randomized study. Reproductive Biomedicine Online 2006;13(2):235-45.

\section{Irvine 1999}

Irvine GA, Cameron IT. Medical management of dysfunctional uterine bleeding. Best Practice and Research in Clinical Obstetrics and Gynaecology 1999;13(2):189-202.

\section{Keltz 2007}

Keltz MD, Gera PS, Skorupski J, Stein DE. Comparison of FSH flare with and without pretreatment with oral contraceptive pills in poor responders undergoing in vitro fertilization. Fertility and Sterility 2007;88(2):350-3. [DOI: 10.1016/j.fertnstert.2006.11.123]

\section{Kolibianakis 2006}

Kolibianakis EM, Papanikolaou EG, Camus M, Tournaye H, Van Steirteghem AC, Devroey P. Effect of oral contraceptive pill pretreatment on ongoing pregnancy rates in patients stimulated with $\mathrm{GnRH}$ antagonists and recombinant FSH for IVF. A randomized controlled trial. Human Reproduction 2006;21(2):352-7. [DOI: 10.1093/ humrep/dei348]

Le Nestour 1993

Le Nestour E, Marraoui J, Lahlou N, Roger M, De Ziegler $\mathrm{D}$, Bouchard P. Role of estradiol in the rise in folliclestimulating hormone levels during the luteal-follicular transition. Journal of Clinical Endocrinology and Metabolism 1993;77(2):439-42.

\section{MDSG Module 2008}

Farquhar C, Clarke J, Lethaby A, Thomas J,

Proctor M, Barlow D, et al.Cochrane Menstrual Disorders and Subfertility Group About The Cochrane Collaboration (Cochrane Review Groups (CRGs)). www.thecochranelibrary.com 2008, issue 4 .

\section{Moudgal 1985}

Moudgal RN, Jagannadha Rao A, Murthy GSRC, Neelakanta R, Banavar SR, Kotagi SG, et al.Effect of intranasal administration of norethisterone and progesterone on pituitary and gonadal function in adult male and female bonnet monkeys (Macaca radiata). Fertility and Sterility 1985;44(1):120-4

\section{Pandian 2005}

Pandian Z, Bhattacharya S, Vale L, Templeton A. In vitro fertilisation for unexplained subfertility. Cochrane Database of Systematic Reviews 2005, Issue 2. [DOI: 10.1002/ 14651858.CD003357.pub2]

\section{RevMan}

The Nordic Cochrane Centre, The Cochrane Collaboration. Review Manager (RevMan). 5.0. Copenhagen: The Nordic Cochrane Centre, The Cochrane Collaboration, 2008.

Rombauts 2006

Rombauts L, Healy D, Norman RJ. A comparative randomized trial to assess the impact of oral contraceptive 
pretreatment on follicular growth and hormone profiles in $\mathrm{GnRH}$ antagonist-treated patients. Human Reproduction 2006;21(1):95-103. [DOI: 10.1093/humrep/dei302]

SIGN

Scottish Intercollegiate Guidelines Network. Search filters. http://www.sign.ac.uk/methodology/filters.html\#random (accessed 18 November 2008).

\section{Tarlatzis 2006}

Tarlatzis BC, Fauser BC, Kolibianakis EM, Diedrich K, Rombauts L, Devroey P. GnRH antagonists in ovarian stimulation for IVF. Human Reproduction Update 2006;12 (4):333-40. [DOI: 10.1093/humupd/dml001]

Van Wely 2003

Van Wely M, Westergaard LG, Bossuyt PM, Van der Veen
F. Human menopausal gonadotropin versus recombinant follicle stimulation hormone for ovarian stimulation in assisted reproductive cycles. Cochrane Database of Systematic Reviews 2003, Issue 1. [DOI: 10.1002/ 14651858.CD003973]

\section{References to other published versions of this review}

\section{Haojie 2006}

Haojie H, Ola B, LIngya P, Shangwei L. Pretreatment with oral contraceptives in a GnRHa program for couples undergoing assisted reproductive techniques. (Protocol). Cochrane Database of Systematic Reviews 2006, issue 3.

* Indicates the major publication for the study 


\section{CHARACTERISTICS OF STUDIES}

\section{Characteristics of included studies [ordered by study ID]}

\section{Aston 1995}

\begin{tabular}{ll} 
Methods & $\begin{array}{l}\text { Parallel group study } \\
\text { Number of women randomised: } 152 \text { (75 in control group, } 77 \text { in study group) } \\
\text { Number of withdrawals: } 8 \text { (7 in control group: } 5 \text { due to endometrioma or cysts and } 2\end{array}$ \\
& $\begin{array}{l}\text { chose not to proceed; } 1 \text { in study group due to endometrioma) } \\
\text { Number of women analysed:144 }\end{array}$ \\
\hline Participants & $\begin{array}{l}\text { Country: authors are from the United Kingdom } \\
\text { Inclusion criteria: women planning to have an IVF cycle on the Southampton IVF }\end{array}$ \\
\hline $\begin{array}{l}\text { programme. } \\
\text { Exclusion criteria: an endometrioma or an ovarian cyst seen on vaginal ultrasound scan }\end{array}$ \\
\hline $\begin{array}{l}\text { on day } 19 \text { of the menstrual cycle (after recruitment) } \\
\text { Mean age and SD } \\
\text { Study group: } 33.8 \pm 4.1 \\
\text { Control group: } 33.5 \pm 3.5\end{array}$ \\
\hline
\end{tabular}

Interventions

1) Medroxyprogesterone acetate $10 \mathrm{mg} /$ day on cycle days $19-25+\mathrm{GnRH}$ agonist (buserelin acetate, nasal administration) $200 \mu \mathrm{g} 3$ times daily from cycle day $21+\mathrm{hMG} 4$ ampoules/day (75 IU FSH and 75 IU LH per ampoule) from day 4 of ensuing menses 2) Placebo on cycle days 19-25 + GnRH agonist (buserelin acetate, nasal administration) $200 \mu \mathrm{g} 3$ times daily from cycle day $21+$ hMG 4 ampoules/day (75 IU FSH and 75 IU LH per ampoule) from day 4 of ensuing menses

Both hMG and GnRH agonist are continued until hCG injection (10,000 IU, IM), administered when the leading 3 follicles reach a diameter of $\geq 18 \mathrm{~mm}$ and the serum oestradiol level is $>300 \mathrm{pmol} / \mathrm{L}$ for every follicle $>14 \mathrm{~mm}$ in diameter

Outcomes

Cyst development; intraovarian sonolucent structure with a mean diameter of $>14 \mathrm{~mm}$, measured after 12 days of pituitary suppression

Clinical pregnancy rates; not defined

\section{Notes}

Power calculation performed: yes

Intention-to-treat analysis performed: no

\section{Risk of bias}

\begin{tabular}{l|ll}
\hline Item & Authors' judgement & Description \\
\hline Adequate sequence generation? & Unclear & $\begin{array}{l}\text { Quote: 'The hospital pharmacy ran- } \\
\text { domised to contain placebo or progesto- } \\
\text { gen.' } \\
\text { Method of randomisation not reported. }\end{array}$ \\
\hline Allocation concealment? & Yes & $\begin{array}{l}\text { Quote: 'The hospital pharmacy provided a } \\
\text { series of consecutively numbered bottles' }\end{array}$
\end{tabular}

Oral contraceptive pill, progestogen or estrogen pre-treatment for ovarian stimulation protocols for women undergoing assisted 


\begin{tabular}{|c|c|c|}
\hline $\begin{array}{l}\text { Blinding? } \\
\text { All outcomes }\end{array}$ & Yes & $\begin{array}{l}\text { Double blind } \\
\text { Women in control group received a } \\
\text { placebo. }\end{array}$ \\
\hline $\begin{array}{l}\text { Incomplete outcome data addressed? } \\
\text { All outcomes }\end{array}$ & Yes & $\begin{array}{l}\text { Reasons for withdrawals reported. With- } \\
\text { drawals due to endometrioma slightly im- } \\
\text { balanced: } 5 \text { in control group, } 1 \text { in study } \\
\text { group }\end{array}$ \\
\hline Free of selective reporting? & Unclear & Planned outcomes not reported. \\
\hline Free of other bias? & Unclear & $\begin{array}{l}\text { Quote: 'No difference was seen between the } \\
\text { study group and control group in the indi- } \\
\text { cation of IVF and age.' No P values given } \\
\text { in table. } \\
\text { Only baseline data available of women } \\
\text { analysed, but not of all the women ran- } \\
\text { domised }\end{array}$ \\
\hline
\end{tabular}

\section{Biljan 1998a}

\begin{tabular}{ll} 
Methods & $\begin{array}{l}\text { Academic centre, parallel group study } \\
\text { Number of women randomised: } 83 \text { women undergoing } 102 \text { cycles }(51 \text { cycles in control } \\
\text { group, } 51 \text { cycles in study group; number of women per group not reported) } \\
\text { Number of withdrawals: not reported } \\
\text { Number of women analysed: only number of cycles analysed reported (n=102) }\end{array}$ \\
\hline Participants & $\begin{array}{l}\text { Country: authors are from Canada } \\
\text { Inclusion criteria: patients who were receiving a long protocol of pituitary suppression }\end{array}$ \\
\hline in the early follicular phase as a part of IVF-ET treatment. \\
\hline Exclusion criteria: not reported \\
\hline Median age and range: \\
Study group: $35.2(32.5-39.1)$ \\
Control group: $33.7(31.6-38.3)$ \\
\hline
\end{tabular}

Interventions

1) Combined OCP on cycle days 1-14 + GnRH agonist (buserelin acetate, long protocol) $500 \mu \mathrm{g} /$ day start on cycle day $14+$ hMG (75 IU FSH and $75 \mathrm{IU} \mathrm{LH}$ ) or pure FSH (75 IU) start after achievement of pituitary suppression.

2) $\mathrm{GnRH}$ agonist (buserelin acetate, long protocol) $500 \mu \mathrm{g} /$ day start on cycle day 2 + hMG (75 IU FSH and 75 IU LH) or pure FSH (75 IU) start after achievement of pituitary suppression

If no pituitary suppression (serum $E_{2}$ concentration $<40 \mathrm{pg} / \mathrm{mL}$ ) is achieved after 14 days of $\mathrm{GnRH}$ agonist administration, the dosage of buserelin acetate is increased to 500 $\mu \mathrm{g}$ twice daily + administration of an IM injection of progesterone $100 \mathrm{mg}$ Both hMG/FSH and GnRH agonist are continued until hCG injection, administered when $\geq 3$ follicles reach a mean diameter of $\geq 18 \mathrm{~mm}$ 
Biljan 1998a (Continued)

Clinical pregnancy rate per cycle started; presence of one or more fetal hearts confirmed
with US performed at least 4 weeks after embryo transfer
Number of patients with a cyst; intraovarian sonolucent structure with a mean diameter
of $>14 \mathrm{~mm}$, measured after 7 days of pituitary suppression
Number of days of GnRH-a treatment
Number of days of gonadotrophin treatment
Total quantity of gonadotrophin administered; measured in ampoules
Number of follicles and
Number of oocytes collected/fertilised
Number of embryos replaced
Implantation rate

Notes

Power calculation performed: yes

Intention-to-treat analysis performed: no

Risk of bias

\begin{tabular}{|c|c|c|}
\hline Item & Authors' judgement & Description \\
\hline Adequate sequence generation? & Yes & $\begin{array}{l}\text { Quote: 'They were randomised in two } \\
\text { groups by drawing sealed envelopes that } \\
\text { contained randomly generated numbers.' }\end{array}$ \\
\hline Allocation concealment? & Yes & Sealed envelopes \\
\hline $\begin{array}{l}\text { Blinding? } \\
\text { All outcomes }\end{array}$ & Unclear & Not reported \\
\hline $\begin{array}{l}\text { Incomplete outcome data addressed? } \\
\text { All outcomes }\end{array}$ & No & $\begin{array}{l}\text { Numbers and reasons for withdrawals not } \\
\text { reported. }\end{array}$ \\
\hline Free of selective reporting? & Unclear & Planned outcomes not reported. \\
\hline Free of other bias? & No & $\begin{array}{l}\text { Only number of cycles per treatment group } \\
\text { known, number of women per group not } \\
\text { reported. } \\
\text { No significant difference in baseline char- } \\
\text { acteristics between groups with regard to } \\
\text { age, cause of infertility, number of previous } \\
\text { attempts, and } \mathrm{E}_{2} \text {, FSH or LH level. }\end{array}$ \\
\hline
\end{tabular}


Methods

Participants

Interventions

1) Norethisterone $10 \mathrm{mg} /$ day for $12-20$ days, start on cycle day $15+\mathrm{GnRH}$ agonist (triptorelin) $100 \mu \mathrm{g} /$ day, start on post-treatment day $3+$ hMG 140-150 IU a.m. start on day 4/5 of $\mathrm{GnRH}$ agonist treatment (dose adjustments if necessary).

2) GnRH agonist (triptorelin) $100 \mu \mathrm{g} /$ day, start on cycle day $1+$ hMG 140-150 IU IM start on cycle day $4 / 5$ (dose adjustments if necessary)

Both hMG and GnRH agonist are continued until hCG injection (10,000 IU), administered when $\geq 2$ follicles reach a diameter of $\geq 18 \mathrm{~mm}$ and serum oestradiol values were $-200 \mathrm{pg} / \mathrm{mL}$ per follicle $>15 \mathrm{~mm}$

\begin{tabular}{ll}
\hline Outcomes & Hormonal values \\
& Day of hCG \\
& Number of hMG vials \\
& Number of oocytes retrieved; defined as mature oocytes or follicles \\
& Number of embryos replaced \\
& Number of pregnancies; not defined. \\
& Number of 'take home babies' \\
\hline \multirow{2}{*}{ Notes } & Power calculation performed: no \\
& Intention-to-treat analysis performed: no \\
\hline
\end{tabular}

Risk of bias

\begin{tabular}{l|ll}
\hline Item & Authors' judgement & Description \\
\hline Adequate sequence generation? & Unclear & $\begin{array}{l}\text { Quote: 'Participating women were ran- } \\
\text { domised...' } \\
\text { Method not reported. }\end{array}$ \\
\hline $\begin{array}{l}\text { Allocation concealment? } \\
\text { Blinding? }\end{array}$ & Unclear & Not reported \\
All outcomes & Unclear & Not reported \\
\hline
\end{tabular}

Oral contraceptive pill, progestogen or estrogen pre-treatment for ovarian stimulation protocols for women undergoing assisted 
Cédrin-Durnerin 1996 (Continued)

\begin{tabular}{l|l|l}
\hline $\begin{array}{l}\text { Incomplete outcome data addressed? } \\
\text { All outcomes }\end{array}$ & Yes & Reasons for withdrawals reported. \\
\hline Free of selective reporting? & Unclear & Planned outcomes not reported. \\
\hline Free of other bias? & No & $\begin{array}{l}\text { Quote: 'There was no difference in the } \\
\text { mean age or in the indication of IVF be- } \\
\text { tween the groups.' } \\
\text { No data on baseline characteristics re- } \\
\text { ported. }\end{array}$ \\
\hline
\end{tabular}

Cédrin-Durnerin 2007

Methods

Multicentre (6 IVF centres), parallel group study

Number of women randomised: 93 (21 in OCP group, 23 in progestogen group, 25 in oestrogen group, 24 in control group)

Number of withdrawals: 3 in oestrogen group ( 1 did not start any treatment, 1 due to an ovarian cyst and one due to major protocol violation)

Number of women analysed: 90

Duration of study: 10 months of recruitment

Participants

Country: authors are from France

Inclusion criteria: (i) regular normo-ovulatory cycles (28 to 35 days), (ii) age $<38$ years, (iii) BMI between 18 and 30.

Exclusion criteria: (i) high levels of baseline serum FSH or $\mathrm{E}_{2}$ values, (ii) $<5$ follicles at the antral follicular count performed on day three of a spontaneous cycle, (iii) a history of high ( $>20$ oocytes) or low ( $<5$ oocytes) ovarian response in a previous IVF attempt Mean age and SD:

OCP group: $30.8 \pm 4.6$

Progestogen group: $32.9 \pm 2.5$

Estrogen group: $31.8 \pm 3.2$

Control group: $31.2 \pm 4.3$

Interventions

1) Combined OCP (ethinyl $30 \mu \mathrm{g}+$ desogestrel $150 \mu \mathrm{g}$ ) daily, start cycle day two or three for 15 to 21 days (stop on a Sunday) $+\mathrm{rFSH}$ (recombinant follitropin beta) 150 to $300 \mathrm{IU} /$ day, start post-treatment day five $+\mathrm{GnRH}$ antagonist (ganirelix acetate) 0.25 $\mathrm{mg} /$ day, start when leading follicle reaches $14 \mathrm{~mm}$ in diameter.

2) Norethisterone $10 \mathrm{mg} /$ day, start cycle day 15 for 10 to 15 days (stop on a Sunday) $+\mathrm{rFSH}$ (recombinant follitropin beta) 150-300 IU/day, start post-treatment day five + $\mathrm{GnRH}$ antagonist (ganirelix acetate) $0.25 \mathrm{mg} /$ day, start when leading follicle reaches 14 $\mathrm{mm}$ in diameter.

3) Micronized 17- $\beta \mathrm{E}_{2} 2 \mathrm{mg}$ twice daily, 10 to 15 days, start 10 days before the presumed menses (stop on a Sunday) + rFSH (recombinant follitropin beta) 150 to $300 \mathrm{IU} /$ day, start post-treatment day five $+\mathrm{GnRH}$ antagonist (ganirelix acetate) $0.25 \mathrm{mg} /$ day, start when leading follicle reaches $14 \mathrm{~mm}$ in diameter.

4) $\mathrm{rFSH}$ (recombinant follitropin beta) 150 to $300 \mathrm{IU} /$ day, start day three after spontaneous menses $+\mathrm{GnRH}$ antagonist (ganirelix acetate) $0.25 \mathrm{mg} /$ day, start when leading follicle reaches $14 \mathrm{~mm}$ in diameter 
Cédrin-Durnerin 2007 (Continued)

rFSH dose according to age, BMI and previous responses to stimulation; after five days of treatment dose adjustment according to ovarian response

Both rFSH and GnRH antagonist are continued until hCG injection (10,000 IU), administered when $\geq$ three mature $(\geq 17 \mathrm{~mm})$ follicles were obtained

$\begin{array}{ll}\text { Outcomes } & \text { Number of live births } \\ \text { Number of positive pregnancy tests } \\ \text { Clinical pregnancy rate; not defined } \\ \text { Ongoing pregnancy rate; a pregnancy developing beyond } 12 \text { weeks } \\ \text { Multiple pregnancy rate; not defined } \\ \text { Hormonal profiles during the 5-day wash-out period } \\ \text { Follicular growth } \\ \text { Antagonist duration } \\ \text { Pre-treatment duration } \\ \text { Number of retrievals } \\ \text { FSH dose } \\ \text { Transferred embryos }\end{array}$

Notes

Power calculation performed: no

Intention-to-treat analysis performed: no (not for oestrogen group)

Risk of bias

\begin{tabular}{|c|c|c|}
\hline Item & Authors' judgement & Description \\
\hline Adequate sequence generation? & Yes & $\begin{array}{l}\text { Quote: 'Random allocation sequence was } \\
\text { generated from a table of random numbers. } \\
\text {.. Randomization was stratified by centre.. } \\
.\end{array}$ \\
\hline Allocation concealment? & Yes & $\begin{array}{l}\text { Quote: 'Random allocation sequence was } \\
\text { concealed to each physician who enrolled } \\
\text { and randomized patients.' } \\
\text { Sealed envelopes }\end{array}$ \\
\hline $\begin{array}{l}\text { Blinding? } \\
\text { All outcomes }\end{array}$ & No & Quote: 'This study was not blind.' \\
\hline $\begin{array}{l}\text { Incomplete outcome data addressed? } \\
\text { All outcomes }\end{array}$ & No & $\begin{array}{l}\text { The reason for one withdrawal in the oe- } \\
\text { strogen group is unclear (quote: 'did not } \\
\text { start any treatment') }\end{array}$ \\
\hline Free of selective reporting? & Unclear & $\begin{array}{l}\text { Hormonal values planned and (incom- } \\
\text { pletely) reported in abstract and also (com- } \\
\text { pletely) reported in journal article. } \\
\text { Other planned outcomes not reported. }\end{array}$ \\
\hline
\end{tabular}

Oral contraceptive pill, progestogen or estrogen pre-treatment for ovarian stimulation protocols for women undergoing assisted 
Cédrin-Durnerin 2007 (Continued)

Free of other bias? No

No

No significant baseline imbalance with regard to age and BMI. No other characteristics mentioned

Daly 2002

\begin{tabular}{ll} 
Methods & $\begin{array}{l}\text { Cross-over study } \\
\text { Number of women randomised: } 25 \text { (13 study group, } 12 \text { in control group) } \\
\text { Number of withdrawals: not reported } \\
\text { Number of women analysed: unclear }\end{array}$ \\
\hline Participants & $\begin{array}{l}\text { Country: authors are from United States of Amerika } \\
\text { Inclusion criteria: women, < 41 years of age, who were anticipated to have limited ovarian }\end{array}$ \\
\hline $\begin{array}{l}\text { reserve (LOR) based on transvaginal ultrasound showing limited follicles on cycle day } \\
\text { 2-3 or hormonal values (inhibin B, FSH, E2) } \\
\text { Exclusion criteria: not reported }\end{array}$ & $\begin{array}{l}\text { Mean age and SD: not reported } \\
\text { Poor response: yes ('limited ovarian reserve') }\end{array}$ \\
\hline
\end{tabular}

Interventions $\quad$ 1) Estradiol $2 \mathrm{mg}$ in the luteal phase of the preparation cycle + FSH $300 \mathrm{IU}$, start cycle day $2+$ GnRH antagonist (ganirelix acetate) start in late follicular phase + hMG (375 IU FSH + 150 IU LH), timing not reported.

2) Combined OCP + GnRH agonist (leuprolide acetate, microdose) + hMG (300 IU FSH +75 IU LH). Timing of administration of combined OCP, hMG and GnRH agonist not reported

Outcomes

Ongoing pregnancy; a viable pregnancy, method of assessment is not reported

Clinical pregnancy; not defined

Number of mature oocytes

Number of good embryos

Implantation rate

Cancellation rate

Notes

Power calculation performed: unclear

Intention-to-treat analysis performed: unclear

\section{Risk of bias}

\begin{tabular}{lll}
\hline Item & Authors' judgement & Description \\
\hline Adequate sequence generation? & Unclear & 'Randomized', method not reported. \\
\hline Allocation concealment? & Unclear & Not reported \\
\hline $\begin{array}{l}\text { Blinding? } \\
\text { All outcomes }\end{array}$ & No & Unblinded \\
\hline
\end{tabular}

Oral contraceptive pill, progestogen or estrogen pre-treatment for ovarian stimulation protocols for women undergoing assisted 
Daly 2002 (Continued)

\begin{tabular}{l|l|l}
\hline $\begin{array}{l}\text { Incomplete outcome data addressed? } \\
\text { All outcomes }\end{array}$ & Unclear & $\begin{array}{l}\text { Only abstract available. Numbers and rea- } \\
\text { sons for withdrawals not reported }\end{array}$ \\
\hline Free of selective reporting? & Unclear & $\begin{array}{l}\text { Data on all planned outcomes reported. } \\
\text { Pre-crossover data on primary outcome re- } \\
\text { ported, but on some secondary outcomes } \\
\text { (implantation rate, mature oocytes, good } \\
\text { embryos) only post-cross-over data is re- } \\
\text { ported }\end{array}$ \\
\hline Free of other bias? & No & No data on baseline characteristics re- \\
\hline
\end{tabular}

Ditkoff 1996

Methods

Participants
Parallel group study

Number of women randomised: 105 (58 in control group and 47 in study group)

Number of withdrawals: 0

Number of women analysed: 105

Length of follow up: until end of treatment cycle.

\begin{tabular}{l} 
Inclusion criteria: day $3 \mathrm{FSH}$ values $<15 \mathrm{mIU} / \mathrm{mL}$ \\
\hline Exclusion criteria: not reported \\
\hline Mean age and SD: \\
Study group: $36.7 \pm 4.8$ \\
Control group: $35.8 \pm 4.57$
\end{tabular}

Interventions

1) Norethindrone acetate (NETA, oral) $10 \mathrm{mg} /$ day on cycle days one to eight $+\mathrm{GnRH}$ agonist (leuprolide acetate, s.c.) $1 \mathrm{mg} /$ day, start cycle day one + hMG $225 \mathrm{IU} /$ day (IM administration), start when serum oestradiol level was $<30 \mathrm{pg} / \mathrm{ml}$.

2) GnRH agonist (leuprolide acetate, s.c.) $1 \mathrm{mg} /$ day, start cycle day $1+\mathrm{hMG} 225 \mathrm{IU} /$ day (IM), start when serum oestradiol level was $<30 \mathrm{pg} / \mathrm{mL}$

Both hMG and GnRH agonist are continued until hCG injection (10,000 IU, IM), administered when the leading follicles reaches a diameter of $\geq 18 \mathrm{~mm}$

Outcomes

Number of deliveries/ongoing pregnancies; positive heart activity on US.

Number of clinical pregnancies; evidence of a clinical gestational sac.

Days until suppression

Number of cysts cycles; intraovarian sonolucent structure with a mean diameter of $>14$ $\mathrm{mm}$, measured after 8 days of pituitary suppression

Number of oocytes retrieved

Days of ovarian stimulation

Number of ampoules of hMG

Notes

Power calculation performed: no

Intention-to-treat analysis performed: no 
Ditkoff 1996 (Continued)

\begin{tabular}{|c|c|c|}
\hline Item & Authors' judgement & Description \\
\hline Adequate sequence generation? & Yes & $\begin{array}{l}\text { Quote: 'Patients were randomly assigned } \\
\text { by tossing a coin to one of two groups.' }\end{array}$ \\
\hline Allocation concealment? & Yes & Centralised randomisation process. \\
\hline $\begin{array}{l}\text { Blinding? } \\
\text { All outcomes }\end{array}$ & No & No blinding \\
\hline $\begin{array}{l}\text { Incomplete outcome data addressed? } \\
\text { All outcomes }\end{array}$ & Yes & No withdrawals \\
\hline Free of selective reporting? & Unclear & Planned outcomes not reported. \\
\hline Free of other bias? & No & $\begin{array}{l}\text { No table of baseline characteristics. } \\
\text { Quote: 'The various infertility diagnoses } \\
\text { were distributed equally between the con- } \\
\text { trol and study groups.' }\end{array}$ \\
\hline
\end{tabular}

\section{Engmann 1999}

$\begin{array}{ll}\text { Methods } & \text { Parallel group study } \\ \text { Number of women recruited: } 123 & \text { Number of women excluded: six (two due to ovarian cysts } \geq 15 \text { mm, two due to raised } \\ & \text { early follicular phase serum FSH, two did not undergo IVF) } \\ \text { Number of women randomised: } 117 \text { ( } 54 \text { in control group, } 63 \text { in study group) } \\ \text { Number of withdrawals: one (in study group, due to violation of the study protocol) } \\ \text { Number of women analysed: } 116\end{array}$

Oral contraceptive pill, progestogen or estrogen pre-treatment for ovarian stimulation protocols for women undergoing assisted 
Engmann 1999 (Continued)

Interventions

Outcomes
1) Norethindrone $10 \mathrm{mg}$ on cycle day 1 and $5 \mathrm{mg}$ twice daily on cycle day two to five $+\mathrm{GnRH}$ agonist (buserelin acetate, s.c., long protocol) $500 \mu \mathrm{g} /$ day, start on cycle day 2 (dose adjustment after pituitary suppression to $200 \mu \mathrm{g} /$ day) + hMG (Normegon, 75 IU FSH) two to five ampoules daily or $\mathrm{rFSH}$, start when serum $\mathrm{E}_{2} \leq 150 \mathrm{pmol} / \mathrm{L}$.

2) $\mathrm{GnRH}$ agonist (buserelin acetate, s.c., long protocol) $500 \mu \mathrm{g} /$ day start on cycle day two (dose adjustment after pituitary suppression to $200 \mu \mathrm{g} /$ day) + hMG (Normegon, $75 \mathrm{IU}$ FSH) two to five ampoules daily or $\mathrm{rFSH}$, start when serum $\mathrm{E}_{2} \leq 150 \mathrm{pmol} / \mathrm{L}$.

Pituitary suppression is achieved when there is an absence of follicular activity and endometrial thickness $<5 \mathrm{~mm}$

hMG or rFSH dose according to patient's age, previous response, basal serum FSH levels and $\mathrm{PCO}$

Both hMG/rFSH and GnRH agonist are continued until hCG injection (10,000 IU, IM), administered when two or three leading follicles are $\geq 18 \mathrm{~mm}$ in diameter

Incidence of functional ovarian cysts $(\geq 10 \mathrm{~mm}$, measured after one week of GnRH agonist)

Number of days required to achieve pituitary desensitization

Number of hospital visits before ovarian stimulation

Number of preovulatory follicles and mature oocytes

Fertilization rate

Number of good-quality embryos produced and transferred

Implantation rate

Clinical pregnancy rate; a positive pregnancy test with evidence of a gestational sac

Amount of gonadotrophins administered; measured in ampoules

Pregnancy loss
Power calculation performed: yes

Intention-to-treat analysis performed: no

\section{Risk of bias}

\begin{tabular}{lll}
\hline Item & Authors' judgement & Description
\end{tabular}

Adequate sequence generation? Yes

Quote: 'Eligible patients were randomly assigned in a ratio of $1: 1$ by means of computer-generated random numbers. To ensure similar distributions of age in the two groups, separate randomization schedules were drawn up for women $<40$ years old and women $\geq 40$ years old by use of stratified randomized blocks.'

Quote: 'Selection into the groups (and of administration of the appropriate treatment protocol) was performed by the clinic nurses by using a series of consecutively numbered sealed envelopes (one for each age group).' 
Engmann 1999 (Continued)

\begin{tabular}{|c|c|c|}
\hline $\begin{array}{l}\text { Blinding? } \\
\text { All outcomes }\end{array}$ & Yes & $\begin{array}{l}\text { Quote: 'Although the patient could guess } \\
\text { her treatment status, treatment allocation } \\
\text { was not recorded in the clinical notes, and } \\
\text { all clinicians were blinded to the status of } \\
\text { study participants until the trial was over.' }\end{array}$ \\
\hline $\begin{array}{l}\text { Incomplete outcome data addressed? } \\
\text { All outcomes }\end{array}$ & Yes & Reasons for withdrawals reported. \\
\hline Free of selective reporting? & Yes & Data on all planned outcomes reported. \\
\hline Free of other bias? & Yes & $\begin{array}{l}\text { No significant baseline imbalance between } \\
\text { groups with regard to age, duration of in- } \\
\text { fertility, previous attempts, baseline serum } \\
\text { FSH, polycystic ovaries and cause of infer- } \\
\text { tility }\end{array}$ \\
\hline
\end{tabular}

Fanchin 2001

\begin{tabular}{ll} 
Methods & $\begin{array}{l}\text { Cross-over study, no pre-cross-over data available. } \\
\text { Crossover design: 'Women randomly started the protocol by control or E2 pre-treated } \\
\text { cycles.' Thereafter, all women did a second (cross-over) cycle. }\end{array}$ \\
$\begin{array}{l}\text { Number of women randomised: } 14 \text { (all these women underwent two cycles of treatment; } \\
\text { one E2 pre-treated cycle and one control cycle) } \\
\text { Number of withdrawals: not reported } \\
\text { Number of women analysed: not reported }\end{array}$ \\
\hline Participants & $\begin{array}{l}\text { Country: authors are from France } \\
\text { Inclusion criteria: not reported }\end{array}$ \\
\hline $\begin{array}{l}\text { Exclusion criteria: not reported } \\
\text { Mean age and SD: not reported }\end{array}$ \\
\hline
\end{tabular}

Interventions

1) $17 \beta$-E2 (oral) $4 \mathrm{mg} /$ day, start cycle day 20 , stop day 2 next cycle + follicular assessment on day three.

2) Follicular assessment on day three in two successive menstrual cycles

Outcomes

Value of FSH, $\mathrm{E}_{2}$ and Inhibit B

Ovarian volume

Number of follicles

Size of follicles

Notes

Power calculation performed: unclear

Intention-to-treat analysis performed: unclear

\section{Risk of bias}

Item

Authors' judgement

Description

Oral contraceptive pill, progestogen or estrogen pre-treatment for ovarian stimulation protocols for women undergoing assisted 
Fanchin 2001 (Continued)

\begin{tabular}{|c|c|c|}
\hline Adequate sequence generation? & Unclear & $\begin{array}{l}\text { Quote: 'Women randomly started...' } \\
\text { Method not reported. }\end{array}$ \\
\hline Allocation concealment? & Unclear & Not reported \\
\hline $\begin{array}{l}\text { Blinding? } \\
\text { All outcomes }\end{array}$ & Unclear & Not reported \\
\hline $\begin{array}{l}\text { Incomplete outcome data addressed? } \\
\text { All outcomes }\end{array}$ & Unclear & $\begin{array}{l}\text { Numbers and reasons for withdrawals not } \\
\text { reported. }\end{array}$ \\
\hline Free of selective reporting? & No & $\begin{array}{l}\text { Data on planned outcomes 'follicular de- } \\
\text { velopment' and 'follicular size on day 3' re- } \\
\text { ported. } \\
\text { No other planned outcomes reported, es- } \\
\text { pecially no data on pregnancy rates. (Ab- } \\
\text { stract) }\end{array}$ \\
\hline Free of other bias? & No & $\begin{array}{l}\text { Number of women per group not reported. } \\
\text { Baseline characteristics not reported. }\end{array}$ \\
\hline
\end{tabular}

Fanchin 2003a

Methods

Parallel group study

Number of women randomised: 100 (number of women per group not reported)

Number of withdrawals: 10 (four due to personal reasons and six due to major protocol violation)

Number of women analysed: 90 (47 in study group and 43 in control group)

Duration of study: one IVF-ET cycle, from day 20 of the previous cycle until day of hCG administration (information obtained from contact person)

Participants

Country: authors are from France

Inclusion criteria: (i) age $\leq 38$ years, (ii) regular, ovulatory menstrual cycles every 25 to 35 days, (iii) both ovaries present, (iv) no current or past diseases affecting ovaries or gonadotrophin or sex steroid secretion, clearance or excretion, (v) BMI ranging from 18 to $27 \mathrm{~kg} / \mathrm{m}^{2}$, (vi) no hormone therapy during the past 6 weeks, (vii) adequate visualization of both ovaries in transvaginal ultrasound scans.

Exclusion criteria: not reported

Median age and range

Study group: 33 (26-38)

Control group: 33 (25-38)

Interventions

1) Micronized $17 \beta-\mathrm{E}_{2}$ (oral tablets) $4 \mathrm{mg} /$ day, start cycle day 20 until day two of the next cycle $+\mathrm{rFSH} 225 \mathrm{IU} /$ day (s.c.) on cycle days three to seven $+\mathrm{GnRH}$ antagonist (cetrorelix acetate, s.c.) three $\mathrm{mg}$ single dose when $\geq$ one follicle $>13 \mathrm{~mm}$ in diameter. 2) $\mathrm{rFSH} 225 \mathrm{IU} /$ day (s.c.) on cycle days three to seven + GnRH antagonist (cetrorelix acetate, s.c.) three $\mathrm{mg}$ single dose when $\geq$ one follicle $>13 \mathrm{~mm}$ in diameter

$\mathrm{rFSH}$ dose adjustments according to follicle growth determined by serum $\mathrm{E}_{2}$ levels and

Oral contraceptive pill, progestogen or estrogen pre-treatment for ovarian stimulation protocols for women undergoing assisted 
Fanchin 2003a (Continued)

ultrasound monitoring.

\begin{tabular}{ll}
\hline Outcomes & Days of GnRH antagonist administration \\
& Day of hCG administration \\
& Dose of gonadotrophins \\
& Number of mature follicles \\
& Number of embryos transferred \\
& Clinical pregnancy rates per cycle; presence of a gestational sac with fetal heart activity \\
& at 6 weeks on US scan \\
\hline \multirow{2}{*}{ Notes } & Power calculation performed: yes \\
& Intention-to-treat analysis performed: no \\
\hline
\end{tabular}

Risk of bias

\begin{tabular}{|c|c|c|}
\hline Item & Authors' judgement & Description \\
\hline Adequate sequence generation? & Yes & $\begin{array}{l}\text { Quote: 'Women randomly received...', } \\
\text { '...according to a computer-generated, } \\
\text { blocked randomization list' }\end{array}$ \\
\hline Allocation concealment? & Yes & $\begin{array}{l}\text { Quote: 'Treatment allocation was decided } \\
\text { by an independent person.' }\end{array}$ \\
\hline $\begin{array}{l}\text { Blinding? } \\
\text { All outcomes }\end{array}$ & No & $\begin{array}{l}\text { No blinding, information obtained from } \\
\text { contact person }\end{array}$ \\
\hline $\begin{array}{l}\text { Incomplete outcome data addressed? } \\
\text { All outcomes }\end{array}$ & No & $\begin{array}{l}\text { Only total number of withdrawals re- } \\
\text { ported, not how many per group }\end{array}$ \\
\hline Free of selective reporting? & Unclear & Planned outcomes not reported. \\
\hline Free of other bias? & No & $\begin{array}{l}\text { Number of women randomised per group } \\
\text { not reported, only number of women anal- } \\
\text { ysed per group. } \\
\text { No difference in baseline characteristics } \\
\text { with regard to age, indication for IVF-ET, } \\
\text { duration of infertility, rank of the current } \\
\text { IVF-ET attempt, menstrual cycle length, } \\
\text { day } 3 \text { serum FSH and } E_{2} \text {. }\end{array}$ \\
\hline
\end{tabular}




\begin{tabular}{ll} 
Methods & $\begin{array}{l}\text { Parallel group study } \\
\text { Number of women recruited: } 22\end{array}$ \\
& $\begin{array}{l}\text { Number of women randomised: } 22 \text { (16 in study group, six in control group) } \\
\text { Number of withdrawals: two (in study group, due to spontaneous pregnancies) } \\
\text { Number of women analysed: } 20\end{array}$ \\
\hline Participants & $\begin{array}{l}\text { Country: authors are from Brazil } \\
\text { Inclusion criteria: patients without specific ovulatory dysfunction, aged } \leq 37 \text { years, that }\end{array}$ \\
\hline would be submitted to ovarian stimulation \\
\hline Exclusion criteria: not reported \\
\hline $\begin{array}{l}\text { Mean age and SD: } \\
\text { Study group: } 32.2 \pm 2.1 \\
\text { Control group: } 31.8 \pm 1.9\end{array}$
\end{tabular}

1) Estradiol valerate $4 \mathrm{mg} /$ day for 14 days, start cycle day $21+\mathrm{rFSH} 150-300 \mathrm{IU}$ (fixed dose for 5 days), start post-treatment day $1+\mathrm{GnRH}$ antagonist (ganirelix acetate) 0.25 $\mathrm{mg} /$ day, start when follicular diameter $\geq 15 \mathrm{~mm}$.

2) $\mathrm{GnRH}$ agonist (nafarelin acetate, nasal) $200 \mu \mathrm{g}$ twice daily, start cycle day $21+\mathrm{rFSH}$ 150-300 IU (fixed dose for 5 days), start stimulation day 14

Both rFSH and GnRH analogues are continued until hCG injection (5,000-10,000 IU) , administered when $\geq 2$ follicles are $\geq 17 \mathrm{~mm}$ in diameter

Outcomes

Clinical pregnancy rate; one or more fetal hearts confirmed with US, performed at least 4 weeks after embryo transfer

Ovarian cyst; intraovarian sonolucent structure with a mean diameter of $>14 \mathrm{~mm}$, time

of measurement not reported

OHS syndrome; not defined

Values of LH, estradiol, progesterone

Dose of FSH

Number of collected oocytes

Number of oocytes in metaphase II

Fertilisation rate

Number of transferred embryos

Embryo implantation rate

Gestation rate per embryo transfer

Notes

Power calculation performed: no

Intention-to-treat analysis performed: no

Risk of bias

\begin{tabular}{lll}
\hline Item & Authors' judgement & Description \\
\hline Adequate sequence generation? & Yes & $\begin{array}{l}\text { Randomisation was done by drawing lots } \\
\text { after constructing a table of distribution. } \\
2: 1 \text { randomisation (study:control) }\end{array}$
\end{tabular}


Franco Jr 2003 (Continued)

\begin{tabular}{|c|c|c|}
\hline Allocation concealment? & No & $\begin{array}{l}\text { After drawing lots, the clinicians and the } \\
\text { participants could see in the table to which } \\
\text { treatment they were assigned to }\end{array}$ \\
\hline $\begin{array}{l}\text { Blinding? } \\
\text { All outcomes }\end{array}$ & No & \\
\hline $\begin{array}{l}\text { Incomplete outcome data addressed? } \\
\text { All outcomes }\end{array}$ & Yes & No withdrawals \\
\hline Free of selective reporting? & Unclear & Planned outcomes not reported. \\
\hline Free of other bias? & No & $\begin{array}{l}\text { No significant difference in baseline charac- } \\
\text { teristics with regard to age. No other base- } \\
\text { line characteristics reported }\end{array}$ \\
\hline
\end{tabular}

\section{Hugues 1994}

Methods

Parallel group study

Number of women randomised: 45 (25 in control group, 20 in study group)

Number of withdrawals: not reported

Number of women analysed: not reported

\begin{tabular}{ll}
\hline Participants & $\begin{array}{l}\text { Country: authors are from France } \\
\text { Inclusion criteria: not reported }\end{array}$ \\
\hline Exclusion criteria: not reported \\
\hline Mean age and SD: not reported
\end{tabular}

Interventions

1) Norethisterone $10 \mathrm{mg} /$ day for 10-15 days + GnRH agonist (DTRP6-LHRH) 100 $\mu \mathrm{g} /$ day.

2) GnRH agonist (DTRP6-LHRH) $100 \mu \mathrm{g} /$ day.

Timing of treatments not reported.

\begin{tabular}{ll}
\hline Outcomes & Values of estradiol and progestogen \\
\hline Notes & $\begin{array}{l}\text { Power calculation performed: unclear } \\
\text { Intention-to-treat analysis performed: unclear }\end{array}$ \\
\hline
\end{tabular}

Risk of bias

\begin{tabular}{lll}
\hline Item & Authors' judgement & Description \\
\hline Adequate sequence generation? & Unclear & 'Randomised', method not reported. \\
\hline Allocation concealment? & Unclear & Not reported
\end{tabular}

Oral contraceptive pill, progestogen or estrogen pre-treatment for ovarian stimulation protocols for women undergoing assisted 


\section{Hugues 1994 (Continued)}

\begin{tabular}{l|l|l}
\hline $\begin{array}{l}\text { Blinding? } \\
\text { All outcomes }\end{array}$ & Unclear & Not reported \\
\hline $\begin{array}{l}\text { Incomplete outcome data addressed? } \\
\text { All outcomes }\end{array}$ & Unclear & $\begin{array}{l}\text { Numbers and reasons of withdrawals not } \\
\text { reported. }\end{array}$ \\
\hline $\begin{array}{l}\text { Free of selective reporting? } \\
\text { Free of other bias? }\end{array}$ & No & $\begin{array}{l}\text { Planned outcomes not reported. No data } \\
\text { on pregnancy rates. }\end{array}$ \\
\hline
\end{tabular}

\section{Huirne 2006a}

Methods
Multicentre (8 IVF centres), parallel group study

Number of women recruited: 216

Number of women excluded: 34 (reasons not reported)

Number of women randomised: 182 (91 in study group, 91 in control group)

Number of withdrawals: 22 (10 in study group: one due to hepatitis $\mathrm{B}$, one due to noncompliance, one due to personal reasons, two due to insufficient follicular response, one due to conversion to IUI, one due to absence of mature oocytes, three due to absence of viable embryos; 12 in control group:two due to spontaneous pregnancy, three due to failure of desensitization, one due to personal reasons, one due to stimulation failure, three due to absence of 'mature' oocytes, two due to failure of fertilisation)

Number of women analysed: 182

Participants

Country: authors are from The Netherlands, Belgium, France and Austria

Inclusion criteria: (i) regular IVF/ICSI indication, (ii) a male partner with viable sperm in the ejaculate, (iii) aged between 18 to 39 years.

Exclusion criteria: (i) any previous ART cycles with $<$ three oocytes or $\geq$ three consecutive ART cycles without a clinical pregnancy, (ii) any contraindication to ART, gonadotrophins or OCPs, (iii) a significant systemic disease

Mean age and SD:

Study group: $32.8 \pm 3.8$

Control group: $32.2 \pm 4.2$
1) Combined OCP (ethinyl $E_{2} 30 \mu \mathrm{g}+$ levonorgestrel $150 \mu \mathrm{g}$ ) daily, start within 5 days of onset of menses for 21-28 days (stop on a Sunday) + r-hFSH 150-225 IU/day, start post-treatment day 5 (= stimulation day 1$)+\mathrm{GnRH}$ antagonist (cetrorelix acetate, s.c.) $0.25 \mathrm{mg} /$ day, start stimulation day six.

2) $\mathrm{GnRH}$ agonist (buserelin acetate, s.c.) $500 \mu \mathrm{g} /$ day, start cycle day 18-22 (reducing dose to $200 \mu \mathrm{g} /$ day when down-regulation is achieved) + r-hFSH 150 to $225 \mathrm{IU} /$ day, start when down-regulation is achieved

After five days of r-hFSH-treatment, the dose can be adjusted by steps of 75 IU (maximal dose $450 \mathrm{IU} /$ day), according to the ovarian response

Both r-hFSH and GnRH analogues were continued until hCG injection, administered when the largest follicle reaches a mean diameter of $\geq 18 \mathrm{~mm}$ and $\geq 2$ other follicles had a mean diameter of $\geq 16 \mathrm{~mm}$ 
Huirne 2006a (Continued)

\begin{tabular}{|c|c|c|}
\hline Outcomes & \multicolumn{2}{|c|}{$\begin{array}{l}\text { Ongoing pregnancy rate; positive heart activity at a gestational age of } 12 \text { weeks } \\
\text { Clinical pregnancy rate; presence of one or more fetal sacs with or without heart activity } \\
\text { confirmed with US, performed at least } 4 \text { weeks after embryo transfer } \\
\text { Numbers of oocytes retrieved per patient } \\
\text { Multiple clinical pregnancies } \\
\text { Total number of oocyte retrievals performed on weekends or public holidays } \\
\text { Cancellation rate } \\
\text { Drug requirements } \\
\text { Total number of (good quality) embryos } \\
\text { Implantation rate }\end{array}$} \\
\hline Notes & \multicolumn{2}{|c|}{$\begin{array}{l}\text { Power calculation performed: yes } \\
\text { Intention-to-treat analysis performed: no }\end{array}$} \\
\hline \multicolumn{3}{|l|}{ Risk of bias } \\
\hline Item & Authors' judgement & Description \\
\hline Adequate sequence generation? & Yes & $\begin{array}{l}\text { Quote: ' } 182 \text { were randomly allocated to...', } \\
\text { 'The treatment assigned to each patient was } \\
\text { determined according to a computer-gen- } \\
\text { erated concealed randomization list. Ran- } \\
\text { domization was performed by centre.' }\end{array}$ \\
\hline Allocation concealment? & Unclear & $\begin{array}{l}\text { 'Concealed randomization list', method } \\
\text { not reported. }\end{array}$ \\
\hline $\begin{array}{l}\text { Blinding? } \\
\text { All outcomes }\end{array}$ & Unclear & Not reported \\
\hline $\begin{array}{l}\text { Incomplete outcome data addressed? } \\
\text { All outcomes }\end{array}$ & Yes & Reasons for withdrawals reported. \\
\hline Free of selective reporting? & Unclear & Data on all planned outcomes reported. \\
\hline Free of other bias? & Yes & $\begin{array}{l}\text { No significant difference in baseline char- } \\
\text { acteristics with regard to age, race, duration } \\
\text { of infertility, cause of infertility, smoking } \\
\text { habits, primary infertility, number of previ- } \\
\text { ous ART attempts, number of follicles, en- } \\
\text { dometrial thickness, FSH levels and estra- } \\
\text { diol levels. } \\
\text { P value of BMI is } 0.04 \text {. }\end{array}$ \\
\hline
\end{tabular}


Methods
Academic, Multicentre, parallel group study

Number of women randomised: 64 (32 in study group, 32 in control group)

Number of withdrawals: one (in study group, due to unwillingness to take OCP)

Number of women analysed: 63

Source of funding: Serono Geneva supplied the antide.
Participants
Country: The Netherlands and Belgium

Inclusion criteria: (i) a regular IVF or ICSI indication (i.e. idiopathic infertility after six unsuccessful IUIs, infertility based on a male or tubal factor), (ii) a spontaneous, regular ovulatory menstrual cycle, (iii) two ovaries and a normal uterine cavity, (iv) age 18 to 38 years

Exclusion criteria: (i) $\mathrm{FSH} \geq 12$ IU/L on cycle day two to four (ii) $\mathrm{BMI}>30 \mathrm{~kg} / \mathrm{m}^{2}$, (iii) abnormal gynaecological bleeding, (iv) an extrauterine pregnancy within the last three months, (v) previous ART cycles with < three oocytes or severe OHS syndrome, (vi) any contraindication to receive gonadotrophins or OCP, (vii) PCOS

Mean age and SD:

Study group: $32.3 \pm 4.0$

Control group: $33.3 \pm 3.8$
Interventions
1) Combined OCP (ethinyl estradiol $30 \mu \mathrm{g}+$ levonorgestrel $150 \mu \mathrm{g}$ ) for 14-28 days, start cycle day 2 or $3+\mathrm{rFSH} 150-300 \mathrm{IU}$, start post-treatment day 2 or 3 (= stimulation day 1) + GnRH antagonist (antide) $0.5 \mathrm{mg} / \mathrm{mL}$ daily, start stimulation day 6 .

2) $\mathrm{rFSH} 150-300 \mathrm{IU}$, start on cycle days 2 or 3 (= stimulation day 1$)+\mathrm{GnRH}$ antagonist (antide) $0.5 \mathrm{mg} / \mathrm{mL}$ daily, start on stimulation day 6

rFSH dose adjustments after 5 days of stimulation (up to a maximum of $450 \mathrm{IU}$ ), according to number and size of oocytes and risk for OHS syndrome

Both rFSH and GnRH antagonist are continued until hCG injection (6,500 IU), administered when $\geq 1$ follicle reached a diameter of $\geq 18 \mathrm{~mm}+\geq 2$ follicles reached a diameter of $\geq 16 \mathrm{~mm}$ gestational age of six weeks.

Number of oocytes retrieved

Ovarian cysts; not defined

Number and size of follicles

Cumulative dose of $\mathrm{rFSH}$

Duration of r-FSH treatment

Implantation rates

Serum hormone concentrations

Endometrial thickness

Bleeding pattern

Power calculation performed: yes

Intention-to-treat analysis performed: no

\section{Risk of bias}


Huirne 2006b (Continued)

\begin{tabular}{|c|c|c|}
\hline Adequate sequence generation? & Yes & $\begin{array}{l}\text { Quote: ' } 64 \text { patients were randomly allo- } \\
\text { cated according to a computer-generated, } \\
\text { blocked randomization list. The randomi- } \\
\text { sation was stratified by centre.' }\end{array}$ \\
\hline Allocation concealment? & Yes & $\begin{array}{l}\text { Quote: 'Treatment allocation was decided } \\
\text { by an independent person from an inde- } \\
\text { pendent monitoring company...' }\end{array}$ \\
\hline $\begin{array}{l}\text { Blinding? } \\
\text { All outcomes }\end{array}$ & No & Open label \\
\hline $\begin{array}{l}\text { Incomplete outcome data addressed? } \\
\text { All outcomes }\end{array}$ & Yes & Reason for withdrawal reported. \\
\hline Free of selective reporting? & Yes & Data on all planned outcomes reported. \\
\hline Free of other bias? & Yes & $\begin{array}{l}\text { No significant differences in baseline char- } \\
\text { acteristics with regard to age, BMI, cycle } \\
\text { length, primary infertility, smoking habits, } \\
\text { duration of infertility, type of infertility and } \\
\text { antral follicle count }\end{array}$ \\
\hline
\end{tabular}

\section{Hwang 2004}

Methods

Participants
Single centre, parallel group study

Number of women recruited: 60

Number of women excluded: 4 ( 2 refused to participate, 2 did not meet inclusion criteria) Number of women randomised: 56 (27 in study group, 29 in control group)

Number of withdrawals: 7 ( 2 in study group: 1 due to poor ovarian response, 1 due to personal reasons; 5 in control group: 2 due to inadequate ovarian response, 3 due to risk of severe OHS syndrome)

Number of women analysed: 49

\section{Country: Taiwan}

Inclusion criteria: polycystic ovary syndrome.

Exclusion criteria: (i) diagnosis of congenital adrenal hyperplasia, Cushing's syndrome, androgen-producing tumours, hyperprolactinaemia or thyroid dysfunction, (ii) age $>38$ years, (iii) serum FSH levels $>12 \mathrm{mIU} / \mathrm{mL}$

Mean age and SD:

Study group: $31.4 \pm 3.5$

Control group: $31.7 \pm 3.7$

Interventions

1) Combined OCP (Diane-35, oral) on cycle days five to 25 for 3 consecutive cycles + $\mathrm{GnRH}$ antagonist (cetrorelix acetate, s.c.) $0.25 \mathrm{mg}$ single dose on post-treatment day 3 , $0.125 \mathrm{mg} /$ day on post-treatment days four to nine, and $0.25 \mathrm{mg} /$ day start post-treatment day $10+$ hMG 150 IU/day, start post-treatment day four.

2) GnRH agonist (buserelin acetate, long protocol) $500 \mu \mathrm{g} /$ day start day three of induced 
or spontaneous menstruation, and $250 \mu \mathrm{g} /$ day start day of ensuing pituitary down regulation + hMG $150 \mathrm{IU} /$ day for six days start when pituitary down regulation is achieved

hMG dose can be adjusted according to patient's follicular response

Pituitary down regulation is achieved when serum $\mathrm{E}_{2}$ levels are $<50 \mathrm{pg} / \mathrm{mL}$ and there is an absence of ovarian cysts $>10 \mathrm{~mm}$ in diameter

Both GnRH analogues and hMG are continued until hCG injection (10,000 IU, IM), administered when $\geq 2$ follicles reached $18 \mathrm{~mm}$ in diameter with adequate $\mathrm{E}_{2}$ response.

$\begin{array}{ll}\text { Outcomes } & \text { Fertilisation } \\ \text { Clinical pregnancy; presence of one or more fetal hearts confirmed with US, performed } \\ \text { 7 weeks after embryo transfer } \\ \text { Implantation rates } \\ \text { Serum LH and testosterone status upon starting and during hMG administration } \\ \text { Total days and amount of gonadotrophins administered; measured in ampoules } \\ \text { Pregnancy loss } \\ \text { Multiple pregnancy rate; ongoing or live born } \\ \text { OHS syndrome; not defined }\end{array}$

Notes

Power calculation performed: yes

Intention-to-treat analysis performed: no

\section{Risk of bias}

\begin{tabular}{|c|c|c|}
\hline Item & Authors' judgement & Description \\
\hline Adequate sequence generation? & Yes & $\begin{array}{l}\text { Quote: 'Randomization was done by open- } \\
\text { ing sealed envelopes containing computer- } \\
\text { generated block randomization numbers } \\
\text { with a block size of } 10 \text {.' }\end{array}$ \\
\hline Allocation concealment? & Yes & Sealed envelopes \\
\hline $\begin{array}{l}\text { Blinding? } \\
\text { All outcomes }\end{array}$ & Yes & $\begin{array}{l}\text { Quote: 'The laboratory staff were blinded } \\
\text { to the stimulation protocol.' Unclear if } \\
\text { treating physicians were blinded }\end{array}$ \\
\hline $\begin{array}{l}\text { Incomplete outcome data addressed? } \\
\text { All outcomes }\end{array}$ & Yes & $\begin{array}{l}\text { Reasons for withdrawals reported. Slight } \\
\text { imbalance in numbers of withdrawal due } \\
\text { to risk of severe OHS syndrome: } 0 \text { in study } \\
\text { group and three in control group }\end{array}$ \\
\hline Free of selective reporting? & Yes & Data on all planned outcomes is reported. \\
\hline Free of other bias? & Unclear & $\begin{array}{l}\text { No significant difference in baseline char- } \\
\text { acteristics with regard to age, duration of } \\
\text { infertility, BMI and hormonal levels }\end{array}$ \\
\hline
\end{tabular}

Oral contraceptive pill, progestogen or estrogen pre-treatment for ovarian stimulation protocols for women undergoing assisted 
Methods

Interventions

Notes

\section{Participants}

Parallel group study

Number of women randomised: 82 (27 in 'combined OCP + GnRH antagonist' group; 27 in $\mathrm{GnRH}$ antagonist group; and 28 in $\mathrm{GnRH}$ agonist group).

Number of withdrawals: 0

Number of women analysed: 82

Duration of study: follow up until 12th week of pregnancy (information obtained from author)

Country: authors are from South Korea

Inclusion criteria: patients who were defined as low responders (defined as patients with repeated high basal serum levels of FSH $>8.5 \mathrm{IU} / \mathrm{L}$ and/or total basal antral follicle count of $\leq$ five), aged 28 to 42 years

Exclusion criteria: not reported

Mean age and $\mathrm{SD}$ :

combined OCP + GnRH antagonist group: $35.0 \pm 3.4$

GnRH antagonist group: $34.8 \pm 3.2$

GnRH agonist group: $35.8 \pm 3.1$

Poor response: Yes

1) Combined $\mathrm{OCP}+\mathrm{GnRH}$ antagonist $+\mathrm{rFSH}$

2) $\mathrm{GnRH}$ antagonist $+\mathrm{rFSH}$

3) $\mathrm{GnRH}$ agonist (low dose, long protocol) $+\mathrm{rFSH}$

Live births

Clinical pregnancy rate; presence of an intrauterine gestational sac confirmed with US performed four weeks after oocyte retrieval

Ongoing pregnancy rate; evidence of a gestational sac with fetal heart motion at 12 weeks of later confirmed with US

Total dose and duration of rhFSH

Number of mature oocytes

Fertilisation rate

Number of grade I, II embryos

Miscarriage rate

Multiple pregnancy rate

Power calculation performed: yes

Intention-to-treat analysis performed: yes

\section{Risk of bias}

\begin{tabular}{|c|c|c|}
\hline Item & Authors' judgement & Description \\
\hline Adequate sequence generation? & Yes & $\begin{array}{l}\text { 'Randomized', computerised allocation } \\
\text { (information obtained from author) }\end{array}$ \\
\hline Allocation concealment? & Unclear & Not reported \\
\hline $\begin{array}{l}\text { Blinding? } \\
\text { All outcomes }\end{array}$ & No & This trial was not blinded \\
\hline
\end{tabular}

Oral contraceptive pill, progestogen or estrogen pre-treatment for ovarian stimulation protocols for women undergoing assisted 
Kim 2005 (Continued)

\begin{tabular}{lll}
\hline $\begin{array}{l}\text { Incomplete outcome data addressed? } \\
\text { All outcomes }\end{array}$ & Unclear & $\begin{array}{l}\text { Number and reasons of withdrawals not re- } \\
\text { ported. }\end{array}$ \\
\hline $\begin{array}{l}\text { Free of selective reporting? } \\
\text { Free of other bias? }\end{array}$ & Unclear & Planned outcomes not reported. \\
\hline
\end{tabular}

Kolibianakis 2006

Methods

Acadamic, single centre, parallel group study

Number of women randomised: 504 (250 in study group, 254 in control group)

Number of withdrawals: 79 (36 in study group: 28 due to personal reasons, six due to abnormal steroid levels, two due to spontaneous pregnancy; 43 in control group:

31 due to personal reasons, 10 due to abnormal steroid levels, two due to spontaneous pregnancy)

Number of women analysed: 425

Duration of study: three years of recruitment

Source of funding: the Fund for Scientific Research Flanders

\begin{tabular}{|c|c|}
\hline Participants & $\begin{array}{l}\text { Country: Belgium } \\
\text { Inclusion criteria: (i) age }<39 \text { years, (ii) } \leq \text { three previous ART attempts, (iii) BMI 18- } \\
29 \mathrm{~kg} / \mathrm{m}^{2}, \text { (iv) levels of } \mathrm{FSH}<10 \mathrm{IU} / \mathrm{L},(\mathrm{v}) \text { levels of } \mathrm{LH}<10 \mathrm{IU} / \mathrm{L} \\
\text { Exclusion criteria: (i) polycystic ovaries, (ii) endometriosis }>\text { stage II, (iii) poor response } \\
\text { to ovarian stimulation } \\
\text { Mean age and SD: } \\
\text { Study group: } 31.2 \pm 0.3 \\
\text { Control group: } 31.5 \pm 0.3\end{array}$ \\
\hline
\end{tabular}

Interventions

1) Combined OCP (ethinyl estradiol $30 \mu \mathrm{g}+$ desogestrel $150 \mu \mathrm{g}$ ) for 14 days, start cycle day one + rFSH $200 \mathrm{IU} /$ day (fixed dose), start post-treatment day $5+\mathrm{GnRH}$ antagonist (ganirelix acetate)

2) $\mathrm{rFSH} 200 \mathrm{IU} /$ day (fixed dose), start cycle day $2+\mathrm{GnRH}$ antagonist (ganirelix acetate) Timing of GnRH antagonist not reported.

Both rFSH and GnRH antagonist are continued until hCG injection (10,000 IU), administered when $\geq 3$ follicles $\geq 17 \mathrm{~mm}$ in diameter

Outcomes

Ongoing pregnancies per started cycle; developing beyond 12 weeks

Stimulation length

Gonadotrophin consumption

Early pregnancy loss; the proportion of patients with initially positive hCG in whom pregnancy failed to develop before 12 weeks of gestation

Notes

Power calculation performed: yes

Intention-to-treat analysis performed: no

Oral contraceptive pill, progestogen or estrogen pre-treatment for ovarian stimulation protocols for women undergoing assisted 
Kolibianakis 2006

(Continued)

\section{Risk of bias}

\begin{tabular}{|c|c|c|}
\hline Item & Authors' judgement & Description \\
\hline Adequate sequence generation? & Yes & $\begin{array}{l}\text { Quote: 'Randomized on the basis of a com- } \\
\text { puter-generated list' }\end{array}$ \\
\hline Allocation concealment? & No & $\begin{array}{l}\text { Quote: '... randomised at the outpatient } \\
\text { clinic by the treating physician.', 'The se- } \\
\text { quence of allocation was not concealed and } \\
\text { thus it was possible for the treating physi- } \\
\text { cian to be aware of the next treatment to } \\
\text { be allocated.' }\end{array}$ \\
\hline $\begin{array}{l}\text { Blinding? } \\
\text { All outcomes }\end{array}$ & No & $\begin{array}{l}\text { Not reported, but treating physician is not } \\
\text { blinded as this was the person to allocate } \\
\text { the participants }\end{array}$ \\
\hline $\begin{array}{l}\text { Incomplete outcome data addressed? } \\
\text { All outcomes }\end{array}$ & Yes & Reasons for withdrawals reported. \\
\hline Free of selective reporting? & Yes & Data on all planned outcomes reported. \\
\hline Free of other bias? & Yes & $\begin{array}{l}\text { No significant differences in baseline char- } \\
\text { acteristics with regard to age, BMI, pri- } \\
\text { mary/secondary infertility, duration of in- } \\
\text { fertility, number of previous IVF trials, in- } \\
\text { dication for treatment }\end{array}$ \\
\hline
\end{tabular}

Obruca 2001

Methods

Parallel group study

Number of women randomised: 150 (75 in study group, 75 in control group)

Number of withdrawals: not reported

Number of women analysed: unclear

\begin{tabular}{ll} 
Participants & $\begin{array}{l}\text { Country: authors are from Austria } \\
\text { Inclusion criteria: patients undergoing COS and IVF }\end{array}$ \\
\hline Exclusion criteria: not reported \\
\hline Mean age and SD: not reported
\end{tabular}

Interventions

1) Combined OCP (ethinyl oestradiol $30 \mu \mathrm{g}+$ desogestrel $150 \mu \mathrm{g}$ ) daily, start cycle day one for 18 to 28 days (stop on a Sunday) + rFSH $150 \mathrm{IU} /$ day, start post-treatment day five (= stimulation day one) $+\mathrm{GnRH}$ antagonist (cetrorelix acetate) $0.25 \mathrm{mg} / \mathrm{day}$, start stimulation day six.

2) $\mathrm{rFSH} 150 \mathrm{IU} /$ day, start cycle day three (= stimulation day 1$)+\mathrm{GnRH}$ antagonist (cetrorelix acetate) $0.25 \mathrm{mg} /$ day, start stimulation day six

Both rFSH and GnRH antagonist are continued until final follicular maturation

Oral contraceptive pill, progestogen or estrogen pre-treatment for ovarian stimulation protocols for women undergoing assisted 
Obruca 2001 (Continued)

\begin{tabular}{|c|c|c|}
\hline Outcomes & \multicolumn{2}{|c|}{$\begin{array}{l}\text { Number of cancelled cycles } \\
\text { Number of oocytes } \\
\text { Number of transferred embryos } \\
\text { Clinical pregnancy rate; not defined } \\
\text { Number of weekend oocyte retrievals }\end{array}$} \\
\hline Notes & \multicolumn{2}{|c|}{$\begin{array}{l}\text { Power calculation performed: unclear } \\
\text { Intention-to-treat analysis performed: unclear }\end{array}$} \\
\hline \multicolumn{3}{|l|}{ Risk of bias } \\
\hline Item & Authors' judgement & Description \\
\hline Adequate sequence generation? & Unclear & 'Randomized', method not reported. \\
\hline Allocation concealment? & Unclear & Not reported \\
\hline $\begin{array}{l}\text { Blinding? } \\
\text { All outcomes }\end{array}$ & Unclear & Not reported \\
\hline $\begin{array}{l}\text { Incomplete outcome data addressed? } \\
\text { All outcomes }\end{array}$ & Unclear & $\begin{array}{l}\text { Number and reasons for withdrawals not } \\
\text { reported. }\end{array}$ \\
\hline Free of selective reporting? & Unclear & Planned outcomes not reported. \\
\hline Free of other bias? & No & $\begin{array}{l}\text { No data on baseline characteristics re- } \\
\text { ported. }\end{array}$ \\
\hline
\end{tabular}

Raoofi 2008

\begin{tabular}{ll} 
Methods & Academic, single centre, parallel group study. \\
& Number of women randomised: 54 women (number of women per group not reported) \\
Number of withdrawals: three women were excluded due to incomplete data & Number of women analysed: 51 \\
& $\begin{array}{l}\text { Duration of study: one year of recruitment } \\
\text { Source of funding: Yazd IVF centre, Yazd, Iran }\end{array}$ \\
\hline Participants & $\begin{array}{l}\text { Country: Iran } \\
\text { Inclusion criteria: patients who were undergoing IVF and ICSI }\end{array}$ \\
\hline Exclusion criteria: not reported \\
\hline Mean age and SD: \\
Study group: $31.48 \pm 5.82$ \\
Control group: $35.27 \pm 4.13$
\end{tabular}

Interventions

1) Combined OCP (ethinyl estradiol $30 \mu \mathrm{g}+$ desogestrel $150 \mu \mathrm{g}$ ), on cycle days one to $14+\mathrm{GnRH}$ agonist (triptorelin acetate depot i.m.) $3.75 \mathrm{mg}$ single dose on posttreatment day one + hMG (75 IU FSH + 75 IU LH), start post-treatment day 2 
2) GnRH agonist (triptorelin acetate depot IM) $3.75 \mathrm{mg}$ single dose on cycle day one + hMG (75 IU FSH + 75 IU LH), start cycle day one

\begin{tabular}{|c|c|c|}
\hline Outcomes & \multicolumn{2}{|c|}{$\begin{array}{l}\text { Cyst formation }>28 \mathrm{~mm} \text {; measured seven and } 14 \text { days after pituitary suppression } \\
\text { Number of follicles } \\
\text { Number of oocytes retrieved } \\
\text { Implantation rate } \\
\text { Clinical pregnancy rate; presence of one or more fetal hearts confirmed with US per- } \\
\text { formed at least } 4 \text { weeks after embryo transfer }\end{array}$} \\
\hline Notes & \multicolumn{2}{|c|}{$\begin{array}{l}\text { Power calculation performed: no } \\
\text { Intention-to-treat analysis performed: unclear }\end{array}$} \\
\hline \multicolumn{3}{|l|}{ Risk of bias } \\
\hline Item & Authors' judgement & Description \\
\hline Adequate sequence generation? & Unclear & $\begin{array}{l}\text { 'Randomized allocation method', method } \\
\text { not reported. }\end{array}$ \\
\hline Allocation concealment? & Unclear & Not reported \\
\hline $\begin{array}{l}\text { Blinding? } \\
\text { All outcomes }\end{array}$ & Unclear & Not reported \\
\hline $\begin{array}{l}\text { Incomplete outcome data addressed? } \\
\text { All outcomes }\end{array}$ & No & $\begin{array}{l}\text { Quote: 'Three patients were excluded from } \\
\text { the study because of incomplete data.' }\end{array}$ \\
\hline Free of selective reporting? & Unclear & Planned outcomes not reported. \\
\hline Free of other bias? & No & $\begin{array}{l}\text { Number of women per group not reported. } \\
\text { Quote: 'The etiology and duration of in- } \\
\text { fertility were equally distributed among the } \\
\text { groups.' No table of characteristics avail- } \\
\text { able }\end{array}$ \\
\hline
\end{tabular}

Rombauts 2006

Methods

Multicentre (ten IVF centres), parallel group study

Number of women randomised: 351 (117 per treatment group)

Number of withdrawals: 19 (five due to spontaneous pregnancy: two in OCP group and three in GnRH-antagonist group). Other reasons not reported.

Number of women analysed: 332 (111 in OCP group, 110 in GnRH-antagonist group and 111 in GnRH-agonist group)

Participants

Country: Australia, Denmark, Jordan and Norway.

Inclusion criteria: (i) healthy females of infertile couples, (ii) age 18-39 years, (iii) BMI $\overline{\text { between } 18-29 \mathrm{~kg}} / \mathrm{m}^{2}$, (iv) body weight $\leq 90 \mathrm{~kg}$, (v) a normal menstrual cycle with a 
Rombauts 2006 (Continued)

range of 24-35 days and an intra-individual variation of \pm 3 days

Exclusion criteria: (i) contraindications for the use of gonadotrophins, (ii) endocrine abnormalities (e.g. PCOS), (iii) > 3 unsuccessful controlled ovarian stimulation cycles, (iv) history of low or no ovarian response during FSH/hMG treatment, (v) clinically relevant abnormal laboratory values (including hormones) or medical examination findings

Mean age and SD:

OCP group: $32.7 \pm 3.9$

GnRH-antagonist group: $32.1 \pm 3.7$

GnRH-agonist group: $32.2 \pm 4.0$

Interventions

1) Combined OCP (ethinyl oestradiol $30 \mu \mathrm{g}+$ desogestrel $150 \mu \mathrm{g}$ ) daily, start cycle day one for 14-28 days (depending on the planned start of rFSH treatment) $+\mathrm{rFSH}$ (follitropin beta, s.c.) $200 \mathrm{IU} /$ day, start post-treatment day two (= stimulation day 1) + GnRH antagonist (ganirelix acetate, s.c.) $0.25 \mathrm{mg} /$ day, start stimulation day 5 or 6 .

2) $\mathrm{rFSH}$ (follitropin beta, s.c.) $200 \mathrm{IU} /$ day, start cycle day two or three (= stimulation day one) $+\mathrm{GnRH}$ antagonist (ganirelix acetate, s.c.) $0.25 \mathrm{mg} /$ day, start stimulation day five or six.

3) $\mathrm{GnRH}$ agonist (nafarelin acetate, intranasal) $0.8 \mathrm{mg} /$ day, start cycle day 21 to $24+$ rFSH (follitropin beta, s.c.) 200 IU/day, start when down regulation (i.e. serum estradiol $\leq 50 \mathrm{pg} / \mathrm{ml}$ ) is achieved (after 2-4 weeks of GnRH agonist treatment)

After five to six days of rFSH treatment, the dose could be adjusted depending on the ovarian response as assessed by ultrasound

rFSH and GnRH analogues are both continued until hCG injection (10,000 IU, s.c. or $\mathrm{IM}$ ), administered when $\geq$ three follicles $\geq 17 \mathrm{~mm}$ in diameter, or $\geq$ one follicle $\geq 20$ $\mathrm{mm}$ in diameter

Outcomes

Ongoing pregnancy rate; assessed by US at $\geq 12$ to 16 weeks

Number of cumulus-oocyte complexes

Number of grade one or two embryos

Number and size of follicles

Serum hormone values

Duration of $\mathrm{rFSH}$ treatment

Total rFSH dose

Number of good quality embryos

Implantation rate

Incidences of $\mathrm{LH}$ rises

Pregnancy loss

OHS syndrome; according to WHO classification

Intention-to-treat analysis performed: no

\section{Risk of bias}

\begin{tabular}{lll} 
Item & Authors' judgement & Description \\
\hline Adequate sequence generation? & Unclear & $\begin{array}{l}\text { Quote: 'The subjects were randomly as- } \\
\text { signed...' 'To improve balance, the random- } \\
\text { ization of subjects to treatment was strati- }\end{array}$
\end{tabular}

Oral contraceptive pill, progestogen or estrogen pre-treatment for ovarian stimulation protocols for women undergoing assisted 
fied for type of infertility (primary or secondary), IVF or ICSI, centre, and age.'

Method not reported.

\begin{tabular}{l|ll}
\hline Allocation concealment? & Yes & Quote: '...by central remote allocation.' \\
\hline $\begin{array}{l}\text { Blinding? } \\
\text { All outcomes }\end{array}$ & No & Open-label study \\
\hline
\end{tabular}

\begin{tabular}{l|l|l}
\hline $\begin{array}{l}\text { Incomplete outcome data addressed? } \\
\text { All outcomes }\end{array}$ & No & $\begin{array}{l}\text { No reasons for 14 withdrawals reported. } \\
\text { Also unclear how many withdrawals per } \\
\text { group }\end{array}$ \\
\hline Free of selective reporting? & Yes & Data on all planned outcomes reported. \\
\hline Free of other bias? & Unclear & $\begin{array}{l}\text { No differences in baseline characteristics } \\
\text { with regard to age, BMI, height and weight. } \\
\text { Other characteristics reported in table, but } \\
\text { no P values given }\end{array}$ \\
\hline
\end{tabular}

\section{Salat-Baroux 1988}

\begin{tabular}{|c|c|}
\hline Methods & $\begin{array}{l}\text { Parallel group study. } \\
\text { Four study arms (A1+A2 and B1+B2), of which we can only include two study arms (A2 } \\
\text { and B2) } \\
\text { Number of women randomised: } 42 \text { ( } 21 \text { in study group (A2), } 21 \text { in control group (B2)) } \\
\text { Number of withdrawals: } 13 \text { (eight in study group: three due to poorly followed treatment, } \\
\text { one due to inadequate response, two due to spontaneous ovulation, two due to other } \\
\text { reasons; five in control group: one due to ovarian cyst, four due to inadequate response) } \\
\text { Number of women analysed: } 29 \\
\text { Duration of study: seven months of recruitment }\end{array}$ \\
\hline Participants & $\begin{array}{l}\text { Country: authors are from France } \\
\text { Inclusion criteria: infertile patients scheduled for IVF treatment, aged }<38 \text { years } \\
\text { Exclusion criteria: not reported } \\
\text { Mean age and } S D \text { : } \\
\text { Study group }(\mathrm{A} 1+\mathrm{A} 2): 32.8 \pm 0.7 \\
\text { Control group }(\mathrm{B} 1+\mathrm{B} 2): 31.7 \pm 0.5\end{array}$ \\
\hline Interventions & $\begin{array}{l}\text { 1) Progestogen (ethynodiol acetate) } 2 \mathrm{mg} \text { twice daily for } 11 \text { to } 17 \text { days, start cycle day } \\
15+\text { pure FSH four ampoules on post-treatment days six to seven and two ampoules on } \\
\text { post-treatment days eight to nine }+ \text { hMG ( } 75 \mathrm{IU} \text { FSH }+75 \mathrm{IU} \mathrm{LH} \text { ) two ampoules on } \\
\text { post-treatment days } 10 \text { to } 11 \\
\text { 2) Pure FSH four ampoules on cycle days tow to three and two ampoules on cycle days } \\
\text { four to five + hMG ( } 75 \mathrm{IU} \text { FSH + } 75 \mathrm{IU} \mathrm{LH}) \text { when needed } \\
\text { FSH and GnRH agonist are both continued until hCG injection (10,000 IU), admin- } \\
\text { istration depending on follicular maturity }\end{array}$ \\
\hline
\end{tabular}


Salat-Baroux 1988 (Continued)

\begin{tabular}{|c|c|c|}
\hline Outcomes & \multicolumn{2}{|c|}{$\begin{array}{l}\text { Clinical pregnancy rate; not defined } \\
\text { Pregnancy loss } \\
\text { Day of hCG } \\
\text { Values of } E_{2} \text { and P on day of hCG } \\
\text { Number of oocytes recovered, cleaved or replaced }\end{array}$} \\
\hline Notes & \multicolumn{2}{|c|}{$\begin{array}{l}\text { Power calculation performed: no } \\
\text { Intention-to-treat analysis performed: no }\end{array}$} \\
\hline \multicolumn{3}{|l|}{ Risk of bias } \\
\hline Item & Authors' judgement & Description \\
\hline Adequate sequence generation? & Unclear & 'Randomized', method not reported. \\
\hline Allocation concealment? & Unclear & Not reported \\
\hline $\begin{array}{l}\text { Blinding? } \\
\text { All outcomes }\end{array}$ & Unclear & Not reported \\
\hline $\begin{array}{l}\text { Incomplete outcome data addressed? } \\
\text { All outcomes }\end{array}$ & Yes & $\begin{array}{l}\text { Reasons for } 11 \text { withdrawals reported. Rea- } \\
\text { sons for } 2 \text { withdrawals unclear. With- } \\
\text { drawals due to inadequate response slightly } \\
\text { imbalanced: } 4 \text { in control group, } 1 \text { in study } \\
\text { group }\end{array}$ \\
\hline Free of selective reporting? & Unclear & Planned outcomes not reported. \\
\hline Free of other bias? & Unclear & $\begin{array}{l}\text { Baseline characteristics reported in table, } \\
\text { but no P values given. Data only reported } \\
\text { on the total number of women in group A } \\
\text { and the total in group B } \\
\text { Slight differences in treatment proto- } \\
\text { col. Control group received hMG when } \\
\text { needed, study group received hMG ( } 2 \text { am- } \\
\text { poules) on day } 10 \text { and } 11 \text {. In study group } \\
\text { hCG was injected on day } 12 \text {, in control } \\
\text { group this day was variable }\end{array}$ \\
\hline
\end{tabular}


Methods

Participants
Parallel group study.

Number of women randomised: 49 (number of women per group not reported; 22 cycles in study group, 29 cycles in control group)

Number of withdrawals: 11 cycles (eight in control group: three due to conversion to IUI, one due to poor response, two due to failed fertilisation, two due to risk of OHS syndrome; three in study group: two due to poor response, one due to failure of embryo cleavage)

Number of women analysed: unclear

Duration of study: eight months of recruitment

Country: authors are from the United Kingdom

Inclusion criteria: patients who underwent IVF treatment cycles and had an ovarian cyst $>15 \mathrm{~mm}$ in diameter or an endometrial thickness $>5 \mathrm{~mm}$ and serum $\mathrm{E}_{2}$ concentration $>100 \mathrm{pmol} / \mathrm{L}$ after 14 days of $\mathrm{GnRH}$ agonist (buserelin acetate) treatment.

Exclusion criteria: relevant uterine or ovarian pathology

Mean age and SEM:

Study group: $36.0 \pm 0.86$

Control group: $35.72 \pm 0.69$
1) GnRH agonist (buserelin acetate) $500 \mu \mathrm{g}$ daily start cycle day two or three + P (IM injection) $100 \mathrm{mg}$ single dose on cycle day 16 or $17+\mathrm{hMG}$, start when serum $\mathrm{E}_{2}$ concentration $\leq 100 \mathrm{pmol} / \mathrm{L}$

2) $\mathrm{GnRH}$ agonist (buserelin acetate) $500 \mu \mathrm{g}$ daily, start cycle day 2 or $3+\mathrm{hMG}$, start when serum $\mathrm{E}_{2}$ concentration $\leq 100 \mathrm{pmol} / \mathrm{L}$

hMG start dose according to women's age, baseline serum FSH level, response to stimulation in previous treatment cycles

hMG and GnRH agonist are both continued until hCG injection (10,000 IU), administered when 3 follicles $\geq 18 \mathrm{~mm}$ in diameter
Outcomes
Clinical pregnancy rate; not defined

Serum $E_{2}$ levels on day of recruitment

Number of days of hMG administration

Number of days of GnRH agonist

Endometrial thickness

Mean diameter of ovarian cyst on day of recruitment and 6 days later

Total number of hMG ampoules

Number of follicles

Number of oocytes retrieved

Number of embryos transferred

Power calculation performed: no

Intention-to-treat analysis performed: unclear 
Shaker 1995 (Continued)

\begin{tabular}{|c|c|c|}
\hline Adequate sequence generation? & Yes & $\begin{array}{l}\text { Quote: 'Randomization was done by draw- } \\
\text { ing sequentially labelled sealed envelops, } \\
\text { each containing a number obtained from a } \\
\text { table of random numbers.' }\end{array}$ \\
\hline Allocation concealment? & Yes & Sealed envelopes \\
\hline $\begin{array}{l}\text { Blinding? } \\
\text { All outcomes }\end{array}$ & Unclear & Not reported \\
\hline $\begin{array}{l}\text { Incomplete outcome data addressed? } \\
\text { All outcomes }\end{array}$ & Yes & $\begin{array}{l}\text { Reasons for withdrawals reported. } \\
\text { two women in control were excluded due } \\
\text { to risk of OHS syndrome, none in study } \\
\text { group }\end{array}$ \\
\hline Free of selective reporting? & Yes & Data on all planned outcomes reported. \\
\hline Free of other bias? & No & $\begin{array}{l}\text { Only number of cycles per treatment group } \\
\text { known, number of women per group not } \\
\text { reported. } \\
\text { No significant differences in baseline char- } \\
\text { acteristics between groups with regard to } \\
\text { age, length of infertility, number of previ- } \\
\text { ous IVF cycles and cause of infertility. Data } \\
\text { only reported on the number of cycles per } \\
\text { group, not on the number of women }\end{array}$ \\
\hline
\end{tabular}

Tan 2001

\begin{tabular}{ll} 
Methods & $\begin{array}{l}\text { Parallel group study. } \\
\text { Number of women randomised: } 117 \text { (number of women per group not reported) } \\
\text { Number of withdrawals: not reported } \\
\text { Number of women analysed: unclear }\end{array}$ \\
\hline Participants & $\begin{array}{l}\text { Country: authors are from Canada } \\
\text { Inclusion criteria: not reported }\end{array}$ \\
\hline Exclusion criteria: not reported \\
\hline Mean age and SD: not reported
\end{tabular}

Interventions

1) Progestogen (norethindrone) for five days, start cycle day one $+\mathrm{GnRH}$ agonist, start cycle day two.

2) GnRH agonist. Timing of treatment not reported.

Outcomes

Cyst formation

Time required to achieve pituitary suppression

Implantation rate

Pregnancy rate

Oral contraceptive pill, progestogen or estrogen pre-treatment for ovarian stimulation protocols for women undergoing assisted 
Tan 2001 (Continued)

\begin{tabular}{l|ll}
\hline Notes & $\begin{array}{l}\text { Power calculation performed: unclear } \\
\text { Intention-to-treat analysis used: unclear }\end{array}$ \\
\hline Risk of bias & Authors' judgement & Description \\
\hline Item & Unclear & Method not reported \\
\hline Adequate sequence generation? & Unclear & Not reported \\
\hline Allocation concealment? & Unclear & Not reported \\
\hline $\begin{array}{l}\text { Blinding? } \\
\text { All outcomes }\end{array}$ & Unclear & No data reported \\
\hline $\begin{array}{l}\text { Incomplete outcome data addressed? } \\
\text { All outcomes }\end{array}$ & No & $\begin{array}{l}\text { No data reported, especially no data on } \\
\text { pregnancy rates. }\end{array}$ \\
\hline Free of selective reporting? & Unclear & Unclear \\
\hline Free of other bias?
\end{tabular}

Wang 2008

Methods

Academic, single centre, cross-over study.

Crossover design: 20 women were treated with GnRH antagonist in the first cycle and with OCP + GnRH agonist in a second cycle.

Number of women randomised: 121 (58 in study group, 63 in control group)

Number of withdrawals: unclear

Number of women analysed: unclear

Participants

Country: authors are from China

Inclusion criteria: not reported

Exclusion criteria: not reported

Mean age and SD:

Study group: $35.27 \pm 4.76$

Control group: $35.53 \pm 4.21$

Poor response: yes

Interventions

1) Combined OCP + GnRH agonist

2) GnRH antagonist

Timing and dosage of treatments unclear.

Outcomes

Clinical pregnancy rate per embryo transfer; not defined

Ampoules of gonadotrophins

Time of Gn

Number of oocytes retrieved

Number of embryos transferred

Oral contraceptive pill, progestogen or estrogen pre-treatment for ovarian stimulation protocols for women undergoing assisted 


\begin{tabular}{l|ll}
\hline Notes & $\begin{array}{l}\text { Power calculation performed: unclear } \\
\text { Intention-to-treat analysis performed: unclear }\end{array}$ \\
\hline Risk of bias & Authors' judgement & Description \\
\hline Item & Unclear & Method not reported \\
\hline Adequate sequence generation? & Unclear & Not reported \\
\hline Allocation concealment? & Unclear & Not reported \\
\hline $\begin{array}{l}\text { Blinding? } \\
\text { All outcomes }\end{array}$ & Unclear & No data reported \\
\hline $\begin{array}{l}\text { Incomplete outcome data addressed? } \\
\text { All outcomes }\end{array}$ & Unclear & No data reported \\
\hline \begin{tabular}{l} 
Free of selective reporting? \\
\hline Free of other bias?
\end{tabular} & Unclear & Unclear \\
\hline
\end{tabular}

\section{Characteristics of excluded studies [ordered by study ID]}

\begin{tabular}{|c|c|}
\hline Study & Reason for exclusion \\
\hline al-Mizyen 2000 & No randomised controlled trial. Retrospective study. \\
\hline Anderson 1990 & $\begin{array}{l}\text { No randomised controlled trial. The women only received controlled ovarian stimulation, but no embryo } \\
\text { transfer as part of an ART cycle }\end{array}$ \\
\hline Bellver 2007 & No randomised controlled trial. Retrospective study. \\
\hline Benadiva 1988 & No randomised controlled trial. \\
\hline Bendikson 2006 & No randomised controlled trial. Retrospective study. \\
\hline Biljan 1998b & No randomised controlled trial. Retrospective study. Each patient served as her own control \\
\hline Branigan 1998 & No randomised controlled trial. Each woman served as her own control \\
\hline Brodt 1993 & No randomised controlled trial. Single arm study. \\
\hline Chung 2006 & $\begin{array}{l}\text { No randomised controlled trial. Retrospective study. } \\
\text { Monophasic OCP versus triphasic OCP. }\end{array}$ \\
\hline
\end{tabular}


(Continued)

\begin{tabular}{|c|c|}
\hline Cohen 1987 & No randomised controlled trial. \\
\hline Copperman 2003 & No randomised controlled trial. \\
\hline Couzinet 1995 & No randomised controlled trial. Naltrexon used in treatment protocol \\
\hline Cédrin-Durnerin 1995 & No randomised controlled trial. \\
\hline Damario 1997 & No randomised controlled trial. Retrospective study. \\
\hline Davy 2004 & Compares different durations of combined OCP pre-treatment. \\
\hline De Ziegler 1999 & No randomised controlled trial. Open single-arm study. \\
\hline Dickey 2001 & No randomised controlled trial. Retrospective study. \\
\hline Ditkoff 1997 & No randomised controlled trial. \\
\hline Doody 2001 & $\begin{array}{l}\text { No randomised controlled trial. The women in the study are oocyte donors. Compares different durations } \\
\text { of combined OCP pre-treatment }\end{array}$ \\
\hline Duvan 2008 & No randomised controlled trial. Retrospective study. \\
\hline Fanchin $2003 b$ & $\begin{array}{l}\text { No randomised controlled trial. Each woman served as her own control. The women only received controlled } \\
\text { ovarian stimulation, but no embryo transfer as part of an ART cycle }\end{array}$ \\
\hline Fisch 1996 & No randomised controlled trial. Each woman served as her own control \\
\hline Forman 1991 & No randomised controlled trial. \\
\hline Frederick 2004 & No randomised controlled trial. Retrospective study. \\
\hline Frydman 1986 & No randomised controlled trial. \\
\hline Galera 2004 & No randomised controlled trial. \\
\hline Gerli 1989 & No randomised controlled trial. Single-arm study. \\
\hline Godin 2003 & No randomised controlled trial. \\
\hline Gomez 2000 & Compares two different ways of administration of oestrogen. \\
\hline Gonen 1990 & No randomised controlled trial. Clomiphene citrate used in treatment protocol \\
\hline Gonzalez 1995 & No randomised controlled trial. Retrospective study. \\
\hline Hugues 1992 & No randomised controlled trial. Single-arm study. \\
\hline
\end{tabular}

Oral contraceptive pill, progestogen or estrogen pre-treatment for ovarian stimulation protocols for women undergoing assisted 
(Continued)

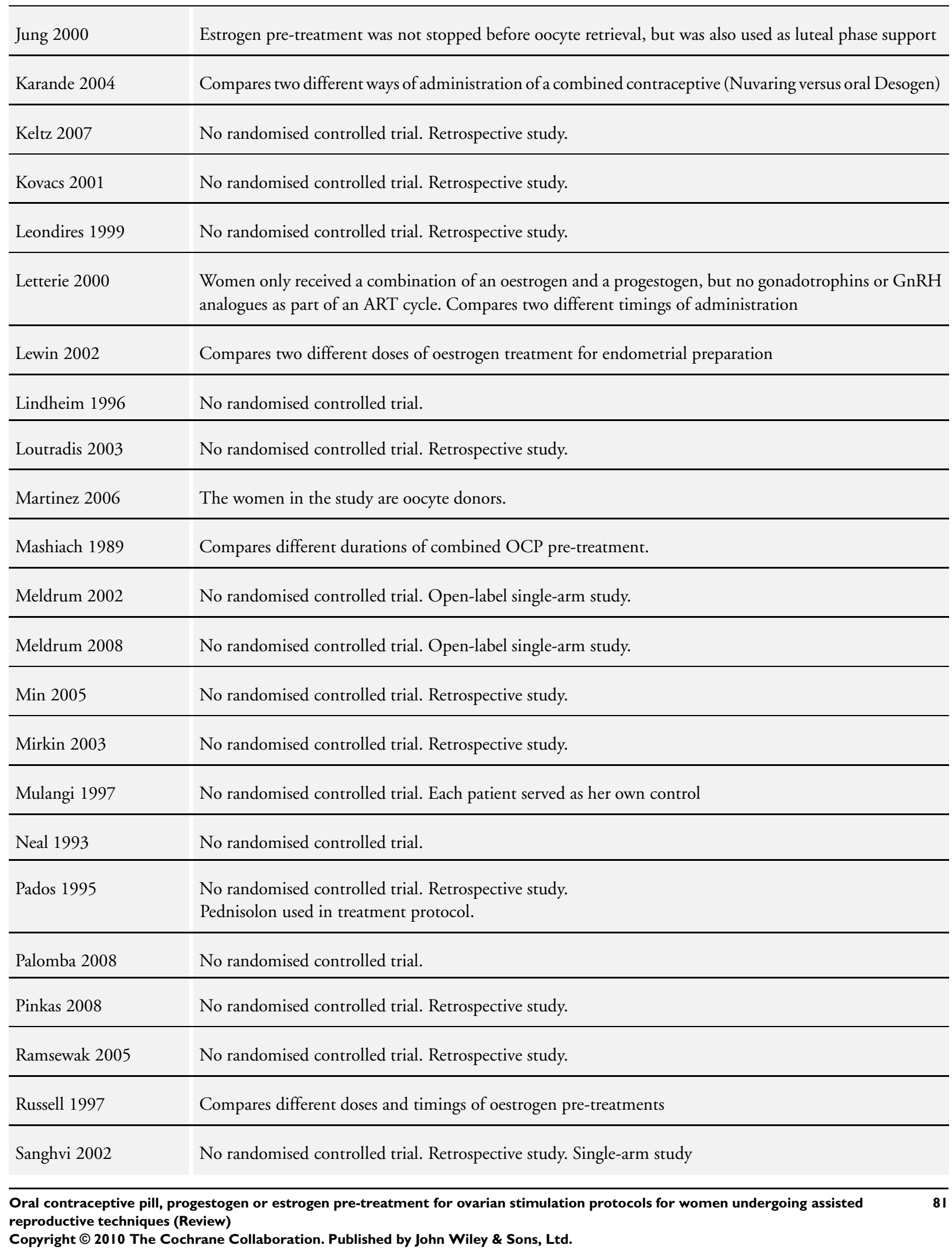


(Continued)

\begin{tabular}{|c|c|}
\hline Schoolcraft 1997 & No randomised controlled trial. \\
\hline Steinkampf 1991 & Women only received ovulation induction, no embryo transfer as part of an ART cycle \\
\hline Surrey 1989 & No randomised controlled trial. \\
\hline Surrey 1998 & No randomised controlled trial. Each woman served as her own control \\
\hline Talebian 2004 & No randomised controlled trial. Retrospective study. \\
\hline Talebian 2007 & No randomised controlled trial. Retrospective study. \\
\hline Tarlatzis 1993 & No randomised controlled trial. \\
\hline Tartagni 2007 & The patients in the study are women with premature ovarian failure \\
\hline Weisman 1989 & No randomised controlled trial. \\
\hline Yokota 2006 & No randomised controlled trial. \\
\hline Yoshida 2005 & No randomised controlled trial. Retrospective study. \\
\hline Zhao 2008 & No randomised controlled trial. Retrospective study. \\
\hline
\end{tabular}

\section{Characteristics of studies awaiting assessment [ordered by study ID]}

\section{Tavmergen 2009}

\begin{tabular}{ll}
\hline Methods & RCT \\
\hline Participants & 422 women \\
\hline Interventions & Two armed study either pre treatment or not with 200IU recFSH in a GnRH antagonist protocol \\
\hline Outcomes & Ongoing pregnancy \\
\hline Notes & \\
\hline
\end{tabular}


Characteristics of ongoing studies [ordered by study ID]

\section{Organon 2008}

\begin{tabular}{|c|c|}
\hline Trial name or title & $\begin{array}{l}\text { A randomised, open-label clinical trial to identify predictive factors for controlled ovarian stimulation using a } \\
\text { fixed daily dose of } 200 \mathrm{IU} \text { recombinant FSH in GnRH antagonist regimen with or without oral contraceptive } \\
\text { scheduling }\end{array}$ \\
\hline Methods & Randomised controlled trial \\
\hline Participants & $\begin{array}{l}\text { Inclusion criteria: (i) females of couples with an indication for IVF and/or ICSI scheduled for their first COS } \\
\text { treatment cycle; (ii) }>18 \text { and } \leq 39 \text { years of age at the time of signing informed consent; (iii) BMI } \leq 32 \mathrm{~kg} / \mathrm{m}^{2} \text {; } \\
\text { (iv) normal menstrual cycle length of } 24 \text { to } 35 \text { days; and (v) availability of ejaculatory sperm (use of donated } \\
\text { and/or cryopreserved sperm is allowed). } \\
\text { Exclusion criteria: (i) (history of) endocrine abnormality; (ii) < two ovaries or any other ovarian abnormality (e. } \\
\text { g. > } 10 \mathrm{~mm} \text { endometrioma); (iii) presence of unilateral or bilateral hydrosalpinx; (iv) presence of any clinically } \\
\text { relevant pathology affecting the uterine cavity or fibroids } \geq \text { five } \mathrm{cm} \text {; (v) history of } \geq \text { three miscarriages; (vi) } \\
\text { FSH or LH > } 12 \text { IU/L during the early } \\
\text { follicular phase; (vii) any clinically relevant abnormal laboratory value (FSH, LH, E2, P, total T, prolactin, } \\
\text { TSH, blood biochemistry, hematology and urinalysis) based on a sample during the } \\
\text { screening phase; (viii) contraindications for the use of gonadotrophins (tumours, pregnancy, lactation, } \\
\text { undiagnosed vaginal bleeding, hypersensitivity, ovarian cysts); (ix) contraindications for the use of oral contra- } \\
\text { ceptive pills (thromboembolism, breast cancer, undiagnosed vaginal bleeding); (x) (recent history of) epilepsy, } \\
\text { HIV infection, diabetes, cardiovascular, gastrointestinal, hepatic, renal or pulmonary disease; (xi) abnormal } \\
\text { karyotyping of the patient or her partner (if karyotyping is performed); (xii) (history of) alcohol or drug } \\
\text { abuse within } 12 \text { months of signing the consent; (xiii) use of hormonal preparations within one month prior } \\
\text { to randomization; (xiv) hypersensitivity to any of the concomitant medication; and (xv) administration of } \\
\text { investigational drugs within three months prior to signing the informed consent }\end{array}$ \\
\hline
\end{tabular}

Interventions $\quad$ 1) combined OCP (Desogen) for one month + ovarian stimulation

2) ovarian stimulation

Outcomes Primary: total number of oocytes

Secondary: number of mature oocytes, number of follicles on stimulation day 8 , number of follicles on day of hCG, number of fertilised (2PN) oocytes, number of good quality embryos, cycle cancellation rate

Starting date October 2006

Contact information $\quad$ Dr. Z. Rosenwaks

Notes $\quad$ Sponsored by Organon/Schering Plough 
DATA ANDANALYSES

\section{Comparison 1. Combined OCP versus no $\mathrm{Rx}$}

\begin{tabular}{|c|c|c|c|c|}
\hline Outcome or subgroup title & $\begin{array}{l}\text { No. of } \\
\text { studies }\end{array}$ & $\begin{array}{c}\text { No. of } \\
\text { participants }\end{array}$ & Statistical method & Effect size \\
\hline 1 Live births & 3 & & Peto Odds Ratio (Peto, Fixed, 95\% CI) & Subtotals only \\
\hline 1.1 COCP + Ant vs Ant & 1 & 45 & Peto Odds Ratio (Peto, Fixed, 95\% CI) & $0.43[0.11,1.74]$ \\
\hline $1.2 \mathrm{COCP}+$ Ant vs Ag & 1 & 182 & Peto Odds Ratio (Peto, Fixed, 95\% CI) & $1.0[0.48,2.10]$ \\
\hline $\begin{array}{l}1.3 \mathrm{COCP}+\text { Ant vs Ant, low } \\
\text { response }\end{array}$ & 1 & 54 & Peto Odds Ratio (Peto, Fixed, 95\% CI) & $1.82[0.53,6.25]$ \\
\hline $\begin{array}{l}1.4 \mathrm{COCP}+\text { Ant vs Ag, low } \\
\text { response }\end{array}$ & 1 & 55 & Peto Odds Ratio (Peto, Fixed, 95\% CI) & $1.53[0.46,5.09]$ \\
\hline 2 Ongoing pregnancies & 6 & & Peto Odds Ratio (Peto, Fixed, 95\% CI) & Subtotals only \\
\hline 2.1 COCP + Ant vs Ant & 4 & 847 & Peto Odds Ratio (Peto, Fixed, 95\% CI) & $0.74[0.53,1.03]$ \\
\hline 2.2 COCP + Ant vs Ag & 2 & 416 & Peto Odds Ratio (Peto, Fixed, 95\% CI) & $0.76[0.47,1.23]$ \\
\hline $\begin{array}{l}2.3 \mathrm{COCP}+\text { Ant vs Ant, low } \\
\text { response }\end{array}$ & 1 & 54 & Peto Odds Ratio (Peto, Fixed, 95\% CI) & $1.82[0.53,6.25]$ \\
\hline $\begin{array}{l}2.4 \mathrm{COCP}+\text { Ant vs Ag, low } \\
\text { response }\end{array}$ & 1 & 55 & Peto Odds Ratio (Peto, Fixed, 95\% CI) & $1.53[0.46,5.09]$ \\
\hline 3 Clinical/ongoing pregnancies & 9 & & Peto Odds Ratio (Peto, Fixed, 95\% CI) & Subtotals only \\
\hline $3.1 \mathrm{COCP}+\mathrm{Ag}$ vs $\mathrm{Ag}$ & 1 & 102 & Peto Odds Ratio (Peto, Fixed, 95\% CI) & $1.19[0.53,2.66]$ \\
\hline 3.2 COCP + Ant vs Ant & 4 & 847 & Peto Odds Ratio (Peto, Fixed, 95\% CI) & $0.69[0.50,0.96]$ \\
\hline $3.3 \mathrm{COCP}+$ Ant vs Ag & 3 & 472 & Peto Odds Ratio (Peto, Fixed, 95\% CI) & $0.82[0.53,1.26]$ \\
\hline $\begin{array}{l}3.4 \mathrm{COCP}+\text { Ant vs Ant, low } \\
\text { response }\end{array}$ & 1 & 54 & Peto Odds Ratio (Peto, Fixed, 95\% CI) & $1.72[0.53,5.60]$ \\
\hline $\begin{array}{l}3.5 \mathrm{COCP}+\text { Ant vs Ag, low } \\
\text { response }\end{array}$ & 1 & 55 & Peto Odds Ratio (Peto, Fixed, 95\% CI) & $1.49[0.47,4.71]$ \\
\hline $\begin{array}{l}3.6 \mathrm{COCP}+\mathrm{Ag} \text { vs Ant, low } \\
\text { response }\end{array}$ & 1 & 121 & Peto Odds Ratio (Peto, Fixed, 95\% CI) & $1.19[0.56,2.53]$ \\
\hline 4 Oocytes retrieved & 9 & & Mean Difference (IV, Fixed, 95\% CI) & Subtotals only \\
\hline 4.1 COCP + Ant vs Ant & 5 & 891 & Mean Difference (IV, Fixed, 95\% CI) & $0.23[-0.55,1.01]$ \\
\hline $4.2 \mathrm{COCP}+$ Ant vs Ag & 3 & 440 & Mean Difference (IV, Fixed, 95\% CI) & $-0.01[-1.54,1.53]$ \\
\hline $\begin{array}{l}4.3 \mathrm{COCP}+\text { Ant vs Ant, low } \\
\text { response }\end{array}$ & 1 & 54 & Mean Difference (IV, Fixed, 95\% CI) & $0.40[-0.61,1.41]$ \\
\hline $\begin{array}{l}4.4 \mathrm{COCP}+\text { Ant vs Ag, low } \\
\text { response }\end{array}$ & 1 & 55 & Mean Difference (IV, Fixed, 95\% CI) & $0.10[-0.98,1.18]$ \\
\hline $\begin{array}{l}4.5 \mathrm{COCP}+\mathrm{Ag} \text { vs Ant, low } \\
\text { response }\end{array}$ & 1 & 110 & Mean Difference (IV, Fixed, 95\% CI) & $-1.01[-1.91,-0.11]$ \\
\hline $\begin{array}{l}5 \text { Days of gonadotrophin } \\
\text { treatment }\end{array}$ & 7 & & Mean Difference (IV, Fixed, 95\% CI) & Subtotals only \\
\hline 5.1 COCP + Ant vs Ant & 3 & 689 & Mean Difference (IV, Fixed, 95\% CI) & $1.44[1.15,1.72]$ \\
\hline 5.2 COCP + Ant vs Ag & 3 & 434 & Mean Difference (IV, Fixed, 95\% CI) & $0.51[0.17,0.84]$ \\
\hline $\begin{array}{l}5.3 \mathrm{COCP}+\text { Ant vs Ant, low } \\
\text { response }\end{array}$ & 1 & 54 & Mean Difference (IV, Fixed, 95\% CI) & $0.30[-0.45,1.05]$ \\
\hline $\begin{array}{l}5.4 \mathrm{COCP}+\text { Ant vs Ag, low } \\
\text { response }\end{array}$ & 1 & 55 & Mean Difference (IV, Fixed, 95\% CI) & $-1.60[-2.42,-0.78]$ \\
\hline
\end{tabular}

Oral contraceptive pill, progestogen or estrogen pre-treatment for ovarian stimulation protocols for women undergoing assisted 


\begin{tabular}{|c|c|c|c|c|}
\hline $\begin{array}{l}5.5 \mathrm{COCP}+\mathrm{Ag} \text { vs Ant, low } \\
\text { response }\end{array}$ & 1 & 110 & Mean Difference (IV, Fixed, 95\% CI) & $-0.05[-0.70,0.60]$ \\
\hline $\begin{array}{l}6 \text { Amount of gonadotrophins } \\
\text { administered }\end{array}$ & 6 & & Mean Difference (IV, Fixed, 95\% CI) & Subtotals only \\
\hline 6.1 COCP + Ant vs Ant & 4 & 734 & Mean Difference (IV, Fixed, 95\% CI) & $\begin{array}{l}231.14[161.50 \\
300.78]\end{array}$ \\
\hline 6.2 COCP + Ant vs Ag & 2 & 385 & Mean Difference (IV, Fixed, 95\% CI) & $\begin{array}{l}209.52[61.16,357 . \\
87]\end{array}$ \\
\hline $\begin{array}{l}6.3 \mathrm{COCP}+\text { Ant vs Ant, low } \\
\text { response }\end{array}$ & 1 & 54 & Mean Difference (IV, Fixed, 95\% CI) & $\begin{array}{l}32.40[-207.04,271 \\
84]\end{array}$ \\
\hline $\begin{array}{l}6.4 \mathrm{COCP}+\text { Ant vs Ag, low } \\
\text { response }\end{array}$ & 1 & 55 & Mean Difference (IV, Fixed, 95\% CI) & $\begin{array}{l}-426.30[-657.90,- \\
194.70]\end{array}$ \\
\hline 7 Pregnancy losses & 7 & & Peto Odds Ratio (Peto, Fixed, 95\% CI) & Subtotals only \\
\hline 7.1 COCP + Ant vs Ant & 4 & 847 & Peto Odds Ratio (Peto, Fixed, 95\% CI) & $1.26[0.76,2.12]$ \\
\hline 7.2 COCP + Ant vs Ag & 3 & 472 & Peto Odds Ratio (Peto, Fixed, 95\% CI) & $0.52[0.24,1.10]$ \\
\hline $\begin{array}{l}7.3 \mathrm{COCP}+\text { Ant vs Ant, low } \\
\text { response }\end{array}$ & 1 & 54 & Peto Odds Ratio (Peto, Fixed, 95\% CI) & $1.0[0.06,16.42]$ \\
\hline $\begin{array}{l}7.4 \mathrm{COCP}+\text { Ant vs Ag, low } \\
\text { response }\end{array}$ & 1 & 55 & Peto Odds Ratio (Peto, Fixed, 95\% CI) & $1.04[0.06,17.04]$ \\
\hline 8 Ovarian cyst formation & 2 & & Peto Odds Ratio (Peto, Fixed, 95\% CI) & Subtotals only \\
\hline $8.1 \mathrm{COCP}+\mathrm{Ag}$ vs Ag & 1 & 102 & Peto Odds Ratio (Peto, Fixed, 95\% CI) & $0.07[0.03,0.16]$ \\
\hline 8.2 COCP + Ant vs Ant & 1 & 64 & Peto Odds Ratio (Peto, Fixed, 95\% CI) & $0.48[0.09,2.57]$ \\
\hline 9 Multiple pregnancies & 4 & & Peto Odds Ratio (Peto, Fixed, 95\% CI) & Subtotals only \\
\hline 9.1 COCP + Ant vs Ant & 1 & 45 & Peto Odds Ratio (Peto, Fixed, 95\% CI) & $2.32[0.23,23.65]$ \\
\hline $9.2 \mathrm{COCP}+$ Ant vs Ag & 2 & 238 & Peto Odds Ratio (Peto, Fixed, 95\% CI) & $1.02[0.37,2.82]$ \\
\hline $\begin{array}{l}9.3 \mathrm{COCP}+\text { Ant vs Ant, low } \\
\text { response }\end{array}$ & 1 & 54 & Peto Odds Ratio (Peto, Fixed, 95\% CI) & $2.00[0.20,20.08]$ \\
\hline $\begin{array}{l}9.4 \mathrm{COCP}+\text { Ant vs Ag, low } \\
\text { response }\end{array}$ & 1 & 55 & Peto Odds Ratio (Peto, Fixed, 95\% CI) & $2.08[0.21,20.84]$ \\
\hline 10 OHS syndrome & 2 & & Peto Odds Ratio (Peto, Fixed, 95\% CI) & Subtotals only \\
\hline 10.1 COCP + Ant vs Ant & 1 & 234 & Peto Odds Ratio (Peto, Fixed, 95\% CI) & $1.50[0.26,8.80]$ \\
\hline 10.2 COCP + Ant vs Ag & 2 & 290 & Peto Odds Ratio (Peto, Fixed, 95\% CI) & $0.63[0.21,1.92]$ \\
\hline
\end{tabular}

\section{Comparison 2. Progestogen versus placebo/ no Rx}

\begin{tabular}{|c|c|c|c|c|}
\hline Outcome or subgroup title & $\begin{array}{l}\text { No. of } \\
\text { studies }\end{array}$ & $\begin{array}{c}\text { No. of } \\
\text { participants }\end{array}$ & Statistical method & Effect size \\
\hline 1 Live births & 3 & & Peto Odds Ratio (Peto, Fixed, 95\% CI) & Subtotals only \\
\hline 1.1 Prog + Ag vs Ag & 2 & 222 & Peto Odds Ratio (Peto, Fixed, 95\% CI) & $1.35[0.69,2.62]$ \\
\hline 1.2 Prog + Ant vs Ant & 1 & 47 & Peto Odds Ratio (Peto, Fixed, 95\% CI) & $0.68[0.19,2.50]$ \\
\hline 2 Ongoing pregnancies & 3 & & Peto Odds Ratio (Peto, Fixed, 95\% CI) & Subtotals only \\
\hline 2.1 Prog + Ag vs Ag & 1 & 105 & Peto Odds Ratio (Peto, Fixed, 95\% CI) & $1.17[0.46,2.95]$ \\
\hline 2.2 Prog + Ant vs Ant & 1 & 47 & Peto Odds Ratio (Peto, Fixed, 95\% CI) & $0.68[0.19,2.50]$ \\
\hline 2.3 Prog + Gon vs Gon & 1 & 42 & Peto Odds Ratio (Peto, Fixed, 95\% CI) & $0.64[0.10,4.06]$ \\
\hline 3 Clinical pregnancies & 5 & & Peto Odds Ratio (Peto, Fixed, 95\% CI) & Subtotals only \\
\hline 3.1 Prog + Ag vs Ag & 3 & 374 & Peto Odds Ratio (Peto, Fixed, 95\% CI) & $1.95[1.20,3.17]$ \\
\hline 3.2 Prog + Ant vs Ant & 1 & 47 & Peto Odds Ratio (Peto, Fixed, 95\% CI) & $0.53[0.17,1.69]$ \\
\hline 3.3 Prog + Gon vs Gon & 1 & 42 & Peto Odds Ratio (Peto, Fixed, 95\% CI) & $0.72[0.14,3.56]$ \\
\hline
\end{tabular}

Oral contraceptive pill, progestogen or estrogen pre-treatment for ovarian stimulation protocols for women undergoing assisted 
4 Oocytes retrieved 4.1 Prog + Ag vs Ag 4.2 Prog + Ant vs Ant 4.3 Prog + Gon vs Gon

5 Days of gonadotrophin treatment 5.1 Prog + Ag vs Ag

6 Amount of gonadotrophins administered

6.1 Prog + Ant vs Ant

7 Pregnancy losses 7.1 Prog + Ag vs Ag 7.2 Prog + Ant vs Ant 7.3 Prog + Gon vs Gon 8 Ovarian cyst formation 8.1 Prog + Ag vs Ag

9 Multiple pregnancies 9.1 Prog + Ant vs Ant
Mean Difference (IV, Fixed, 95\% CI)

Mean Difference (IV, Fixed, 95\% CI)

Mean Difference (IV, Fixed, 95\% CI)

Mean Difference (IV, Fixed, 95\% CI)

Mean Difference (IV, Fixed, 95\% CI)

Mean Difference (IV, Fixed, 95\% CI)

Mean Difference (IV, Fixed, 95\% CI)

47

Mean Difference (IV, Fixed, 95\% CI)

Peto Odds Ratio (Peto, Fixed, 95\% CI)

222 Peto Odds Ratio (Peto, Fixed, 95\% CI)

47 Peto Odds Ratio (Peto, Fixed, 95\% CI)

42 Peto Odds Ratio (Peto, Fixed, 95\% CI)

Peto Odds Ratio (Peto, Fixed, 95\% CI)

374 Peto Odds Ratio (Peto, Fixed, 95\% CI)

Peto Odds Ratio (Peto, Fixed, 95\% CI)

47

Peto Odds Ratio (Peto, Fixed, 95\% CI)
Subtotals only

$-0.56[-2.13,1.01]$

$2.70[-0.98,6.38]$

Not estimable

Subtotals only

$0.08[-0.35,0.50]$

Subtotals only

$276.0[-75.53,627$.

$53]$

Subtotals only

$2.17[0.71,6.69]$

$0.39[0.08,1.92]$

$1.0[0.06,16.55]$

Subtotals only

$0.21[0.12,0.35]$

Subtotals only $1.04[0.06,17.23]$

Comparison 3. Estrogen versus no $\mathbf{R x}$

\begin{tabular}{|c|c|c|c|c|}
\hline Outcome or subgroup title & $\begin{array}{l}\text { No. of } \\
\text { studies }\end{array}$ & $\begin{array}{c}\text { No. of } \\
\text { participants }\end{array}$ & Statistical method & Effect size \\
\hline 1 Live births & 2 & & Peto Odds Ratio (Peto, Fixed, 95\% CI) & Subtotals only \\
\hline 1.1 Estr + Ant vs Ant & 1 & 49 & Peto Odds Ratio (Peto, Fixed, 95\% CI) & $0.36[0.09,1.41]$ \\
\hline 1.2 Estr + Ant vs Ag & 1 & 22 & Peto Odds Ratio (Peto, Fixed, 95\% CI) & $0.91[0.13,6.53]$ \\
\hline 2 Ongoing pregnancies & 2 & & Peto Odds Ratio (Peto, Fixed, 95\% CI) & Subtotals only \\
\hline 2.1 Estr + Ant vs Ant & 1 & 49 & Peto Odds Ratio (Peto, Fixed, 95\% CI) & $0.36[0.09,1.41]$ \\
\hline 2.2 Estr + Ant vs Ag & 1 & 22 & Peto Odds Ratio (Peto, Fixed, 95\% CI) & $0.91[0.13,6.53]$ \\
\hline 3 Clinical pregnancies & 3 & & Peto Odds Ratio (Peto, Fixed, 95\% CI) & Subtotals only \\
\hline 3.1 Estr + Ant vs Ant & 2 & 139 & Peto Odds Ratio (Peto, Fixed, 95\% CI) & $0.79[0.38,1.62]$ \\
\hline 3.2 Estr + Ant vs Ag & 1 & 22 & Peto Odds Ratio (Peto, Fixed, 95\% CI) & $0.91[0.13,6.53]$ \\
\hline 4 Oocytes retrieved & 3 & & Mean Difference (IV, Fixed, 95\% CI) & Subtotals only \\
\hline 4.1 Estr + Ant vs Ant & 2 & 136 & Mean Difference (IV, Fixed, 95\% CI) & $2.01[1.76,2.25]$ \\
\hline 4.2 Estr + Ant vs Ag & 1 & 20 & Mean Difference (IV, Fixed, 95\% CI) & $0.40[-4.61,5.41]$ \\
\hline $\begin{array}{l}5 \text { Days of gonadotrophin } \\
\text { treatment }\end{array}$ & 1 & & Mean Difference (IV, Fixed, 95\% CI) & Subtotals only \\
\hline 5.1 Estr + Ant vs Ag & 1 & 20 & Mean Difference (IV, Fixed, 95\% CI) & $-2.5[-4.10,-0.90]$ \\
\hline $\begin{array}{l}6 \text { Amount of gonadotrophins } \\
\text { administered }\end{array}$ & 3 & & Mean Difference (IV, Fixed, 95\% CI) & Subtotals only \\
\hline 6.1 Estr + Ant vs Ant & 2 & 136 & Mean Difference (IV, Fixed, 95\% CI) & $\begin{array}{l}207.08[167.77, \\
246.39]\end{array}$ \\
\hline 6.2 Estr + Ant vs Ag & 1 & 20 & Mean Difference (IV, Fixed, 95\% CI) & $\begin{array}{l}-16.0[-478.88,446 . \\
88]\end{array}$ \\
\hline 7 Pregnancy losses & 2 & & Peto Odds Ratio (Peto, Fixed, 95\% CI) & Subtotals only \\
\hline 7.1 Estr + Ant vs Ant & 1 & 49 & Peto Odds Ratio (Peto, Fixed, 95\% CI) & $0.22[0.04,1.17]$ \\
\hline 7.2 Estr + Ant vs Ag & 1 & 22 & Peto Odds Ratio (Peto, Fixed, 95\% CI) & Not estimable \\
\hline
\end{tabular}

Oral contraceptive pill, progestogen or estrogen pre-treatment for ovarian stimulation protocols for women undergoing assisted 


\begin{tabular}{|c|c|c|c|c|}
\hline 8 Ovarian cyst formation & 1 & & Peto Odds Ratio (Peto, Fixed, 95\% CI) & Subtotals only \\
\hline 8.1 Estr + Ant vs Ag & 1 & 22 & Peto Odds Ratio (Peto, Fixed, 95\% CI) & Not estimable \\
\hline 9 Multiple pregnancies & 2 & & Peto Odds Ratio (Peto, Fixed, 95\% CI) & Subtotals only \\
\hline 9.1 Estr + Ant vs Ant & 1 & 49 & Peto Odds Ratio (Peto, Fixed, 95\% CI) & $0.13[0.00,6.55]$ \\
\hline 9.2 Estr + Ant vs Ag & 1 & 20 & Peto Odds Ratio (Peto, Fixed, 95\% CI) & $4.52[0.20,101.00]$ \\
\hline 10 OHS syndrome & 1 & & Peto Odds Ratio (Peto, Fixed, 95\% CI) & Subtotals only \\
\hline 10.1 Estr + Ant vs Ag & 1 & 22 & Peto Odds Ratio (Peto, Fixed, 95\% CI) & Not estimable \\
\hline
\end{tabular}

\section{Comparison 4. Combined OCP versus progestogen}

\begin{tabular}{|c|c|c|c|c|}
\hline Outcome or subgroup title & $\begin{array}{l}\text { No. of } \\
\text { studies }\end{array}$ & $\begin{array}{c}\text { No. of } \\
\text { participants }\end{array}$ & Statistical method & Effect size \\
\hline 1 Live births & 1 & & Peto Odds Ratio (Peto, Fixed, 95\% CI) & Subtotals only \\
\hline $\begin{array}{l}1.1 \text { COCP + Ant vs Prog + } \\
\text { Ant }\end{array}$ & 1 & 44 & Peto Odds Ratio (Peto, Fixed, 95\% CI) & $0.61[0.13,2.79]$ \\
\hline 2 Ongoing pregnancies & 1 & & Peto Odds Ratio (Peto, Fixed, 95\% CI) & Subtotals only \\
\hline $\begin{array}{l}2.1 \text { COCP }+ \text { Ant vs Prog }+ \\
\text { Ant }\end{array}$ & 1 & 44 & Peto Odds Ratio (Peto, Fixed, 95\% CI) & $0.61[0.13,2.79]$ \\
\hline 3 Clinical pregnancies & 1 & & Peto Odds Ratio (Peto, Fixed, 95\% CI) & Subtotals only \\
\hline $\begin{array}{l}\text { 3.1 COCP + Ant vs Prog + } \\
\text { Ant }\end{array}$ & 1 & 44 & Peto Odds Ratio (Peto, Fixed, 95\% CI) & $0.72[0.19,2.68]$ \\
\hline 4 Oocytes retrieved & 1 & & Mean Difference (IV, Fixed, 95\% CI) & Subtotals only \\
\hline $\begin{array}{l}\text { 4.1 COCP + Ant vs Prog + } \\
\text { Ant }\end{array}$ & 1 & 44 & Mean Difference (IV, Fixed, 95\% CI) & $1.40[-3.24,6.04]$ \\
\hline $\begin{array}{l}5 \text { Amount of gonadotrophins } \\
\text { administered }\end{array}$ & 1 & & Mean Difference (IV, Fixed, 95\% CI) & Subtotals only \\
\hline $\begin{array}{l}\text { 5.1 COCP + Ant vs Prog + } \\
\text { Ant }\end{array}$ & 1 & 44 & Mean Difference (IV, Fixed, 95\% CI) & $\begin{array}{l}164.0[-249.03,577 . \\
03]\end{array}$ \\
\hline 6 Pregnancy losses & 1 & & Peto Odds Ratio (Peto, Fixed, 95\% CI) & Subtotals only \\
\hline $\begin{array}{l}\text { 6.1 COCP + Ant vs Prog + } \\
\text { Ant }\end{array}$ & 1 & 44 & Peto Odds Ratio (Peto, Fixed, 95\% CI) & $1.10[0.14,8.43]$ \\
\hline 7 Multiple pregnancies & 1 & & Peto Odds Ratio (Peto, Fixed, 95\% CI) & Subtotals only \\
\hline $\begin{array}{l}\text { 7.1 COCP + Ant vs Prog + } \\
\text { Ant }\end{array}$ & 1 & 44 & Peto Odds Ratio (Peto, Fixed, 95\% CI) & $2.22[0.22,22.56]$ \\
\hline
\end{tabular}

\section{Comparison 5. Combined OCP versus estrogen}

\begin{tabular}{|c|c|c|c|c|}
\hline Outcome or subgroup title & $\begin{array}{l}\text { No. of } \\
\text { studies }\end{array}$ & $\begin{array}{c}\text { No. of } \\
\text { participants }\end{array}$ & Statistical method & Effect size \\
\hline 1 Live births & 1 & & Peto Odds Ratio (Peto, Fixed, 95\% CI) & Subtotals only \\
\hline 1.1 COCP + Ant vs Estr + Ant & 1 & 46 & Peto Odds Ratio (Peto, Fixed, 95\% CI) & $1.22[0.22,6.69]$ \\
\hline 2 Ongoing pregnancies & 2 & & Peto Odds Ratio (Peto, Fixed, 95\% CI) & Subtotals only \\
\hline 2.1 COCP + Ant vs Estr + Ant & 1 & 46 & Peto Odds Ratio (Peto, Fixed, 95\% CI) & $1.22[0.22,6.69]$ \\
\hline $2.2 \mathrm{COCP}+\mathrm{Ag}$ vs Estr + Ant & 1 & 25 & Peto Odds Ratio (Peto, Fixed, 95\% CI) & $0.13[0.03,0.70]$ \\
\hline 3 Clinical pregnancies & 2 & & Peto Odds Ratio (Peto, Fixed, 95\% CI) & Subtotals only \\
\hline
\end{tabular}

Oral contraceptive pill, progestogen or estrogen pre-treatment for ovarian stimulation protocols for women undergoing assisted 


\begin{tabular}{|c|c|c|c|c|}
\hline 3.1 COCP + Ant vs Estr + Ant & 1 & 46 & Peto Odds Ratio (Peto, Fixed, 95\% CI) & $1.62[0.38,6.90]$ \\
\hline 3.2 COCP + Ag vs Estr + Ant & 1 & 25 & Peto Odds Ratio (Peto, Fixed, 95\% CI) & $0.17[0.03,0.80]$ \\
\hline 4 Oocytes retrieved & 1 & & Mean Difference (IV, Fixed, 95\% CI) & Subtotals only \\
\hline 4.1 COCP + Ant vs Estr + Ant & 1 & 43 & Mean Difference (IV, Fixed, 95\% CI) & $0.90[-3.70,5.50]$ \\
\hline $\begin{array}{l}5 \text { Amount of gonadotrophins } \\
\text { administered }\end{array}$ & 1 & & Mean Difference (IV, Fixed, 95\% CI) & Subtotals only \\
\hline 5.1 COCP + Ant vs Estr + Ant & 1 & 43 & Mean Difference (IV, Fixed, 95\% CI) & $\begin{array}{l}474.0[95.10,852 . \\
90]\end{array}$ \\
\hline 6 Pregnancy losses & 2 & & Peto Odds Ratio (Peto, Fixed, 95\% CI) & Subtotals only \\
\hline 6.1 COCP + Ant vs Estr + Ant & 1 & 46 & Peto Odds Ratio (Peto, Fixed, 95\% CI) & $2.43[0.24,24.79]$ \\
\hline 6.2 COCP + Ag vs Estr + Ant & 1 & 25 & Peto Odds Ratio (Peto, Fixed, 95\% CI) & $1.09[0.06,18.49]$ \\
\hline 7 Multiple pregnancies & 1 & & Peto Odds Ratio (Peto, Fixed, 95\% CI) & Subtotals only \\
\hline 7.1 COCP + Ant vs Estr + Ant & 1 & 46 & Peto Odds Ratio (Peto, Fixed, 95\% CI) & $9.40[0.56,156.66]$ \\
\hline
\end{tabular}

Comparison 6. Progestogen versus estrogen

\begin{tabular}{|c|c|c|c|c|}
\hline Outcome or subgroup title & $\begin{array}{l}\text { No. of } \\
\text { studies }\end{array}$ & $\begin{array}{c}\text { No. of } \\
\text { participants }\end{array}$ & Statistical method & Effect size \\
\hline 1 Live births & 1 & & Peto Odds Ratio (Peto, Fixed, 95\% CI) & Subtotals only \\
\hline 1.1 Prog + Ant vs Estr + Ant & 1 & 48 & Peto Odds Ratio (Peto, Fixed, 95\% CI) & $1.99[0.44,8.94]$ \\
\hline 2 Ongoing pregnancies & 1 & & Peto Odds Ratio (Peto, Fixed, 95\% CI) & Subtotals only \\
\hline 2.1 Prog + Ant vs Estr + Ant & 1 & 48 & Peto Odds Ratio (Peto, Fixed, 95\% CI) & $1.99[0.44,8.94]$ \\
\hline 3 Clinical pregnancies & 1 & & Peto Odds Ratio (Peto, Fixed, 95\% CI) & Subtotals only \\
\hline 3.1 Prog + Ant vs Estr + Ant & 1 & 48 & Peto Odds Ratio (Peto, Fixed, 95\% CI) & $2.23[0.59,8.44]$ \\
\hline 4 Oocytes retrieved & 1 & & Mean Difference (IV, Fixed, 95\% CI) & Subtotals only \\
\hline 4.1 Prog + Ant vs Estr + Ant & 1 & 45 & Mean Difference (IV, Fixed, 95\% CI) & $-0.5[-4.68,3.68]$ \\
\hline $\begin{array}{l}5 \text { Amount of gonadotrophins } \\
\text { administered }\end{array}$ & 1 & & Mean Difference (IV, Fixed, 95\% CI) & Subtotals only \\
\hline 5.1 Prog + Ant vs Estr + Ant & 1 & 45 & Mean Difference (IV, Fixed, 95\% CI) & $\begin{array}{l}310.0[-40.60,660 \\
60]\end{array}$ \\
\hline 6 Pregnancy losses & 1 & & Peto Odds Ratio (Peto, Fixed, 95\% CI) & Subtotals only \\
\hline 6.1 Prog + Ant vs Estr + Ant & 1 & 48 & Peto Odds Ratio (Peto, Fixed, 95\% CI) & $2.19[0.22,22.19]$ \\
\hline 7 Multiple pregnancies & 1 & & Peto Odds Ratio (Peto, Fixed, 95\% CI) & Subtotals only \\
\hline 7.1 Prog + Ant vs Estr + Ant & 1 & 48 & Peto Odds Ratio (Peto, Fixed, 95\% CI) & $8.06[0.16,407.60]$ \\
\hline
\end{tabular}

Oral contraceptive pill, progestogen or estrogen pre-treatment for ovarian stimulation protocols for women undergoing assisted 


\section{Analysis I.I. Comparison I Combined OCP versus no Rx, Outcome I Live births.}

Review: Oral contraceptive pill, progestogen or estrogen pre-treatment for ovarian stimulation protocols for women undergoing assisted reproductive techniques

Comparison: I Combined OCP versus no Rx

Outcome: I Live births

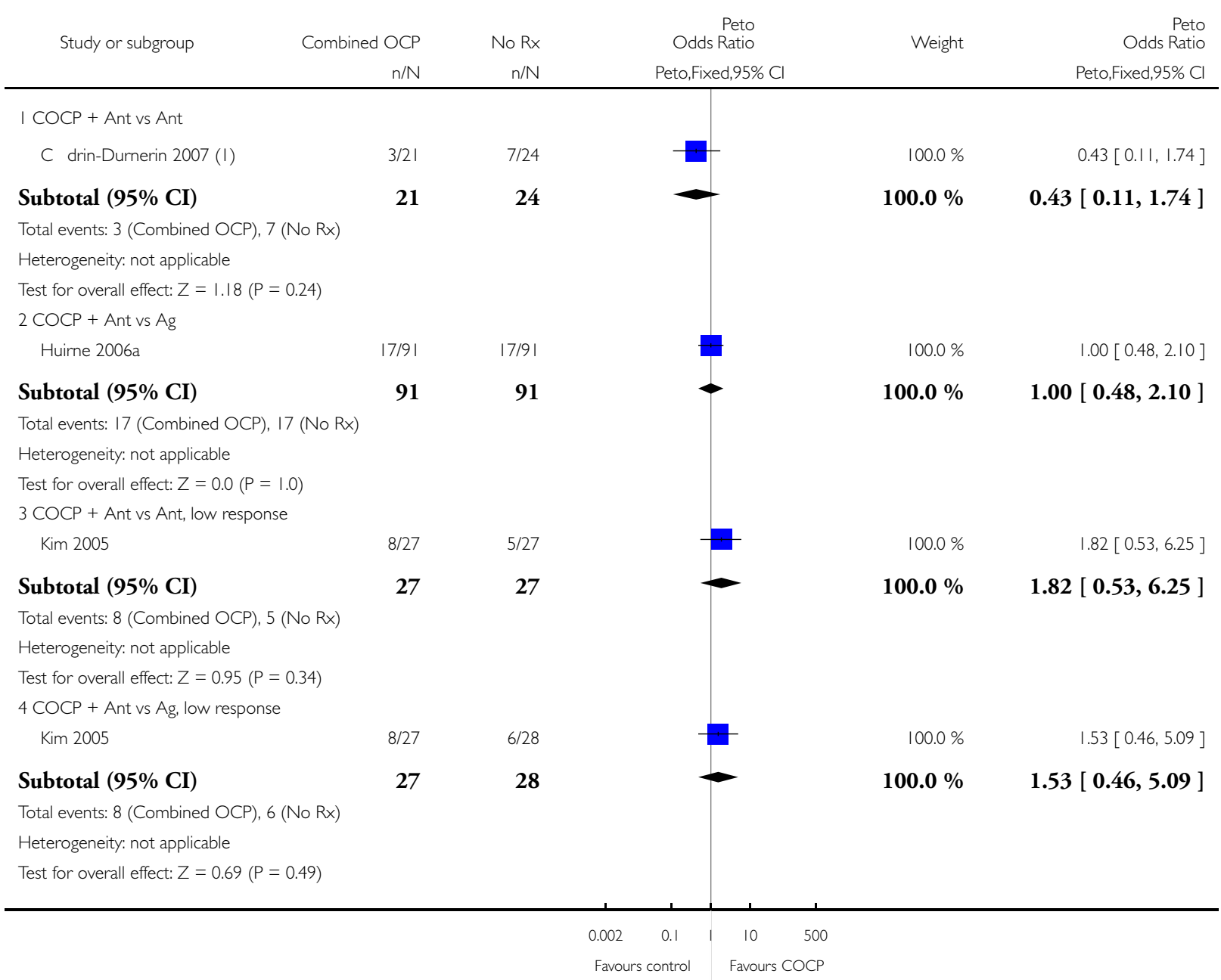

( I) Data obtained from Dr. Griesinger. 


\section{Analysis I.2. Comparison I Combined OCP versus no Rx, Outcome 2 Ongoing pregnancies.}

Review: Oral contraceptive pill, progestogen or estrogen pre-treatment for ovarian stimulation protocols for women undergoing assisted reproductive techniques

Comparison: I Combined OCP versus no Rx

Outcome: 2 Ongoing pregnancies

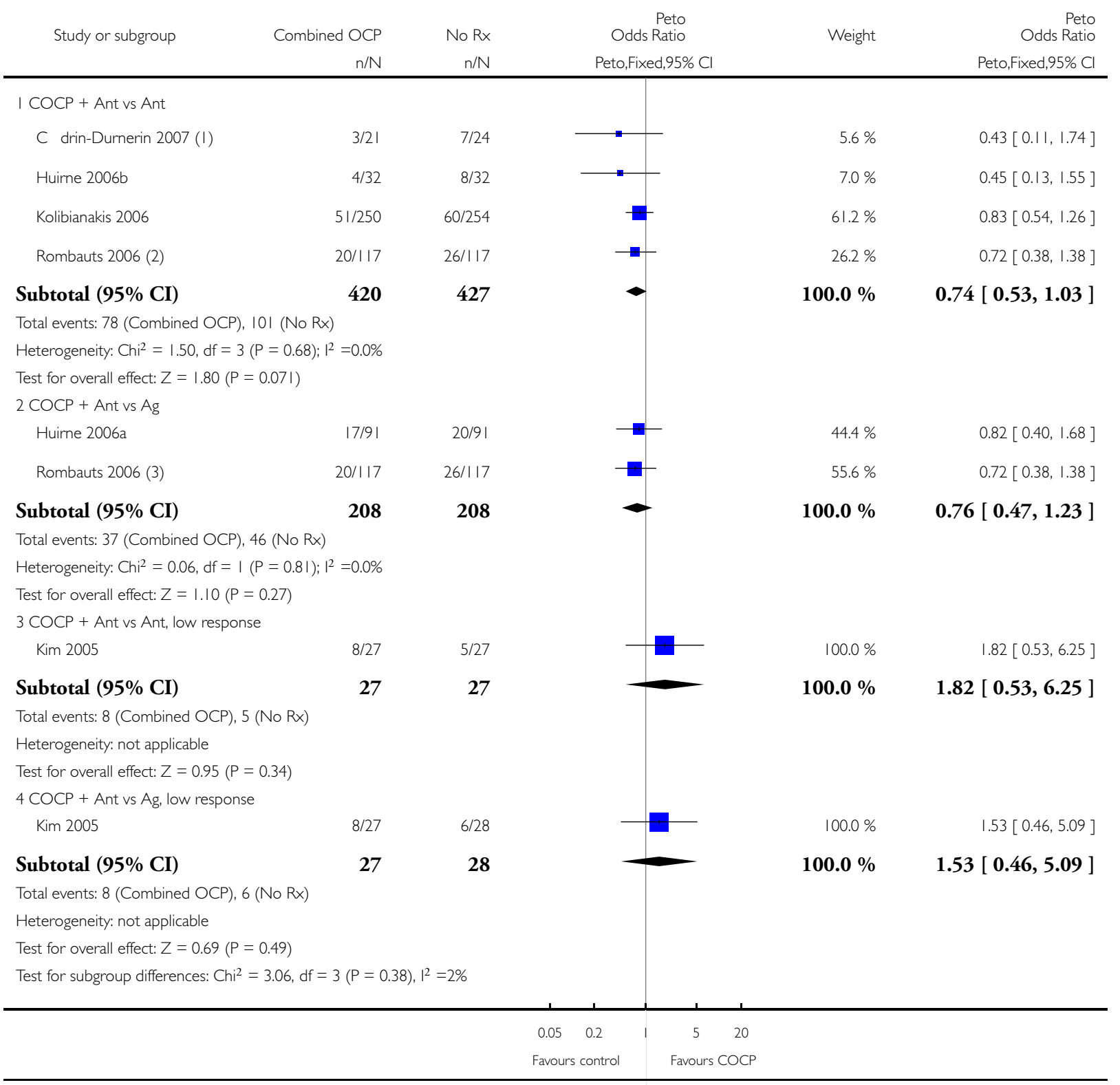

Oral contraceptive pill, progestogen or estrogen pre-treatment for ovarian stimulation protocols for women undergoing assisted 
( I) Data obtained from Dr. C drin-Durnerin.

(2) Includes 2 spontaneous pregnancies in the study group and 3 in the control group.

(3) Includes 2 spontaneous pregnancies in the study group.

\section{Analysis I.3. Comparison I Combined OCP versus no Rx, Outcome 3 Clinical/ongoing pregnancies.}

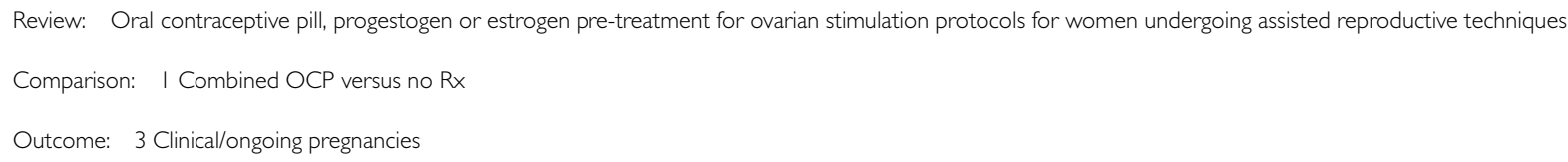
Peto,Fixed, $95 \% \mathrm{Cl}$

$\mathrm{n} / \mathrm{N} \quad \mathrm{n} / \mathrm{N}$

$\mathrm{n} / \mathrm{N}$ Peto,Fixed,95\% Cl

I COCP + Ag vs Ag

Biljan 1998a (I)

Subtotal (95\% CI)

Total events: 19 (Combined OCP), 17 (No Rx)

Heterogeneity: not applicable

Test for overall effect: $Z=0.4 \mathrm{I}(P=0.68)$

2 COCP + Ant vs Ant

C drin-Durnerin 2007 (2)

Huirne 2006b

Kolibianakis 2006 (3)

Rombauts 2006 (4)

Subtotal (95\% CI)

Total events: 80 (Combined OCP), 109 (No Rx)

Heterogeneity: $\mathrm{Chi}^{2}=4.30, \mathrm{df}=3(\mathrm{P}=0.23) ; \mathrm{I}^{2}=30 \%$

Test for overall effect: $Z=2.23(P=0.025)$

$3 \mathrm{COCP}+$ Ant vs Ag

Huirne 2006a

Hwang 2004 (5)

Rombauts 2006 (6)

Subtotal $(\mathbf{9 5} \% \mathrm{CI})$

Total events: 49 (Combined OCP), 58 (No Rx)

Heterogeneity: $\mathrm{Chi}^{2}=0.45, \mathrm{df}=2(\mathrm{P}=0.80) ; \mathrm{I}^{2}=0.0 \%$

Test for overall effect: $Z=0.91 \quad(P=0.36)$

$19 / 51$

51

$17 / 51$

51

$\begin{array}{rr}5 / 21 & 11 / 24 \\ 4 / 32 & 12 / 32 \\ 51 / 250 & 60 / 254 \\ 20 / 117 & 26 / 117\end{array}$

420

427

$$
19 / 91
$$

10/27

$20 / 117$

235

237

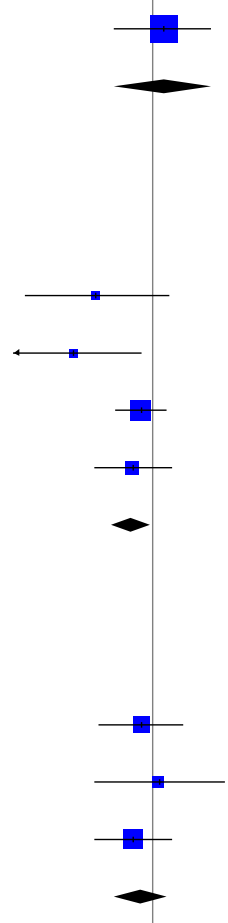

$100.0 \%$

$100.0 \%$

$7.2 \%$

$8.3 \%$

$59.2 \%$

$25.3 \%$

$100.0 \%$

$38.9 \%$

$15.9 \%$

$45.2 \%$

$100.0 \%$
$1.19[0.53,2.66]$

1.19 [ $0.53,2.66$ ]

$$
\begin{aligned}
& 0.39[0.12,1.31] \\
& 0.27[0.09,0.83] \\
& 0.83[0.54,1.26] \\
& 0.72[0.38,1.38]
\end{aligned}
$$

0.69 [ $0.50,0.96$ ]

$$
\begin{aligned}
& 0.83[0.41,1.66] \\
& 1.12[0.38,3.30] \\
& 0.72[0.38,1.38]
\end{aligned}
$$

$0.82[0.53,1.26]$ 


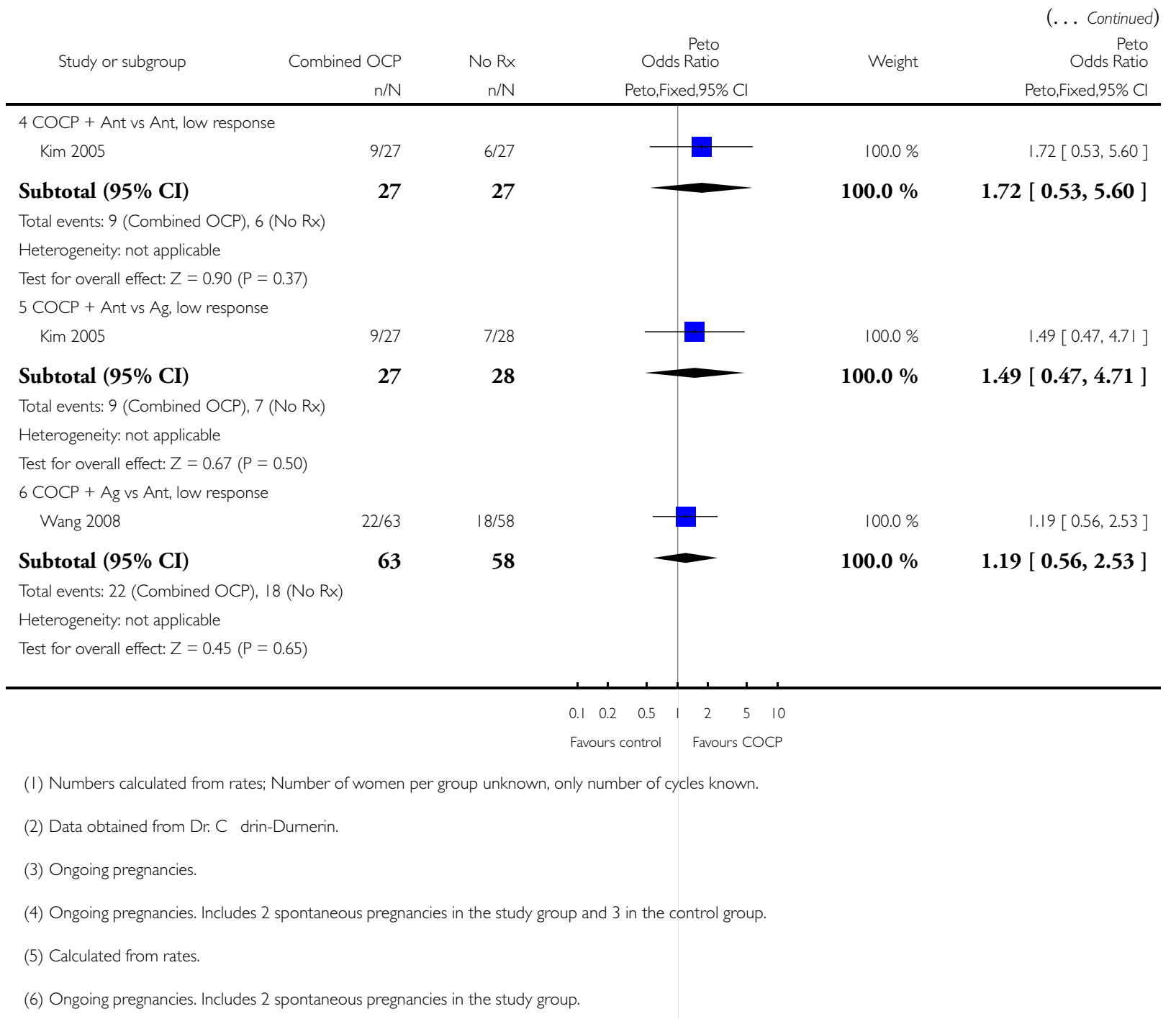




\section{Analysis I.4. Comparison I Combined OCP versus no Rx, Outcome 4 Oocytes retrieved.}

Review: Oral contraceptive pill, progestogen or estrogen pre-treatment for ovarian stimulation protocols for women undergoing assisted reproductive techniques

Comparison: I Combined OCP versus no Rx

Outcome: 4 Oocytes retrieved

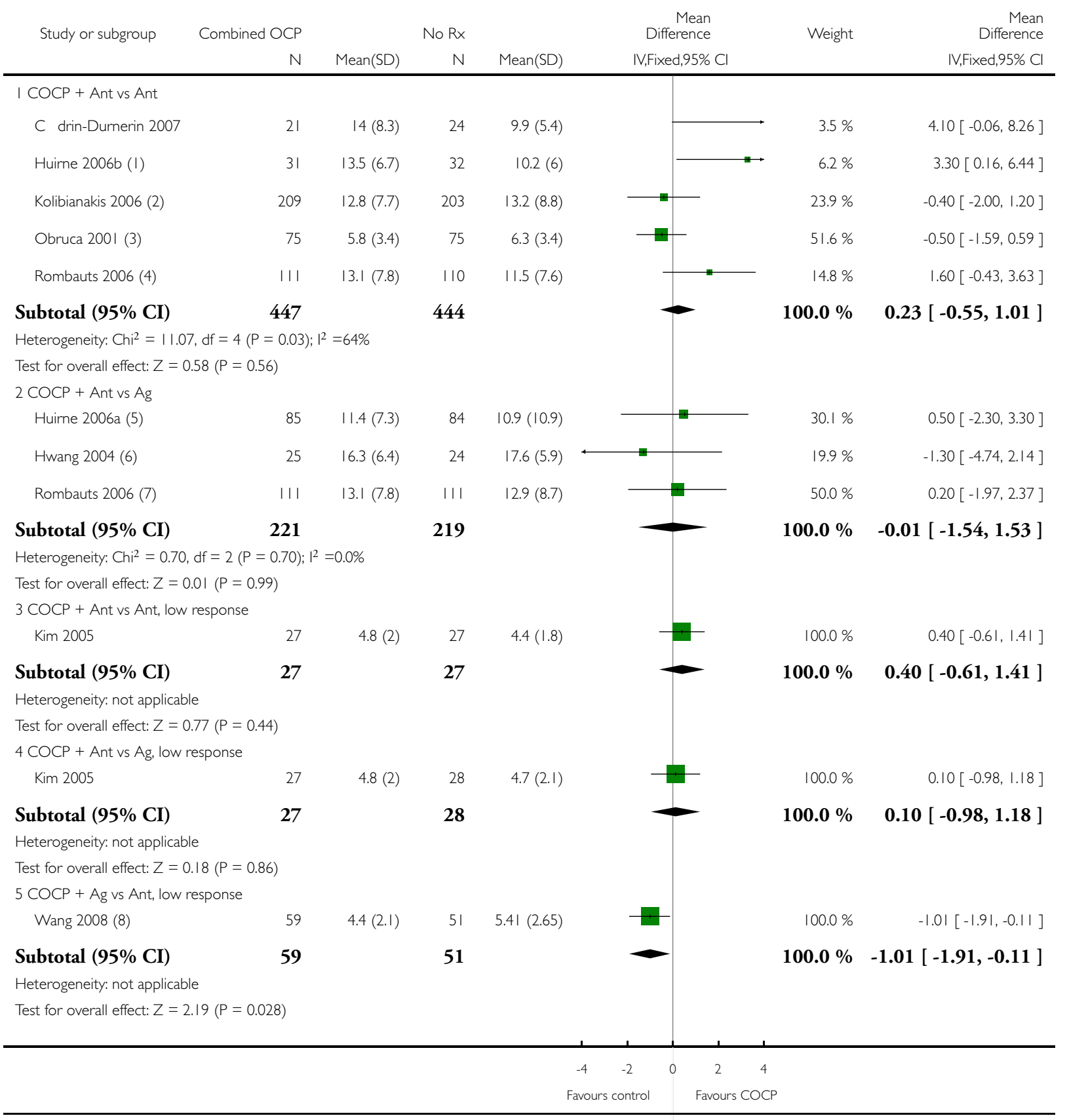

Oral contraceptive pill, progestogen or estrogen pre-treatment for ovarian stimulation protocols for women undergoing assisted 

(I) No ITT in COCP group.
(2) No ITT. 'Cumulus oocyte complexes'.
(3) Unsure about ITT.
(4) No ITT.
(5) No ITT.
(6) No ITT.
(7) No ITT.
(8) No ITT.

\section{Analysis I.5. Comparison I Combined OCP versus no Rx, Outcome 5 Days of gonadotrophin treatment.}

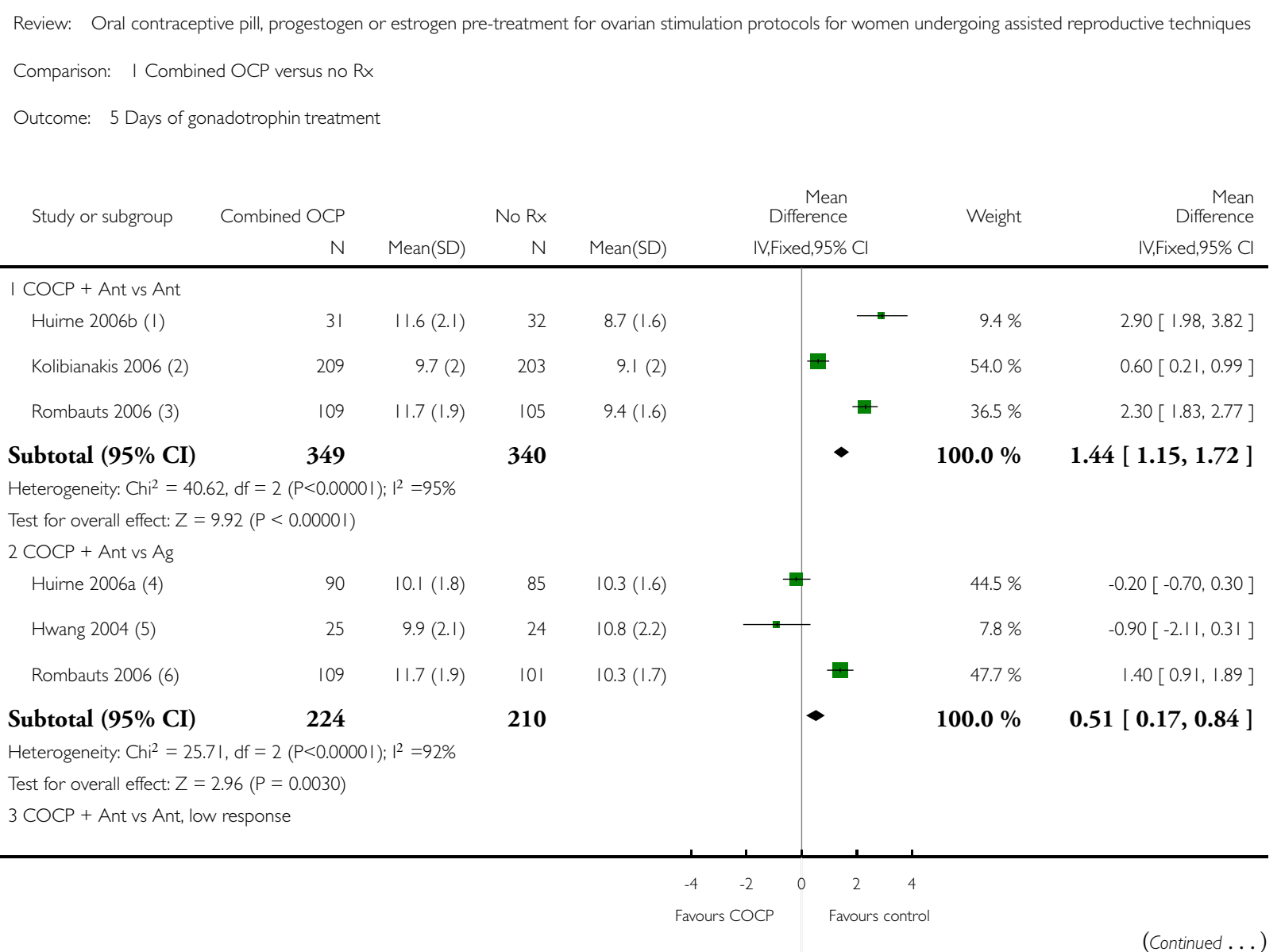




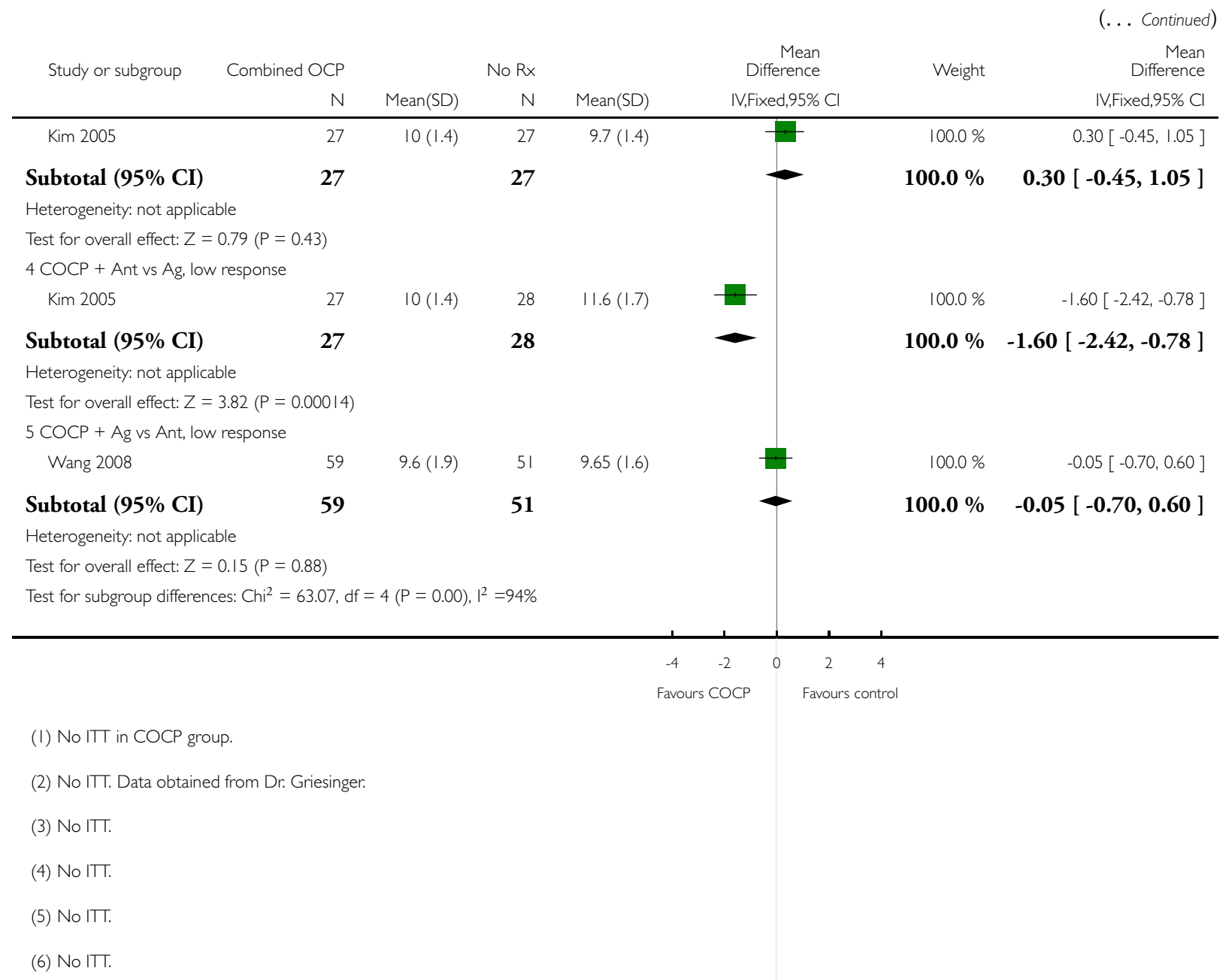




\section{Analysis I.6. Comparison I Combined OCP versus no Rx, Outcome 6 Amount of gonadotrophins administered.}

Review: Oral contraceptive pill, progestogen or estrogen pre-treatment for ovarian stimulation protocols for women undergoing assisted reproductive techniques

Comparison: I Combined OCP versus no $\mathrm{Rx}$

Outcome: 6 Amount of gonadotrophins administered

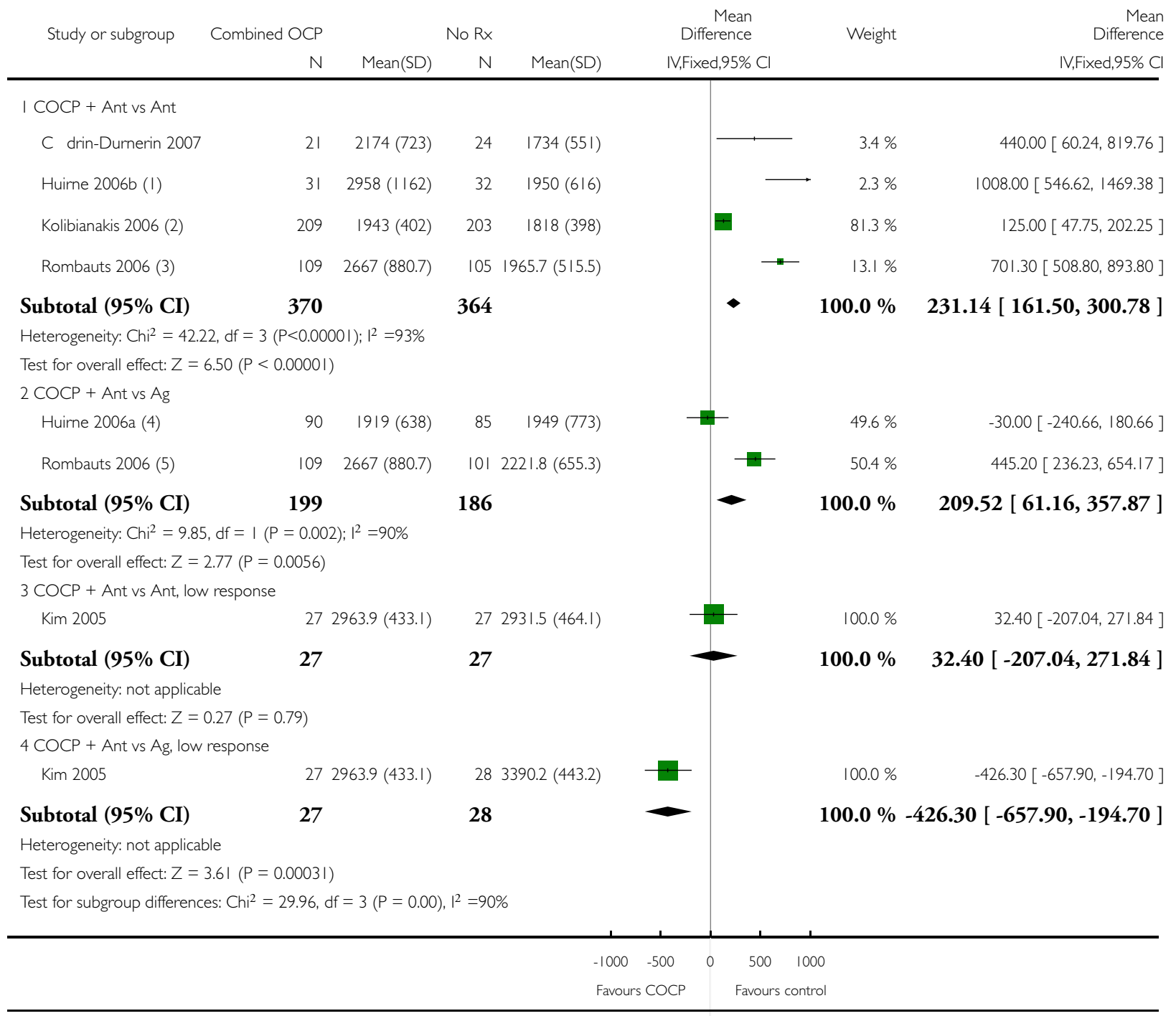

Oral contraceptive pill, progestogen or estrogen pre-treatment for ovarian stimulation protocols for women undergoing assisted 

( I) No ITT in COCP group.
(2) No ITT. Data obtained from Dr. Griesinger.
(3) No ITT.
(4) No ITT.
(5) No ITT.

\section{Analysis I.7. Comparison I Combined OCP versus no Rx, Outcome 7 Pregnancy losses.}

Review: Oral contraceptive pill, progestogen or estrogen pre-treatment for ovarian stimulation protocols for women undergoing assisted reproductive techniques Comparison: I Combined OCP versus no $\mathrm{Rx}$

Outcome: 7 Pregnancy losses

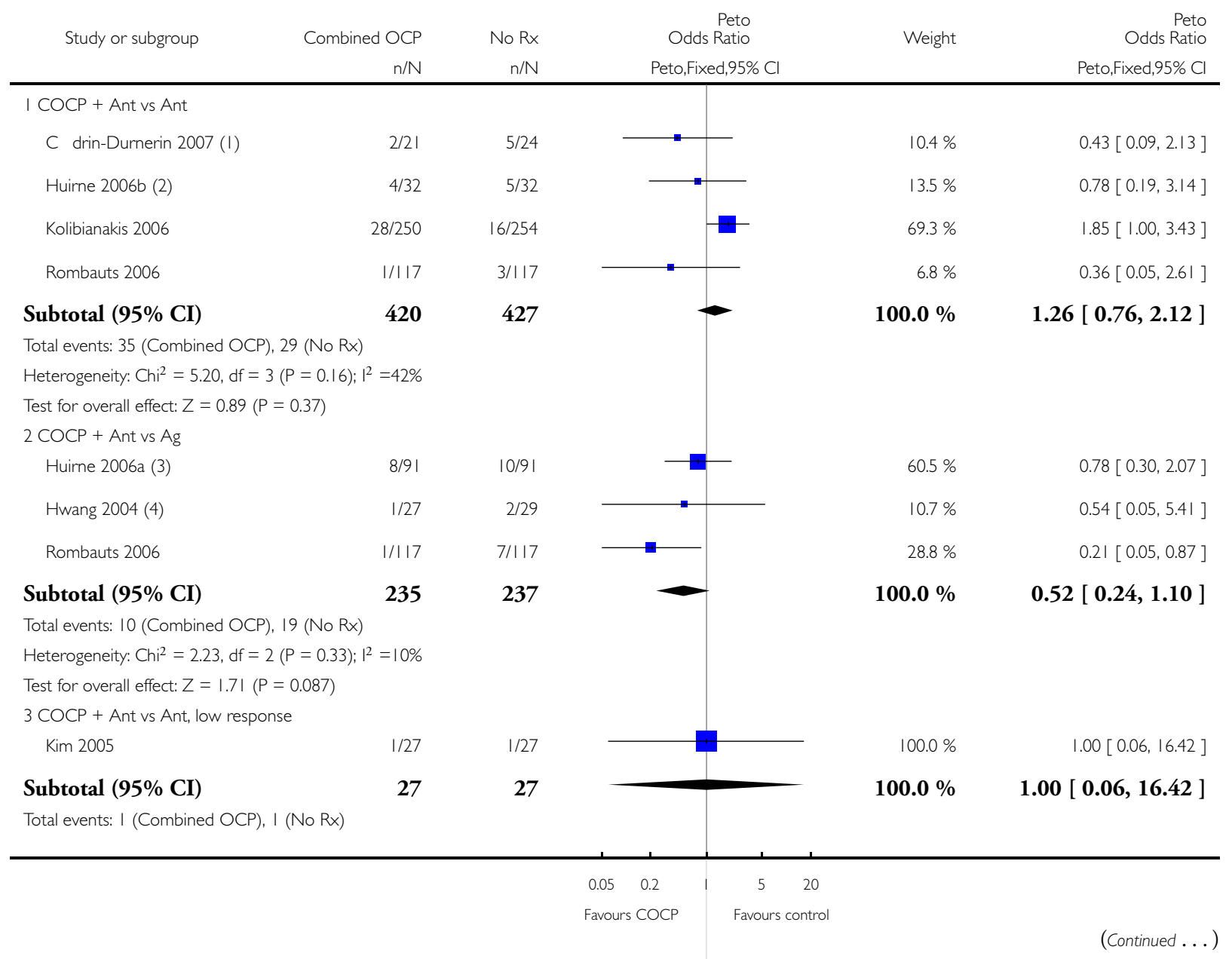

Oral contraceptive pill, progestogen or estrogen pre-treatment for ovarian stimulation protocols for women undergoing assisted 


\begin{tabular}{|c|c|c|c|c|c|c|c|c|}
\hline \multirow[t]{2}{*}{ Study or subgroup } & Combined OCP & No Rx & \multirow{2}{*}{\multicolumn{4}{|c|}{$\begin{array}{c}\text { Peto } \\
\text { Odds Ratio } \\
\text { Peto,Fixed,95\% Cl }\end{array}$}} & \multirow[t]{2}{*}{ Weight } & $\begin{array}{r}\text { (... Continued) } \\
\text { Peto } \\
\text { Odds Ratio }\end{array}$ \\
\hline & $\mathrm{n} / \mathrm{N}$ & $\mathrm{n} / \mathrm{N}$ & & & & & & Peto,Fixed,95\% Cl \\
\hline \multicolumn{9}{|c|}{ Heterogeneity: not applicable } \\
\hline \multicolumn{9}{|c|}{ Test for overall effect: $Z=0.0(P=1.0)$} \\
\hline \multicolumn{9}{|c|}{4 COCP + Ant vs Ag, low response } \\
\hline Kim 2005 & $1 / 27$ & $1 / 28$ & & & & & $100.0 \%$ & $1.04[0.06,17.04]$ \\
\hline Subtotal $(95 \% \mathrm{CI})$ & 27 & 28 & & & & & $100.0 \%$ & $1.04[0.06,17.04]$ \\
\hline \multicolumn{9}{|c|}{ Total events: I (Combined OCP), I (No Rx) } \\
\hline \multicolumn{9}{|c|}{ Heterogeneity: not applicable } \\
\hline \multicolumn{9}{|c|}{ Test for overall effect: $Z=0.03(P=0.98)$} \\
\hline & & & 0.05 & 0.2 & 5 & 20 & & \\
\hline \multicolumn{9}{|c|}{ Favours COCP Favours control } \\
\hline \multicolumn{9}{|c|}{ (I) Calculated from the number of clinical pregnancies minus the number of live births. } \\
\hline \multicolumn{9}{|c|}{ (2) Calculated from the number of positive pregnancy tests minus the number of ongoing pregnancies. } \\
\hline \multicolumn{9}{|c|}{ (3) Calculated from the number of positive pregnancy tests minus the number of live births. } \\
\hline
\end{tabular}




\section{Analysis 1.8. Comparison I Combined OCP versus no Rx, Outcome 8 Ovarian cyst formation.}

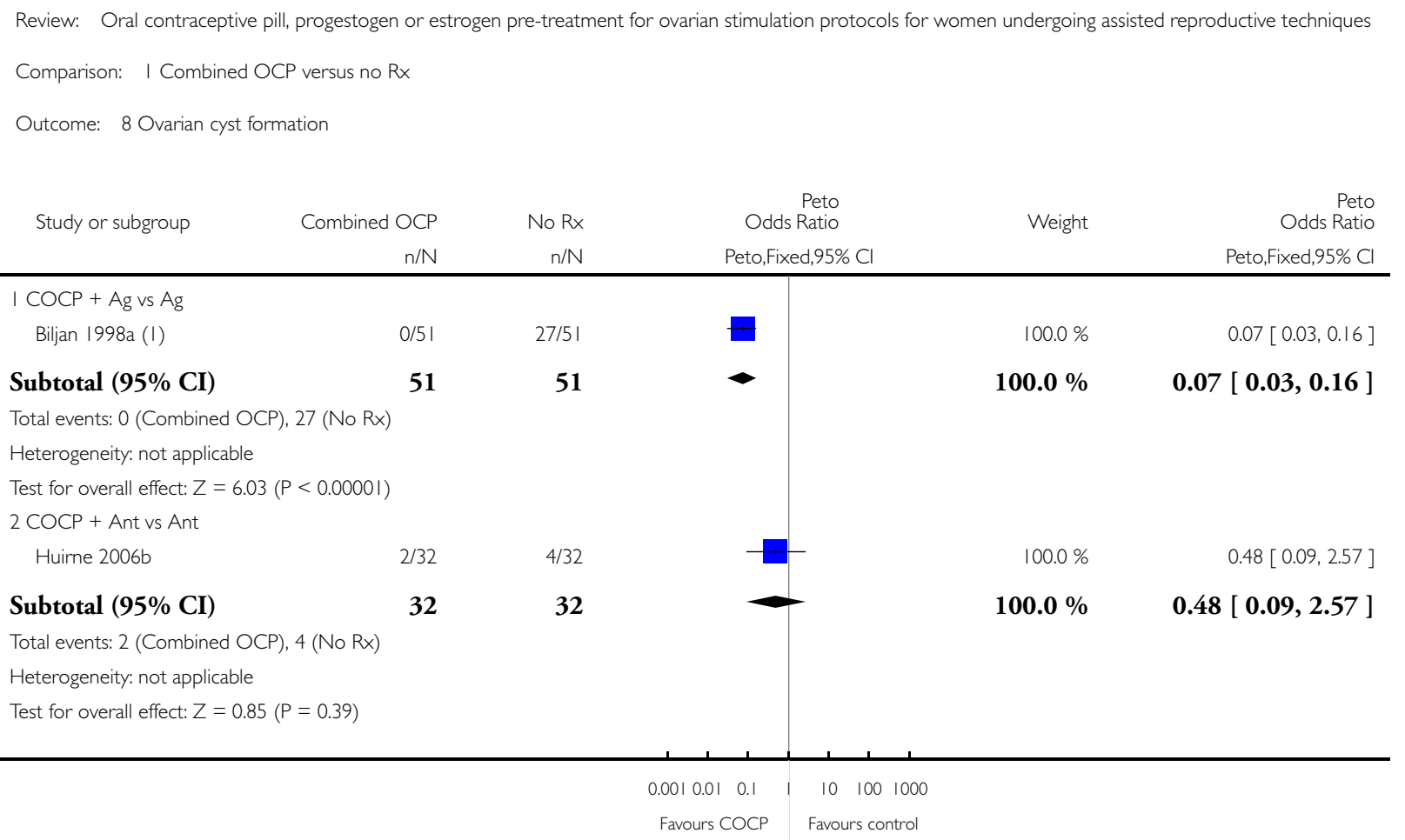

(I) Number of women per group unknown, only number of cycles known. 


\section{Analysis I.9. Comparison I Combined OCP versus no Rx, Outcome 9 Multiple pregnancies.}

Review: Oral contraceptive pill, progestogen or estrogen pre-treatment for ovarian stimulation protocols for women undergoing assisted reproductive techniques

Comparison: I Combined OCP versus no Rx

Outcome: 9 Multiple pregnancies

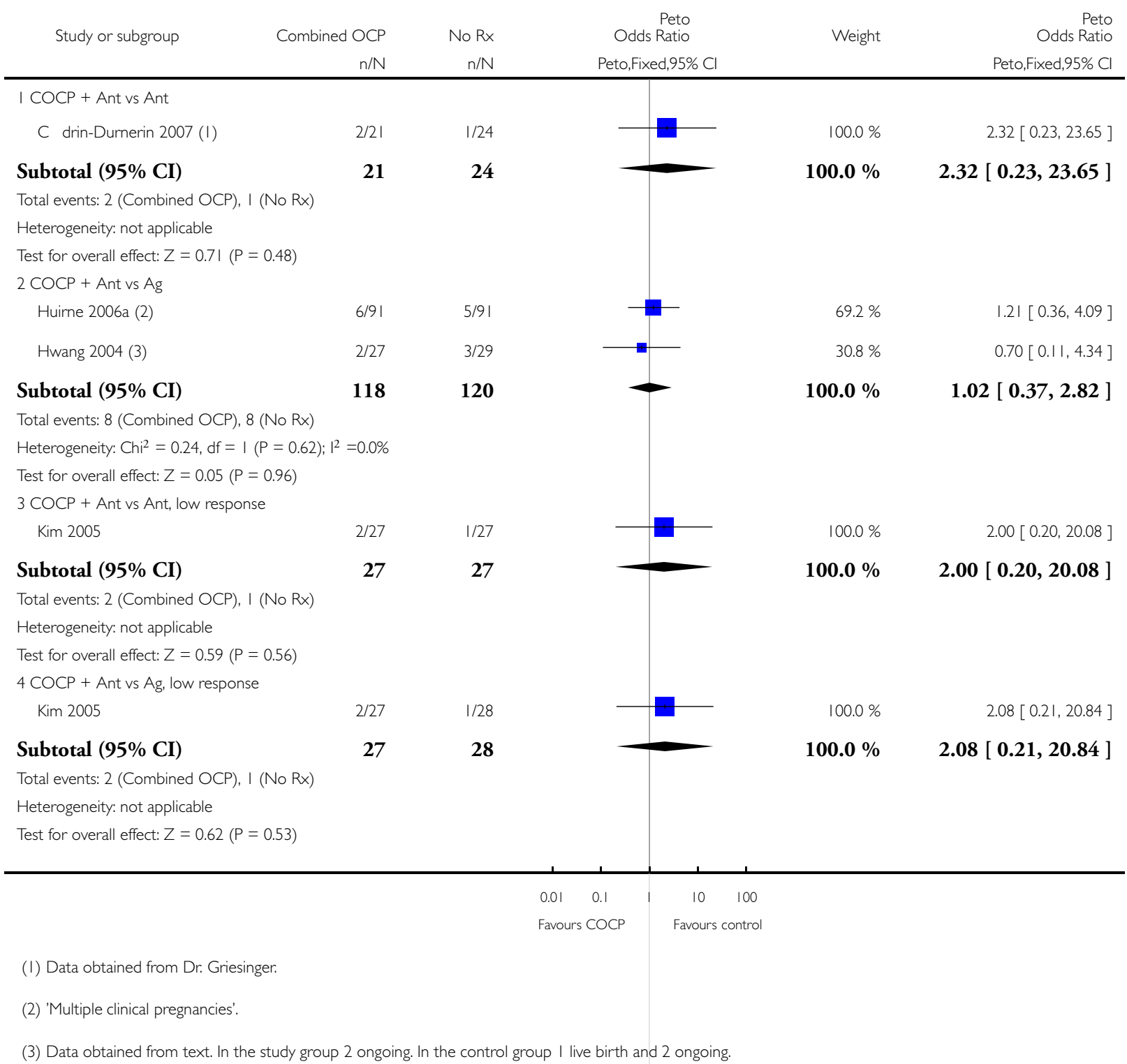




\section{Analysis I.10. Comparison I Combined OCP versus no Rx, Outcome 10 OHS syndrome.}

Review: Oral contraceptive pill, progestogen or estrogen pre-treatment for ovarian stimulation protocols for women undergoing assisted reproductive techniques

Comparison: I Combined OCP versus no Rx

Outcome: $10 \mathrm{OHS}$ syndrome

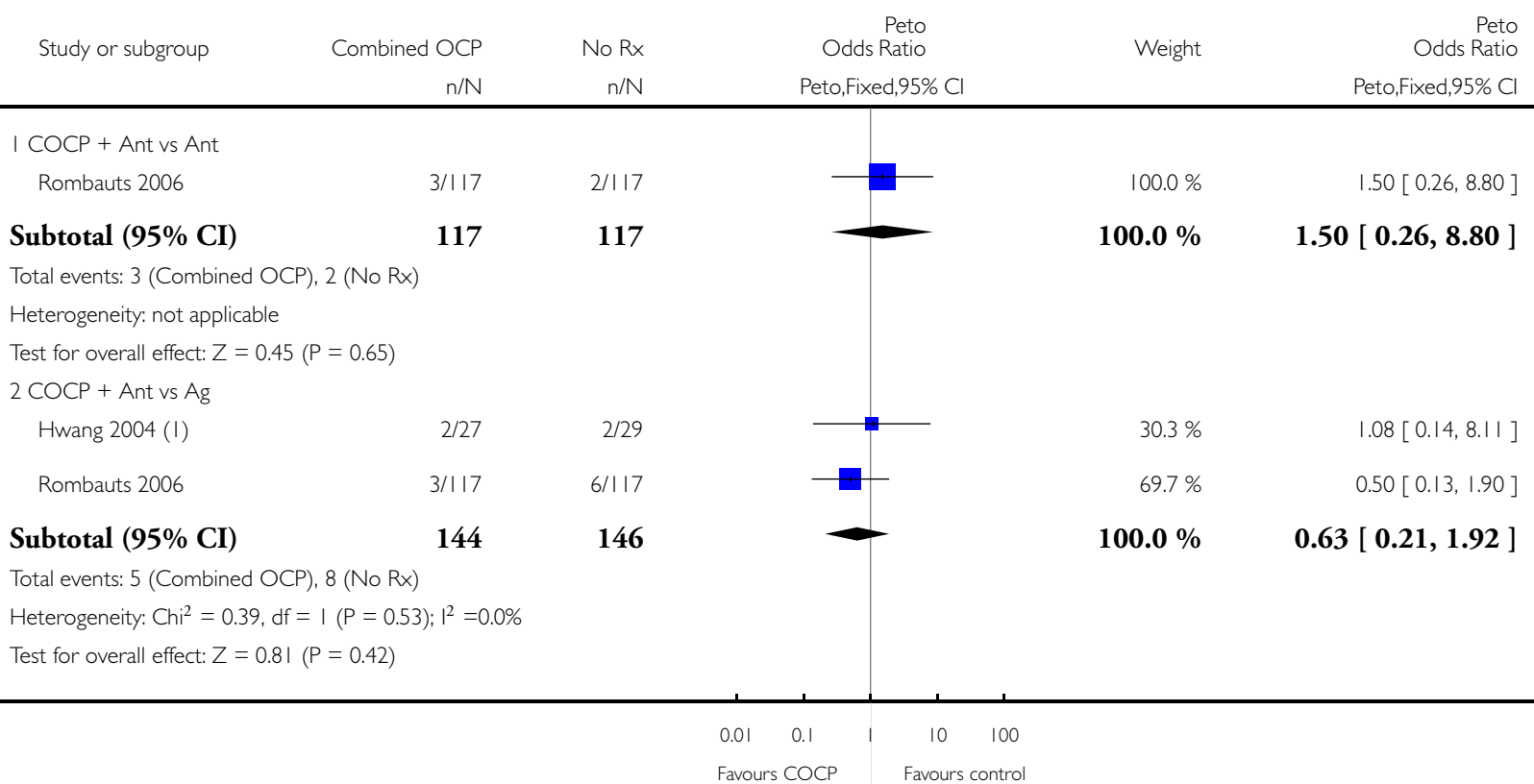

( ) Calculated from rates. 


\section{Analysis 2.I. Comparison 2 Progestogen versus placebo/ no Rx, Outcome I Live births.}

Review: Oral contraceptive pill, progestogen or estrogen pre-treatment for ovarian stimulation protocols for women undergoing assisted reproductive techniques Comparison: 2 Progestogen versus placebo/ no $\mathrm{Rx}$

Outcome: I Live births

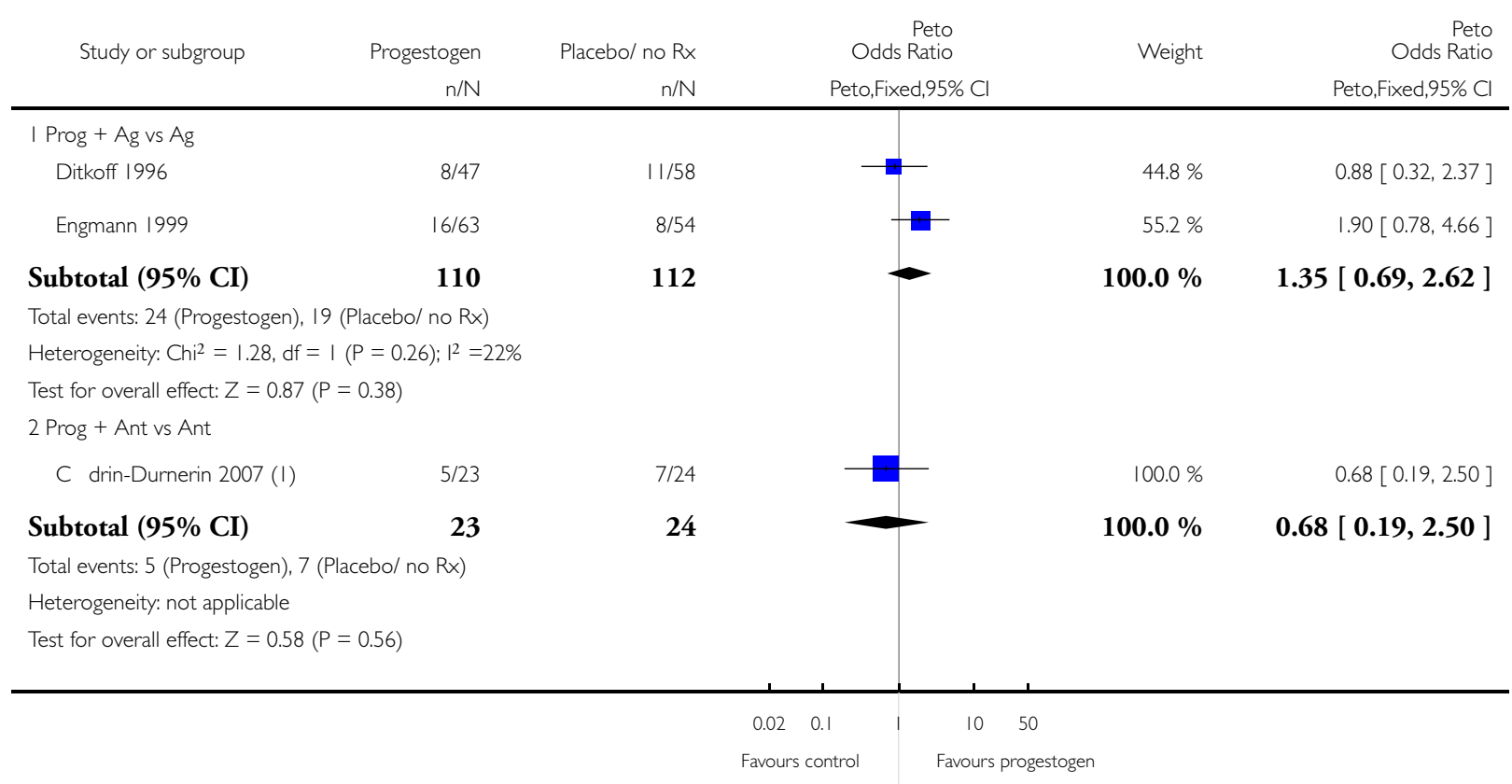

( I) Data obtained from Dr. Griesinger. 


\section{Analysis 2.2. Comparison 2 Progestogen versus placebo/ no Rx, Outcome 2 Ongoing pregnancies.}

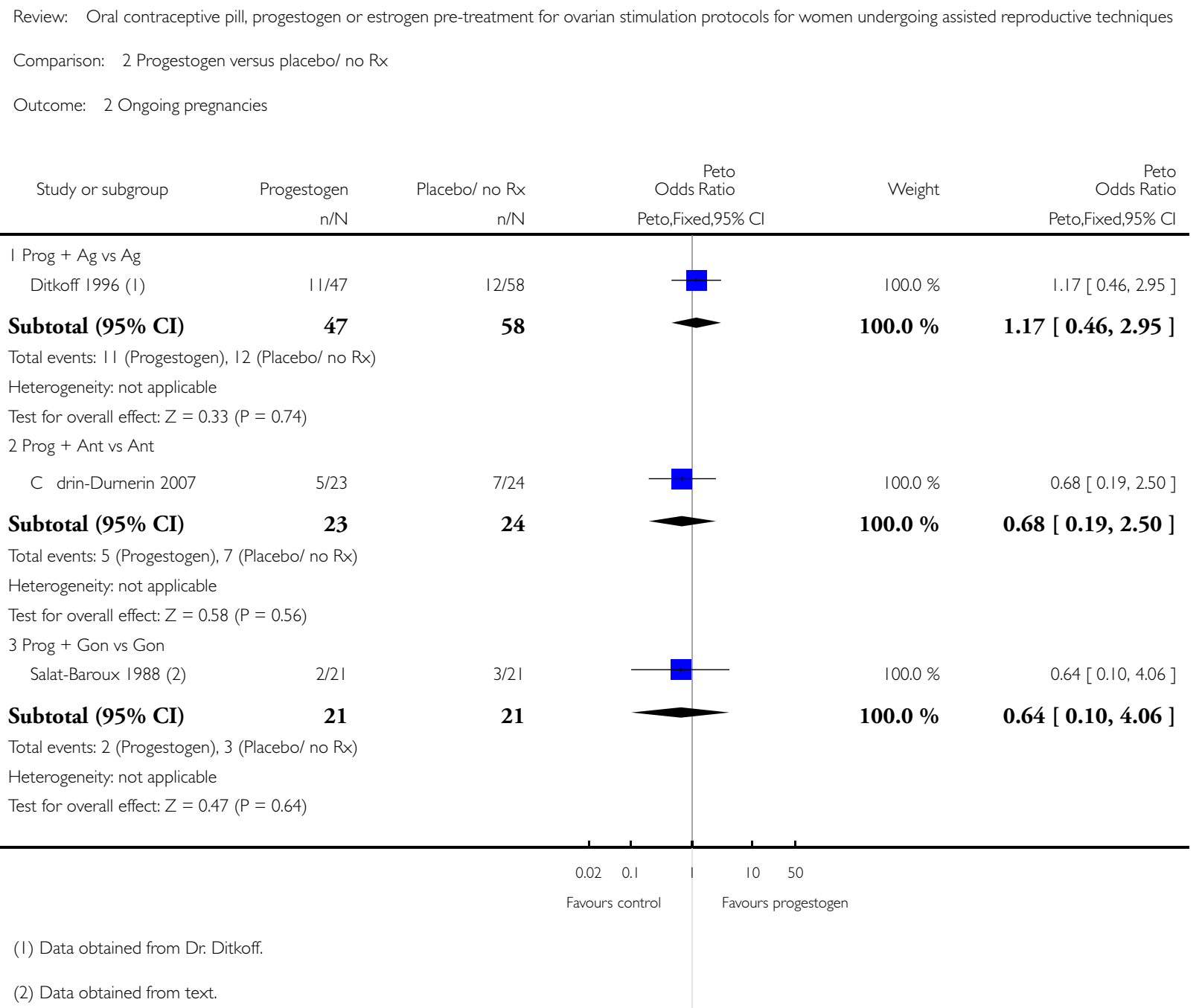




\section{Analysis 2.3. Comparison 2 Progestogen versus placebo/ no Rx, Outcome 3 Clinical pregnancies.}

Review: Oral contraceptive pill, progestogen or estrogen pre-treatment for ovarian stimulation protocols for women undergoing assisted reproductive techniques

Comparison: 2 Progestogen versus placebo/ no $R x$

Outcome: 3 Clinical pregnancies

Study or subgroup

Progestogen

$n / N$

I Prog + Ag vs Ag
Aston $1995(\mathrm{I})$
Ditkoff 1996
Engmann 1999 (2)

22/77

| $1 / 47$

$20 / 63$
187

Subtotal (95\% CI)

Total events: 53 (Progestogen), 31 (Placebo/ no Rx)

Heterogeneity: $\mathrm{Chi}^{2}=1.64, \mathrm{df}=2(\mathrm{P}=0.44) ;\left.\right|^{2}=0.0 \%$

Test for overall effect: $Z=2.69(P=0.007 \mathrm{I})$

2 Prog + Ant vs Ant

C drin-Durnerin 2007 (3)

$$
7 / 23
$$

Subtotal (95\% CI)

23

Total events: 7 (Progestogen), I I (Placebo/ no Rx)

Heterogeneity: not applicable

Test for overall effect: $Z=1.07(P=0.28)$

3 Prog + Gon vs Gon

Salat-Baroux 1988

Subtotal (95\% CI)

Total events: 3 (Progestogen), 4 (Placebo/ no Rx)

Heterogeneity: not applicable

Test for overall effect: $Z=0.4 \mathrm{I}(P=0.68)$
Peto,Fixed,95\% Cl

$10 / 75$

$12 / 58$

$9 / 54$

187

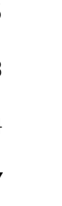

\begin{tabular}{lll}
$-39.0 \%$ & $2.49[1.14,5.41]$ \\
\hline- & $27.5 \%$ & $1.17[0.46,2.95]$ \\
$33.5 \%$ & $2.23[0.96,5.16]$
\end{tabular}

1.95 [ 1.20, 3.17 ]

Peto
Weight Odds Ratio Peto,Fixed,95\% Cl

- $\quad 100.0 \% \quad 1.95[1.20,3.17]$




\section{Analysis 2.4. Comparison 2 Progestogen versus placebo/ no Rx, Outcome 4 Oocytes retrieved.}

Review: Oral contraceptive pill, progestogen or estrogen pre-treatment for ovarian stimulation protocols for women undergoing assisted reproductive techniques

Comparison: 2 Progestogen versus placebo/ no $\mathrm{Rx}$

Outcome: 4 Oocytes retrieved

\begin{tabular}{|c|c|c|c|c|c|c|c|}
\hline \multirow[t]{2}{*}{ Study or subgroup } & \multirow{2}{*}{$\begin{array}{r}\text { Progestogen } \\
N\end{array}$} & \multicolumn{2}{|c|}{ Placebo/ no Rx } & \multirow{2}{*}{\multicolumn{2}{|c|}{$\begin{array}{c}\text { Mean } \\
\text { Difference } \\
\text { IV,Fixed,95\% Cl }\end{array}$}} & \multirow[t]{2}{*}{ Weight } & \multirow{2}{*}{$\begin{array}{r}\text { Mean } \\
\text { Difference } \\
\text { IV,Fixed,95\% Cl }\end{array}$} \\
\hline & & Mean(SD) & $\mathrm{N}$ & & & & \\
\hline \multicolumn{8}{|l|}{ I Prog + Ag vs Ag } \\
\hline Ditkoff I996 (I) & 41 & | $3.8(7.6)$ & 53 & $12.8(8.9)$ & & $22.0 \%$ & $1.00[-2.34,4.34]$ \\
\hline Engmann $1999(2)$ & 62 & $8.4(4.7)$ & 54 & $9.4(5)$ & & $78.0 \%$ & $-1.00[-2.77,0.77]$ \\
\hline Subtotal (95\% CI) & 103 & & 107 & & & $100.0 \%$ & $-0.56[-2.13,1.01]$ \\
\hline \multicolumn{8}{|c|}{ Heterogeneity: $\mathrm{Chi}^{2}=1.07, \mathrm{df}=\mathrm{I}(\mathrm{P}=0.30) ; \mathrm{I}^{2}=7 \%$} \\
\hline \multicolumn{8}{|c|}{ Test for overall effect: $Z=0.70(P=0.48)$} \\
\hline \multicolumn{8}{|c|}{2 Prog + Ant vs Ant } \\
\hline C drin-Durnerin 2007 & 23 & $12.6(7.3)$ & 24 & $9.9(5.4)$ & & $100.0 \%$ & $2.70[-0.98,6.38]$ \\
\hline Subtotal (95\% CI) & 23 & & 24 & & & $100.0 \%$ & $2.70[-0.98,6.38]$ \\
\hline \multicolumn{8}{|c|}{ Heterogeneity: not applicable } \\
\hline \multicolumn{8}{|c|}{ Test for overall effect: $Z=1.44(P=0.15)$} \\
\hline \multicolumn{8}{|c|}{3 Prog + Gon vs Gon } \\
\hline Salat-Baroux 1988 (3) & 13 & $4.9(0.9)$ & 16 & $4.9(0.6)$ & & $100.0 \%$ & $0.0[-0.57,0.57]$ \\
\hline Subtotal (95\% CI) & 13 & & 16 & & $\rightarrow$ & $100.0 \%$ & $0.0[-0.57,0.57]$ \\
\hline \multicolumn{8}{|c|}{ Heterogeneity: not applicable } \\
\hline \multicolumn{8}{|c|}{ Test for overall effect: $Z=0.0(P=1.0)$} \\
\hline \multicolumn{8}{|c|}{ Test for subgroup differences: $\mathrm{Chi}^{2}=2.55, \mathrm{df}=2(\mathrm{P}=0.28), \mathrm{I}^{2}=22 \%$} \\
\hline & & & & -10 & -5 & 10 & \\
\hline & & & & Favo & ontrol & ggestogen & \\
\hline
\end{tabular}

( I) No ITT.

(2) No ITT in progestogen group. 'Mature oocytes'.

(3) No ITT. 


\section{Analysis 2.5. Comparison 2 Progestogen versus placebo/ no Rx, Outcome 5 Days of gonadotrophin}

treatment.

Review: Oral contraceptive pill, progestogen or estrogen pre-treatment for ovarian stimulation protocols for women undergoing assisted reproductive techniques Comparison: 2 Progestogen versus placebo/ no $\mathrm{Rx}$

Outcome: 5 Days of gonadotrophin treatment

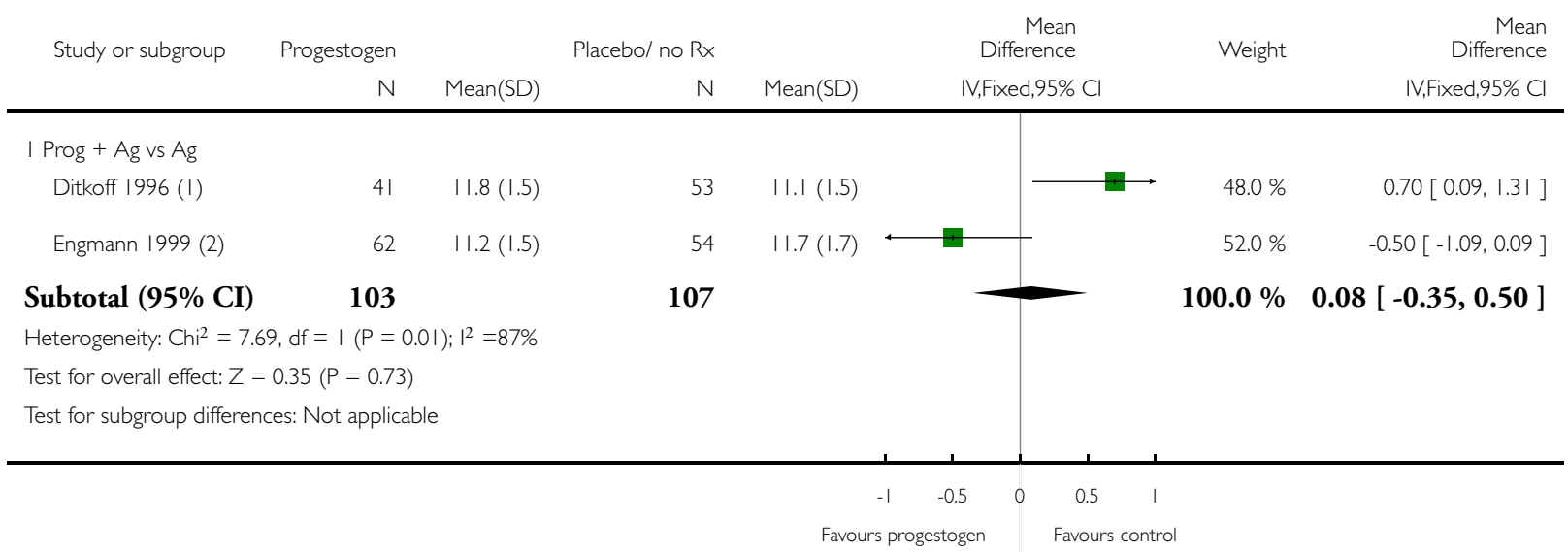

( I) No ITT.

(2) No ITT in progestogen group. 


\section{Analysis 2.6. Comparison 2 Progestogen versus placebo/ no Rx, Outcome 6 Amount of gonadotrophins}

administered.

Review: Oral contraceptive pill, progestogen or estrogen pre-treatment for ovarian stimulation protocols for women undergoing assisted reproductive techniques

Comparison: 2 Progestogen versus placebo/ no $\mathrm{Rx}$

Outcome: 6 Amount of gonadotrophins administered

\begin{tabular}{|c|c|c|c|c|c|c|c|c|}
\hline \multirow[t]{2}{*}{ Study or subgroup } & \multirow{2}{*}{$\begin{array}{r}\text { Progestogen } \\
N\end{array}$} & \multicolumn{3}{|c|}{ Placebo/ no Rx } & \multicolumn{2}{|c|}{$\begin{array}{r}\text { Mean } \\
\text { Difference }\end{array}$} & \multirow[t]{2}{*}{ Weight } & \multirow{2}{*}{$\begin{array}{r}\text { Mear } \\
\text { Difference } \\
\text { IV,Fixed,95\% C }\end{array}$} \\
\hline & & Mean(SD) & $\mathrm{N}$ & Mean(SD) & & $\mathrm{ked}, 95 \% \mathrm{Cl}$ & & \\
\hline \multicolumn{9}{|l|}{ I Prog + Ant vs Ant } \\
\hline C drin-Durnerin 2007 & 23 & $2010(670)$ & 24 & | $734(55 \mid)$ & & & $100.0 \%$ & $276.00[-75.53,627.53]$ \\
\hline Subtotal (95\% CI) & 23 & & 24 & & & & $100.0 \%$ & $276.00[-75.53,627.53]$ \\
\hline \multicolumn{9}{|c|}{ Heterogeneity: not applicable } \\
\hline \multicolumn{9}{|c|}{ Test for overall effect: $Z=1.54(P=0.12)$} \\
\hline & & & & -1000 & -500 & 500 & 1000 & \\
\hline \multicolumn{9}{|c|}{ Favours progestogen } \\
\hline
\end{tabular}

Oral contraceptive pill, progestogen or estrogen pre-treatment for ovarian stimulation protocols for women undergoing assisted 


\section{Analysis 2.7. Comparison 2 Progestogen versus placebo/ no Rx, Outcome 7 Pregnancy losses.}

Review: Oral contraceptive pill, progestogen or estrogen pre-treatment for ovarian stimulation protocols for women undergoing assisted reproductive techniques Comparison: 2 Progestogen versus placebo/ no $\mathrm{Rx}$

Outcome: 7 Pregnancy losses

\begin{tabular}{|c|c|c|c|c|c|}
\hline \multirow[t]{2}{*}{ Study or subgroup } & \multirow{2}{*}{$\begin{array}{r}\text { Progestogen } \\
\mathrm{n} / \mathrm{N}\end{array}$} & \multirow{2}{*}{$\begin{array}{r}\text { Placebo/ no Rx } \\
n / N\end{array}$} & $\begin{array}{r}\text { Peto } \\
\text { Odds Ratio }\end{array}$ & \multirow[t]{2}{*}{ Weight } & $\begin{array}{r}\text { Peto } \\
\text { Odds Ratio }\end{array}$ \\
\hline & & & Peto,Fixed,95\% Cl & & Peto,Fixed,95\% Cl \\
\hline \multicolumn{6}{|l|}{ I Prog + Ag vs Ag } \\
\hline Ditkoff 1996 (I) & $3 / 47$ & $1 / 58$ & - & $31.6 \%$ & $3.52[0.48,26.03]$ \\
\hline Engmann 1999 & $6 / 63$ & $3 / 54$ & & $68.4 \%$ & $1.74[0.45,6.77]$ \\
\hline Subtotal (95\% CI) & 110 & 112 & & $100.0 \%$ & $2.17[0.71,6.69]$ \\
\hline \multicolumn{6}{|c|}{ Total events: 9 (Progestogen), 4 (Placebo/ no Rx) } \\
\hline \multicolumn{6}{|c|}{ Heterogeneity: Chi $^{2}=0.33, \mathrm{df}=\mathrm{I}(P=0.57) ; \mathrm{I}^{2}=0.0 \%$} \\
\hline \multicolumn{6}{|c|}{ Test for overall effect: $Z=1.35(P=0.18)$} \\
\hline \multicolumn{6}{|l|}{2 Prog + Ant vs Ant } \\
\hline C drin-Durnerin 2007 (2) & $2 / 23$ & $5 / 24$ & + & $100.0 \%$ & $0.39[0.08,1.92]$ \\
\hline Subtotal (95\% CI) & 23 & 24 & & $100.0 \%$ & $0.39[0.08,1.92]$ \\
\hline \multicolumn{6}{|c|}{ Total events: 2 (Progestogen), 5 (Placebo/ no Rx) } \\
\hline \multicolumn{6}{|c|}{ Heterogeneity: not applicable } \\
\hline \multicolumn{6}{|c|}{ Test for overall effect: $Z=1.16(P=0.25)$} \\
\hline \multicolumn{6}{|c|}{3 Prog + Gon vs Gon } \\
\hline Salat-Baroux 1988 (3) & $|/ 2|$ & $|/ 2|$ & & $100.0 \%$ & $1.00[0.06,16.55]$ \\
\hline Subtotal (95\% CI) & 21 & 21 & & $100.0 \%$ & $1.00[0.06,16.55]$ \\
\hline \multicolumn{6}{|c|}{ Total events: I (Progestogen), I (Placebo/ no Rx) } \\
\hline \multicolumn{6}{|c|}{ Heterogeneity: not applicable } \\
\hline \multicolumn{6}{|c|}{ Test for overall effect: $Z=0.0(P=1.0)$} \\
\hline & & 0.01 & 10 & 100 & \\
\hline & & Favours pro & Favours & ontrol & \\
\hline
\end{tabular}

(I) Calculated from the number of clinical pregnancies minus the number of live births.

(2) Calculated from the number of clinical pregnancies minus the number of live births.

(3) Data obtained from text, not sure whether follow up was long enough. 


\section{Analysis 2.8. Comparison 2 Progestogen versus placebo/ no Rx, Outcome 8 Ovarian cyst formation.}

Review: Oral contraceptive pill, progestogen or estrogen pre-treatment for ovarian stimulation protocols for women undergoing assisted reproductive techniques

Comparison: 2 Progestogen versus placebo/ no $\mathrm{Rx}$

Outcome: 8 Ovarian cyst formation

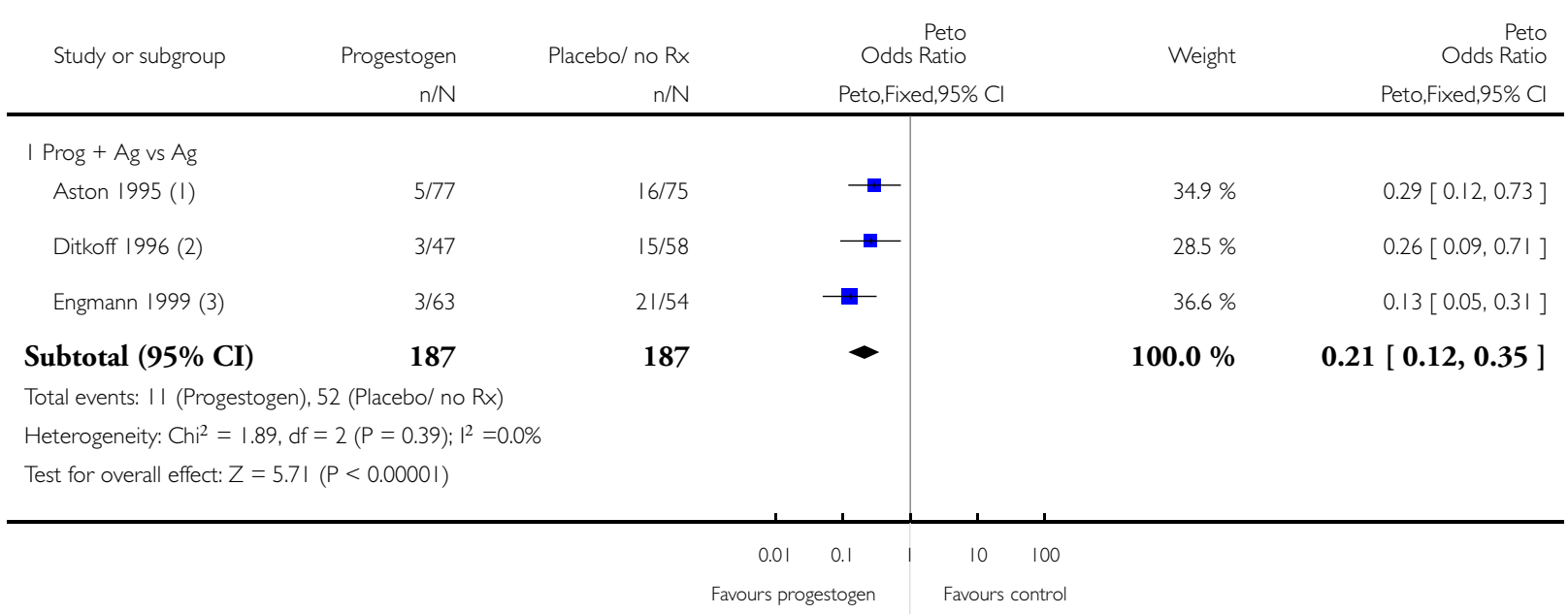

\footnotetext{
( I) Measured after 12 days of pituitary suppression.

(2) Measured after 8 days of pituitary suppression.

(3) Measured after 7 days of pituitary suppression.
} 


\section{Analysis 2.9. Comparison 2 Progestogen versus placebo/ no Rx, Outcome 9 Multiple pregnancies.}

Review: Oral contraceptive pill, progestogen or estrogen pre-treatment for ovarian stimulation protocols for women undergoing assisted reproductive techniques Comparison: 2 Progestogen versus placebo/ no $\mathrm{Rx}$

Outcome: 9 Multiple pregnancies

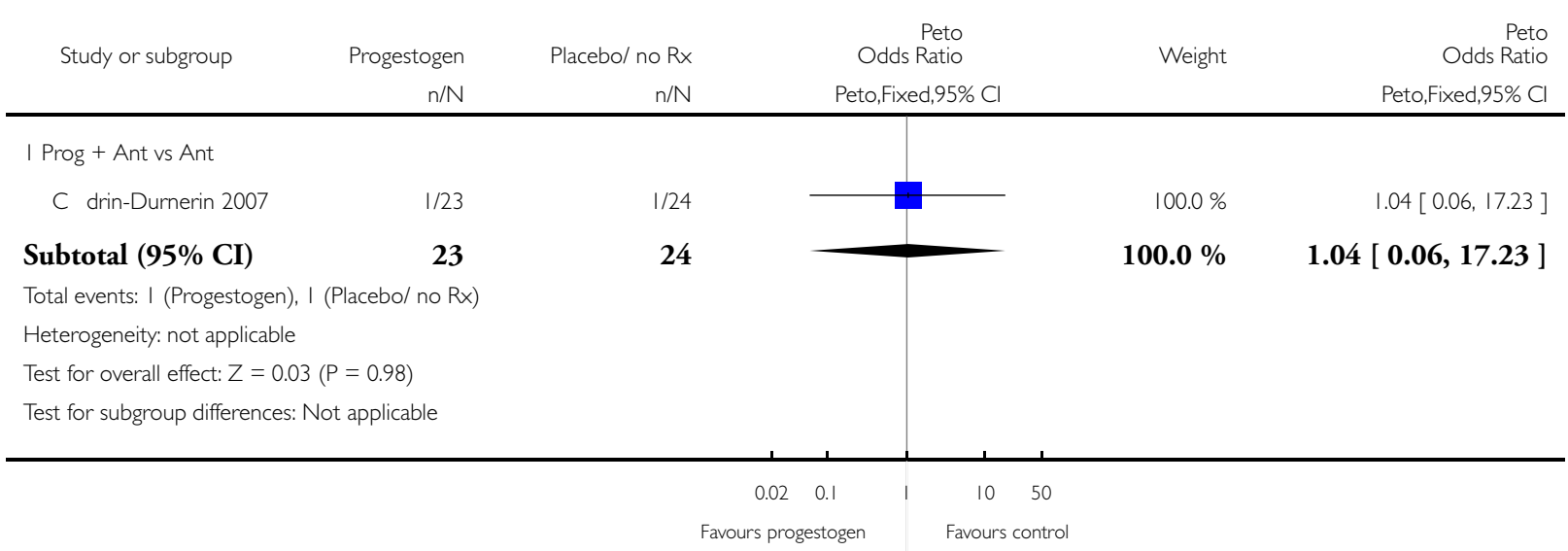




\section{Analysis 3.I. Comparison 3 Estrogen versus no Rx, Outcome I Live births.}

Review: Oral contraceptive pill, progestogen or estrogen pre-treatment for ovarian stimulation protocols for women undergoing assisted reproductive techniques

Comparison: 3 Estrogen versus no $\mathrm{Rx}$

Outcome: I Live births

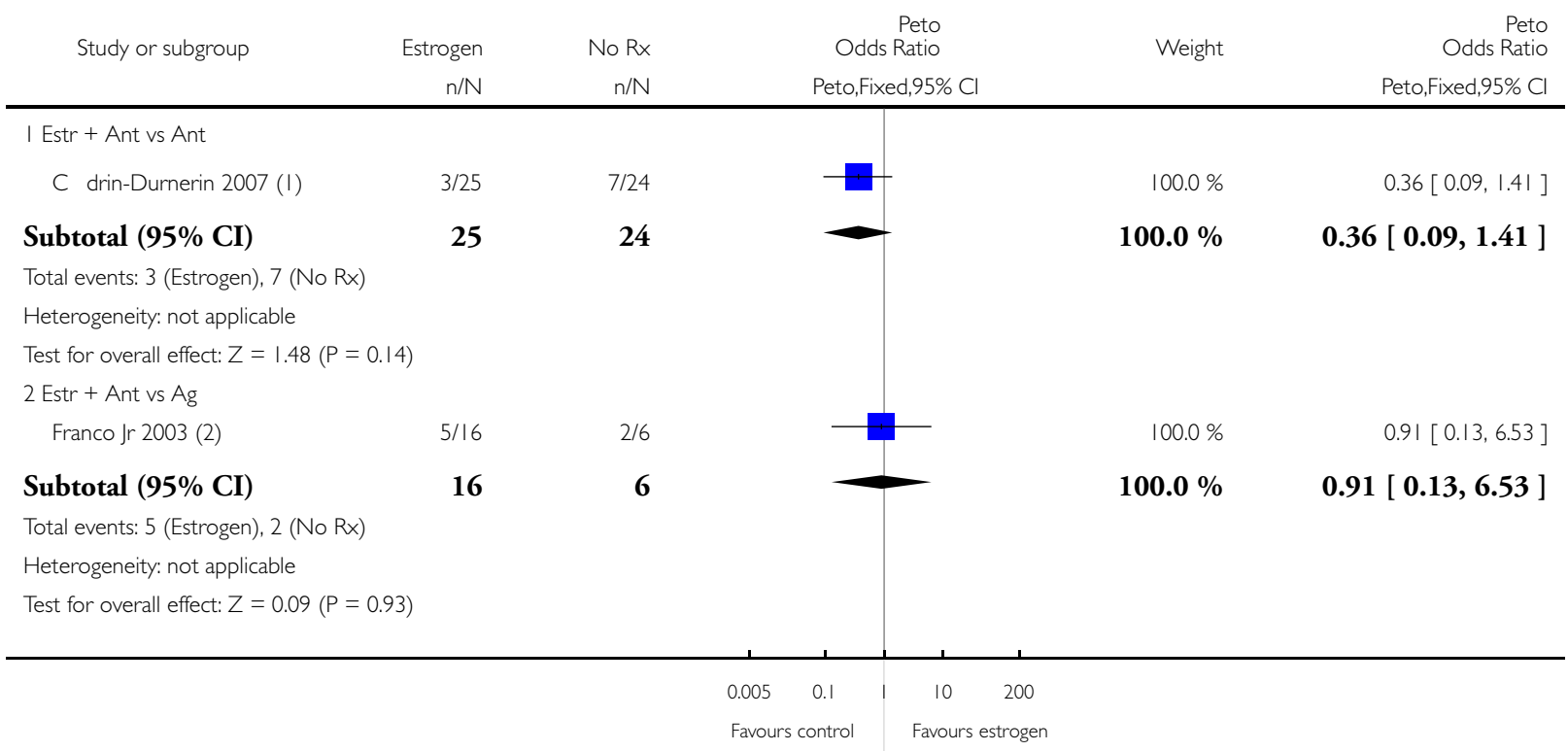

( I) Data obtained from Dr. Griesinger.

(2) Includes 2 spontaneous pregnancies in the study group. Data obtained from Dr. Franco Jr. 


\section{Analysis 3.2. Comparison 3 Estrogen versus no Rx, Outcome 2 Ongoing pregnancies.}

Review: Oral contraceptive pill, progestogen or estrogen pre-treatment for ovarian stimulation protocols for women undergoing assisted reproductive techniques Comparison: 3 Estrogen versus no $\mathrm{Rx}$

Outcome: 2 Ongoing pregnancies

\begin{tabular}{|c|c|c|c|c|c|c|}
\hline \multirow[t]{2}{*}{ Study or subgroup } & \multirow{2}{*}{$\begin{array}{r}\text { Estrogen } \\
n / N\end{array}$} & No $R x$ & \multicolumn{2}{|r|}{$\begin{array}{r}\text { Peto } \\
\text { Odds Ratio }\end{array}$} & \multirow[t]{2}{*}{ Weight } & \multirow{2}{*}{$\begin{array}{r}\text { Peto } \\
\text { Odds Ratio } \\
\text { Peto,Fixed,95\% Cl }\end{array}$} \\
\hline & & $\mathrm{n} / \mathrm{N}$ & \multicolumn{2}{|r|}{ Peto,Fixed,95\% Cl } & & \\
\hline \multicolumn{7}{|l|}{ I Estr + Ant vs Ant } \\
\hline C drin-Durnerin 2007 (I) & $3 / 25$ & $7 / 24$ & & & $100.0 \%$ & $0.36[0.09,1.41]$ \\
\hline Subtotal (95\% CI) & 25 & 24 & & & $100.0 \%$ & $0.36[0.09,1.41]$ \\
\hline \multicolumn{7}{|c|}{ Total events: 3 (Estrogen), 7 (No Rx) } \\
\hline \multicolumn{7}{|c|}{ Heterogeneity: not applicable } \\
\hline \multicolumn{7}{|c|}{ Test for overall effect: $Z=1.48(P=0.14)$} \\
\hline \multicolumn{7}{|l|}{2 Estr + Ant vs Ag } \\
\hline Franco Jr 2003 (2) & $5 / 16$ & $2 / 6$ & & & $100.0 \%$ & $0.91[0.13,6.53]$ \\
\hline Subtotal (95\% CI) & 16 & 6 & & & $100.0 \%$ & $0.91[0.13,6.53]$ \\
\hline \multicolumn{7}{|c|}{ Total events: 5 (Estrogen), 2 (No Rx) } \\
\hline \multicolumn{7}{|l|}{ Heterogeneity: not applicable } \\
\hline \multicolumn{7}{|c|}{ Test for overall effect: $Z=0.09(P=0.93)$} \\
\hline & & & 0.01 & 0.1 & 100 & \\
\hline & & & Favour & Favours & strogen & \\
\hline
\end{tabular}

( I) Data obtained from Dr. C drin-Durnerin.

(2) Includes 2 spontaneous pregnancies in the study group. 


\section{Analysis 3.4. Comparison 3 Estrogen versus no Rx, Outcome 4 Oocytes retrieved.}

Review: Oral contraceptive pill, progestogen or estrogen pre-treatment for ovarian stimulation protocols for women undergoing assisted reproductive techniques

Comparison: 3 Estrogen versus no $\mathrm{Rx}$

Outcome: 4 Oocytes retrieved

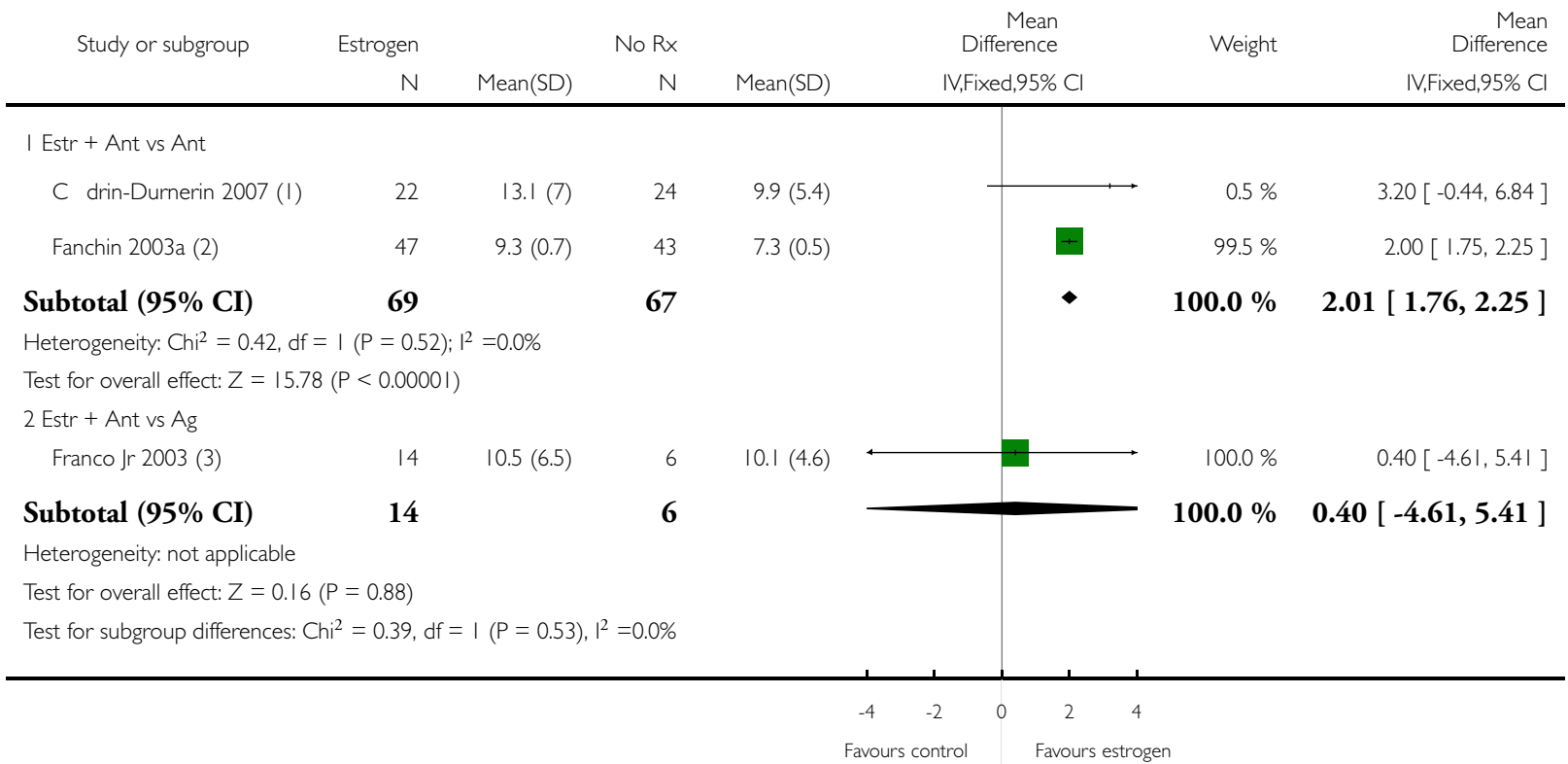

(I) No ITT in estrogen group.

(2) No ITT. 'Mature follicles'.

(3) No ITT. 


\section{Analysis 3.5. Comparison 3 Estrogen versus no Rx, Outcome 5 Days of gonadotrophin treatment.}

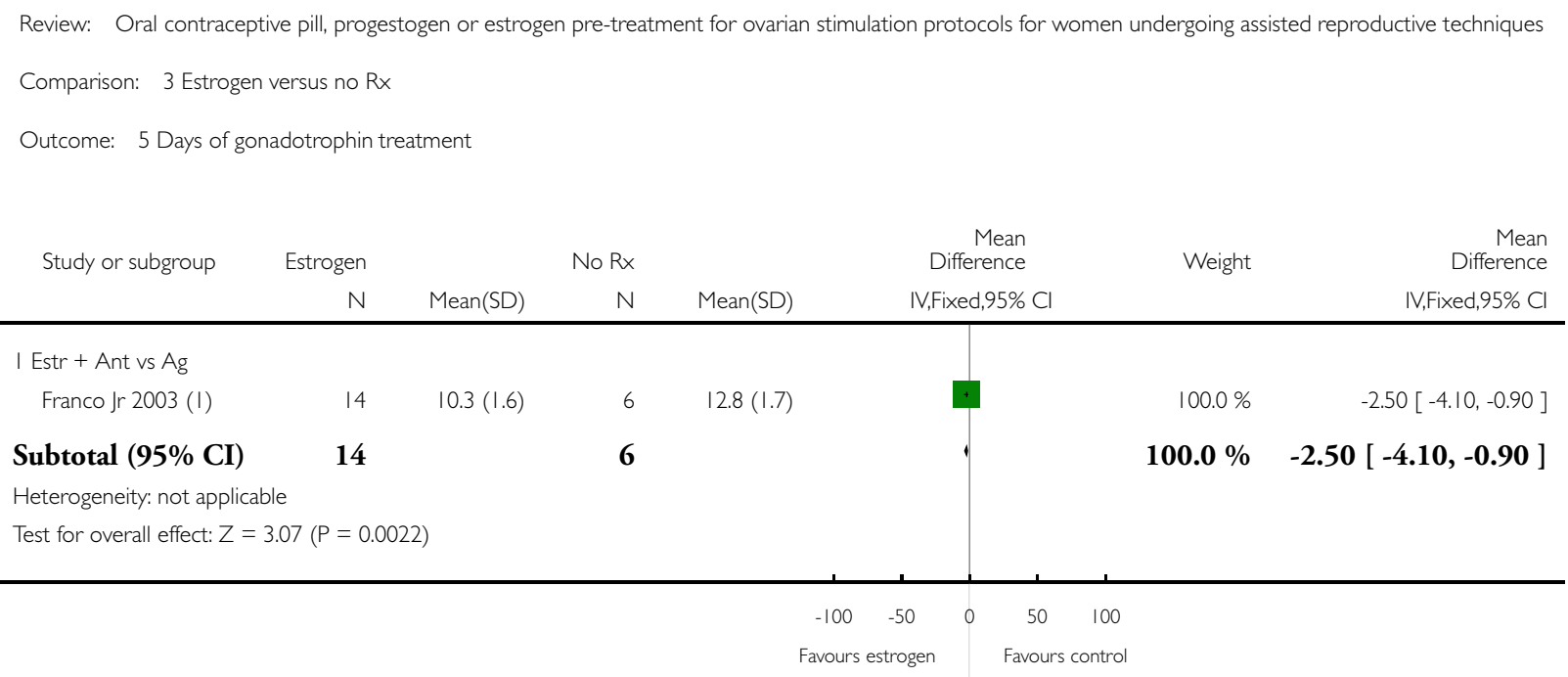

( I) No ITT. Data obtained from Dr. Franco Jr. 
Analysis 3.6. Comparison 3 Estrogen versus no Rx, Outcome 6 Amount of gonadotrophins administered.

Review: Oral contraceptive pill, progestogen or estrogen pre-treatment for ovarian stimulation protocols for women undergoing assisted reproductive techniques

Comparison: 3 Estrogen versus no $\mathrm{Rx}$

Outcome: 6 Amount of gonadotrophins administered

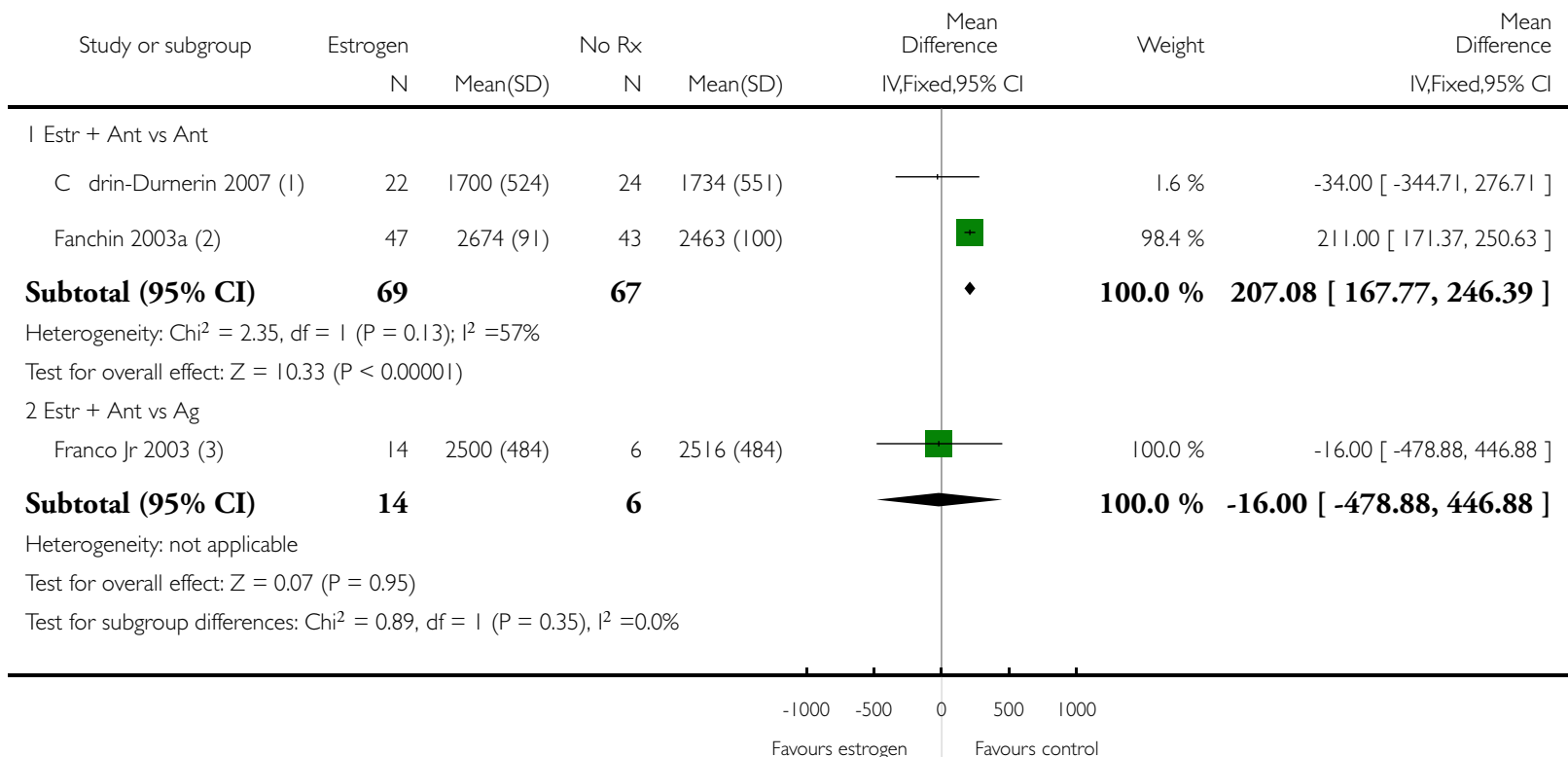

( I) No ITT in estrogen group.

(2) No ITT.

(3) No ITT. 


\section{Analysis 3.7. Comparison 3 Estrogen versus no Rx, Outcome 7 Pregnancy losses.}

Review: Oral contraceptive pill, progestogen or estrogen pre-treatment for ovarian stimulation protocols for women undergoing assisted reproductive techniques

Comparison: 3 Estrogen versus no $\mathrm{Rx}$

Outcome: 7 Pregnancy losses

$\begin{array}{llr}\text { Peto } & \text { Peto } & \text { Odds Ratio }\end{array}$

$n / N \quad n / N$

Peto,Fixed,95\% C

Peto,Fixed,95\% Cl

I Estr + Ant vs Ant

C drin-Durnerin 2007 (I)

$1 / 25$

$5 / 24$

$0.22[0.04,1.17]$

Subtotal $(\mathbf{9 5 \%} \mathrm{CI})$

25

24

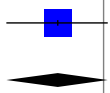

Total events: I (Estrogen), 5 (No Rx)

Heterogeneity: not applicable

Test for overall effect: $Z=1.78(P=0.075)$

2 Estr + Ant vs Ag

Franco Jr 2003

$0 / 16$

$0 / 6$

$0.0[0.0,0.0]$

Subtotal (95\% CI)

16

6

$0.0[0.0,0.0]$

Total events: 0 (Estrogen), 0 (No Rx)

Heterogeneity: not applicable

Test for overall effect: $Z=0.0(P<0.0000$ I $)$

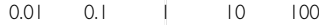

Favours estrogen

Favours control

( I) Calculated from the number of clinical pregnancies minus the number of live births.

Oral contraceptive pill, progestogen or estrogen pre-treatment for ovarian stimulation protocols for women undergoing assisted 


\section{Analysis 3.8. Comparison 3 Estrogen versus no Rx, Outcome 8 Ovarian cyst formation.}

Review: Oral contraceptive pill, progestogen or estrogen pre-treatment for ovarian stimulation protocols for women undergoing assisted reproductive techniques Comparison: 3 Estrogen versus no $\mathrm{Rx}$

Outcome: 8 Ovarian cyst formation

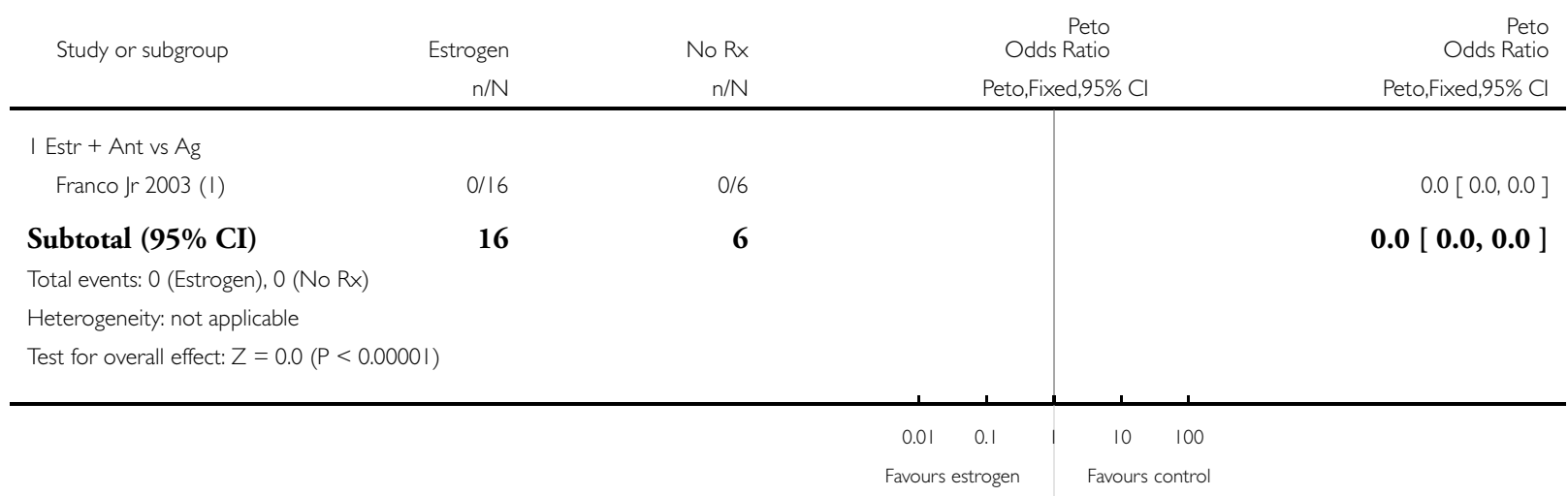

( I) Data obtained from Dr. Franco Jr. 


\section{Analysis 3.9. Comparison 3 Estrogen versus no Rx, Outcome 9 Multiple pregnancies.}

Review: Oral contraceptive pill, progestogen or estrogen pre-treatment for ovarian stimulation protocols for women undergoing assisted reproductive techniques

Comparison: 3 Estrogen versus no $\mathrm{Rx}$

Outcome: 9 Multiple pregnancies

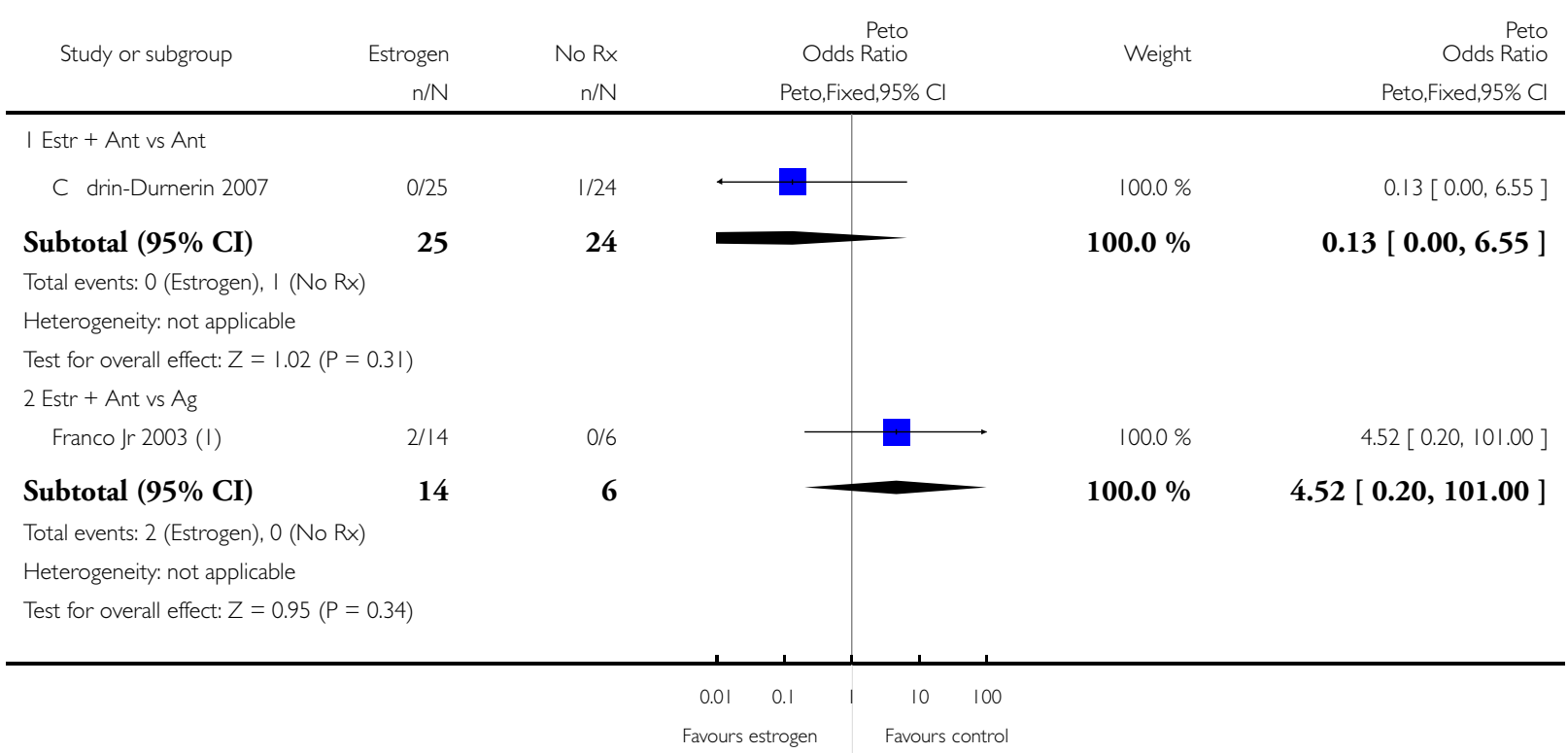

( I) No ITT. Data obtained from Dr. Franco Jr. 


\section{Analysis 3.10. Comparison 3 Estrogen versus no Rx, Outcome 10 OHS syndrome.}

Review: Oral contraceptive pill, progestogen or estrogen pre-treatment for ovarian stimulation protocols for women undergoing assisted reproductive techniques

Comparison: 3 Estrogen versus no $\mathrm{Rx}$

Outcome: $10 \mathrm{OHS}$ syndrome

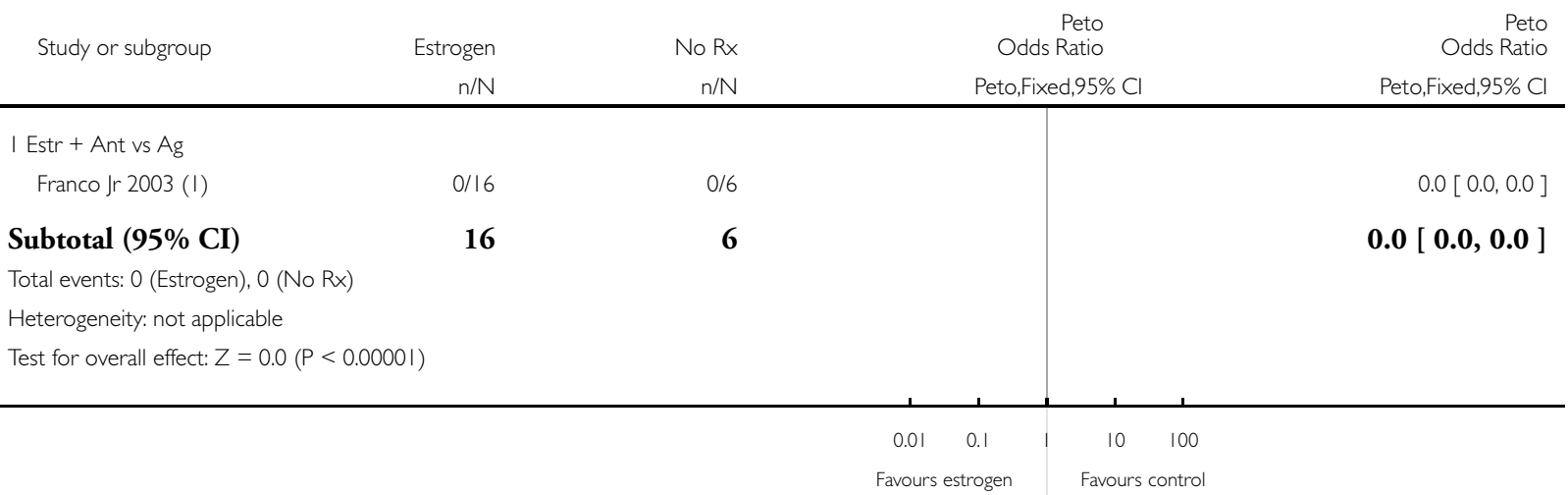

( I) Data obtained from Dr. Franco Jr.

Analysis 4.I. Comparison 4 Combined OCP versus progestogen, Outcome I Live births.

Review: Oral contraceptive pill, progestogen or estrogen pre-treatment for ovarian stimulation protocols for women undergoing assisted reproductive techniques

Comparison: 4 Combined OCP versus progestogen

Outcome: I Live births

\begin{tabular}{|c|c|c|c|c|c|c|}
\hline \multirow[t]{2}{*}{ Study or subgroup } & \multirow{2}{*}{$\begin{array}{r}\text { Combined OCP } \\
n / N\end{array}$} & Progestogen & \multicolumn{2}{|r|}{$\begin{array}{r}\text { Peto } \\
\text { Odds Ratio }\end{array}$} & \multirow[t]{2}{*}{ Weight } & $\begin{array}{r}\text { Peto } \\
\text { Odds Ratio }\end{array}$ \\
\hline & & $\mathrm{n} / \mathrm{N}$ & \multicolumn{2}{|r|}{ Peto,Fixed,95\% Cl } & & Peto,Fixed,95\% Cl \\
\hline \multicolumn{7}{|l|}{ I COCP + Ant vs Prog + Ant } \\
\hline C drin-Durnerin 2007 & $3 / 21$ & $5 / 23$ & & & $100.0 \%$ & $0.61[0.13,2.79]$ \\
\hline Subtotal (95\% CI) & 21 & 23 & & & $100.0 \%$ & $0.61[0.13,2.79]$ \\
\hline \multicolumn{7}{|c|}{ Total events: 3 (Combined OCP), 5 (Progestogen) } \\
\hline \multicolumn{7}{|l|}{ Heterogeneity: not applicable } \\
\hline \multicolumn{7}{|c|}{ Test for overall effect: $Z=0.63(P=0.53)$} \\
\hline & & & 0.002 & 110 & 500 & \\
\hline \multicolumn{7}{|c|}{ Favours progestogen $\quad$ Favours $\mathrm{COCP}$} \\
\hline
\end{tabular}

Oral contraceptive pill, progestogen or estrogen pre-treatment for ovarian stimulation protocols for women undergoing assisted 


\section{Analysis 4.2. Comparison 4 Combined OCP versus progestogen, Outcome 2 Ongoing pregnancies.}

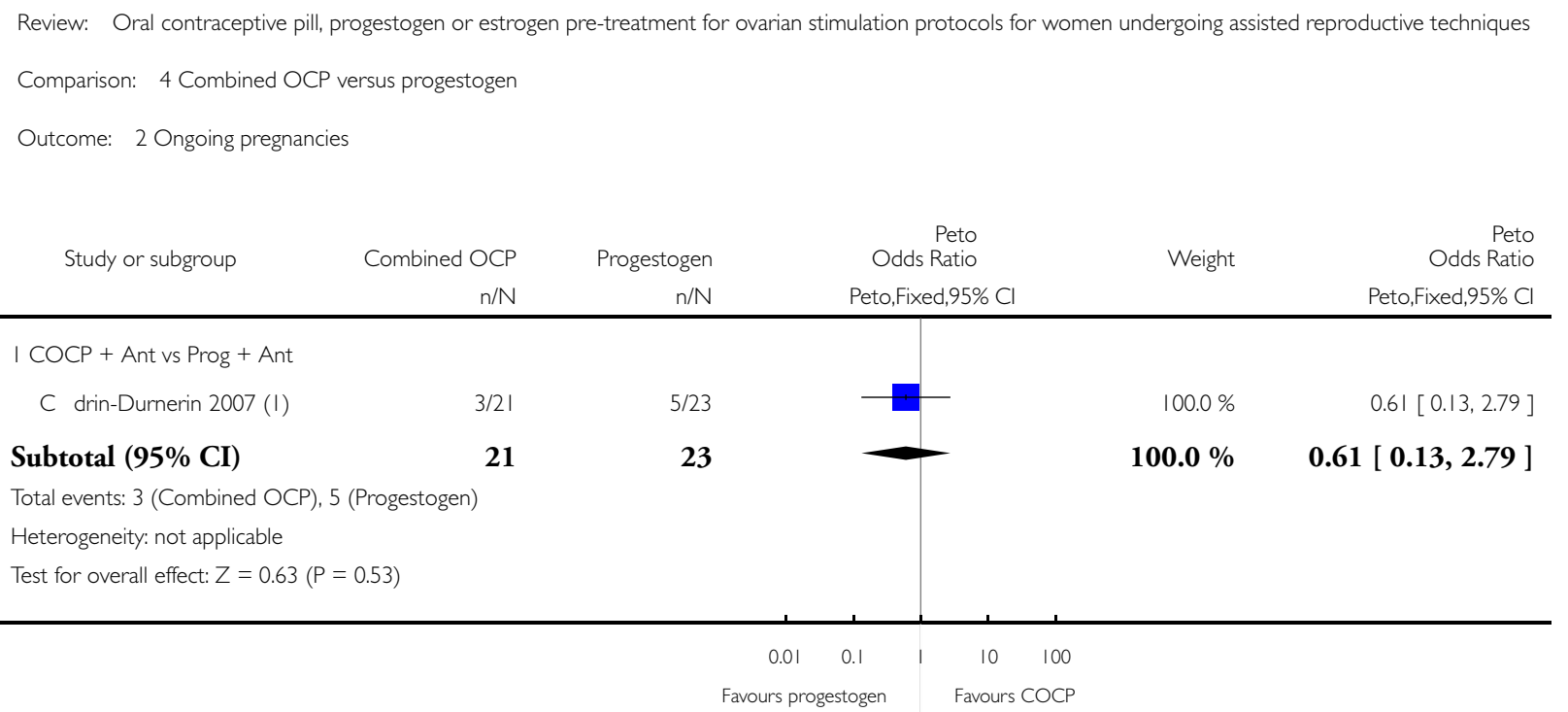

( I) Data obtained from Dr. C drin-Durnerin.

\section{Analysis 4.3. Comparison 4 Combined OCP versus progestogen, Outcome 3 Clinical pregnancies.}

Review: Oral contraceptive pill, progestogen or estrogen pre-treatment for ovarian stimulation protocols for women undergoing assisted reproductive techniques Comparison: 4 Combined OCP versus progestogen

Outcome: 3 Clinical pregnancies

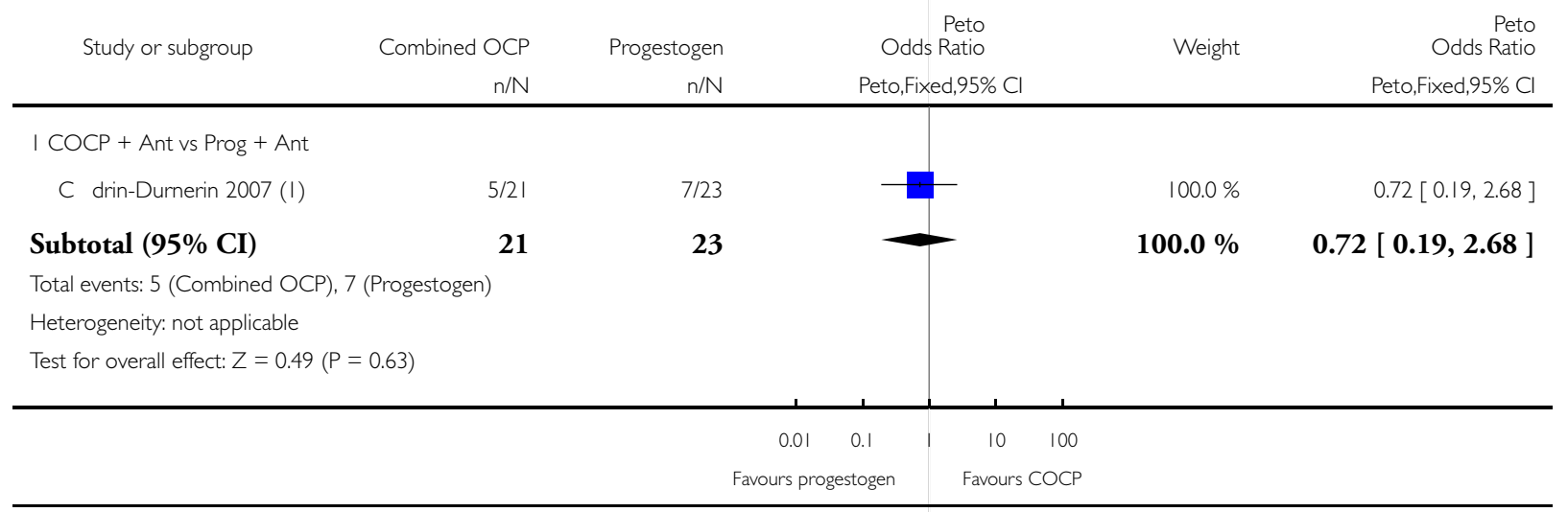

Oral contraceptive pill, progestogen or estrogen pre-treatment for ovarian stimulation protocols for women undergoing assisted 


\section{Analysis 4.4. Comparison 4 Combined OCP versus progestogen, Outcome 4 Oocytes retrieved.}

Review: Oral contraceptive pill, progestogen or estrogen pre-treatment for ovarian stimulation protocols for women undergoing assisted reproductive techniques

Comparison: 4 Combined OCP versus progestogen

Outcome: 4 Oocytes retrieved

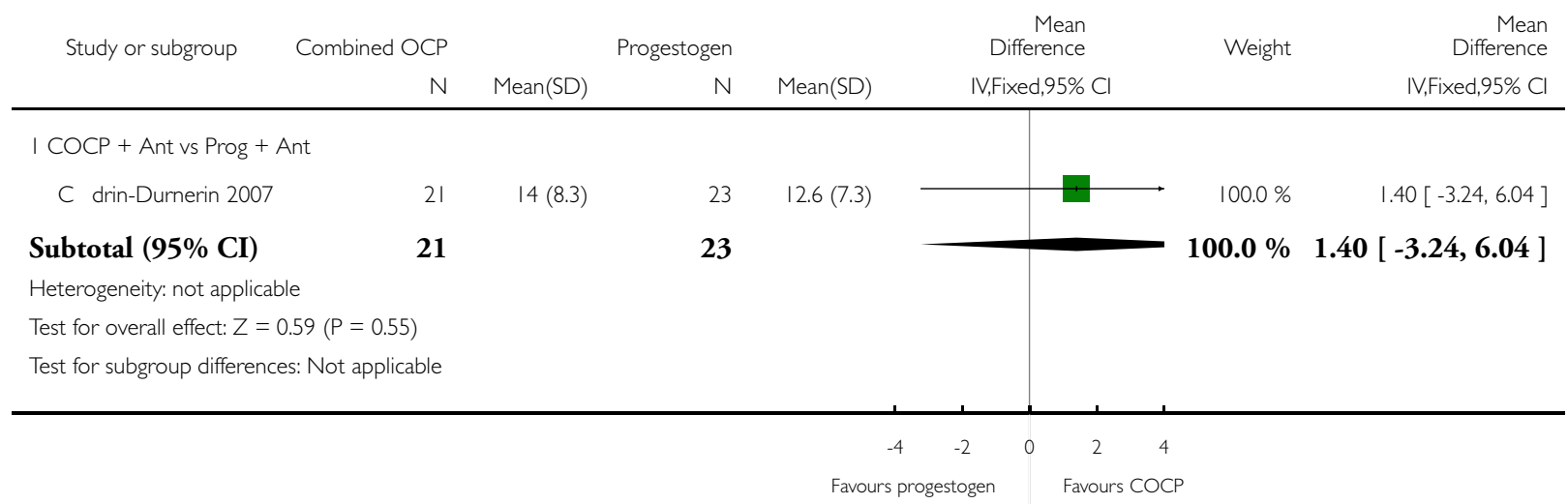

Oral contraceptive pill, progestogen or estrogen pre-treatment for ovarian stimulation protocols for women undergoing assisted 


\section{Analysis 4.5. Comparison 4 Combined OCP versus progestogen, Outcome 5 Amount of gonadotrophins} administered.

Review: Oral contraceptive pill, progestogen or estrogen pre-treatment for ovarian stimulation protocols for women undergoing assisted reproductive techniques

Comparison: 4 Combined OCP versus progestogen

Outcome: 5 Amount of gonadotrophins administered

\begin{tabular}{|c|c|c|c|c|c|c|c|c|}
\hline \multirow[t]{2}{*}{ Study or subgroup } & Combined OCP & \multicolumn{3}{|c|}{ Progestogen } & \multicolumn{2}{|c|}{$\begin{array}{r}\text { Mean } \\
\text { Difference }\end{array}$} & \multirow[t]{2}{*}{ Weight } & \multirow{2}{*}{$\begin{array}{r}\text { Mean } \\
\text { Difference } \\
\text { IV,Fixed,95\% C }\end{array}$} \\
\hline & $N$ & Mean(SD) & $N$ & Mean(SD) & & ked,95\% Cl & & \\
\hline \multicolumn{9}{|c|}{ I COCP + Ant vs Prog + Ant } \\
\hline C drin-Durnerin 2007 & 21 & $2174(723)$ & 23 & $2010(670)$ & & + & $100.0 \%$ & I $64.00[-249.03,577.03]$ \\
\hline Subtotal (95\% CI) & 21 & & 23 & & & & $-100.0 \%$ & $0[-249.03,577.03]$ \\
\hline \multicolumn{9}{|l|}{ Heterogeneity: not applicable } \\
\hline \multicolumn{9}{|c|}{ Test for overall effect: $Z=0.78(P=0.44)$} \\
\hline \multicolumn{9}{|c|}{ Test for subgroup differences: Not applicable } \\
\hline & & & & -500 & -250 & 250 & 500 & \\
\hline & & & & Favou & s COCP & Favour & rogestogen & \\
\hline
\end{tabular}

Analysis 4.6. Comparison 4 Combined OCP versus progestogen, Outcome 6 Pregnancy losses.

Review: Oral contraceptive pill, progestogen or estrogen pre-treatment for ovarian stimulation protocols for women undergoing assisted reproductive techniques

Comparison: 4 Combined OCP versus progestogen

Outcome: 6 Pregnancy losses

$\begin{array}{llrl} & \text { Peto } & \text { Peto } \\ \text { Study or subgroup } & \text { Combined OCP } & \text { Progestogen } & \text { Odds Ratio }\end{array}$

$\mathrm{n} / \mathrm{N} \quad \mathrm{n} / \mathrm{N} \quad$ Peto,Fixed,95\% Cl Peto,Fixed,95\% Cl

\footnotetext{
I COCP + Ant vs Prog + Ant
}

C drin-Durnerin 2007 (I)

$2 / 21 \quad 2 / 23$

Subtotal (95\% CI)

21

23

$100.0 \%$

I. $10[0.14,8.43]$

Total events: 2 (Combined OCP), 2 (Progestogen)

Heterogeneity: not applicable

Test for overall effect: $Z=0.09(P=0.92)$

\section{$\begin{array}{lllllll}0.1 & 0.2 & 0.5 & 1 & 2 & 5 & 10\end{array}$ \\ Favours COCP Favours progestogen}

Oral contraceptive pill, progestogen or estrogen pre-treatment for ovarian stimulation protocols for women undergoing assisted 
( I) Calculated from the number of clinical pregnancies minus the number of live births.

Analysis 4.7. Comparison 4 Combined OCP versus progestogen, Outcome 7 Multiple pregnancies.

Review: Oral contraceptive pill, progestogen or estrogen pre-treatment for ovarian stimulation protocols for women undergoing assisted reproductive techniques

Comparison: 4 Combined OCP versus progestogen

Outcome: 7 Multiple pregnancies

Peto

Study or subgroup Combined OCP Progestogen Odds Ratio Odds Ratio

$\mathrm{n} / \mathrm{N} \quad \mathrm{n} / \mathrm{N} \quad$ Peto,Fixed,95\% Cl Peto,Fixed,95\% Cl

I COCP + Ant vs Prog + Ant

C drin-Durnerin 2007

$2 / 21$

$1 / 23$

$100.0 \%$

$2.22[0.22,22.56]$

Subtotal $(95 \% \mathrm{CI})$

21

23

$100.0 \%$

$2.22[0.22,22.56]$

Total events: 2 (Combined OCP), I (Progestogen)

Heterogeneity: not applicable

Test for overall effect: $Z=0.67(P=0.50)$

Test for subgroup differences: Not applicable

$0.01 \quad 0.1$

$10 \quad 100$

Favours COCP

Favours progestogen

Oral contraceptive pill, progestogen or estrogen pre-treatment for ovarian stimulation protocols for women undergoing assisted 


\section{Analysis 5.I. Comparison 5 Combined OCP versus estrogen, Outcome I Live births.}

Review: Oral contraceptive pill, progestogen or estrogen pre-treatment for ovarian stimulation protocols for women undergoing assisted reproductive techniques Comparison: 5 Combined OCP versus estrogen

Outcome: I Live births

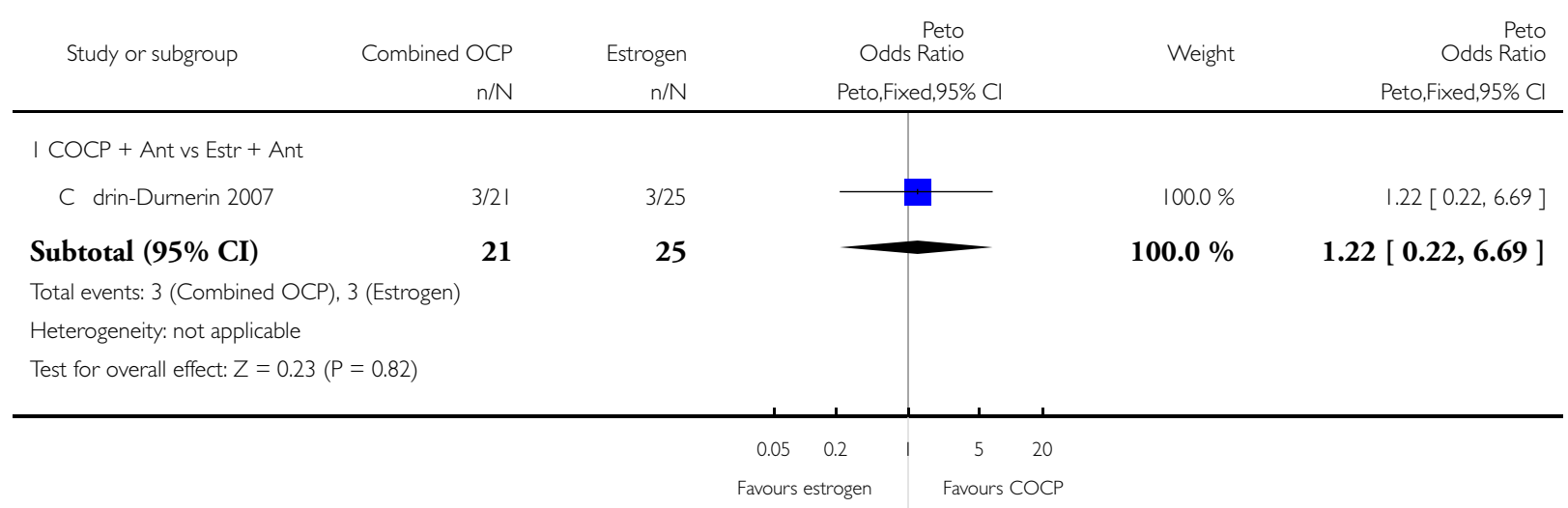

Oral contraceptive pill, progestogen or estrogen pre-treatment for ovarian stimulation protocols for women undergoing assisted 


\section{Analysis 5.2. Comparison 5 Combined OCP versus estrogen, Outcome 2 Ongoing pregnancies.}

Review: Oral contraceptive pill, progestogen or estrogen pre-treatment for ovarian stimulation protocols for women undergoing assisted reproductive techniques

Comparison: 5 Combined OCP versus estrogen

Outcome: 2 Ongoing pregnancies

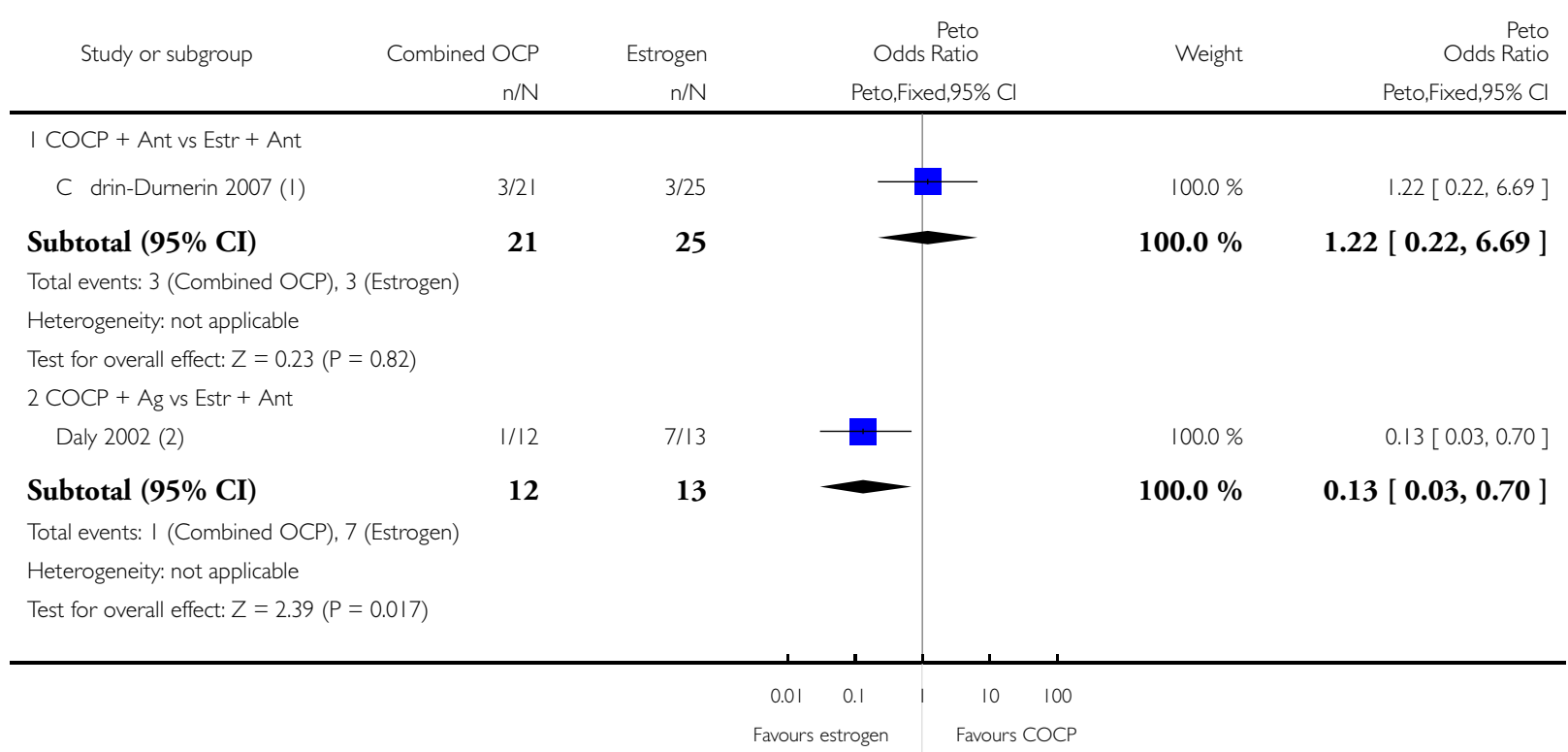

( I) Data obtained from Dr. C drin-Durnerin.

(2) Viable pregnancies 


\section{Analysis 5.3. Comparison 5 Combined OCP versus estrogen, Outcome 3 Clinical pregnancies.}

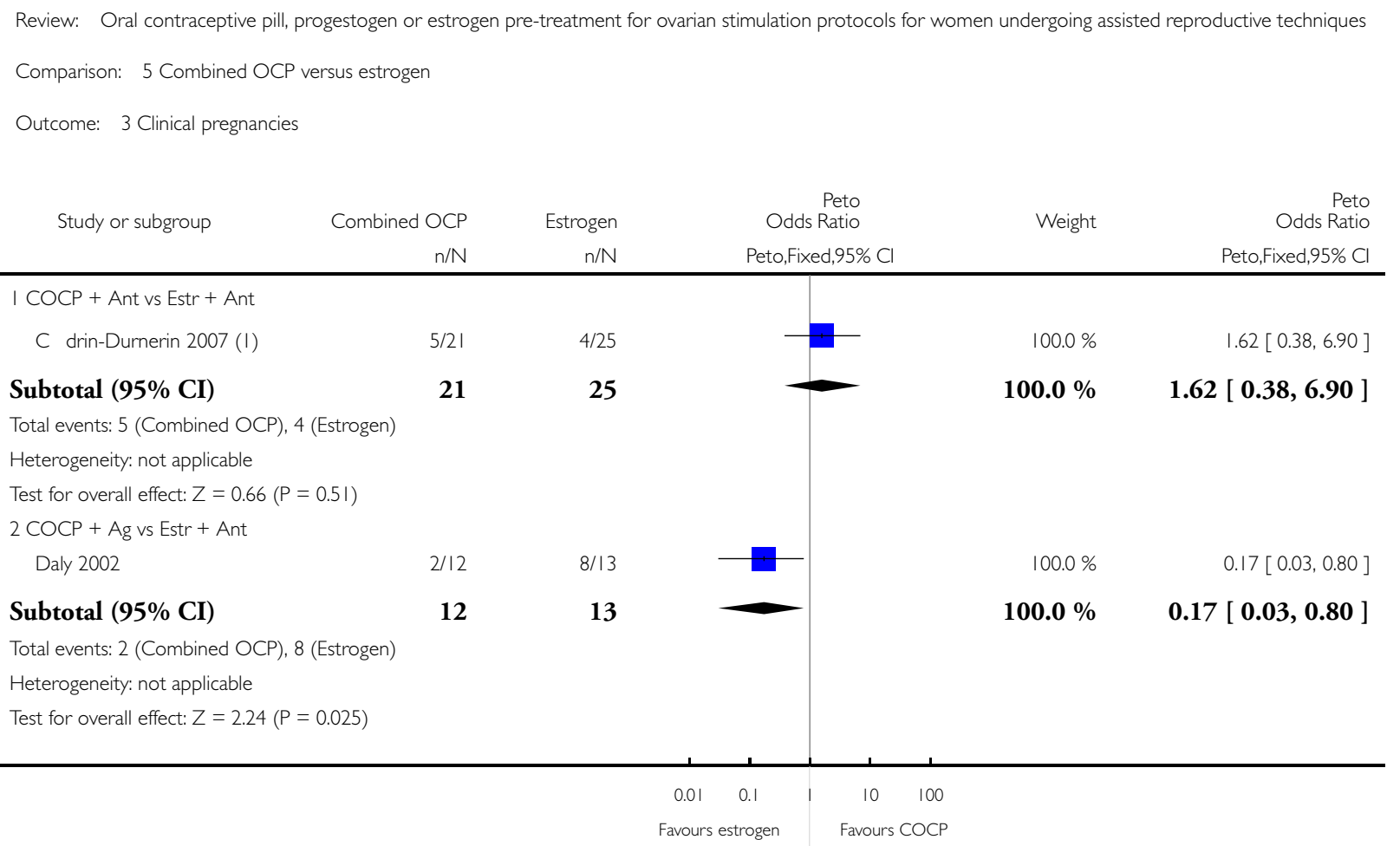

(I) Data obtained from Dr. C drin-Durnerin. 


\section{Analysis 5.4. Comparison 5 Combined OCP versus estrogen, Outcome 4 Oocytes retrieved.}

Review: Oral contraceptive pill, progestogen or estrogen pre-treatment for ovarian stimulation protocols for women undergoing assisted reproductive techniques

Comparison: 5 Combined OCP versus estrogen

Outcome: 4 Oocytes retrieved

\begin{tabular}{|c|c|c|c|c|c|c|c|c|}
\hline \multirow[t]{2}{*}{ Study or subgroup } & Combined OCP & \multicolumn{2}{|r|}{ Estrogen } & \multicolumn{3}{|c|}{$\begin{array}{r}\text { Mean } \\
\text { Difference }\end{array}$} & Weight & \multirow{2}{*}{$\begin{array}{r}\text { Mean } \\
\text { Difference } \\
\text { IV,Fixed,95\% Cl }\end{array}$} \\
\hline & $N$ & Mean(SD) & N & Mean(SD) & & ed, $95 \% \mathrm{Cl}$ & & \\
\hline \multicolumn{9}{|l|}{ I COCP + Ant vs Estr + Ant } \\
\hline C drin-Durnerin 2007 (I) & 21 & $14(8.3)$ & 22 & 13.1 (7) & & & $100.0 \%$ & $0.90[-3.70,5.50]$ \\
\hline Subtotal (95\% CI) & 21 & & 22 & & & & $100.0 \%$ & $0.90[-3.70,5.50]$ \\
\hline \multicolumn{9}{|l|}{ Heterogeneity: not applicable } \\
\hline \multicolumn{9}{|c|}{ Test for overall effect: $Z=0.38(P=0.70)$} \\
\hline & & & & -10 & -5 & 0 & 10 & \\
\hline & & & & Favours & roge & Favour & OCP & \\
\hline
\end{tabular}

( I) No ITT in estrogen group.

\section{Analysis 5.5. Comparison 5 Combined OCP versus estrogen, Outcome 5 Amount of gonadotrophins} administered.

Review: Oral contraceptive pill, progestogen or estrogen pre-treatment for ovarian stimulation protocols for women undergoing assisted reproductive techniques

Comparison: 5 Combined OCP versus estrogen

Outcome: 5 Amount of gonadotrophins administered

\begin{tabular}{|c|c|c|c|c|c|c|c|c|}
\hline \multirow[t]{2}{*}{ Study or subgroup } & Combined OCP & \multicolumn{2}{|r|}{ Estrogen } & \multicolumn{3}{|c|}{$\begin{array}{r}\text { Mean } \\
\text { Difference }\end{array}$} & \multicolumn{2}{|r|}{$\begin{array}{r}\text { Mean } \\
\text { Difference }\end{array}$} \\
\hline & $N$ & Mean(SD) & N & Mean(SD) & \multicolumn{2}{|c|}{ IV,Fixed,95\% Cl } & & IV,Fixed,95\% Cl \\
\hline \multicolumn{9}{|l|}{ I COCP + Ant vs Estr + Ant } \\
\hline C drin-Durnerin $2007(\mathrm{I})$ & 21 & $2174(723)$ & 22 & I $700(524)$ & & & $100.0 \%$ & $474.00[95.10,852.90]$ \\
\hline Subtotal (95\% CI) & 21 & & 22 & & & & $100.0 \%$ & $0[95.10,852.90]$ \\
\hline \multicolumn{9}{|c|}{ Heterogeneity: not applicable } \\
\hline \multicolumn{9}{|c|}{ Test for overall effect: $Z=2.45(P=0.014)$} \\
\hline & & & & -1000 & -500 & 500 & 1000 & \\
\hline
\end{tabular}

( I) No ITT in estrogen group

Oral contraceptive pill, progestogen or estrogen pre-treatment for ovarian stimulation protocols for women undergoing assisted 


\section{Analysis 5.6. Comparison 5 Combined OCP versus estrogen, Outcome 6 Pregnancy losses.}

Review: Oral contraceptive pill, progestogen or estrogen pre-treatment for ovarian stimulation protocols for women undergoing assisted reproductive techniques

Comparison: 5 Combined OCP versus estrogen

Outcome: 6 Pregnancy losses

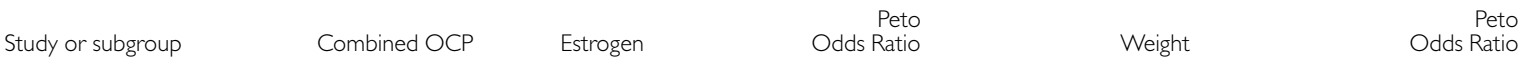

Peto,Fixed,95\% Cl

I COCP + Ant vs Estr + Ant

C drin-Durnerin 2007 (I)

2/21 $\quad \mid / 25$

$1 / 25$
25

Peto,Fixed,95\% Cl

Subtotal $(95 \% \mathrm{CI})$

21

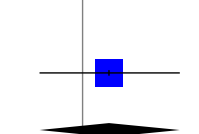

$100.0 \%$

$2.43[0.24,24.79]$

Total events: 2 (Combined OCP), I (Estrogen)

Heterogeneity: not applicable

Test for overall effect: $Z=0.75(P=0.45)$

$2 \mathrm{COCP}+\mathrm{Ag}$ vs Estr + Ant

Daly 2002

$1 / 12$

$1 / 13$

$100.0 \%$

$1.09[0.06,18.49]$

Subtotal $(95 \% \mathrm{CI})$

12

13

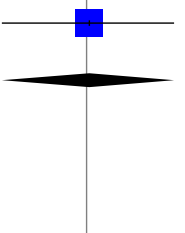

$100.0 \%$

$1.09[0.06,18.49]$

Total events: I (Combined OCP), I (Estrogen)

Heterogeneity: not applicable

Test for overall effect: $Z=0.06(P=0.95)$

$\begin{array}{ccccc}0.01 & 0.1 & 1 & 10 & 100 \\ \text { Favours } & \mathrm{COCP} & & \text { Favours estrogen }\end{array}$

(I) Calculated from the number of clinical pregnancies minus the number of live births.

Oral contraceptive pill, progestogen or estrogen pre-treatment for ovarian stimulation protocols for women undergoing assisted 


\section{Analysis 5.7. Comparison 5 Combined OCP versus estrogen, Outcome 7 Multiple pregnancies.}

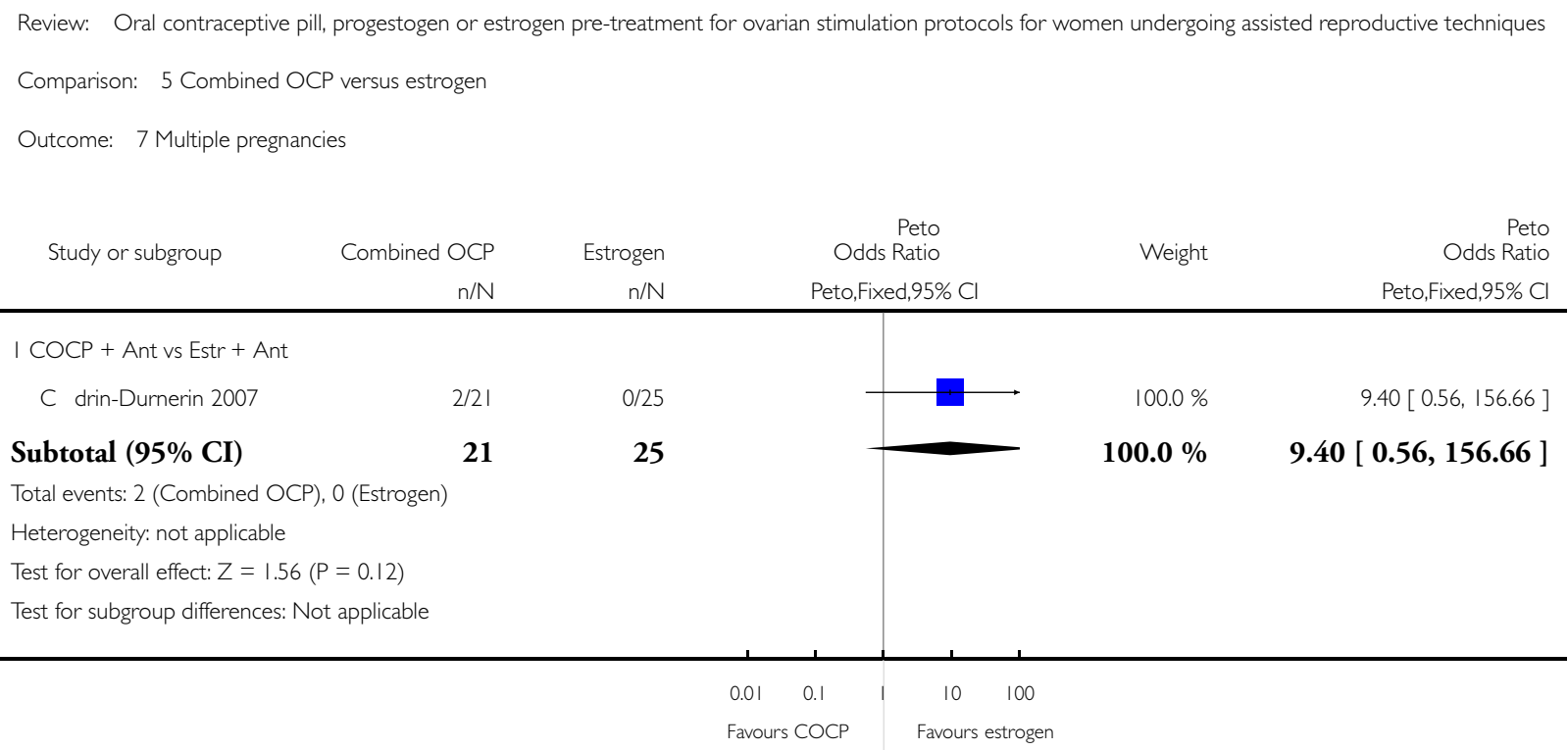

\section{Analysis 6.I. Comparison 6 Progestogen versus estrogen, Outcome I Live births.}

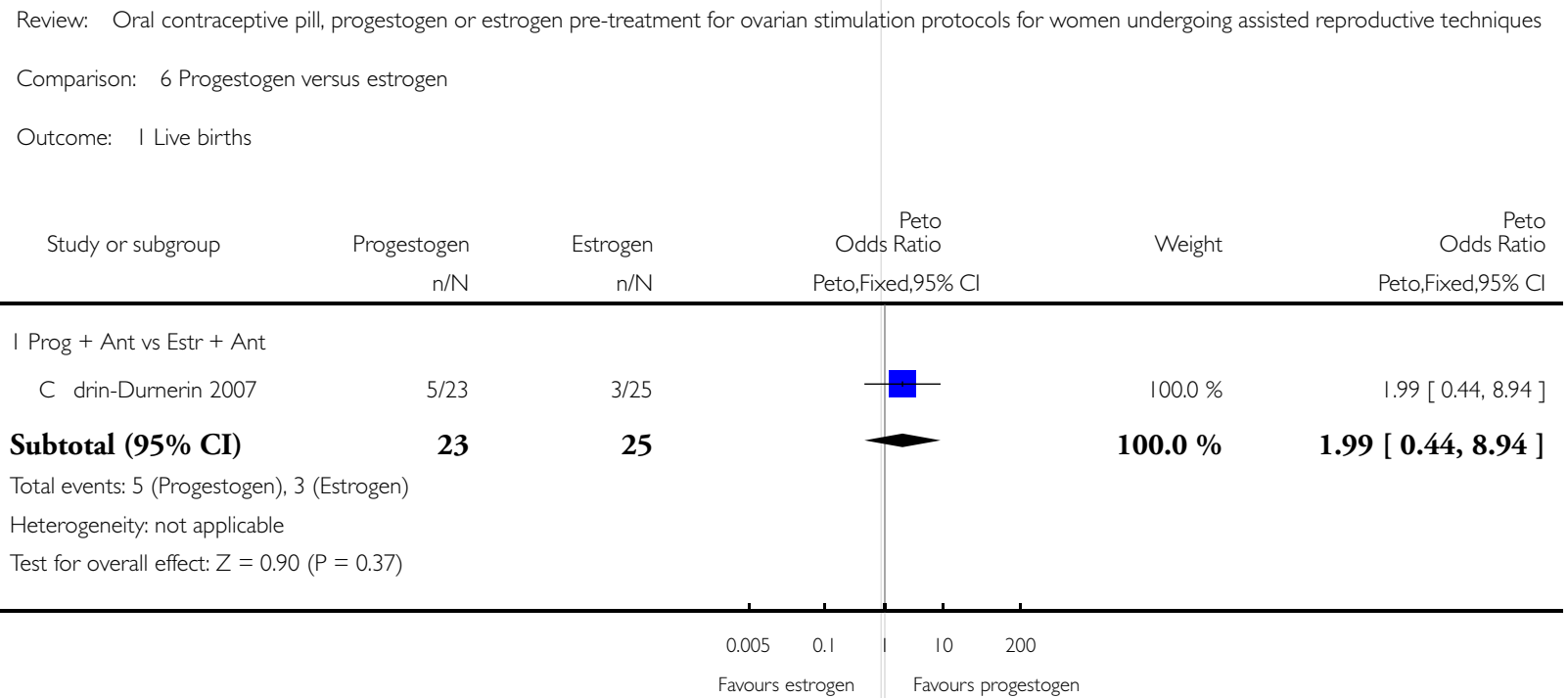




\section{Analysis 6.2. Comparison 6 Progestogen versus estrogen, Outcome 2 Ongoing pregnancies.}

Review: Oral contraceptive pill, progestogen or estrogen pre-treatment for ovarian stimulation protocols for women undergoing assisted reproductive techniques

Comparison: 6 Progestogen versus estrogen

Outcome: 2 Ongoing pregnancies

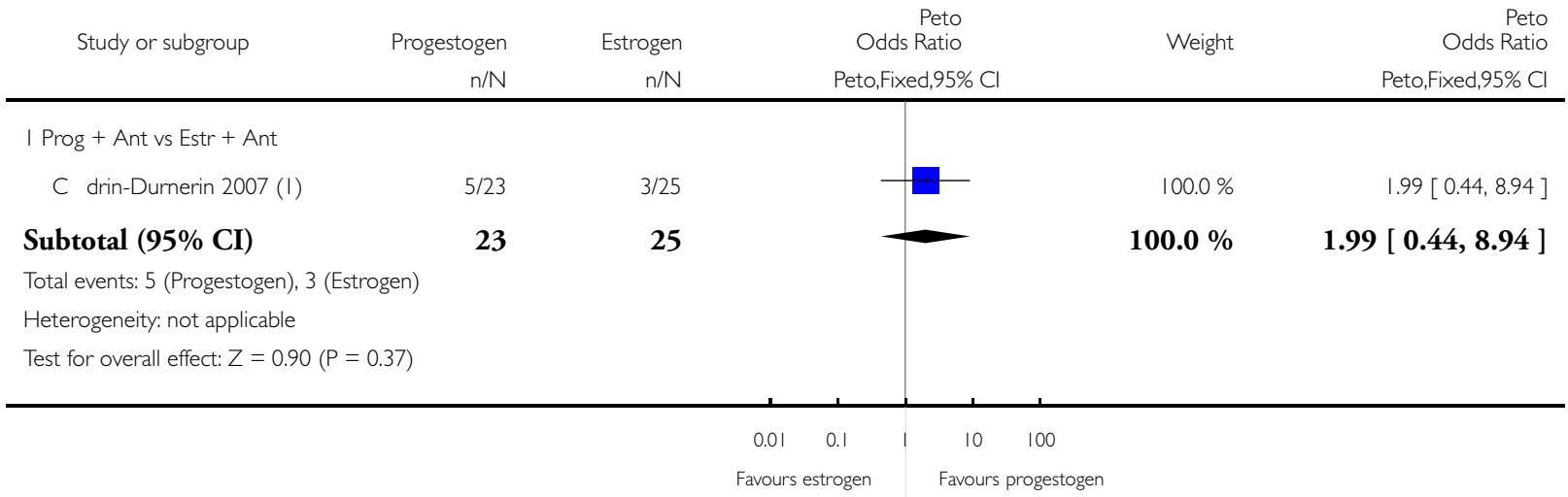

( I) Data obtained from Dr. C drin-Durnerin.

Analysis 6.3. Comparison 6 Progestogen versus estrogen, Outcome 3 Clinical pregnancies.

Review: Oral contraceptive pill, progestogen or estrogen pre-treatment for ovarian stimulation protocols for women undergoing assisted reproductive techniques

Comparison: 6 Progestogen versus estrogen

Outcome: 3 Clinical pregnancies

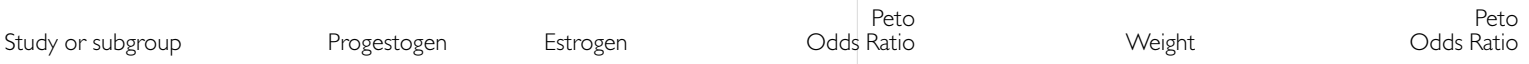

$\mathrm{n} / \mathrm{N} \quad \mathrm{n} / \mathrm{N} \quad$ Peto,Fixed,95\% Cl

Peto,Fixed,95\% Cl

I Prog + Ant vs Estr + Ant

C drin-Durnerin 2007 (I)

$7 / 23 \quad 4 / 25$

23

25

$100.0 \%$

$2.23[0.59,8.44]$

Subtotal (95\% CI)

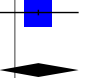

$100.0 \%$

$2.23[0.59,8.44]$

Total events: 7 (Progestogen), 4 (Estrogen)

Heterogeneity: not applicable

Test for overall effect: $Z=1.18(P=0.24)$

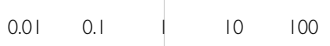

Favours estrogen Favours progestogen

Oral contraceptive pill, progestogen or estrogen pre-treatment for ovarian stimulation protocols for women undergoing assisted 


\section{Analysis 6.4. Comparison 6 Progestogen versus estrogen, Outcome 4 Oocytes retrieved.}

Review: Oral contraceptive pill, progestogen or estrogen pre-treatment for ovarian stimulation protocols for women undergoing assisted reproductive techniques

Comparison: 6 Progestogen versus estrogen

Outcome: 4 Oocytes retrieved

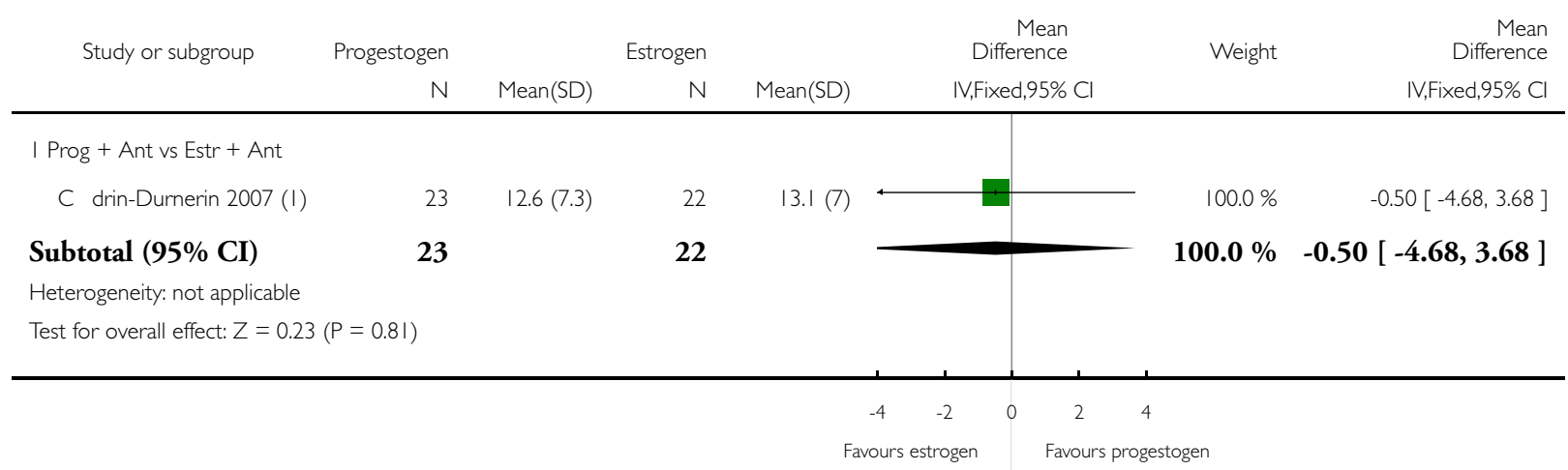

( I) No ITT in estrogen group. 


\section{Analysis 6.5. Comparison 6 Progestogen versus estrogen, Outcome 5 Amount of gonadotrophins}

administered.

Review: Oral contraceptive pill, progestogen or estrogen pre-treatment for ovarian stimulation protocols for women undergoing assisted reproductive techniques Comparison: 6 Progestogen versus estrogen

Outcome: 5 Amount of gonadotrophins administered

\begin{tabular}{|c|c|c|c|c|c|c|c|c|}
\hline \multirow[t]{2}{*}{ Study or subgroup } & \multirow{2}{*}{$\begin{array}{r}\text { Progestogen } \\
\mathrm{N}\end{array}$} & \multicolumn{3}{|c|}{ Estrogen } & \multicolumn{2}{|c|}{$\begin{array}{r}\text { Mean } \\
\text { Difference }\end{array}$} & \multirow[t]{2}{*}{ Weight } & \multirow{2}{*}{$\begin{array}{r}\text { Mean } \\
\text { Difference } \\
\text { IV,Fixed,95\% Cl }\end{array}$} \\
\hline & & Mean(SD) & $\mathrm{N}$ & Mean(SD) & $\mathrm{IV}, \mathrm{F}$ & xed,95\% Cl & & \\
\hline \multicolumn{9}{|l|}{ I Prog + Ant vs Estr + Ant } \\
\hline C drin-Durnerin 2007 (I) & 23 & $2010(670)$ & 22 & $1700(524)$ & & & $100.0 \%$ & $310.00[-40.60,660.60]$ \\
\hline Subtotal (95\% CI) & 23 & & 22 & & & & $-100.0 \%$ & $310.00[-40.60,660.60]$ \\
\hline \multicolumn{9}{|c|}{ Heterogeneity: not applicable } \\
\hline \multicolumn{9}{|c|}{ Test for overall effect: $Z=1.73(P=0.083)$} \\
\hline & & & & -500 & -250 & 250 & 500 & \\
\hline & & & & Favours pro & gestogen & Favour & trogen & \\
\hline
\end{tabular}

(I) No ITT in estrogen group.

Analysis 6.6. Comparison 6 Progestogen versus estrogen, Outcome 6 Pregnancy losses.

Review: Oral contraceptive pill, progestogen or estrogen pre-treatment for ovarian stimulation protocols for women undergoing assisted reproductive techniques

Comparison: 6 Progestogen versus estrogen

Outcome: 6 Pregnancy losses

$\begin{array}{llrr} & \text { Peto } & \text { Peto } \\ \text { Study or subgroup } & \text { Progestogen } & \text { Estrogen } & \text { Odds Ratio }\end{array}$

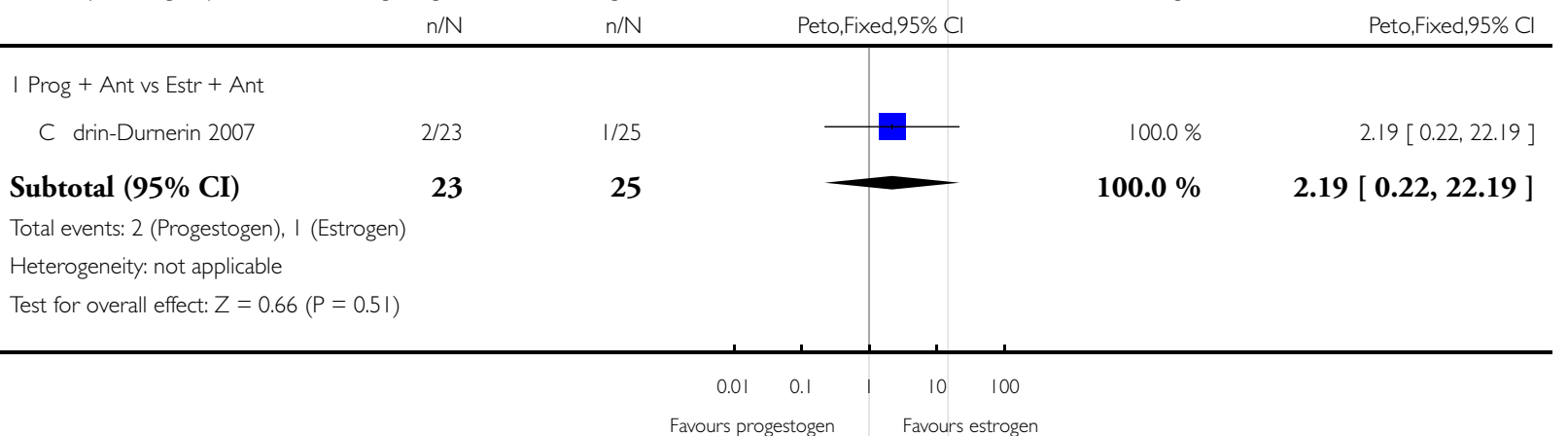

Oral contraceptive pill, progestogen or estrogen pre-treatment for ovarian stimulation protocols for women undergoing assisted 


\section{Analysis 6.7. Comparison 6 Progestogen versus estrogen, Outcome 7 Multiple pregnancies.}

Review: Oral contraceptive pill, progestogen or estrogen pre-treatment for ovarian stimulation protocols for women undergoing assisted reproductive techniques

Comparison: 6 Progestogen versus estrogen

Outcome: 7 Multiple pregnancies

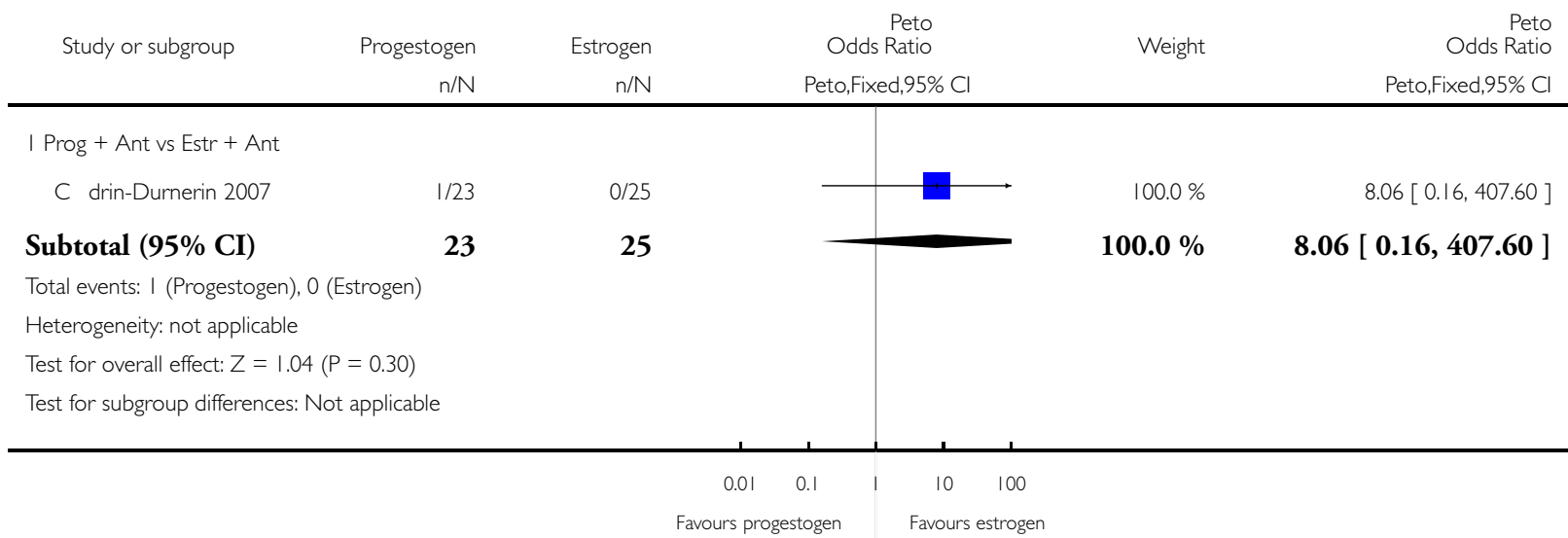

ADDITIONAL TABLES

Table 1. Heterogeneity Analysis 1.4.2 + 1.5.2 + 1.6.2

\begin{tabular}{l|lllll}
\hline & $\begin{array}{l}\text { Cédrin-Durnerin } \\
2007\end{array}$ & Huirne 2006b & Kolibianakis 2006 & Obruca 2001 & Rombauts 2006 \\
\hline Inclusion criteria & & & & & \\
\hline Age limit used & $<38$ & $<38$ & $<39$ & No limit & $<39$ \\
\hline Only regular cycles & Yes & Yes & No & No & Yes \\
\hline Exclusion criteria & & No & Yes & No & Yes \\
\hline $\begin{array}{l}\text { Poor responders in- } \\
\text { cluded }\end{array}$ & Yes & & & & \\
\hline Pre-treatment & Ethinyl estradiol + & $\begin{array}{l}\text { Ethinyl estradiol }+ \\
\text { Levonorgestrel }\end{array}$ & $\begin{array}{l}\text { Ethinyl estradiol }+ \\
\text { Desogestrel }\end{array}$ & $\begin{array}{l}\text { Ethinyl estradiol + } \\
\text { Desogestrel }\end{array}$ & $\begin{array}{l}\text { Ethinyl estradiol + } \\
\text { Desogestrel }\end{array}$ \\
\hline $\begin{array}{l}\text { Type of OCP } \\
\text { Desogestrel }\end{array}$ & CD 2 or 3 & CD 2 or 3 & CD 1 & CD 1 & CD 1 \\
\hline Starting day & & & &
\end{tabular}

Oral contraceptive pill, progestogen or estrogen pre-treatment for ovarian stimulation protocols for women undergoing assisted 
Table 1. Heterogeneity Analysis 1.4.2 + 1.5.2 + 1.6.2 (Continued)

\begin{tabular}{|c|c|c|c|c|c|}
\hline Duration & 15-21 days & 14-28 days & 14 days & 18-28 days & 14-28 days \\
\hline \multicolumn{6}{|l|}{ GnRH analogue } \\
\hline Type antagonist & Ganirelix & Antide & Ganirelix & Cetrorelix & Ganirelix \\
\hline Dose & $0.25 \mathrm{mg} / \mathrm{day}$ & $0.5 \mathrm{mg} / \mathrm{mL}$ & Unknown & $0.25 \mathrm{mg} /$ day & $0.25 \mathrm{mg} /$ day \\
\hline Starting day & Follicle $>14 \mathrm{~mm}$ & SD 6 & Unknown & SD 6 & CD 21-24 \\
\hline \multicolumn{6}{|l|}{ Gonadotrophins } \\
\hline Type & $\mathrm{rFSH}$ & $\mathrm{rFSH}$ & $\mathrm{rFSH}$ & $\mathrm{rFSH}$ & $\mathrm{rFSH}$ \\
\hline Dose (IU/day) & $150-300$ & $150-300$ & 200 & 150 & 200 \\
\hline
\end{tabular}

$\mathrm{SD}=$ Stimulation Day

Table 2. Heterogeneity Analysis 1.5.3 + 1.6.3

\begin{tabular}{|c|c|c|c|}
\hline & Huirne 2006a & Hwang 2004 & Rombauts 2006 \\
\hline \multicolumn{4}{|l|}{ Inclusion criteria } \\
\hline Only PCOS included & No & Yes & No \\
\hline \multicolumn{4}{|l|}{ Pre-treatment } \\
\hline Type of OCP & $\begin{array}{l}\text { Ethinyl estradiol + } \\
\text { Levonorgestrel }\end{array}$ & $\begin{array}{l}\text { Ethinyl estradiol + } \\
\text { Cyproterone acetate }\end{array}$ & $\begin{array}{l}\text { Ethinyl estradiol + } \\
\text { Desogestrel }\end{array}$ \\
\hline Starting day & $\mathrm{CD} 1$ to 5 & $\mathrm{CD} 5$ & CD 1 \\
\hline Duration & 21 to 28 days & three cycles & 14 to 28 days \\
\hline \multicolumn{4}{|l|}{ GnRH analogue } \\
\hline Type antagonist & Cetrorelix & Cetrorelix & Ganirelix \\
\hline Dose (mg/day) & 0.25 & 0.25 & 0.25 \\
\hline Starting day & SD 6 & PD 3 & SD 5 or 6 \\
\hline Type agonist & Buserelin & Buserelin & Nafarelin \\
\hline
\end{tabular}

Oral contraceptive pill, progestogen or estrogen pre-treatment for ovarian stimulation protocols for women undergoing assisted 
Table 2. Heterogeneity Analysis 1.5 .3 + 1.6.3. (Continued)

\begin{tabular}{|c|c|c|c|}
\hline Dose ( $\mu \mathrm{g} /$ day $)$ & 500 & 500 & 800 \\
\hline Starting day & CD 18 to 22 & $\mathrm{CD} 3$ & CD 21 to 24 \\
\hline \multicolumn{4}{|c|}{ Gonadotrophins } \\
\hline Type & $\mathrm{rFSH}$ & hMG & $\mathrm{rFSH}$ \\
\hline Dose (IU/day) & 150 to 225 & 150 & 200 \\
\hline
\end{tabular}

$\mathrm{CD}=$ Cycle Day

$\mathrm{SD}=$ Stimulation Day

$\mathrm{PD}=$ Post-treatment Day

Table 3. Heterogeneity Analysis 3.6.1

\begin{tabular}{|c|c|c|}
\hline & Cédrin-Durnerin 2007 & Fanchin 2003a \\
\hline \multicolumn{3}{|l|}{ Inclusion criteria } \\
\hline Age limit & $<38$ & $<39$ \\
\hline \multicolumn{3}{|l|}{ Pre-treatment } \\
\hline Type of oestrogen & Micronized $17-\beta \mathrm{E}_{2}$ & Micronized $17-\beta \mathrm{E}_{2}$ \\
\hline Starting day & 10 days before presumed menses & $\mathrm{CD} 20$ \\
\hline Duration & 10 to 15 days & 11 days \\
\hline \multicolumn{3}{|l|}{ GnRH analogue } \\
\hline Type antagonist & Ganirelix & Cetrorelix \\
\hline Dose & $0.25 \mathrm{mg} /$ day & 3 mg (single dose) \\
\hline Starting day & Follicle $>14 \mathrm{~mm}$ & $\geq 1$ follicle $<13 \mathrm{~mm}$ in diameter \\
\hline \multicolumn{3}{|l|}{ Gonadotrophins } \\
\hline Type & rFSH & $\mathrm{rFSH}$ \\
\hline Dose (IU/day) & 150 to 300 & 225 \\
\hline
\end{tabular}

Oral contraceptive pill, progestogen or estrogen pre-treatment for ovarian stimulation protocols for women undergoing assisted 


\section{A P P E N D I C E S}

\section{Appendix I. MDSG Specialised Register search strategy}

Keywords CONTAINS 'IVF' or 'in vitro fertilization' or 'in-vitro fertilisation' or 'in-vitro fertilization' or 'ICSI' or 'intracytoplasmic sperm injection' or 'embryo' or 'ART' or 'controlled ovarian' or ' COH' or Title CONTAINS 'IVF' or 'in vitro fertilization' or 'invitro fertilisation' or 'in-vitro fertilization' or 'ICSI' or 'intracytoplasmic sperm injection' or 'embryo' or 'ART' or 'controlled ovarian' or ' $\mathrm{COH}$

AND

Keywords CONTAINS 'oral contraceptive' or 'oral contraceptives' or 'OCP' or 'oral contraceptive agent' or 'combined oral contraceptives' or 'progestagen' or 'progesterone' or 'progestin' or 'progestogen' or 'norgestrel' or 'norethisterone' or 'desogestrel' or 'gestodene' or 'oestrogen' or 'oestrogen' or 'oestrodiol' or 'estradiol' or 'pretreatment' or Title CONTAINS 'oral contraceptive' or 'oral contraceptives' or 'oral contraceptive agent' or 'combined oral contraceptives' or 'progestagen' or 'progesterone' or 'progestin' or 'progestogen' or 'norgestrel' or 'norethisterone' or 'desogestrel' or 'gestodene' or 'oestrogen' or 'oestrogen' or 'oestrodiol' or 'estradiol' or 'pretreatment'

\section{Appendix 2. CENTRAL search strategy}

1 reproductive techniques/ or exp reproductive techniques, assisted/ or exp embryo transfer/ or exp fertilization in vitro/ or exp sperm injections, intracytoplasmic/ or exp gamete intrafallopian transfer/

2 ART.tw.

3 (IVF or ICSI).tw.

4 embryo transfer.tw.

5 (in vitro fertilisation or in vitro fertilization).tw.

6 intracytoplasmic sperm injection $\$$.tw.

7 COH.tw.

8 ovar\$ stimulat\$.tw.

9 or/ $1-8$

10 oral contracepti\$.tw.

11 (OC or OCP\$).tw.

12 (pretreatment\$ or pre-treatment\$).tw.

13 contraceptives, oral/ or exp gestrinone/ or exp contraceptives, oral, combined/ or exp ethinyl estradiol-norgestrel combination/ or exp contraceptives, oral, hormonal/ or exp contraceptives, oral, sequential/ or exp contraceptives, oral, synthetic/ or exp desogestrel/or exp dimethisterone/ or exp levonorgestrel/ or exp norethindrone/ or exp norgestrel/ or exp norgestrienone/

14 gestrinone $\$$.tw.

15 ethinyl estradiol.tw.

16 norgestrel.tw.

17 desogestrel.tw.

18 dimethisterone.tw.

19 levonorgestrel.tw.

20 norethindrone.tw.

21 norgestrel.tw.

22 norgestrienone.tw.

23 gestodene.tw.

24 norgestimate.tw.

25 dienogest.tw.

26 progestogen $\$$.tw.

27 progestagen\$.tw.

28 progestin\$.tw.

29 or/ $10-27$

309 and 29

31 luteal phase.ti.

32 luteal support.ti.

33 or $/ 31-32$

Oral contraceptive pill, progestogen or estrogen pre-treatment for ovarian stimulation protocols for women undergoing assisted 


\section{Appendix 3. MEDLINE search strategy}

1 reproductive techniques/ or exp reproductive techniques, assisted/ or exp embryo transfer/ or exp fertilization in vitro/ or exp sperm injections, intracytoplasmic/ or exp gamete intrafallopian transfer/

2 ART.tw.

3 (IVF or ICSI).tw.

4 embryo transfer.tw.

5 (in vitro fertilisation or in vitro fertilization).tw.

6 intracytoplasmic sperm injection $\$$.tw.

7 COH.tw.

8 ovar\$ stimulat\$.tw.

9 or/ $1-8$

10 oral contracepti $\$$.tw.

11 (OC or OCP\$).tw.

12 (pretreatment\$ or pre-treatment $\$$ ).tw.

13 contraceptives, oral/ or exp gestrinone/ or exp contraceptives, oral, combined/ or exp ethinyl estradiol-norgestrel combination/ or exp contraceptives, oral, hormonal/ or exp contraceptives, oral, sequential/ or exp contraceptives, oral, synthetic/ or exp desogestrel/ or exp dimethisterone/ or exp levonorgestrel/ or exp norethindrone/ or exp norgestrel/ or exp norgestrienone/

14 gestrinone\$.tw.

15 ethinyl estradiol.tw.

16 norgestrel.tw.

17 desogestrel.tw.

18 dimethisterone.tw.

19 levonorgestrel.tw.

20 norethindrone.tw.

21 norgestrel.tw.

22 norgestrienone.tw.

23 gestodene.tw.

24 norgestimate.tw.

25 dienogest.tw.

26 progestogen $\$$.tw.

27 progestagen $\$$.tw.

28 progestin $\$$.tw.

29 or/ $10-27$

309 and 29

31 randomised controlled trial.pt.

32 controlled clinical trial.pt.

33 (randomised or randomised).ab.

34 placebo.ab.

35 drug therapy.fs.

36 randomly.ab.

37 trial.ab.

38 groups.ab.

39 or/31-38

40 (animals not (humans and animals)).sh.

4139 not 40

4241 and 30

43 luteal support.ti.

44 luteal phase.ti.

4543 or 44

Oral contraceptive pill, progestogen or estrogen pre-treatment for ovarian stimulation protocols for women undergoing assisted 


\section{Appendix 4. EMBASE search strategy}

1 reproductive techniques/ or exp reproductive techniques, assisted/ or exp embryo transfer/ or exp fertilization in vitro/ or exp sperm injections, intracytoplasmic/ or exp gamete intrafallopian transfer/

2 ART.tw.

3 (IVF or ICSI).tw.

4 embryo transfer.tw.

5 (in vitro fertilisation or in vitro fertilization).tw.

6 intracytoplasmic sperm injection\$.tw.

7 COH.tw.

8 ovar\$ stimulat $\$$.tw.

9 or/ $1-8$

10 oral contracepti $\$$.tw.

11 (OC or OCP\$).tw.

12 (pretreatment\$ or pre-treatment $\$$ ).tw.

13 contraceptives, oral/ or exp gestrinone/ or exp contraceptives, oral, combined/ or exp ethinyl estradiol-norgestrel combination/ or exp contraceptives, oral, hormonal/ or exp contraceptives, oral, sequential/ or exp contraceptives, oral, synthetic/ or exp desogestrel/ or exp dimethisterone/ or exp levonorgestrel/ or exp norethindrone/ or exp norgestrel/ or exp norgestrienone/

14 gestrinone\$.tw.

15 ethinyl estradiol.tw.

16 norgestrel.tw.

17 desogestrel.tw.

18 dimethisterone.tw.

19 levonorgestrel.tw.

20 norethindrone.tw.

21 norgestrel.tw.

22 norgestrienone.tw.

23 gestodene.tw.

24 norgestimate.tw.

25 dienogest.tw.

26 progestogen $\$$.tw.

27 progestagen $\$$.tw.

28 progestin $\$$.tw.

29 or/10-27

309 and 29

31 luteal phase.ti.

32 luteal support.ti.

33 or/31-32

3430 not 33

35 Clinical Trial/ (520486)

36 Randomized Controlled Trial/

37 exp randomization/

38 Single Blind Procedure/

39 Double Blind Procedure/

40 Crossover Procedure/

41 Placebo/

42 Randomi?ed controlled trial\$.tw.

43 Rct.tw.

44 random allocation.tw.

45 randomly allocated.tw.

Oral contraceptive pill, progestogen or estrogen pre-treatment for ovarian stimulation protocols for women undergoing assisted 
46 allocated randomly.tw.

47 (allocated adj2 random).tw.

48 Single blind \$.tw.

49 Double blind \$.tw.

50 ((treble or triple) adj blind\$).tw.

51 placebo\$.tw.

52 prospective study/

53 or $/ 35-52$

54 case study/

55 case report.tw.

56 abstract report/ or letter/

57 or/54-56

5853 not 57

5934 and 58

60 limit 59 to $y r=$ “2007 - 2008”

\section{Appendix 5. CINAHL search strategy}

1 reproductive techniques/ or exp reproductive techniques, assisted/ or exp embryo transfer/ or exp fertilization in vitro/ or exp sperm injections, intracytoplasmic/ or exp gamete intrafallopian transfer/

2 ART.tw.

3 (IVF or ICSI).tw.

4 embryo transfer.tw.

5 (in vitro fertilisation or in vitro fertilization).tw.

6 intracytoplasmic sperm injection $\$$.tw.

7 COH.tw.

8 ovar\$ stimulat\$.tw.

9 or/ $1-8$

10 oral contracepti $\$ . t w$.

11 (OC or OCP\$).tw.

12 (pretreatment\$ or pre-treatment\$).tw.

13 contraceptives, oral/ or exp gestrinone/ or exp contraceptives, oral, combined/ or exp ethinyl estradiol-norgestrel combination/ or exp contraceptives, oral, hormonal/ or exp contraceptives, oral, sequential/ or exp contraceptives, oral, synthetic/ or exp desogestrel/ or exp dimethisterone/ or exp levonorgestrel/ or exp norethindrone/ or exp norgestrel/ or exp norgestrienone/

14 gestrinone\$.tw.

15 ethinyl estradiol.tw.

16 norgestrel.tw.

17 desogestrel.tw.

18 dimethisterone.tw.

19 levonorgestrel.tw.

20 norethindrone.tw.

21 norgestrel.tw.

22 norgestrienone.tw.

23 gestodene.tw.

24 norgestimate.tw.

25 dienogest.tw.

26 progestogen $\$$.tw.

27 progestagen $\$$.tw.

28 progestin $\$$.tw.

29 or/ $10-27$

309 and 29

31 luteal phase.ti.

Oral contraceptive pill, progestogen or estrogen pre-treatment for ovarian stimulation protocols for women undergoing assisted 
32 luteal support.ti.

33 or $/ 31-32$

3430 not 33

35 exp clinical trials/

36 Clinical trial.pt.

37 (clinic\$ adj trial\$1).tw.

38 ((singl\$ or doubl $\$$ or trebl $\$$ or tripl\$) adj (blind $\$ 3$ or mask $\$ 3)$ ).tw.

39 Randomi?ed control\$ trial\$.tw.

40 Random assignment/

41 Random $\$$ allocat\$.tw.

42 Placebo\$.tw.

43 Placebos/

44 Quantitative studies/

45 Allocat\$ random $\$$. tw.

46 or $/ 35-45$

4734 and 46

\section{Appendix 6. PsycINFO search strategy}

1 reproductive techniques/ or exp reproductive techniques, assisted/ or exp embryo transfer/ or exp fertilization in vitro/ or exp sperm injections, intracytoplasmic/ or exp gamete intrafallopian transfer/

2 ART.tw.

3 (IVF or ICSI).tw.

4 embryo transfer.tw.

5 (in vitro fertilisation or in vitro fertilization).tw.

6 intracytoplasmic sperm injection\$.tw.

7 COH.tw.

8 ovar\$ stimulat\$.tw.

9 or/ $1-8$

10 oral contracepti\$.tw.

11 (OC or OCP\$).tw.

12 (pretreatment $\$$ or pre-treatment $\$$ ).tw.

13 contraceptives, oral/ or exp gestrinone/ or exp contraceptives, oral, combined/ or exp ethinyl estradiol-norgestrel combination/ or exp contraceptives, oral, hormonal/ or exp contraceptives, oral, sequential/ or exp contraceptives, oral, synthetic/ or exp desogestrel/ or exp dimethisterone/ or exp levonorgestrel/ or exp norethindrone/ or exp norgestrel/ or exp norgestrienone/

14 gestrinone\$.tw.

15 ethinyl estradiol.tw.

16 norgestrel.tw.

17 desogestrel.tw.

18 dimethisterone.tw.

19 levonorgestrel.tw.

20 norethindrone.tw.

21 norgestrel.tw.

22 norgestrienone.tw.

23 gestodene.tw.

24 norgestimate.tw.

25 dienogest.tw.

26 progestogen \$.tw.

27 progestagen\$.tw.

28 progestin\$.tw.

29 or/ $10-27$

309 and 29

Oral contraceptive pill, progestogen or estrogen pre-treatment for ovarian stimulation protocols for women undergoing assisted 
31 luteal phase.ti.

32 luteal support.ti.

33 or $/ 31-32$

3430 not 33

\section{Appendix 7. Data extraction form (part I)}

\section{Assessment}

Assessor $\quad \mathrm{SvO} / \mathrm{BS}$

Date

Final conclusion

Inclusion

Exclusion

Reason for exclusion:

\section{A. Study information}

\section{Title}

\section{First author}

3. Year

4. Published Yes / No

5. Journal

\section{B. Criteria for eligibility}

\begin{tabular}{l|l}
\hline Design & Described as randomised? \\
& no, then exclude \\
\hline Patients & $\begin{array}{l}\text { Women with subfertility, regard- } \\
\text { less of any cause, undergoing } \\
\text { ART }\end{array}$
\end{tabular}

Oral contraceptive pill, progestogen or estrogen pre-treatment for ovarian stimulation protocols for women undergoing assisted reproductive techniques (Review)

Copyright $\odot 2010$ The Cochrane Collaboration. Published by John Wiley \& Sons, Ltd. 
(Continued)

\begin{tabular}{|c|c|}
\hline Intervention & $\begin{array}{l}\text { - OCP prior to gonadotrophins } \\
\text { - OCP prior to gonadotrophins } \\
+ \text { GnRH agonist } \\
\text { - OCP prior to gonadotrophins } \\
+ \text { GnRH antagonist } \\
\text { Estrogen prior to go- } \\
\text { nadotrophins } \\
\text { Estrogen prior to go- } \\
\text { nadotrophins + GnRH agonist } \\
\cdot \quad \text { Estrogen prior to go- } \\
\text { nadotrophins + GnRH antago- } \\
\text { nist } \quad \text { Progestogen prior to go- } \\
\cdot \text { nadotrophins } \\
\text { Progestogen prior to go- } \\
\text { nadotrophins + GnRH agonist } \\
\text { Progestogen prior to go- } \\
\text { nadotrophins + GnRH antago- } \\
\text { nist }\end{array}$ \\
\hline
\end{tabular}

\begin{tabular}{|c|c|}
\hline Comparison & $\begin{array}{l}\text { Placebo prior to go- } \\
\text { nadotrophins } \\
\cdot \text { Placebo prior to go- } \\
\text { nadotrophins + GnRH agonist } \\
\text { - Placebo prior to go- } \\
\text { nadotrophins + GnRH antago- } \\
\text { nist } \\
\text { - No pretreatment prior to go- } \\
\text { nadotrophins } \\
\text { - No pretreatment prior to go- } \\
\text { nadotrophins + GnRH agonist } \\
\text { - No pretreatment prior to go- } \\
\text { nadotrophins + GnRH antago- } \\
\text { nist } \\
\text { - } \\
\text { gonadotrophins } \\
\text { - OCP prior to gonadotrophins } \\
+ \text { GnRH agonist } \\
\text { - OCP prior to gonadotrophins } \\
+ \text { GnRH antagonist } \\
\text { - Estrogen prior to go- } \\
\text { nadotrophins } \\
\cdot \text { Estrogen prior to go- } \\
\text { nadotrophins + GnRH agonist }\end{array}$ \\
\hline
\end{tabular}


(Continued)

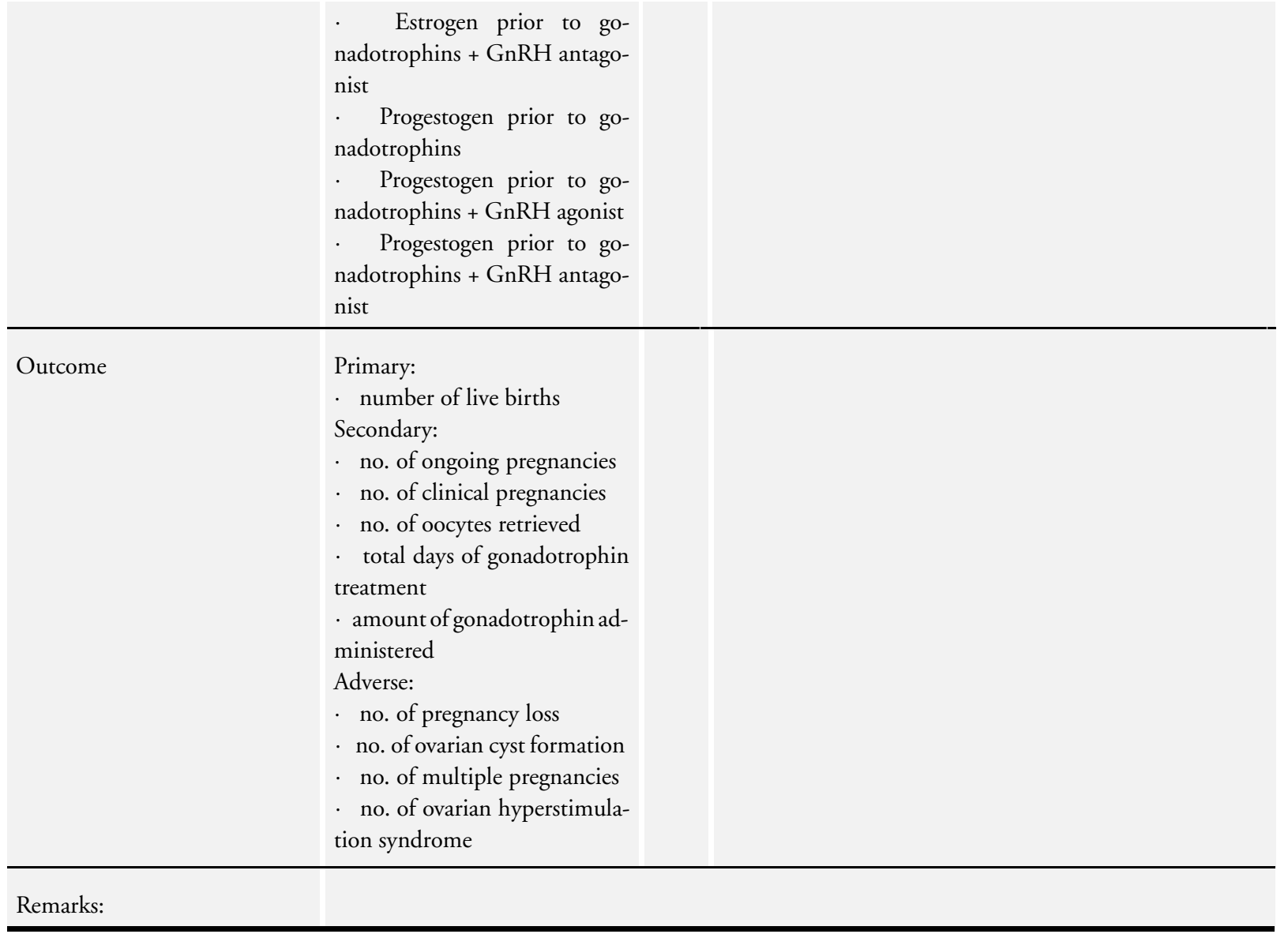

\section{Characteristics}

\section{C1. Trial characteristics}

Country of investigation

\begin{tabular}{llll}
\hline Setting & Single & Multicentre & Unclear \\
\hline & Academic & Non-academic & Unclear \\
\hline Duration of trial & $\mathrm{Y}=$ & $\mathrm{M}=$ & $\mathrm{D}=$ \\
\hline Design & Parallel & Crossover & \\
\hline
\end{tabular}

Number of participants In-

ter-

ven- 
(Continued)

$$
\begin{aligned}
& \text { tion } \\
& \text { group } \\
& \text { Com- } \\
& \text { pari- } \\
& \text { son } \\
& \text { group } \\
& \text { To- } \\
& \text { tal: }
\end{aligned}
$$

\begin{tabular}{|c|c|c|c|c|}
\hline \multirow[b]{2}{*}{ Age } & \multicolumn{2}{|c|}{ Intervention group } & \multicolumn{2}{|c|}{ Comparison group } \\
\hline & $\begin{array}{l}\text { Mean: } \\
\text { SD: } \\
\text { Not reported: }\end{array}$ & & $\begin{array}{l}\text { Mean: } \\
\text { SD: } \\
\text { Not reported: }\end{array}$ & \\
\hline BMI & $\begin{array}{l}\text { Mean: } \\
\text { SD: } \\
\text { Not reported: }\end{array}$ & & $\begin{array}{l}\text { Mean: } \\
\text { SD: } \\
\text { Not reported: }\end{array}$ & \\
\hline $\begin{array}{l}\text { Duration of sub- } \\
\text { fertility }\end{array}$ & $\begin{array}{l}\text { Mean: } \\
\text { SD: } \\
\text { Not reported: }\end{array}$ & & $\begin{array}{l}\text { Mean: } \\
\text { SD: } \\
\text { Not reported: }\end{array}$ & \\
\hline $\begin{array}{l}\text { No. of previous } \\
\text { IVF trials }\end{array}$ & $\begin{array}{l}\text { Mean: } \\
\text { SD: } \\
\text { Not reported: }\end{array}$ & & $\begin{array}{l}\text { Mean: } \\
\text { SD: } \\
\text { Not reported: }\end{array}$ & \\
\hline Subfertility & $\begin{array}{l}\text { Primary: } \\
\text { Secondary: } \\
\text { Not reported: }\end{array}$ & $\begin{array}{l}\mathrm{N}= \\
\mathrm{N}=\end{array}$ & $\begin{array}{l}\text { Primary: } \\
\text { Secondary: } \\
\text { Not reported: }\end{array}$ & $\begin{array}{l}\mathrm{N}= \\
\mathrm{N}=\end{array}$ \\
\hline $\begin{array}{l}\text { Causes of subfer- } \\
\text { tility }\end{array}$ & $\begin{array}{l}\text { Tubal: } \\
\text { Male: } \\
\text { Endometriosis: } \\
\text { Idiopathic: } \\
\text { Other: } \\
\text { Not reported: }\end{array}$ & $\begin{array}{l}\mathrm{N}= \\
\mathrm{N}= \\
\mathrm{N}= \\
\mathrm{N}= \\
\mathrm{N}=\end{array}$ & $\begin{array}{l}\text { Tubal: } \\
\text { Male: } \\
\text { Endometriosis: } \\
\text { Idiopathic: } \\
\text { Other: } \\
\text { Not reported: }\end{array}$ & $\begin{array}{l}N= \\
N= \\
N= \\
N= \\
N=\end{array}$ \\
\hline Poor response & $\begin{array}{l}\text { YES } \\
\text { Defined as: }{ }^{*} \mathrm{M} \\
<3 \text { with a mear } \\
{ }^{*} \mathrm{O}\end{array}$ & varia & $\begin{array}{l}\text { follicles: } \\
17 \mathrm{~mm} \\
\text { ed: }\end{array}$ & \\
\hline
\end{tabular}

Remarks:

\section{C2. Participants characteristics}


(Continued)

$<3$

* Other:

C2. Flowchart of participants

Remarks:

C3. Protocol characteristics

\begin{tabular}{lll}
\hline Pre-treatment & $\begin{array}{l}\text { Combined OCP Estrogen } \\
\text { Name of preparation: } \\
\text { Dosage: } \\
\text { Start: }\end{array}$ & \multicolumn{1}{c}{ Progestogen } \\
\hline Ovarian stimulation & $\begin{array}{l}\text { hame of preparation: } \\
\text { Dosage: } \\
\text { Start: }\end{array}$ \\
\hline Pituitary desensitization & $\begin{array}{l}\text { GnRH agonist GnRH antagonist } \\
\text { Name of preparation: } \\
\text { Dosage: } \\
\text { Start: } \\
\text { Protocol: }\end{array}$ \\
\hline Treatment schedule & & Stop: \\
\hline
\end{tabular}

\section{C4. Follow-up}

Duration of follow-up

Analysis of loss to follow-up Per protocol Intention-to-treat

Remarks:

D. Risk of bias assessment

YES NO Unclear

Study size Was a power calculation performed and adhered?

Oral contraceptive pill, progestogen or estrogen pre-treatment for ovarian stimulation protocols for women undergoing assisted 
(Continued)

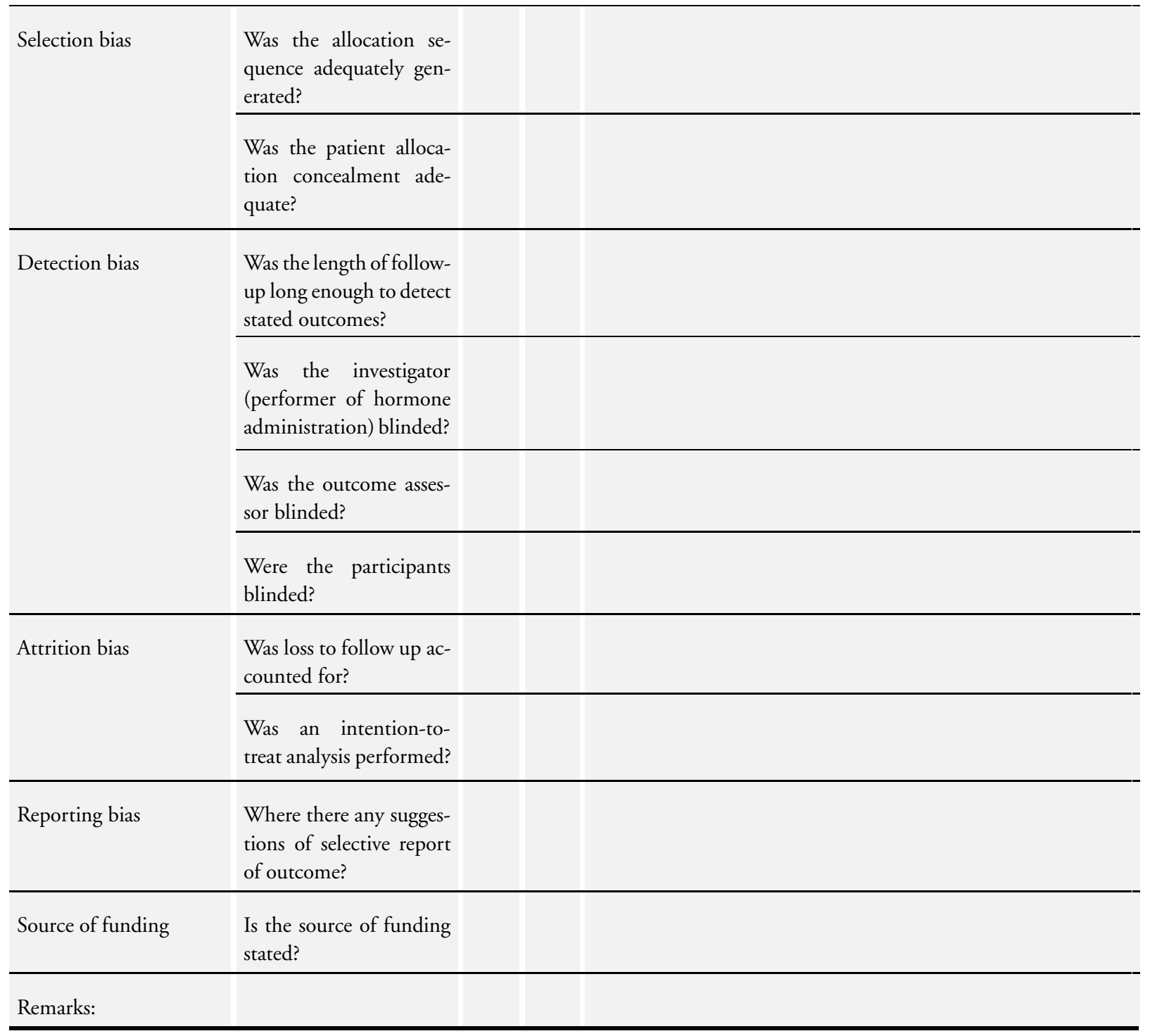

\section{Appendix 8. Data extraction form (part 2)}

\section{Risk of bias assessment}

\section{YES NO Unclear}

Study size

Was a power calculation performed and adhered? 
(Continued)

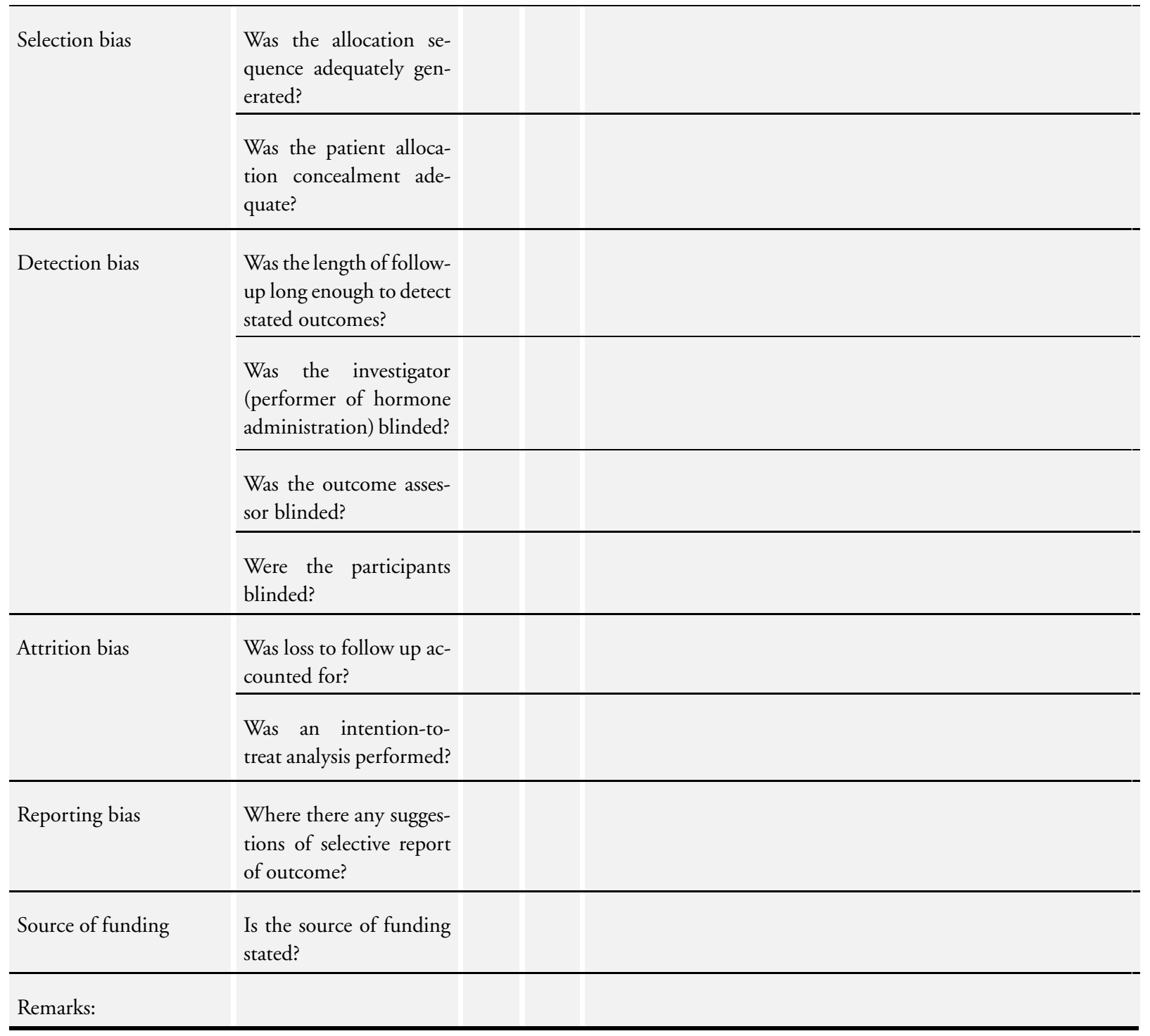

\section{E. Outcomes}

Comparison a. Define treatment:

b. Define control: 


\section{E1. Primary outcomes}

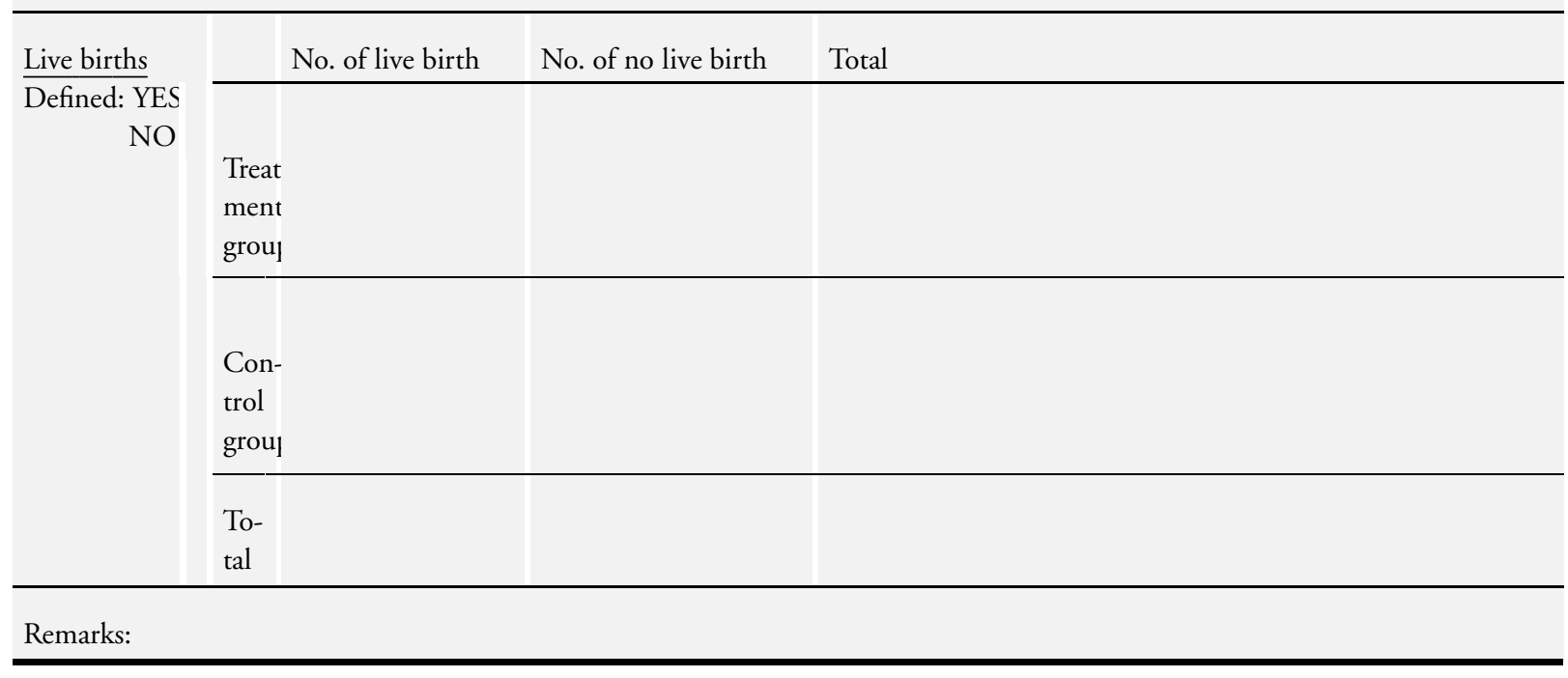

E2. Secondary outcomes

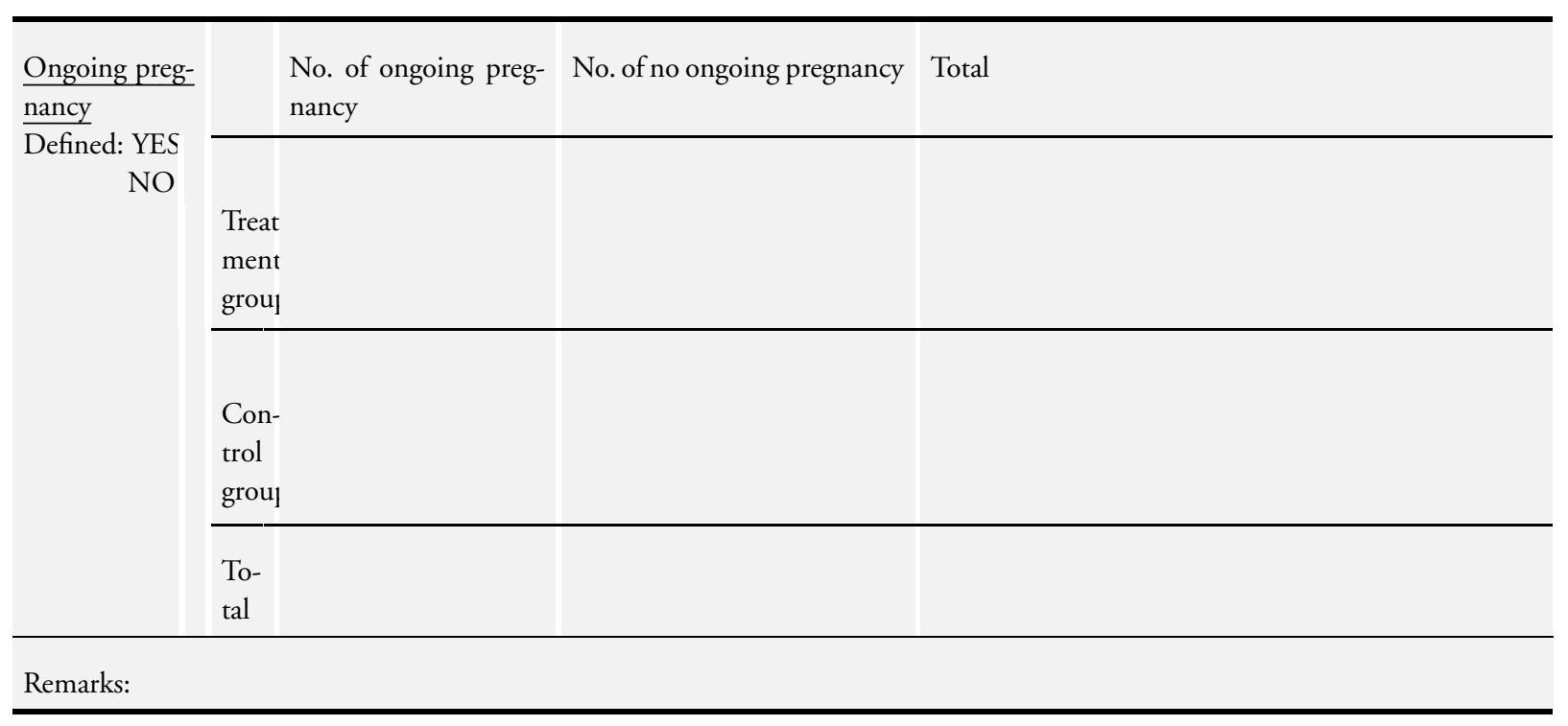

Oral contraceptive pill, progestogen or estrogen pre-treatment for ovarian stimulation protocols for women undergoing assisted 


\begin{tabular}{|c|c|c|c|c|}
\hline \multirow{4}{*}{$\begin{array}{r}\text { Clinical } \\
\text { nancy } \\
\begin{aligned} & \text { Defined: } \text { YES } \\
& \text { NO }\end{aligned}\end{array}$} & & $\begin{array}{l}\text { No. of clinical preg- } \\
\text { nancy }\end{array}$ & No. of no clinical pregnancy & Total \\
\hline & $\begin{array}{l}\text { Treat } \\
\text { ment } \\
\text { groul }\end{array}$ & & & \\
\hline & $\begin{array}{l}\text { Con- } \\
\text { trol } \\
\text { groul }\end{array}$ & & & \\
\hline & $\begin{array}{l}\text { To- } \\
\text { tal }\end{array}$ & & & \\
\hline Remarks: & & & & \\
\hline
\end{tabular}

\begin{tabular}{|l|l}
\hline$\frac{\text { Oocytes }}{\text { retrieved }}$ & $\begin{array}{l}\text { Mean no. of oocytes re- SD } \\
\text { trieved }\end{array}$ \\
\cline { 2 - 2 } $\begin{array}{c}\text { Defined: YES } \\
\text { NO }\end{array}$ & $\begin{array}{l}\text { Treat } \\
\text { ment } \\
\text { grou }\end{array}$ \\
\hline
\end{tabular}

Con-

trol

grou]

Remarks:

\begin{tabular}{|c|c|c|c|}
\hline $\begin{array}{l}\text { Days of } \\
\text { gonadotrophins } \\
\text { treatment }\end{array}$ & & $\begin{array}{l}\text { Mean no. of days of } \\
\text { gonadotrophins treatment }\end{array}$ & SD \\
\hline $\begin{array}{r}\text { Defined: YES } \\
\text { NO }\end{array}$ & $\begin{array}{l}\text { Treat } \\
\text { ment } \\
\text { grou }\end{array}$ & & \\
\hline
\end{tabular}

Con- 
(Continued)

trol

grou

Remarks:

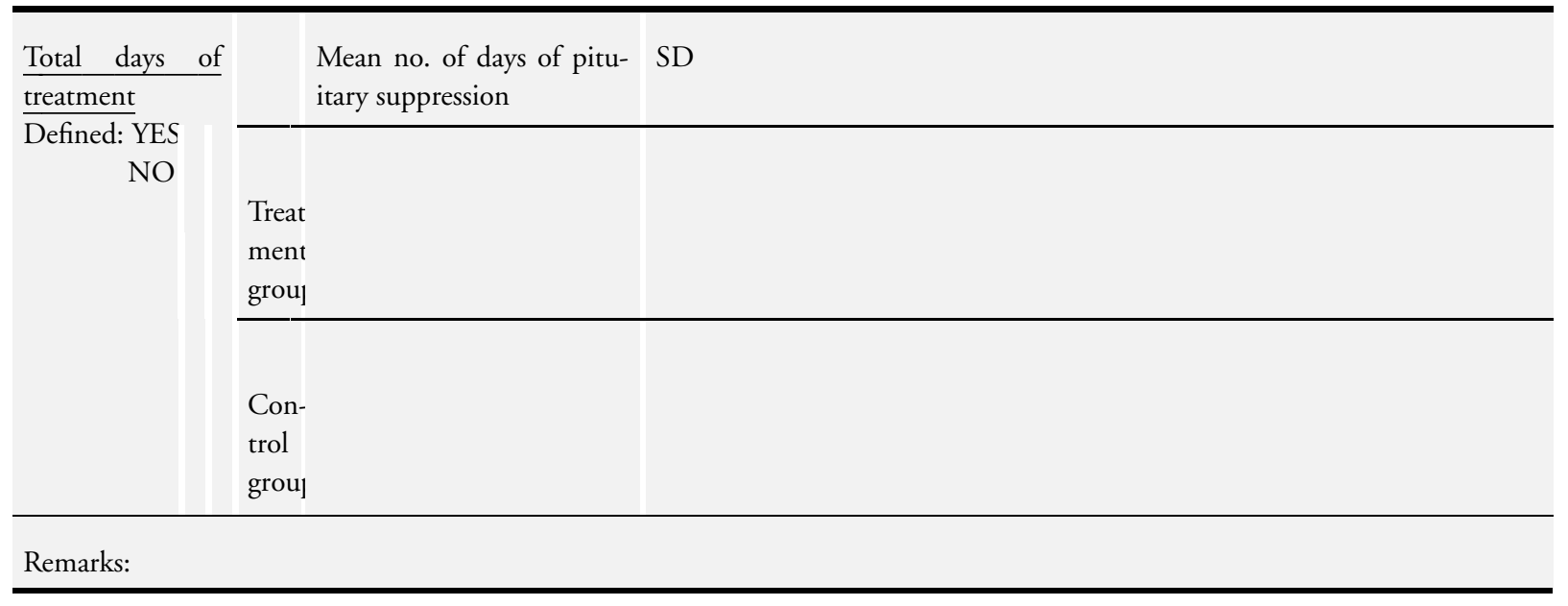

\section{E3. Adverse outcomes}

\begin{tabular}{|c|c|c|c|c|}
\hline \multirow{4}{*}{$\begin{array}{r}\frac{\text { Pregnancy loss }}{\text { Defined: YES }} \\
\text { NO }\end{array}$} & & No. of pregnancy loss & No. of no pregnancy loss & Total \\
\hline & Treatment group & & & \\
\hline & Control group & & & \\
\hline & Total & & & \\
\hline
\end{tabular}

Ovarian cyst formation

Defined: YES

NO

\begin{tabular}{|c|c|c|c|}
\hline & $\begin{array}{l}\text { No. of ovarian } \\
\text { cyst formation }\end{array}$ & $\begin{array}{l}\text { No. of no ovarian } \\
\text { cyst formation }\end{array}$ & Total \\
\hline Treatment group & & & \\
\hline Control group & & & \\
\hline
\end{tabular}

Oral contraceptive pill, progestogen or estrogen pre-treatment for ovarian stimulation protocols for women undergoing assisted 


\section{Total}

Remarks:

\begin{tabular}{|c|c|c|c|c|}
\hline \multirow{4}{*}{$\begin{array}{c}\text { Multiple pregnancy } \\
\text { Defined: YES } \\
\text { NO }\end{array}$} & & $\begin{array}{l}\text { No. of multiple } \\
\text { pregnancies }\end{array}$ & $\begin{array}{l}\text { No. of no multiple } \\
\text { pregnancies }\end{array}$ & Total \\
\hline & Treatment group & & & \\
\hline & Control group & & & \\
\hline & Total & & & \\
\hline
\end{tabular}

\begin{tabular}{|c|c|c|c|c|}
\hline \multirow{4}{*}{$\begin{array}{l}\frac{\text { Ovarian hyperstimula- }}{\text { tion }} \\
\frac{\text { syndrome }}{\text { Defined: } \text { YES }} \\
\text { NO }\end{array}$} & & No. of OHS syndrome & No. of no OHS syndrome & Total \\
\hline & Treatment group & & & \\
\hline & Control group & & & \\
\hline & Total & & & \\
\hline
\end{tabular}

\section{Appendix 9. Glossary}

Embryo The product of conception from the time of fertilisation to the end of the embryonic stage eight weeks after fertilisation.

Embryo transfer (ET) Procedure of which embryos are placed in the uterus or fallopian tube.

Endogenous Developed or originated inside the organism. For example hormones produced by the pituitary gland would be an endogenous supply, but hormones produced in the laboratory and then given to the body is called an exogenous supply.

Fertilisation The penetration of the ovum by the sperm cell and fusion of genetic materials, resulting in the development of an embryo. Follicle The sac in which an egg develops in the ovary.

Follicle cohort synchronisation In the ovaries a few eggs are maturing at the same time. These eggs are all in a different stage of maturation. If one egg reaches a threshold at the right time in the menstrual cycle, the final maturation process will start and this egg will reach ovulation. For IVF/ICSI cycles it is important that more than one egg reaches this threshold at the same time, so they can be retrieved at once before spontaneous ovulation occurs. This is called synchronisation of the follicle cohort.

Follicle Stimulating Hormone (FSH) A hormone produced and released from the pituitary gland. In women it stimulates the production of oestrogen and follicles in the ovary ready for ovulation.

Gestational sac A fluid-filled structure containing an embryo that develops early in pregnancy, usually within the uterus.

Gonadotrophin Releasing Hormone (GnRH) A substance produced by the hypothalamus (part of the brain) to enable the pituitary gland to secrete LH and FSH.

Gonadotrophins Pituitary hormones FSH and LH which stimulate the ovaries in women.

Oral contraceptive pill, progestogen or estrogen pre-treatment for ovarian stimulation protocols for women undergoing assisted 
Human Menopausal Gonadotrophin (hMG) An injectable preparation that is obtained from the urine of menopausal women and has biological activity similar to that of FSH.

Luteal phase The last 14 days of the menstrual cycle.

Luteinising Hormone (LH) A hormone produced and released by the pituitary gland. In women it is responsible for ovulation and progestogen production.

Negative feedback A common regulation mechanism to stabilise the body's internal environment. An example is the temperature control of the human body. When your temperature is too high, the body will react in such a way that you cool down, by opening pores and sweating. In this way the body's temperature will not fluctuate too much. The same kind of mechanism is used to keep hormone values stable. An increase in gonadotrophin values will (through negative feedback) result in fewer GnRH receptors. The binding of $\mathrm{GnRH}$ to a GnRH receptor in the pituitary gland will result in the release of gonadotrophins, but with fewer GnRH receptors, the releasing process will be lowered and the gonadotrophin levels in the body will drop.

Oocyte The egg from a woman's ovary.

Ova A woman's reproductive cell, also known as egg or oocyte.

Ovarian Hyperstimulation (OHS) Syndrome A condition that occurs from fertility drugs when a large number of follicles in the ovary are stimulated to develop and ovulate. This stimulation causes an enlargement of the ovaries.

Ovulation The release of an egg/ova from an ovarian follicle.

Ovulation induction Medical procedure to produce ovulation.

Polycystic Ovary Syndrome (PCOS) When a woman has enlarged ovaries with multiple cysts and the surface of the ovary is thickened. The woman may ovulate infrequently or not at all.

Premature LH-surge In a normal menstrual cycle an increase in LH-levels (LH-surge) is needed to start ovulation. In IVF/ICSI cycles it is important that the ovulation does not start before the oocytes are mature enough to be retrieved. A LH-surge that occurs too early is called premature and is an unwanted event in IVF/ICSI cycles.

Recombinant (as in recombinant FSH or rFSH) A naturally occurring hormone which has been made in the laboratory with the use of DNA technology.

Subfertility Failure to achieve pregnancy after at least one year of unprotected coitus.

Ultrasound Radiology sounds waves of a high frequency used to visualise the developing foetus in the uterus to check size, growth and the presence of abnormalities.

All these definitions (except for follicle cohort synchronisation, negative feedback and premature LH-surge) were achieved from the glossary of the MDSG Module 2008.

\section{WHAT'S NEW}

Last assessed as up-to-date: 15 November 2008.

\begin{tabular}{l|l|l}
\hline Date & Event & Description \\
\hline 20 September 2010 & Amended & Contact details updated. \\
\hline
\end{tabular}

\section{H I S T O R Y}

Protocol first published: Issue 3, 2006

Review first published: Issue 1, 2010

Oral contraceptive pill, progestogen or estrogen pre-treatment for ovarian stimulation protocols for women undergoing assisted 


\begin{tabular}{lll}
\hline Date & Event & Description \\
\hline 16 August 2010 & Amended & Minor edits made no change to conclusion \\
\hline 18 December 2008 & Amended & Title changed \\
\hline 23 November 2008 & Amended & $\begin{array}{l}\text { New authors added } \\
\text { All aspects of original protocol revised }\end{array}$ \\
\hline 13 April 2008 & Amended & Converted to new review format. \\
\hline 19 May 2006 & New citation required and major changes & Substantive amendment \\
\hline
\end{tabular}

\section{CONTRIBUTIONSOFAUTHORS}

Brechtje Smulders and Sanne van Oirschot contributed equally to this review.

Brechtje Smulders drafted the Background and Objectives of the review, and performed the search, selected the studies, extracted and analysed the data, contacted the authors of trials and drafted the Results, Discussion and Authors' conclusions of the review together with Sanne M van Oirschot. BS also drafted half of the tables of Characteristics of included studies and drafted Table 1, Table 2 and Table 3.

Sanne M van Oirschot drafted the Methods of the review, and performed the search, selected the studies, extracted and analysed the data, contacted the authors of trials and drafted the Results, Discussion and Authors' conclusions of the review together with Brechtje Smulders. SvO also drafted half of the tables of Characteristics of included studies and all the tables of Characteristics of excluded studies.

Cindy Farquhar helped to solve differences of opinion as a third review author, commented on the review and helped with drafting the Discussion and Authors' conclusions of the review.

Luk Rombauts acted as a clinical expert and commented on the review.

Jan Kremer acted as a clinical expert and commented on the review.

\section{DECLARATIONSOF INTEREST}

Luk Rombauts was the first author of a randomised trial about oral contraceptive pre-treatment (Rombauts 2006). This study was sponsored by Organon/Schering Plough. 


\section{SOURCES OF SUPPORT}

\section{Internal sources}

- No sources of support supplied

\section{External sources}

- Stichting Nijmeegs Universiteitsfonds (SNUF), Netherlands.

Scholarship to support students of the University of Nijmegen to do a study, internship or research outside The Netherlands.

- CVSB (Commissie Voorzieningen Studenten Budget), Netherlands.

Compensation for studying outside The Netherlands.

\section{DIFFERENCES BETWEEN PROTOCOLANDREVIEW}

The biggest change between the protocol and the review is the formation of different subgroups. In the protocol we described that we would perform subgroup analyses on women's age; poor response; agonist long, short and ultra-short protocol; and the duration of pre-treatment. After regarding the included studies, we thought it would make more sense to perform subgroup analyses on the type of $\mathrm{GnRH}$ analogue used in the treatment cycles. After this, we could not perform any more subgroup analysis on the planned subjects, because there were not enough studies per subgroup. Furthermore, we did not perform any sensitivity analyses due to the small number of included studies per subgroup.

Other minor things that we changed in this review was the exclusion of oocyte donors as participants, we rewrote the interventions to make them more understandable, we changed the outcome 'ovarian cysts per woman randomised' to 'number of women with ovarian cysts' and we removed a few items of the data extraction because we thought they were less important. At last, we were unable to perform a funnel plot because of the limited number of included studies to each subgroup.

\section{N D EX TERMS}

\section{Medical Subject Headings (MeSH)}

Contraceptives, Oral [*administration \& dosage]; Estrogens [*administration \& dosage]; Fertilization in Vitro [*methods]; Gonadotropin-Releasing Hormone [antagonists \& inhibitors]; Live Birth; Ovulation Induction [* methods]; Pregnancy Rate; Progestins [*administration \& dosage]; Randomized Controlled Trials as Topic; Sperm Injections, Intracytoplasmic; Treatment Outcome

\section{MeSH check words}

Female; Humans; Pregnancy 